\title{
Untersuchung der Fruchtkörperentwicklung bei dem Hyphenpilz Sordaria macrospora
}

\author{
Dissertation \\ zur Erlangung des Doktorgrades \\ der Mathematisch-Naturwissenschaftlichen Fakultäten \\ der Georg-August-Universität zu Göttingen
}

vorgelegt von

Yasmine Bernhards

aus Dortmund

Göttingen 2010 
D7

Referent:

Prof. Dr. Stefanie Pöggeler

Korreferent:

PD Dr. Michael Hoppert

Tag der mündlichen Prüfung: $\quad$ 28.10.2010 
Teile der vorliegenden Arbeit wurden zur Veröffentlichung eingereicht oder als Manuskript vorbereitet.

\section{eingereichtes Manuskript}

Bernhards Y and Pöggeler S (2010) The phocein homologue SmMOB3 is essential for vegetative cell fusion and sexual development in the filamentous ascomycete Sordaria macrospora. Submitted to Journal.

Das eingereichte Manuskript umfasst folgende Kapitel und Abbildungen dieser Arbeit:

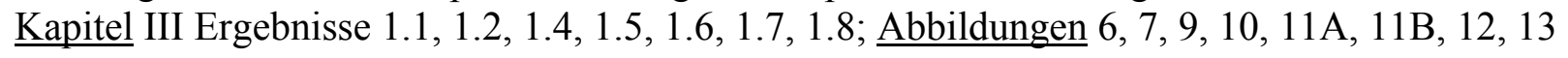

Die Planung der Experimente und die Analyse der Daten erfolgten in Zusammenarbeit von Frau Prof. Pöggeler und mir. Alle Experimente, die Abbildungen und der Entwurf des Manuskripts wurden von mir durchgeführt bzw. erstellt.

\section{Manuskript in Vorbereitung}

Bloemendal S, Bernhards Y, Bartho K, Engh I, Seiler S, Wolters DA, Pöggeler S, Kück U (2010) Fungal homologues of a human STRIPAK complex control sexual development. Manuscript in preparation.

Das vorbereitete Manuskript basiert auf folgenden Kapiteln und Abbildungen dieser Arbeit:

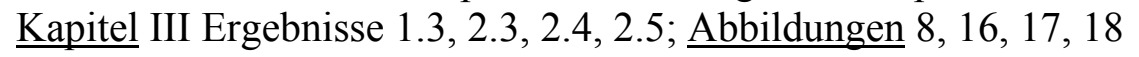

Die konzeptionelle Planung des Manuskripts erfolgte von Herrn Prof. Kück, Frau Dr. Engh und Frau Bloemendal (Lehrstuhl Allgemeine und Molekulare Botanik, Ruhr-Universität Bochum) in Zusammenarbeit mit Frau Prof. Pöggeler und mir. Die in dem Manuskript aus dieser Arbeit enthaltenen experimentellen Daten, sowie die zugehörigen Abbildungen wurden von mir erstellt und zusammen mit Frau Prof. Pöggeler ausgewertet.

\section{Weitere Publikationen im Rahmen der Promotion}

Nolting N*, Bernhards $Y^{*}$, Pöggeler S (2009) SmATG7 is required for viability in the homothallic ascomycete Sordaria macrospora. Fungal Genetics and Biology 46: 531-542.

*Beide Autoren trugen in gleichem Maße zu der Veröffentlichung bei

Elleuche S, Bernhards Y, Schäfers C, Varghese JM, Nolting N, Pöggeler S (2010) The small serine-threonine protein SIP2 interacts with STE12 and is involved in ascospore germination in Sordaria macrospora. European Journal of Cell Biology. doi:10.1016/j.ejcb.2010.06.014. 


\section{EINFÜHRUNG}

1 Einleitung $\quad 1$

$2 \quad$ Die Familie der Striatin-Proteine aus Eukaryoten $\quad 2$

$2.1 \quad$ Die vielfältigen Funktionen von Striatin-Proteinen 7

2.2 Interaktionspartner von Striatin-Proteinen und die Signalwege in denen sie wirken $\quad 8$

2.2.1 Phocein/Mob3 - ein Protein aus der Mob-Familie 8

2.2.2 Die Protein-Phosphatase 2A (PP2A) 11

2.2.3 ER $\alpha$ - Östrogen-vermittelte nicht-genomische und genomische Signalwege 13

2.2.4 Die Rolle von Striatin-Proteinen bei der Zell-Adhäsion $\quad 13$

2.2.5 Die Rolle von Striatin-Proteinen bei der Virus-Assemblierung $\quad 14$

3 Sordaria macrospora - Ein Hyphenpilz als Modell-Organismus zur Erforschung molekularer Differenzierungsprozesse 16

$4 \quad$ Experimentelle Zielsetzung $\quad 18$

II MATERIAL UND METHODEN

$1 \quad$ Material $\quad 21$

$\begin{array}{lll}1.1 & \text { Stämme } & 21\end{array}$

1.2 Plasmide $\quad 23$

1.3 Oligonukleotide (Primer) 25

1.4 Chemikalien und Verbrauchsmaterial 28

1.4.1 Radiochemikalien 28

$\begin{array}{ll}1.4 .2 \text { Kits } & 28\end{array}$

$\begin{array}{ll}1.4 .3 \text { Enzyme } & 29\end{array}$

$\begin{array}{lll}1.5 & \text { Nährmedien } & 29\end{array}$

1.6 Nährmedien 29

$2 \quad$ Methoden $\quad 30$

$2.1 \quad$ Kulturbedingungen von E. coli, S. cerevisiae und S. macrospora-Stämmen 30

2.2 Kreuzung von $S$. macrospora-Stämmen 30

$2.3 \quad$ Vorbereitung und Transformation von $E$. coli und $S$. cerevisiae 30

$2.4 \quad$ Protoplastierung und Transformation von S. macrospora 31

2.5 Präparation von Nukleinsäuren $\quad 31$

2.5.1 Isolierung von Plasmid-DNA aus E. coli und S. cerevisiae 31

2.5.2 Isolierung von genomischer DNA und RNA aus S. macrospora 32

2.6 Hydrolyse und Ligation von Nukleinsäuren $\quad 32$

$2.7 \quad$ Natriumacetat-Fällung und Mikrodialyse 32

2.8 Gelelektrophorese von Nukleinsäuren und Gelextraktion 32

$\begin{array}{ll}2.8 .1 \text { DNA } & 32\end{array}$

2.8.2 RNA

$\begin{array}{lll}2.9 & \text { Radioaktive Markierung von Nukleinsäuren } & 33\end{array}$

$\begin{array}{lll}2.10 & \text { Southern-Blotverfahren und Hybridisierung } & 33\end{array}$

2.11 Oligonukleotidsynthese und Sequenzierung 33

2.12 PCR und Kolonie-PCR 33

2.13 cDNA Synthese und quantitative Real-Time PCR 33

2.14 Analyse von Nukleotid- und Aminosäuresequenzen 34

2.15 Isolierung und Sequenzierung der Gene Smmob3 und Sm9375 34

2.16 Herstellung von S. macrospora Knockout-Stämmen $\quad 35$

2.17 Herstellung von S. macrospora RNAi- und Doppel-Knockout-Stämmen 35

2.18 Komplementationsanalyse 36

2.18.1 Herstellung von Smmob3-Komplementationskonstrukten 36 
2.18.2 Herstellung von prol1-Komplementationskonstrukten 37

2.19 Morphologische Analyse von S. macrospora-Stämmen 37

2.20 Analyse von Hyphenfusionen $\quad 38$

$2.21 \quad$ Lokalisierungsstudie von SmMOB3 und PRO11 38

2.22 Licht- und Fluoreszenzmikroskopie 38

2.23 Analyse von Protein-Protein-Interaktionen 39

2.23.1 Hefe Two-Hybrid-Analyse der Proteine PRO11 und SmMOB3

2.23.2 Hefe Two-Hybrid-Screen einer S. macrospora und N. crassa cDNA-Bank mit PRO11 und SmMOB3 als Köderprotein

$\begin{array}{lll}2.24 & \text { Sicherheitsmaßnahmen } & 40\end{array}$

\section{ERGEBNISSE}

$1 \quad$ Funktionelle Charakterisierung des $S$. macrospora Proteins SmMOB3

1.1 S. macrospora kodiert für ein Phocein/Mob3-Homolog

1.2 Expressionsanalyse der beiden S. macrospora Gene Smmob3 und pro11

1.3 Two-Hybrid Studie der Proteine SmMOB3 und PRO11 aus S. macrospora

$1.4 \quad$ Konstruktion eines $S$. macrospora Smmob3 Knockout-Stamms

1.5 Morphologische Charakterisierung des S. macrospora $\Delta$ Smmob3-Stamms

1.6 SmMOB3-Komplementationsanalyse in S. macrospora und N. crassa

1.7 Ausbildung von Hyphen-Fusionen der Stämme $\Delta$ Smmob3 und pro11

1.8 Herunterregulierung der Gene proll und Smmob3 mittels RNAi

2 Funktionelle Charakterisierung des $S$. macrospora Proteins PRO11

2.1 In silico Strukturanalyse des PRO11 N-Terminus

2.2 Identifizierung einer alternativ gespleißten pro11 Variante

2.3 Konstruktion eines $S$. macrospora pro11 Knockout-Stamms

2.4 Morphologische Charakterisierung des S. macrospora $\Delta$ pro11 Stamms

2.5 PRO11-Komplementationsstudie

2.6 Expression von Smmob3 in $\Delta$ pro11 und pro 11 in $\Delta$ Smmob3

3 Identifizierung und Charakterisierung weiterer Interaktionspartner von SmMOB3 und PRO11

3.2 Charakterisierung des Gens Sm9375 aus S. macrospora

3.4 Morphologische Charakterisierung des S. macrospora $\Delta$ Sm9375 Stamms und der

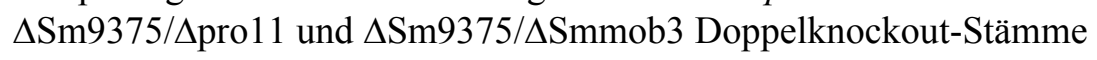

\section{DISKUSSION}

1 Das $S$. macrospora Protein PRO11 interagiert mit SmMOB3, einem konservierten Protein aus der Mob-Familie

1.1 Das PRO11 „WD-repeat“-Motiv interagiert mit dem SmMOB3 N-Terminus

1.2 Die Homodimerisierung von PRO11 und die besondere Rolle des N-Terminus

2 Der PRO11/SmMOB3-Komplex reguliert in $S$. macrospora die sexuelle Differenzierung und die Hyphenfusion

2.1 Die Gene pro11 und Smmob3 werden während der sexuellen Entwicklung exprimiert

2.2 Der $\Delta$ pro11-Stamm weist einen stärkeren Entwicklungsdefekt auf als die pro11-Mutante

2.3 Der $\Delta$ Smmob3-Stamm ist auf der Stufe der Protoperithezien-Entwicklung arretiert

2.4 Die Stämme $\Delta$ Smmob3 und pro11 weisen einen Defekt bei der Hyphenfusion auf 
3 Das S. macrospora Protein Sm9375 - Beteiligung eines GPI-geankerten Proteins am SmMOB3/PRO11-Komplex

$4 \quad$ Reguliert der PRO11/SmMOB3-Komplex während Hyphenfusion und Fruchtkörperentwicklung die Endocytose und den Vesikel-Transport?

$5 \quad$ Zusammenfassung der vielfältigen Funktionen von $S$. macrospora PRO11Proteinkomplexen bei zellulären Differenzierungsprozessen

V ZUSAMMENFASSUNG

$1 \quad$ Zusammenfassung 104

2 Summary 106

VI LITERATURVERZEICHNIS

VII DANKSAGUNG

VIII Curriculum Vitae 


\section{Verwendete Abkürzungen und Symbole}

Abkürzungen, die im Text oder in Bildunterschriften erläutert werden, sowie allgemein gebräuchliche Abkürzungen und Maßeinheiten sind nicht gesondert aufgeführt

\begin{tabular}{|c|c|}
\hline A. dest & destilliertes Wasser \\
\hline $\mathrm{amp}^{\mathrm{R}}$ & Ampicillin-resistent \\
\hline BLAST & „Basic Local Alignment Search Tool” \\
\hline bp & Basenpaare \\
\hline C-Terminus & Carboxy-Terminus \\
\hline cas 2 & $\begin{array}{l}\text { kodiert für mitochondriale Pflanzen-ähnliche } \beta \text {-Carboanhydrase aus Sordaria } \\
\text { macrospora }\end{array}$ \\
\hline cDNA & „,complementary“ DNA \\
\hline Contig & „contiguous stretches of sequence“ \\
\hline $\mathrm{d}$ & „dies“, Tag \\
\hline DNA & „deoxyribonucleic acid”, Desoxyribonukleinsäure \\
\hline DsRed & kodiert für rot fluoreszierendes Protein aus Discosoma $s p$. \\
\hline egfp & kodiert für eine Variante des grün fluoreszierenden Proteins aus Aequorea victoria \\
\hline ER & Endoplasmatisches Retikulum \\
\hline ESI & Einzelsporisolat \\
\hline EST & „Expressed Sequence Tags“ \\
\hline $\mathrm{EtBr}$ & Ethidiumbromid \\
\hline $\mathrm{EtOH}$ & Ethanol \\
\hline GAL4-AD & $\begin{array}{l}\text { kodiert für die Aktivierungsdomäne des GAL4-Transkriptionsfaktors aus } \\
\text { Saccharomyces cerevisiae }\end{array}$ \\
\hline$G A L 4-B D$ & $\begin{array}{l}\text { kodiert für die Bindedomäne des GAL4-Transkriptionsfaktors aus Saccharomyces } \\
\text { cerevisiae }\end{array}$ \\
\hline gDNA & genomische DNA \\
\hline GPI & Glycosylphosphatidylinositol \\
\hline$h p h$ & $\begin{array}{l}\text { Hygromycin-Resistenzkassette: bakterielles } h p h \text {-Gen reguliert durch trpC- } \\
\text { Promotor aus Aspergillus nidulans }\end{array}$ \\
\hline hyg $^{\mathrm{R}}$ & Hygromycin-resistent \\
\hline $\operatorname{kan}^{\mathrm{R}}$ & Kanamycin-resistent \\
\hline $\mathrm{kb}$ & Kilobasen \\
\hline $\mathrm{kDa}$ & Kilodalton \\
\hline $\operatorname{lacz} \alpha$ & kodiert für das $\alpha$-Monomer der $\beta$-Galactosidase \\
\hline LEU2 & kodiert ein Enzym für die Leucin-Biosynthese \\
\hline M. $m ., M m$ & Mus musculus \\
\hline Mo & Magnaporthe oryzae \\
\hline mRNA & „messenger”-RNA, Boten-RNA \\
\hline MTS & mitochondriale Signalsequenz \\
\hline N-Terminus & Amino-Terminus \\
\hline nat & $\begin{array}{l}\text { Nourseothricin-Resistenzkassette: natl-Gen unter der Kontrolle des trpC } \\
\text { Promotors aus Aspergillus. nidulans }\end{array}$ \\
\hline nat $^{\mathrm{R}}$ & Nourseothricin-resistent \\
\hline$N c$ & Neurospora crassa \\
\hline OD & optische Dichte \\
\hline ORF & „open reading frame”, offener Leserahmen \\
\hline PCCG1 & Promotor des „, clock controlled protein CCG-1“-Gens aus Neurospora crassa \\
\hline PCR & polymerase chain reaction", Polymerase-Kettenreaktion \\
\hline
\end{tabular}


Pgpd Promotor des Glycerinaldehyd 3-Phosphat Dehydrogenase-Gens aus Aspergillus

PTS1 Peroxisomale Signalsequenz 1

RNA „ribonucleic acid”, Ribonukleinsäure

rpm „revolutions per minute”, Umdrehungen pro Minute

RT reverse Transkription

RTmp Raumtemperatur

SC „Supercontig”

SKL Serin/Lysin/Leucin-Tripeptid

S. m., Sm Sordaria macrospora

TtrpC Terminator des Anthranilat Synthase-Gens aus Aspergillus nidulans

UE Untereinheit

URA2 kodiert ein Enzym für die Uracil-Biosynthese

UTR untranslatierte Region

$:: \quad$ ersetzt durch

: fusioniert an

» Anzahl kodierter Aminosäuren

i Zentrifugation 


\section{EINFÜHRUNG}

\section{$1 \quad$ Einleitung}

Die Zellen eines Organismus unterstehen dem ständigen Einfluss vielfältiger äußerer und innerer Stimuli und die Generierung einer geeigneten Zell-Antwort ist die entscheidende Strategie, von der das Überleben des Organismus abhängt.

Äußere Reize stellen beispielsweise Gerüche, Licht, Pheromone, das Nährstoffangebot, die SalzKonzentration oder der pH-Wert des umgebenden Habitats dar (Maller 2003). Innere Reize werden vor allem durch biochemische Botenstoffe (Hormone, Neurotransmitter) generiert. Aber auch die Schädigung der DNA oder oxidativer Stress, ausgelöst durch reaktive Sauerstoffspezies (,reactive oxygen species“, ROS) können einen Reiz darstellen, welcher eine spezifische ZellAntwort erfordert (Apel und Hirt 2004, Chen und Keaney 2004, Muthusamy und Piva 2010, Raz et al. 2008).

Auf der molekularen Ebene wird die Reizaufnahme und -weiterleitung über Signaltransduktionswege kommuniziert. Es existiert eine Vielzahl verschiedener Systeme für die Signalweiterleitung, die innerhalb eines komplexen Kommunikationssystems untereinander vernetzt sein und sich in ihrer Aktivität überlagern können. Der grundlegende Ablauf der Signalweiterleitung ist jedoch meist ähnlich: Die spezifische Bindung eines Signalmoleküls an einen Rezeptor auf der Zelloberfläche markiert den Startpunkt der Signalübertragung in die Zelle. Innerhalb der Zelle kann das Signal durch die Wirkung sekundärer Botenstoffe (beispielsweise Calciumionen) verstärkt und über die Phosphorylierung von Proteinen weitergeleitet werden. Die Signalweiterleitung mündet häufig in der Aktivierung von Transkriptionsfaktoren, welche daraufhin die Expression spezifischer Zielgene regulieren (Xue et al. 2008, Dodge-Kafka et al. 2008).

Eine gestörte Informationsverarbeitung und die damit verbundene Fehlfunktion der Kommunikationsnetzwerke können ernsthafte Erkrankungen, wie z. B. Krebs auslösen (Wu et al. 2010). Im Fokus der Wissenschaft steht daher insbesondere die Aufklärung von Signaltransduktionswegen, welche zelluläre Differenzierungsprozesse regulieren.

In diesem Zusammenhang gewinnt die funktionelle Analyse von Proteinen aus der StriatinFamilie und deren Interaktionspartnern eine immer stärkere Bedeutung, da Striatin-Proteine vermutlich eine zentrale Rolle bei der Regulation vielfältiger zellulärer Differenzierungsprozesse einnehmen (Benoist et al. 2006). Im Folgenden sollen daher die bisherigen Erkenntnisse über die Struktur und Funktion von Proteinen aus der Striatin-Familie vorgestellt werden. 


\section{Die Familie der Striatin-Proteine aus Eukaryoten}

Die Familie der Striatin-Proteine umfasst eine kleine hoch konservierte Gruppe eukaryotischer Proteine, deren Vertreter aus so verschiedenen Organismen wie den filamentösen Pilzen und dem Mensch stammen. In Prokaryoten und Pflanzen existieren keine Homologe der Striatin-Proteine (Benoist et al. 2006). Die Ursprungsmitglieder dieser Protein-Familie werden durch die drei Säugerproteine Striatin, SG2NA und Zinedin repräsentiert, die nachfolgend im Detail beschrieben werden.

Das 780 Aminosäuren (AS) große Striatin-Protein wurde erstmals in isolierten Synaptosomen aus Rattenhirn gefunden, welche eine ungewöhnlich hohe Adenylyl-Zyklase Aktivität aufwiesen (Castets et al. 1996). Die Bezeichnung ergab sich aus der hohen Expression des Proteins im Striatum, welches Teil der zum Großhirn gehörenden Basalganglien ist.

Der Begriff Synaptosom bezeichnet die isolierte axonale Endigung einer Nervenzelle, an welche noch die postsynaptische Membran gebunden ist. Ein Synaptosom steht somit als Synonym für eine isolierte Synapse. Präparierte Synaptosomen werden bereits seit mehreren Jahrzehnten in der Forschung bevorzugt für in vitro Studien des synaptischen Stoffwechsels eingesetzt (Whittaker 1993).

Die Adenylyl Cyclase ist ein integrales Membranprotein mit enzymatischer Aktivität, welches im Rahmen von G-Protein (GTP-bindendes Protein) gesteuerten Signaltrans-duktionsprozessen die Synthese des sekundären Botenstoffs cAMP (zyklisches Adenosinmonophosphat) katalysiert (Hurley 1999).

SG2NA (S/G , „nuclear antigen“, nukleäres Antigen) wurde erstmals in einer Studie von Landberg und Tan (1994) als Zielprotein von Autoantikörpern entdeckt, welche aus dem Blutserum eines Blut- und Lungenkrebs-Patienten gewonnen wurden.

Die Bildung von Autoantikörpern gegen autologe Tumor-assoziierte Antigene (,tumorassociated antigens“, TAA) in frühen Phasen der Karzinogenese wird als Immunantwort des Organismus verstanden, welche dazu dient prämaligne Schädigungen zu beseitigen. Da TAAs und ihre spezifischen Autoantikörper bereits in der asymptomatischen Phase der Krebserkrankung aus dem Blutserum von Patienten isoliert und somit non-invasiv analysiert werden können, stellen sie einen geeigneten Biomarker für die KrebsFrüherkennung dar. Viele wissenschaftliche Studien beschäftigen sich daher mit der Identifizierung möglichst vieler TAAs und Autoantikörper, welche bei bestimmten Krebsarten spezifisch auftreten (Tan et al. 2009).

Die Namensgebung wurde aus der vornehmlichen Expression in der S- und $\mathrm{G}_{2}$-Phase des Zellzyklus und der zunächst im Nukleus detektierten Lokalisierung des Proteins abgeleitet (Muro et al. 1995). Spätere immunocytochemische Analysen und subzelluläre ZellfraktionierungsStudien konnten die nukleäre Lokalisierung von SG2NA jedoch nicht bestätigen. Vielmehr wurde deutlich, dass SG2NA ausschließlich im Cytoplasma und Membran-gebunden vorliegt (Baillat et 
al. 2001, Blondeau et al. 2003, Castets et al. 2000, Gaillard et al. 2006, Lu et al. 2004, Moreno et al. 2001). Das SG2NA-Protein kommt in mindestens zwei Isoformen vor, welche durch alternatives Spleißen entstehen. Die zunächst isolierte Form SG2NA $\alpha$ umfasst 713 AS während die größere Isoform SG2NAß 797 AS enthält (Castets et al. 2000, Muro et al. 1995). Eine Studie von Sanghamitra et al. (2008) weist jedoch darauf hin, dass darüber hinaus noch fünf weitere alternativ gespleißte Isoformen des SG2NA-Proteins existieren, welche Gewebe-abhängig und zu unterschiedlichen Entwicklungszeitpunkten exprimiert werden.

Der dritte Vertreter, das 753 AS große Protein Zinedin, wurde auf der Grundlage einer „TBLASTN“-Suche mit der NCBI EST-Datenbank als Striatin- und SG2NA-homologes Protein identifiziert (Castets et al. 2000).

Detaillierte Studien gaben Aufschluss darüber, dass Striatin, SG2NA und Zinedin in verschiedenen Bereichen des Säugerhirns lokalisiert sind. Eine vermehrte Expression von Striatin wurde im Striatum, olfaktorischen Tuberkel, Nucleus ruber, Nucleus subthalamicus und den Kranialnerv-Motorkernen festgestellt (Salin et al. 1998). SG2NA wurde vorwiegend im Kleinhirn (Cerebellum), trigeminalen und cochlearen Kern und im Hippocampus gefunden (Castets et al. 2000). Zinedin wurde primär im Hippocampus, in der Großhirnrinde (Cortex cerebri), im Riechkolben (Bulbus olfactorius) und im Caudate-Putamen-Kern (dorsales Striatum) lokalisiert (Benoist et al. 2008). Alle drei Proteine akkumulieren vorwiegend in den somato-dendritischen Bereichen von Neuronen und dort insbesondere in den dendritischen Dornen exzitatorischer Synapsen. In Axonen hingegen wurden die Proteine bisher nicht nachgewiesen (Benoist et al. 2008, Castets et al. 1996, Gaillard et al. 2006, Kachidian et al. 1998).

Darüber hinaus wurden die Striatin-Proteine auch in Neuronen des peripheren Nervensystems und in verschiedenen Gewebetypen wie beispielsweise Herz-, Muskel-, Nieren- oder Hoden-Gewebe nachgewiesen (Blondeau et al. 2003, Moreno et al. 2000, Moqrich et al. 1998, Sanghamitra et al. 2008).

Die Proteine Striatin, SG2NA und Zinedin weisen eine charakteristische modulare Proteinstruktur auf (Abb. 1A). Sie enthalten mehrere für die Ausbildung von Protein-Protein-Interaktionen typische Domänen. Im N-terminalen Bereich der Proteine befindet sich ein Domänen-,Cluster“ bestehend aus Caveolin-Bindedomäne, ,coiled-coil“"-Motiv und Calmodulin-Bindedomäne. Der C-Terminus ist durch ein „WD-repeat“-Motiv geprägt (Gaillard et al. 2001, Gaillard et al. 2006, Bartoli et al. 1998). Diese vier Domänen sind in allen Proteinen der Striatin-Familie in der gleichen Reihenfolge angeordnet und sind darüber hinaus zwischen verschiedenen Spezies hoch konserviert, was darauf hindeutet, dass Striatin-Proteine eine fundamentale Funktion erfüllen. 


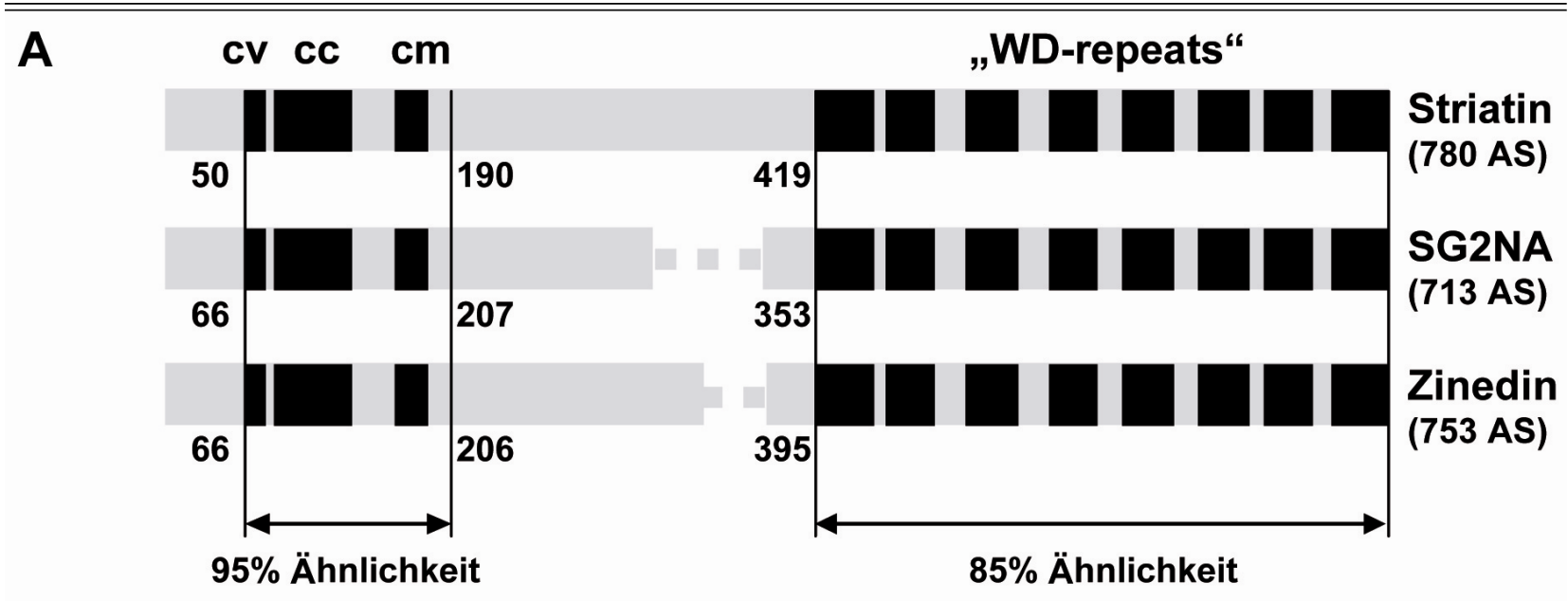

B

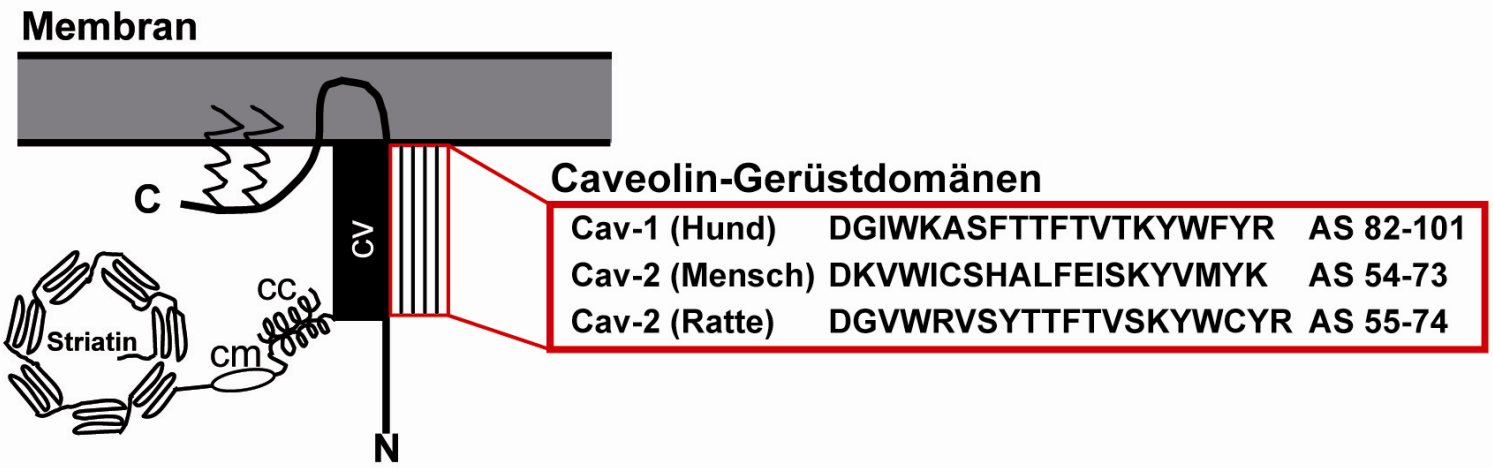

C Calmodulin-Bindedomänen

$\begin{array}{llll}149 & \text { QNSQLMWKQGRQLLRQYL } & 166 & \text { Striatin } \\ 166 & \text { QNSQLTWKQGRQLLRQYL } & 183 & \text { SG2NA } \\ 165 & \text { ENSPLVWWKEGRQLRQYL } & 182 & \text { Zinedin }\end{array}$

\begin{abstract}
Abb. 1 Struktureller Aufbau von Proteinen der Striatin-Familie aus Säugern. (A) Schematische Darstellung der Striatin-Proteine mit der Anordnung der Protein-Protein-Interaktionsdomänen (schwarze Boxen). Das N-terminale Domänen-,,Cluster“ bestehend aus Caveolin-Bindedomäne (cv), ,,coiled-coil“Motiv (cc) und Calmodulin-Bindedomäne $(\mathrm{cm})$ und das C-terminale „WD-repeat"-Motiv sind in den drei Proteinen stark konserviert (95\% und $85 \%$ Ähnlichkeit). Die AS-Größen der Proteine sind angegeben (verändert nach Castets et al. 2000). (B) Cytoplasma/Membran-Topologie des Caveolin-Proteins. Durch Palmitolyierung wird das Caveolin in der Membran verankert (gezackte Linien). Die CaveolinBindedomäne der Striatin-Proteine interagiert mit der Caveolin-Gerüstdomäne (schraffierte Box). Die Propeller-ähnliche-Struktur des Striatin C-Terminus und die gewundene Struktur des „coiled-coil“-Motivs sind angedeutet. Die für die Interaktionen mit der Caveolin-Bindedomäne obligate Sequenz der CaveolinGerüstdomäne ist für alle Mitglieder der Caveolin-Familie jeweils angegeben (verändert nach Couet et al. 1997). (C) AS-Sequenzen der experimentell bestätigten Calmodulin-Bindedomänen von Striatin, SG2NA und Zinedin. Jeweils abweichende AS sind unterstrichen (Castets et al. 2000).
\end{abstract}

Eine umfassende „BLAST“-Datenbanksuche ergab keine weitere Protein-Kategorie mit der gleichen Domänen-Anordnung, weswegen diese als spezifische Signatur von Proteinen der Striatin-Familie angesehen werden kann (Benoist et al. 2006). 
Gaillard et al. (2001) bestätigte die Funktionalität der in Striatin, SG2NA und Zinedin enthaltenen

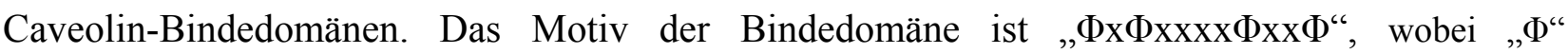
aromatische und „x“ beliebige AS darstellen. Die Fähigkeit zur direkten Bindung von Caveolin-1 wurde experimentell durch „Pull-down“-Experimente nachgewiesen. Darüber hinaus wurde die inhibierende Wirkung von $\mathrm{Ca}^{2+}$ auf die Interaktion gezeigt.

Caveoline sind 21-24 kDa große integrale Membranproteine. Der N- und C-terminale Teil des Proteins befindet sich im Cytoplasma. Dieser cytoplasmatische Bereich von Caveolin enthält ein spezifisches Motiv, die Caveolin-Gerüstdomäne, welche eine Homodimerisierung des Proteins aber auch cytoplasmatische Protein-Protein Interaktionen mit Lipiden (z. B. Cholesterol, Glykosphingolipide) und mit Lipid-modifizierten Signalproteinen (z. B. G-Proteine, Src-Kinasen) vermittelt (Dupree et al. 1993, Sargiacomo et al. 1995, Murata et al. 1995, Li et al. 1996a, Li et al. 1996b). In Säugern existieren drei Caveolin-Proteine. Couet et al. (1997) identifizierten jeweils eine 20 AS lange Gerüstdomänen-Sequenz, welche obligat für die Interaktion mit der CaveolinBindedomäne ist (Abb. 1B).

Caveoline bilden die Hauptstrukturkomponente der sogenannten Caveolae, welche 50-100 nm große Einstülpungen der Plasmamembran darstellen (Fujimoto et al. 1998, Simons und Toomre 2000). Caveolae werden als dynamische Mikrodomänen angesehen, in welchen die spezifische Zusammenführung bestimmter Signalmoleküle dazu dient zelluläre Signaltransduktionsprozesse in Abhängigkeit von $\mathrm{Ca}^{2+} \mathrm{zu}$ kompartimentalisieren (Brazer et al. 2003, Murata et al. 2007, Pani und Singh 2009, Pike 2006). Darüber hinaus können durch die Bildung solcher Membranstrukturen Proteine in räumliche Nähe zueinander gebracht werden, die in unterschiedlichen Organellen lokalisiert sind, wie z. B. Mitochondrien und endoplasmatisches Reticulum und somit eine direkte Kommunikation zwischen verschiedenen Zellkompartimenten ermöglichen (Duchen et al. 2008). Es wird postuliert, dass Membran-Mikrodomänen wie Caveolae und ihre strukturellen Verwandten die „Lipid rafts“ neben der Vermittlung von Signaltransduktionskaskaden eine wichtige Rolle bei einer Vielzahl biologischer Prozesse wie beispielsweise Apoptose, virale Infektion, Zelladhäsion, Organisation des Zytoskeletts oder Exo- und Endocytose spielen (Brown und London 1998, Patel et al. 2008, Simons und Toomre 2000).

Ultrastrukturelle Studien von Petralia et al. (2003) demonstrierten eine Anreicherung von Caveolin-1 in den dendritischen Dornen von Neuronen aus dem Hippocampus. Es wird daher vermutet, dass Striatin-Proteine aus Säugern durch ihre Interaktion mit Caveolin spezifisch an Membran-Mikrodomänen in den dendritischen Dornen assoziiert und dort in $\mathrm{Ca}^{2+}$-abhängige Signaltransduktionsprozesse involviert sind (Benoist et al. 2006).

Die zweite N-terminale Domäne der Striatin-Proteine, das „,coiled-coil“-Motiv, scheint funktionell zu der Lokalisierung der Proteine in den dendritischen Dornen beizutragen. Das „coiled-coil“Motiv besteht aus mindestens zwei $\alpha$-Helices, welche umeinander zu einer Mehrfachhelix gewunden sein können. Die „coiled-coil“-Domäne ist eines der in Proteinen am häufigsten 
identifizierten Strukturmotive, welches die Homo- oder Hetero-Dimerisierung vieler Gerüstproteine vermittelt (Kammerer 1997, Lupas 1996, Yu 2002, Gonzalez et al. 1996). So demonstrierten Gaillard et al. (2006) auch für die Proteine aus der Striatin-Familie eine Homound Heterodimer-Bildung über das „,coiled-coil“-Motiv. Darüber hinaus zeigten sie auf, dass die Oligomerisierung die Voraussetzung für die Lokalisierung der Striatin-Proteine in den dendritischen Dornen ist.

Ein weiterer Beleg für die Beteiligung von Striatin-Proteinen in $\mathrm{Ca}^{2+}$-abhängigen Signaltransduktionswegen wurde über die funktionelle Bestätigung der Calmodulin-Bindedomäne von Striatin, SG2NA und Zinedin erbracht (Abb. 1C). Die Bindung an Calmodulin wird über eine amphipatische Helix vermittelt (Bartoli et al. 1998, Castets et al. 1996, Castets et al. 2000). Calmodulin (CaM) ist ein ubiquitäres $17 \mathrm{kDa}$ großes Protein. Durch seine charakteristische „helix-loop-helix“"-Struktur („EF-hand“-Motiv) ist es zur Bindung von $\mathrm{Ca}^{2+}$-Ionen fähig. Die $\mathrm{Ca}^{2+}$-Bindung führt $\mathrm{zu}$ einer Konformationsänderung des CaM, welche Protein-ProteinInteraktionen und hierdurch die Regulation der Zielproteine ermöglicht (Chou et al. 2001). Durch den $\mathrm{Ca}^{2+} / \mathrm{CaM}-$ Komplex aktivierte Proteine sind z. B. die bereits vorgestellte Adenylyl-Zyklase und mehrere CaM-abhängige Kinasen. Die Regulation umfasst vielfältige biologische Prozesse wie Metabolismus, Apoptose, Muskelkontraktion, Kurzzeit- und Langzeitgedächtnis, neuronales Wachstum und Immunantwort (Colomer und Means 2007, Wayman et al. 2008, Witczak et al. 2008).

Wie aus Abbildung 1A hervorgeht sind die C-terminalen Bereiche der Striatin-Proteine jeweils durch acht putative „WD-repeat“-Motive charakterisiert. Die „WD-repeat“-Protein-Familie umfasst eine große Anzahl an Proteinen, welche vielfältige Funktionen wie beispielsweise Transkription, Organisation des Zytoskeletts, vesikuläre Transportprozesse oder Signalweiterleitung aufweisen (Smith et al. 1999). Das „WD-repeat"-Sequenzmotiv wurde erstmals in der $\beta$-Untereinheit des retinalen G-Proteins Transducin aus dem Rind identifiziert (Fong et al. 1986). Es zeichnet sich strukturell durch eine 40 AS lange konservierte KonsensusSequenz aus, welche N-terminal von den AS Glycin $(\mathrm{G})$ und Histidin $(\mathrm{H})$ und C-terminal von den AS Tryptophan (W) und Asparaginsäure (D) flankiert wird. N-terminal schließt sich ein weniger stark konservierter Sequenzbereich variabler Länge an (Neer et al. 1994).

Röntgenstrukturanalysen ergaben, dass die „WD-repeats“ räumlich eine Propeller-ähnliche Struktur einnehmen (Lambright et al. 1996, Sondek et al. 1996). Es wird davon ausgegangen, dass diese Struktur als stabile Plattform für aufeinanderfolgende oder gleichzeitig stattfindende Protein-Protein-Interaktionen dienen kann und „WD-repeat“-Proteine somit als Gerüstproteine die 
Ausbildung multimerer Proteinkomplexe vermitteln. Innerhalb der großen Familie der „WDrepeat"-Proteine sind Striatin-Proteine bislang die einzigen bekannten Vertreter, welche Calmodulin in $\mathrm{Ca}^{2+}$-abhängiger Weise binden können (Benoist et al. 2006).

Neben den drei Striatin-Proteinen aus Säugern wurden bisher insgesamt sieben homologe Proteine aus filamentösen Ascomyceten und Tieren beschrieben. Dazu gehören das Protein PRO11 aus dem homothallischen Ascomyceten Sordaria macrospora, HAM3 (Hyphenanastomose-Mutante 3) aus dem heterothallischen Ascomyeten Neurospora crassa, Fsr1 aus den pflanzenpathogenen Pilzen Fusarium verticillioides und Fusarium graminearum, StrA aus Aspergillus nidulans, CKA (,connector of kinase to AP-1“) aus der Fruchtfliege Drosophila melanogaster und die beiden durch alternatives Spleißen hervorgebrachten Isoformen SG2NA $\alpha$ und SG2NA ${ }^{+}$aus dem Goldfisch Carassius auratus (Chen et al. 2002, Ma et al. 2009, Pöggeler und Kück 2004, Shim et al. 2006, Simonin et al. 2010, Wang et al. 2010, Yamamura und Shim 2008).

Diese Proteine zeigen den gleichen modularen Aufbau wie die Striatin-Proteine aus Säugern. Überraschenderweise, konnte darüber hinaus auch eine partielle funktionelle Konservierung zwischen den Striatin-Proteinen aus Säugern und filamentösen Pilzen nachgewiesen werden. In einer Komplementationsanalyse restaurierte eine eingebrachte Mus musculus striatin-cDNA den Differenzierungsdefekt der S. macrospora pro11-Punktmutante (Pöggeler und Kück 2004).

\subsection{Die vielfältigen Funktionen von Striatin-Proteinen}

Die zellulären Funktionen von Striatin-Proteinen in lebenden Organismen sind bisher nur wenig verstanden, da insbesondere die gezielte molekularbiologische Modifizierung von ModellOrganismen aus der Gruppe der höheren Eukaryoten (z. B. Maus) diffizil bleibt. Die bisherigen Erkenntnisse geben jedoch Aufschluss darüber, dass Striatin-Proteine eine Schlüsselfunktion in einer Vielzahl von Prozessen spielen, deren Fehlregulation unter anderem zu ernsthaften Beeinträchtigungen der Vitalität führen kann.

So wurde Striatin kürzlich eine Beteiligung bei der Pathogenese der arrhythmogenen rechtsventrikulären Kardiomyopathie (ARVC) zugeschrieben, eine erbliche Herzerkrankung, die für den plötzlichen Herztod verantwortlich gemacht wird. In der korrespondierenden Studie wurde bei von ARVC betroffenen Hunden eine Deletion von 8 bp in der 3'-UTR des striatin Gens identifiziert, welche zu einer Mutation in der Stammschleifenstruktur der striatin mRNA und zu einem jeweils verminderten Transkript- und Proteinlevel führte (Meurs et al. 2010).

In einer Studie von Bartoli et al. (1999) wurde mit Hilfe einer Oligonukleotid-basierten AntisenseStrategie die striatin Expression im Hirn der Ratte herunterreguliert und bei den entsprechenden 
Tieren eine Beeinträchtigung in der nächtlichen lokomotorischen Aktivität und eine Verminderung des Dendritenwachstums festgestellt.

Die Zerstörung der zu striatin homologen pilzlichen Gene FSRI aus F. graminearum, ham-3 aus $N$. crassa und strA aus $A$. nidulans führte in allen Organismen zum Verlust der Fertilität. Darüber hinaus konnte für F. graminearum eine reduzierte Virulenz und für $N$. crassa ein Verlust der Fähigkeit zur vegetativen Zellfusion festgestellt werden (Shim et al. 2006, Simonin et al. 2010, Wang et al. 2010, Yamamura und Shim 2008). Die S. macrospora pro11-Mutante, welche eine Punktmutation im proll-Gen aufweist ist ebenfalls in der Ausbildung sexueller Fortpflanzungsstrukturen gestört (Pöggeler und Kück 2004).

\subsection{Interaktionspartner von Striatin-Proteinen und die Signalwege in denen sie wirken}

\subsubsection{Phocein/Mob3 - ein Protein aus der Mob-Familie}

Einer der ersten in einem Hefe Two-Hybrid „Screen“ identifizierten Interaktionspartner von Striatin-Proteinen aus Rattus norvegicus war das 225 AS große Protein Phocein/Mob3 (Baillat et al. 2001). Studien zur Ko-Lokalisierung von Phocein/Mob3 und den Vertretern der StriatinFamilie zeigten auf, dass die Proteine dasselbe Verteilungsmuster in den somato-dendritischen Kompartimenten verschiedener Neuronen-Typen, insbesondere in den dendritischen Dornen, aufwiesen. Die erstmals in der Hefe Two-Hybrid-Analyse gezeigte Interaktion wurde so auch auf der subzellulären Ebene bestätigt (Baillat et al. 2001, Bailly und Castets 2007, Haeberle et al. 2006).

Phocein/Mob3 gehört zu der Familie der Mob- (,,monopolar spindle-one-binder" ${ }^{6}$ Proteine. MobProteine kommen konserviert von Bäckerhefe bis Mensch in einer Vielzahl von Organismen vor und zeichnen sich strukturell durch eine charakteristische Kern-Sequenz, die ca. 180-200 AS lange sogenannte Mob-Domäne aus (Baillat et al. 2001, Luca und Winey 1998, Ponchon et al. 2004).

Die Proteine der Mob-Familie werden nach zwei unterschiedlichen Klassifizierungen verschiedenen Untergruppen zugeordnet. In dem Modell von Mrkobrada et al. (2006) werden die Mob-Proteine basierend auf einem Homologie-Vergleich der konservierten Mob-Domänen in den drei Untergruppen Mob1-ähnliche Proteine, Mob2-ähnliche Proteine und Mob3-ähnliche Proteine zusammengefasst. Ausgehend von den Ergebnissen phylogenetischer Analysen können Mob-Proteine nach dem Modell von Vitulo et al. (2007) in fünf verschiedene Untergruppen (Mob1, Mob2, Mob3, Mob4 und Mobp) eingeordnet werden. Phocein wird in beiden Modellen der jeweils divergentesten Mob3Gruppe zugeordnet und daher auch als Mob3-Protein bezeichnet.

Die Hefe Saccharomyces cerevisiae besitzt zwei Mob-Proteine, Mob1p und Mob2p, welche durch die Interaktion mit Dbf-2-Kinasen die Beendigung der Mitose, die Zytokinese, die Septenbildung 
und die Steuerung der Zell-Polarität regulieren (Hou et al. 2003, Hou et al. 2004, Lee et al. 2001, Luca et al. 2001, Surana und Lim 2002). Ein Mob3-Homolog wird von der Hefe hingegen nicht kodiert. Der filamentöse Ascomycet $N$. crassa und die Fruchtfliege D. melanogaster weisen jeweils vier und Homo sapiens sieben Mob-Proteine auf, von denen jeweils eines ein Mob3Protein repräsentiert (Maerz et al. 2009, Trammell et al. 2008, Chow et al. 2010).

In höheren Eukaryoten interagieren die zu Mob1p und Mob2p aus S. cerevisiae homologen Proteine mit NDR („nuclear Dbf2-related“) Serin/Threonin Protein-Kinasen und sind hierdurch an der Kontrolle des Zell-Zyklus, der Zellproliferation, der Tumor-Suppression und an apoptotischen Prozessen beteiligt (Maerz et al. 2009, Ma et al. 2010, He et al. 2005, Devroe et al. 2004, Lai et al. 2005).

Mit Hilfe der Röntgenstruktur-Analyse konnte die Proteinstruktur von Mob1-Proteinen aus $S$. cerevisiae, Xenopus laevis und H. sapiens aufgeklärt werden (Mrkobrada et al. 2006, Ponchon et al. 2004, Stavridi et al. 2003). Wie Abb. 2A am Beispiel des H. sapiens Mob1-Proteins zeigt, beinhaltet die konservierte Mob-Domäne die Hauptstruktur-gebenden Elemente (neun Helices und ein $\beta$-,,hairpin“ aus den zwei antiparallel angeordneten $\beta$-Faltblättern S1 und S2). Das Protein nimmt eine globuläre Struktur ein, die als Kernelement ein Bündel aus den vier langen Helices H2, H4, H5 und H7 aufweist (Abb. 2B). Das Helixbündel wird von den zwei kurzen Helices H3 und H6 und dem $\beta$-,,hairpin“ flankiert und durch ein tetraedisch koordiniertes Zink-Atom stabilisiert. Darüber hinaus enthält die Sequenz N-terminal der Kernstruktur die kurze Helix H1 und die Sequenz C-terminal der Kernstruktur die beiden kurzen Helices H8 und H9.

Vitulo et al. (2007) erarbeiteten basierend auf einem multiplen Sequenz-Alignment eine Konsensus-Sequenz für die in Mob-Proteinen konservierte charakteristische Mob-Domäne. Mob3-Proteine bilden wie erwähnt die divergenteste Untergruppe der Mob-Familie und weisen daher im Vergleich zu den Proteinen der anderen Untergruppen eine relativ geringe Homologie zu der Konsensus-Sequenz der Mob-Domäne auf (Abb. 2A). Dennoch können sie zweifellos als Proteine der Mob-Familie klassifiziert werden, da einige der wichtigsten strukturgebenden Elemente wie die Helices 2 und 5, die beiden „Loops“ (Sequenzschleifen) L1 und L2, die Sequenz und Position der $\beta$-Faltblätter und die Zink-Bindestelle bestehend aus jeweils zwei Cystein- und Histidin-Resten zumindest teilweise konserviert sind. 


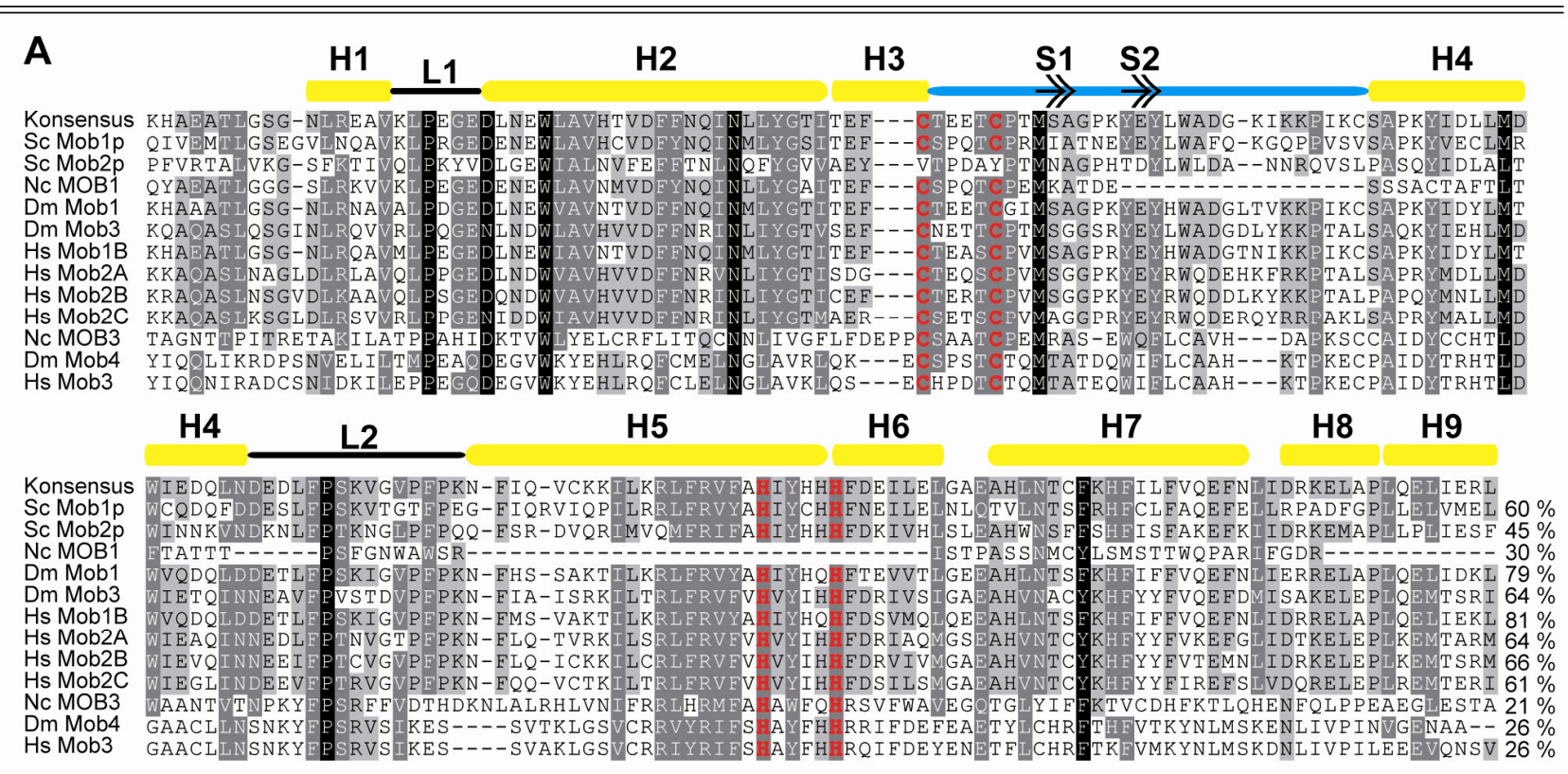

B
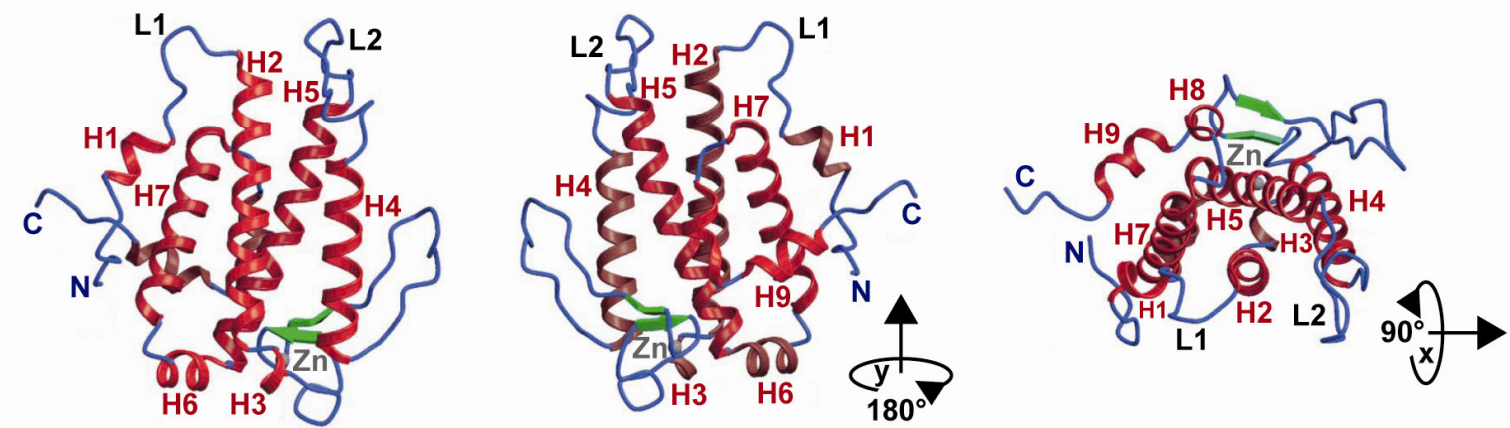

Abb. 2 Struktureller Aufbau von Proteinen aus der Mob-Familie. (A) Die AS-Sequenzen der MobDomänen verschiedener Proteine aus der Mob1- und Mob3-Gruppe wurden mit der Konsensus-Sequenz der Mob-Domäne in einem multiplen Alignment verglichen (verändert nach Vitulo et al. 2007). Die drei unteren Sequenzen repräsentieren jeweils das Phocein/Mob3-Homolog des angegebenen Organismus. Die prozentuale Sequenz-Identität der jeweiligen Mob-Domäne zu der Konsensus-Sequenz ist für jedes Protein rechts angegeben. Schwarz hinterlegte AS sind in allen verglichenen Sequenzen konserviert, dunkelgrau hinterlegte AS in mind. 10 und hellgrau hinterlegte AS in mind. 8 Sequenzen. Die Cystein- und HistidinReste der Zink-Bindestelle sind rot markiert. Die experimentell nachgewiesene Anordnung der Strukturelemente des Mob1-Proteins aus H. sapiens ist über dem Alignment angegeben (Erläuterungen siehe Textfluss). Abkürzungen: Sc-Saccharomyces cerevisiae, Nc-Neurospora crassa, Dm-Drosophila melanogaster, Hs-Homo sapiens. Accession-Nummern und Angabe der in dem Alignment verwendeten Proteinbereiche + Gesamtlänge der Proteine: Sc Mob1p (NP 012160.2) AS 129-311 (314), Sc Mob2p (NP 116618.1) AS 99-278 (287), Nc MOB1 (XP 956516.2) AS 33-149 (149), Dm Mob1 (NP 651041.3) AS 30-211 (219), Dm Mob3 (NP_609364.1) AS 33-183 (220), Hs Mob1B (NP_060691.2) AS 30-210 (216), Hs Mob2A (NP 570719.1) AS 33-215 (217), Hs Mob2B (NP 079037.3) AS 32-214 (216), Hs Mob2C (NP_958805.1) AS 32-214 (216), Nc MOB3 (XP_962316.2) AS 91-274 (598), Dm Mob4 (NP_610229.1) AS 42-217 (223), Hs Mob3 (NP_056202.2) AS 42-219 (225). (B) Dreidimensionale Ansicht der Tertiärstruktur des Mob1-Proteins aus H. sapiens (Stavridi et al. 2003).

Insgesamt scheinen die Mob3-Proteine im Vergleich $\mathrm{zu}$ den Mob-Proteinen der anderen Untergruppen jedoch unterschiedliche zelluläre Aufgaben zu übernehmen, da sie neben den bestehenden strukturellen Unterschieden andere Interaktionspartner aufweisen. 
Neben der eingangs erwähnten Interaktion des Säuger Mob3-Proteins mit den Vertretern der Striatin-Familie konnten als weitere Interaktionspartner von Mob3 die Nukleosid-Diphosphat Kinase (NDPK), Eps15 (,epidermal growth factor receptor substrate 15“) und Dynamin I identifiziert werden. Da diese Proteine nachweislich eine Rolle in der Endocytose und bei dem vesikulären Transport spielen, wird dem Mob3 Protein ebenfalls eine Funktion in diesen biologischen Prozessen zugeschrieben (Baillat et al. 2002). Ob die Vermittlung von Endocytose und vesikulärem Transport über eine Protein-Komplexbildung erfolgt an der auch die Proteine der Striatin-Familie beteiligt sind oder ob diese Prozesse unabhängig hiervon reguliert werden, muss jedoch in zukünftigen Studien noch eindeutig verifiziert werden.

Die Endocytose dient der Aufnahme extrazellulärer Nährstoffe und der Regulierung Rezeptor-vermittelter extrazellulärer Signale durch die Internalisierung von Liganden, Rezeptoren und assoziierten Membranproteinen (Mellman 1996). Bei der Clathrinvermittelten Endocytose wird durch die Anlagerung der Clathrin-Triskelions das Einstülpen der Membran und die Bildung eines Vesikels induziert. Nach der Abschnürung des Vesikels bildet das polygonale Clathrin-Gitter die Hülle des Vesikels. Bei der Entstehung der Vesikel spielen auch Aktin-Filamente eine entscheidende Rolle. Für die Bindung des Clathrin-Gitters an die Plasmamembran und die Selektion der Proteinfracht (Cargo) sind Adaptor-Protein (AP)-Komplexe notwendig (Ohno 2006, Kaksonen et al. 2006). Der heterotetramere AP-Komplex besteht aus zwei großen Untereinheiten und den zwei kleinen Untereinheiten $\mu$ und $\sigma$ (Ohno 2006, Boehm und Bonifacino 2001). Jede der Untereinheiten erfüllt eine spezifische Funktion. Der kleinen Untereinheit $\sigma$ wird eine stabilisierende Funktion innerhalb des AP-Komplexes und eine Beteiligung bei der CargoAuswahl zugedacht (Collins et al. 2002).

In anderen Eukaryoten wurden bislang keine Interaktionspartner von Mob3-Proteinen identifiziert. Funktionelle Studien ergaben, dass das Mob3-Homolog DMob4 aus D. melanogaster in die Anordnung der Spindelfasern, die Ausbildung von Synapsen, den axonalen Transport in Neuronen und die zelluläre Organisation der Mikrotubuli involviert ist (Schulte et al. 2010, Trammell et al. 2008). Darüber hinaus wurde für das homologe Protein MOB3 in N. crassa eine Beteiligung bei der Fusion vegetativer Zellen und bei der sexuellen Differenzierung nachgewiesen. In derselben Studie wurde außerdem gezeigt, dass diese Funktion unabhängig von der Aktivität des NDR-Kinase-Signalwegs ist (Maerz et al. 2009).

\subsubsection{Die Protein-Phosphatase 2A (PP2A)}

Als weiterer Interaktionspartner von den Proteinen der Striatin-Familie aus Säugern konnte die Protein-Phosphatase 2 A (PP2A) identifiziert werden. In biochemischen Studien wurde gezeigt, dass die A/C-Untereinheit von PP2A stabile Protein-Komplexe mit Striatin und SG2NA in Abwesenheit von B, B' oder B', Untereinheiten ausbildet (Moreno et al. 2000). Die Assoziierung 
der Proteine ist dabei unabhängig von der Methylierung der katalytischen Untereinheit C (Yu et al. 2001).

PP2A ist eine multifunktionale heterotrimere Serin/Threonin-Phosphatase, welche aus einer strukturellen Untereinheit A, einer katalytischen Untereinheit $\mathrm{C}$ und einer regulatorischen Untereinheit B besteht (Berndt 2003). PP2A ist in eine Vielzahl zellulärer Prozesse, wie DNA-Replikation, Transkription, Translation, neuronale Signalübertragung, Zell-ZyklusRegulation und Zell-Teilung involviert (Janssens und Goris 2001, Lechward et al. 2001). Die Ausübung dieser vielfältigen und unterschiedlichen Funktionen wird durch die Interaktion der heterodimeren A/C-Form von PP2A mit einer Vielzahl regulatorischer Untereinheiten (B, B' und B') ermöglicht, welche die Phosphatase innerhalb der Zelle zu spezifischen Mikrodomänen und/oder Signal-Komplexen dirigieren und die Aktivität der Phosphatase modulieren (Moreno et al. 2000). Die katalytische Untereinheit C wird in posttranslationalen Modifikationen phosphoryliert oder methyliert und insbesondere die Methylierung ist entscheidend für die Assoziierung mit der regulatorischen B-Untereinheit (Yu et al. 2001).

Darüber hinaus führte die Inhibierung von PP2A durch Okadainsäure zu einem starken Anstieg der Phosphorylierung von Striatin und SG2NA, was darauf hindeutet, dass beide Proteine Substrate von PP2A darstellen. Striatin und SG2NA wurden daher als neue Subklasse regulatorischer B-Untereinheiten von PP2A vorgeschlagen (Moreno et al. 2001).

Mit Hilfe detaillierter biochemischer Analysen konnten kürzlich im sogenannten STRIPAKKomplex (,striatin-interacting phosphatase and kinase“) weitere Proteine identifiziert werden, welche an der Striatin bzw. SG2NA/PP2A-Komplexbildung beteiligt sind (Goudreault et al. 2009). Dazu gehören Phocein/Mob3, die bislang uncharakterisierten Proteine STRIP1 und STRIP2 (,striatin-interacting proteins 1 und 2“), CCM3 (,cerebral cavernous malformation 3”) und alle Mitglieder der „Germinal Center Kinase III“-Familie der Ste20-Kinasen. Darüber hinaus bildet der STRIPAK-Komplex jeweils zusätzlich eine Interaktion mit CTTNBP2 („,cortactinbinding protein 2") und SLMAP (,sarcolemmal membrane-associated protein“) aus.

Eine CCM3-Genmutation bewirkt, dass im Gehirn abnormal geformte Blutgefäße mit einer dünnen und porösen Gefäßwand ausgebildet werden. In der Folge kann dies zu einem Gehirnschlag führen, welcher häufig tödlich verläuft (Bergametti et al. 2005, Guclu et al. 2005).

Die Beteiligung von Phosphatasen und Kinasen in dem STRIPAK-Komplex, sowie die Tatsache, dass STRIPAK zusätzliche Interaktionen mit funktionell verschiedenen Proteinen eingeht, weist darauf hin, dass es sich hierbei um einen Multiprotein-Signalkomplex handelt, welcher unterschiedliche Signalwege steuert. Die genauen Regulationsmechanismen des STRIPAKKomplexes aus Säugern und die resultierenden Zell-Antworten sind jedoch gänzlich unbekannt. 
Einige der STRIPAK-Komponenten sind auch in der Hefe S. cerevisiae konserviert und bilden den sogenannten Far-Komplex. Dieser scheint während der sexuellen Paarung an der Steuerung des Pheromon-induzierten $\mathrm{G}_{1}$-Zellzyklus-Arrests beteiligt zu sein (Kemp und Sprague 2003). Auch in filamentösen Pilzen wurden Homologe STRIPAK-Komponenten identifiziert, auf die in IV Diskussion näher eingegangen wird.

\subsubsection{ER $\alpha$ - Östrogen-vermittelte nicht-genomische und genomische Signalwege}

Eine weitere interessante Beteiligung von Striatin und SG2NA wurde bei der nicht-genomischen und genomischen Regulation der Östrogen-vermittelten Signalweiterleitung gefunden. Wie Lu et al. (2004) zeigten, wird bei der nicht-genomischen Signalweiterleitung der Östrogen-Rezeptor ER $\alpha$ durch die Interaktion mit Striatin im Bereich von Mikrodomänen an die Plasmamembran assoziiert. Dabei dient Striatin gleichzeitig als Gerüstprotein, welches eine Komplexbildung zwischen ER $\alpha$ und der G-Protein-Untereinheit Gai vermittelt. Nachfolgend werden die Mitogenaktivierte Proteinkinase (MAPK)- und Phosphatidylinositol-3 Kinase (PI3K)/Akt-KinaseSignalwege induziert, welche wiederum die membran-assoziierte endotheliale NO-Synthase (eNOS) aktivieren. Dieser Östrogen-vermittelte nicht-genomische Signalweg trägt zu der Regulation der arteriellen Erweiterung der Blutgefäße bei. Bei der genomischen Signalweiterleitung bewirkt die Komplexbildung von ER $\alpha$, PP2A und einer alternativ gespleißten Form von SG2NA die Dephosphorylierung von ER $\alpha$ und der Rezeptor wird dadurch in seiner Funktion als Transkriptionsfaktor gehemmt (Tan et al. 2008).

\subsubsection{Die Rolle von Striatin-Proteinen bei der Zell-Adhäsion}

Kürzlich wurde eine Interaktion von Striatin-Proteinen mit dem multifunktionalen Tumorsupressor des Wnt-Signalweges Adenomatous polyposis coli (APC) identifiziert (Breitman et al. 2008).

Der Wnt-Signalweg steuert essentielle Abläufe während der Embryogenese. Dabei übernimmt APC durch die Förderung des proteasomalen Abbaus von $\beta$-Catenin eine inhibierende Funktion, da hierdurch die $\beta$-Catenin-abhängige Transkription spezifischer Zielgene verhindert wird (Cadigan und Nusse 1997). APC übernimmt außerdem eine Schlüsselfunktion bei der Tumor-Suppression. Mutationen in dem $A P C$-Gen werden mit der Entwicklung von Dickdarm-Tumoren in Zusammenhang gebracht (Polakis 2000).

Breitman et al. (2008) zeigten, dass die Interaktion zwischen dem „WD-repeat“-Motiv von Striatin und dem „Armadillo-repeat“ von APC erfolgt, ein ca. 40 AS langes Sequenzmotiv, 
welches eine aus zwei $\alpha$-Helices bestehende „hairpin“-Konformation einnimmt und ein spezialisiertes Motiv für Protein-Protein-Interaktionen darstellt (Hatzfeld 1999).

Darüber hinaus zeigten Striatin und APC eine Aktin-abhängige Ko-Lokalisierung in den ZellZell-Kontaktstellen (,tight junctions“) von Epithelzellen, was darauf hindeutet, dass der Striatin/APC-Komplex an der Vermittlung der Zell-Zell-Adhäsion beteiligt ist (Breitman et al. 2008).

Auch das zu Striatin homologe CKA aus D. melanogaster scheint eine wichtige Rolle bei der Zell-Zell-Adhäsion zu spielen. Chen et al. (2002) demonstrierten, dass CKA vermutlich als Gerüstprotein im Zuge einer MAPK-Signalkaskade einen Komplex mit der JUN-N-terminalen Kinase (DJNK; auch BSK, „,basket“), der Kinase HEP („hemipterous“) und den Transkriptionsaktivatoren DJUN und DFOS bildet und so die Schließung des dorsalen RückenEpithels im Verlauf der Embryogenese koordiniert.

\subsubsection{Die Rolle von Striatin-Proteinen bei der Virus-Assemblierung}

Sleeman und Baron (2005) zeigten in Hefe Two-Hybrid und Ko-Immunopräzipitationsstudien eine Interaktion zwischen Striatin und der katalytischen Untereinheit „L“ der RNA-abhängigen RNA-Polymerase des Rinderpest-Virus (RPV). Die Polymerase besteht aus zwei Untereinheiten, dem Phosphoprotein (P) und dem großen Protein (L). Es wird vermutet, dass das Protein L als multifunktionelles Enzym alle katalytisch notwendigen Prozesse während der viralen RNASynthese übernimmt (Horikami et al. 1994). Daneben wurden auch einige Wirts-Proteine identifiziert, die für die virale RNA-Synthese notwendig sind. Dazu gehören Tubulin, Aktin, Profilin (ein Aktin-bindendes Protein), Translations-Elongationsfaktor 1 $\alpha$, Dynein und verschiedene Hitzeschock-Proteine (Moyer et al. 1990, De et al. 1993, Burke et al. 2000, Das et al. 1998, Qanungo et al. 2004, Poisson et al. 2001, Zhang et al. 2002a). Es wurde außerdem gezeigt, dass die Phosphorylierung der RPV P-Untereinheit durch die Casein-Kinase II (CK2) die Polymerase-Aktivität reguliert (Kaushik und Shaila 2004). CK2 und PP2A bilden in Zellen selbstregulierende Komplexe und es wurde daher hypothetisiert, dass das Gerüstprotein Striatin über die Interaktion mit L die Phosphatase PP2A und die Kinase CK2 in räumliche Nähe zu der Untereinheit P bringt und so die Aktivität der Polymerase reguliert wird (Heriche et al. 1997, Sleeman und Baron 2005).

Abbildung 3 fasst die vorgestellten Interaktionspartner und die Funktionen der Proteinkomplexe in denen Striatin-Proteine wirken zusammen. 


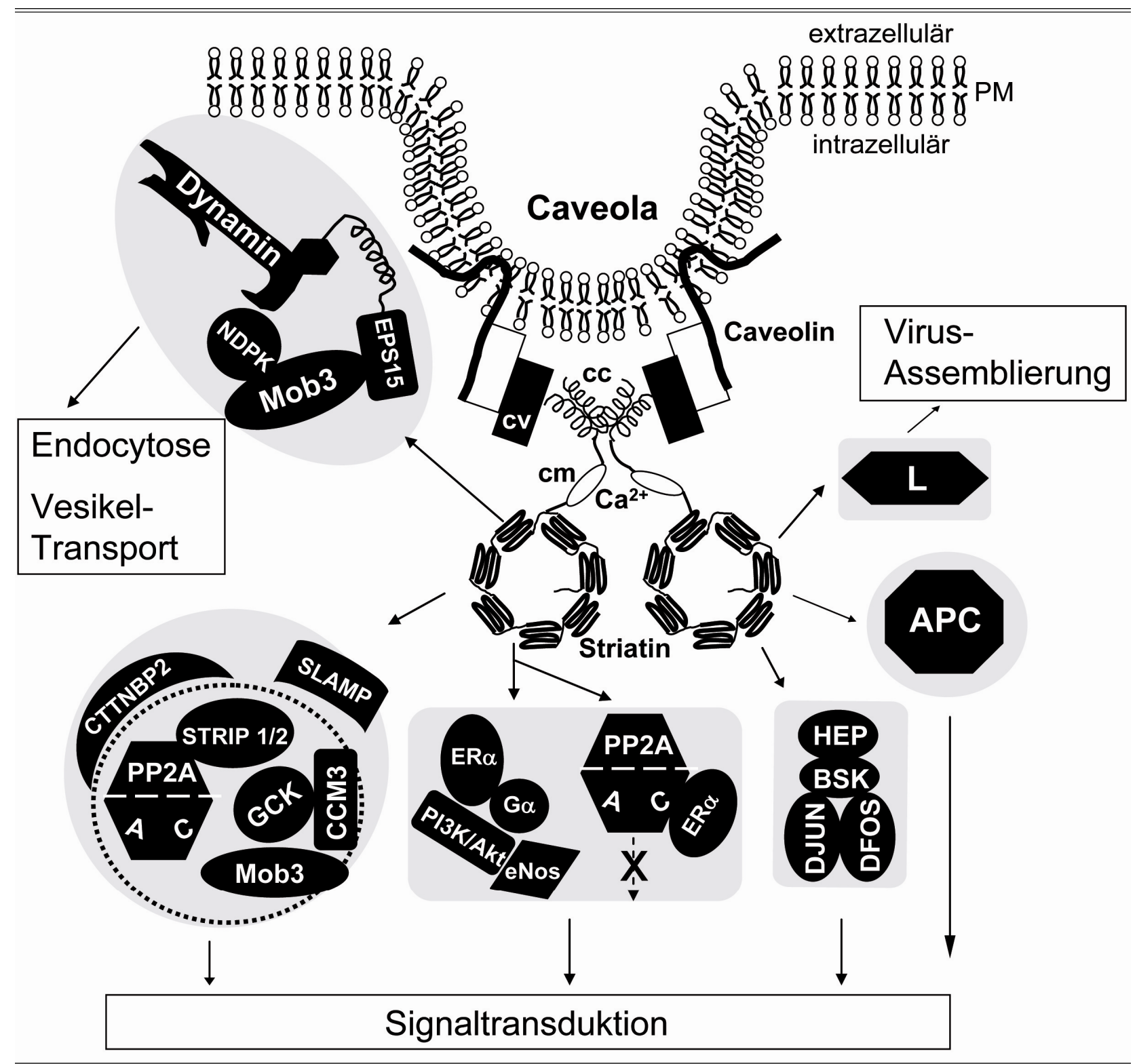

Abb. 3 Übersichtsmodell der Funktionen von Striatin-Proteinkomplexen. Erklärungen im Textfluss. PM-Plasmamembran (verändert nach Benoist et al. 2006).

Es wird deutlich, dass Striatine vermutlich als Gerüstproteine die Assemblierung vielfältiger Signalkomplexe vermitteln und so die Voraussetzung für die Regulierung verschiedener zellulärer Prozesse schaffen. Der in Abbildung 3 dargestellte Wirkungsort von Striatin-Komplexen ist eine der zahlreichen spezialisierten Mikrodomänen (Caveolae) der Plasmamembran. Es ist jedoch nicht auszuschließen, dass Striatine in Abhängigkeit von der funktionellen Zielsetzung auch an den Membranen anderer Zellorganellen Signalkomplexe organisieren. 


\section{Sordaria macrospora - Ein Hyphenpilz als Modell-Organismus zur Erforschung molekularer Differenzierungsprozesse}

Filamentöse Ascomyceten sind ideale multizelluläre Modell-Organismen für die Erforschung molekularer Mechanismen, welche entwicklungsbiologische Differenzierungsprozesse steuern. Als echte Eukaryoten enthalten sie Zellkerne und Mitochondrien und verfügen zudem über eine ähnliche genetische Ausstattung wie höhere Eukaryoten. Während der sexuellen Reproduktion durchlaufen filamentöse Pilze einen hochkomplexen Differenzierungsprozess: an einem gleichförmig gestalteten Myzel werden multizelluläre dreidimensionale Fruchtkörper gebildet (Pöggeler et al. 2006a). Auf der zellulären Ebene unterliegt diesem Differenzierungsprozess ein komplexes Wechselspiel molekularer Komponenten, von denen eine Vielzahl in höheren Eukaryoten konserviert ist (Pöggeler und Kück 2004, Xiang et al. 2002, Maerz et al. 2009).

Die Analyse des filamentösen Ascomyceten S. macrospora (Familie Sordariaceae, Unterklasse Pyrenomycetidae) als Modellorganismus bietet mehrere Vorteile (Engh et al. 2010, Kück et al. 2009). Der Pilz ist nicht infektiös, lässt sich unter Laborbedingungen einfach kultivieren und weist mit sieben Tagen einen kurzen Lebenszyklus auf. Das Genom ist mit 39,5 Mb relativ klein und die Genomsequenz vollständig sequenziert, wodurch sich der Organismus sehr gut für genetische Analysen eignet (Nowrousian et al. 2010, Walz und Kück 1995, Esser 1982). Außerdem sind viele aktuelle molekularbiologische Methoden für S. macrospora gut etabliert, wie z. B. Transformation, Konstruktion von Gen-Deletionsstämmen, RNA-Interferenz (RNAi)Studien oder Fluoreszenz-Mikroskopie (Pöggeler et al. 2003, Pöggeler und Kück 2006, Nolting et al. 2009, Walz und Kück 1995).

S. macrospora ist nah verwandt mit dem Modell-Organismus N. crassa, aber im Gegensatz zu diesem heterothallischen, selbststerilen Pilz ist $S$. macrospora homothallisch und selbstfertil, was bedeutet, dass kein Kreuzungspartner für die sexuelle Fortpflanzung notwendig ist. Darüber hinaus produziert S. macrospora ausschließlich meiotische Ascosporen. Asexuelle Sporen, wie z. B. Konidien bei N. crassa, fehlen (Esser 1982). Der Pilz eignet sich deswegen besonders zur Untersuchung von Genen, die in den sexuellen Differenzierungsprozess involviert sind, da rezessive, die Fruchtkörperentwicklung betreffende Mutationen ohne vorherige Kreuzung mit einem Kreuzungspartner erkannt werden können und es keine Überlagerung von sexuellen und asexuellen Entwicklungsprogrammen gibt.

Der Lebenszyklus von S. macrospora beginnt mit dem Auskeimen einer Ascospore zu einem gleichförmig gestalteten Myzel (Abb. 4). Nach ca. drei Tagen wird die sexuelle Entwicklung mit der Bildung der weiblichen Gametangien (Ascogone) eingeläutet. Diese werden von sterilen 
Hyphen umhüllt und differenzieren so zunächst zu Vor-Fruchtkörpern (Protoperithezien), welche nach ca. sieben Tagen zu den komplex strukturierten Fruchtkörpern (Perithezien) ausgereift sind.

Die Perithezien enthalten schlauchförmige Asci mit jeweils acht linear angeordneten Ascosporen. Diese werden ausgeschleudert und wachsen nach der Keimung zu einem neuen Myzel heran (Esser 1982).

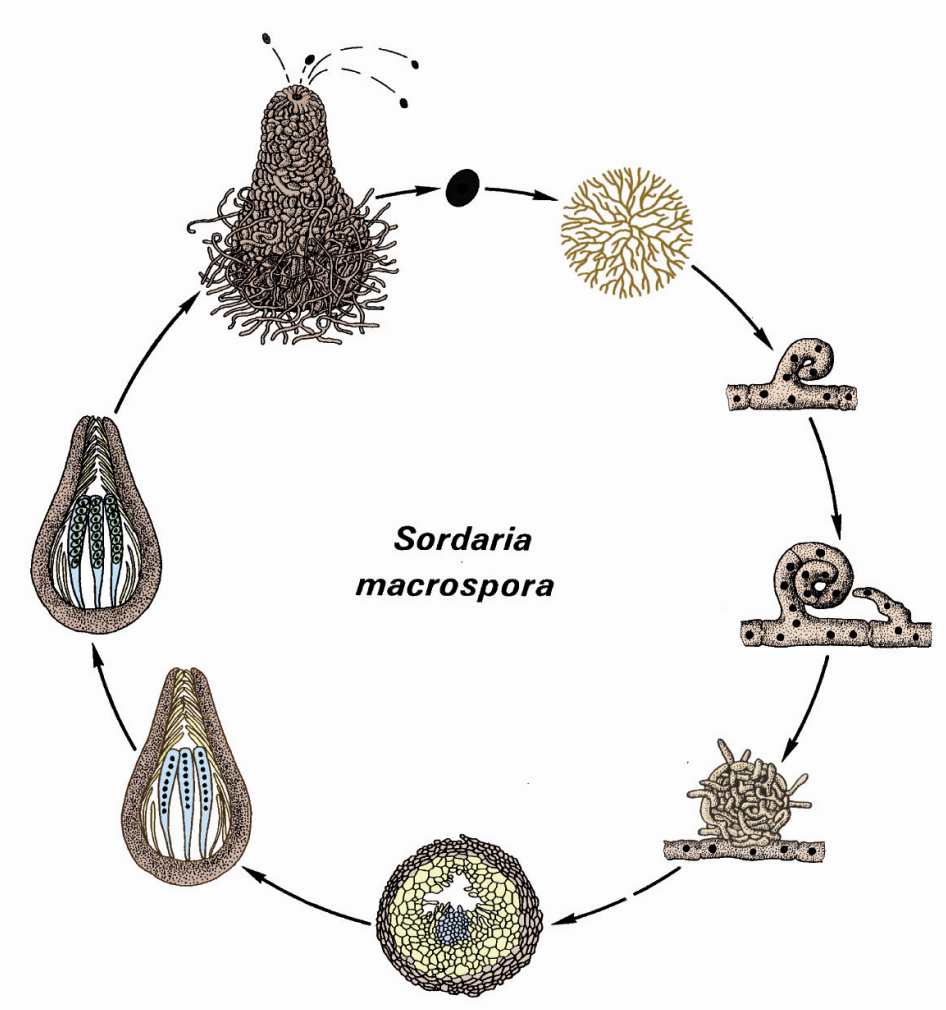

Abb. 4 Der Entwicklungszyklus von $S$. macrospora (verändert nach Rathke).

S. macrospora wird seit langem als Modell-Organismus für konventionelle genetische Studien und für die molekularbiologische Analyse der Fruchtkörperentwicklung genutzt. So konnten bereits verschiedene $S$. macrospora-Mutanten charakterisiert werden, die in der Entwicklung von den Protoperithezien zu den Perithezien gestört sind (pro-Mutanten) und eine per-Mutante, welche einen Defekt bei der vollständigen Reifung der Perithezien aufweist.

Neben 45 pro- und 44 per-Mutanten, existieren von S. macrospora auch die sogenannten asc- und pile-Mutanten. Die asc-Mutanten weisen einen Arrest in der ersten Stufe der Ascogonenbildung auf. Die ausgebildeten Ascogone besitzen im Vergleich zu dem wtStamm jedoch häufig eine entartete Struktur. Die asc-Mutanten sind steril und Protoperithezien werden nie ausgebildet. Interessanterweise zeigen nur fünf aus den über 100 Stämmen der S. macrospora Mutanten-Kollektion einen asc-Phänotyp. In den pileMutanten ist die räumliche Anordnung der Perithezien gestört. Die Perithezien werden 
häufig stapelartig übereinander gebildet. Es wurden 16 Mutanten mit diesem Phänotyp identifiziert, welche jedoch eine genetische Instabilität aufweisen (Kück et al. 2009).

Die korrespondierenden Gene kodieren für funktionell diverse Proteine: die Untereinheit einer ATP-Citrat-Lyase (per5-Mutante), eine Isopropylmalat-Dehydrogenase (Enzym der LeucinBiosynthese) (pro4-Mutante), einen C6-Zinkfingertranskriptionsfaktor (pro1-Mutante), ein putatives Transmembranprotein (pro22-Mutante), ein „Woronin-body“-assoziiertes Protein (pro40-Mutante), ein ER-assoziiertes Protein (pro41-Mutante) und schließlich das zu Striatin homologe Protein PRO11 (pro11-Mutante) (Engh et al. 2007, Kück 2005, Masloff et al. 1999, Masloff et al. 2002, Nowrousian et al. 1999, Nowrousian et al. 2007, Pöggeler und Kück 2004, Rech et al. 2007).

Die pro11-Mutante wurde bereits ausführlich charakterisiert (Pöggeler und Kück 2004). Im nachfolgenden Kapitel werden die weiterführenden Analysen, welche im Rahmen dieser Arbeit bearbeitet werden sollten, erläutert.

\section{$4 \quad$ Experimentelle Zielsetzung}

Durch chemische Mutagenese mit Ethyl-Methansulfonat (EMS), wurde die S. macrospora Mutante pro11 generiert, welche auf der Stufe der Protoperithezien-Entwicklung arretiert ist. Die Komplementationstransformation der pro11-Mutante mit einer Cosmidbank führte zu der Identifizierung und Isolierung des Entwicklungsgens prol1 (Pöggeler et al. 1997, Pöggeler und Kück 2004). Der ORF des prol1-Gens weist 2716 bp auf und ist von drei Introns (69 bp, 54 bp und 55 bp) unterbrochen. Das aus der pro11-cDNA abgeleitete PRO11-Protein umfasst 845 AS. Ein Sequenzvergleich ergab eine signifikante Homologie von PRO11 zu den Striatin-Proteinen aus Säugern. PRO11 zeigt den gleichen strukturellen Aufbau wie die Proteine der StriatinFamilie. Im N-Terminus von PRO11 konnte ein „coiled-coil“-Motiv und eine CalmodulinBindedomäne vorhergesagt werden. Der C-terminale Teil des Proteins wird durch sieben „WDrepeats“" charakterisiert (Pöggeler und Kück 2004) (Abb. 5). 


\section{Sm PR011}

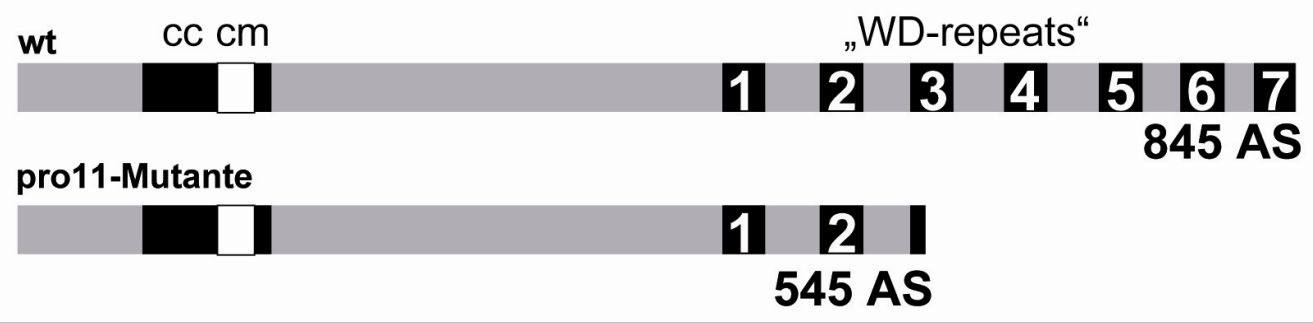

Abb. 5 Schematische Darstellung des PRO11-Proteins aus $\boldsymbol{S}$. macrospora. Oben ist das native PRO11Protein und unten die verkürzte PRO11-Version in der pro11-Mutante dargestellt, welche auf Grund einer Punktmutation eine verkürzte Länge von 545 AS aufweist. Abkürzungen: cc-,,coiled-coil“-Motiv (schwarze Box), cm-putative Calmodulin-Bindedomäne (weiße Box).

Bei der Behandlung mit EMS entstehen durch die Induktion von Basenfehlpaarungen häufig Punktmutationen in Form von GC- zu AT-Transitionen (Ashman 1992). So ergab auch die Sequenzierung des prol1-Lokus in der pro11-Mutante, dass eine GC-/AT-Transition zu der Kodierung eines Stopp-Codons (TGA) anstelle eines Tryptophan-Rests (TGG) zu einer verkürzten 545 AS großen PRO11-Version führt (Pöggeler und Kück 2004).

Wie Abb. 5 verdeutlicht, wird hierdurch das PRO11-Protein nur noch bis zum zweiten „WDrepeat" vollständig gebildet.

Als einer der ersten Interaktionspartner von Striatin-Proteinen aus Säugern wurde das Protein Phocein/Mob3 identifiziert (Baillat et al. 2001). In einer vorangegangenen Arbeit konnte das Homolog Smmob3 bereits aus S. macrospora isoliert und kloniert werden (Bernhards 2005).

Im Rahmen dieser Arbeit sollte mit Hilfe einer Hefe Two-Hybrid Studie untersucht werden, ob auch in S. macrospora eine Interaktion der homologen Proteine PRO11 und SmMOB3 vorliegt.

Ein weiterer Schwerpunkt sollte auf der Untersuchung der Beteiligung von PRO11 und SmMOB3 bei der sexuellen Entwicklung von $S$. macrospora liegen. Bislang gibt es kaum Erkenntnisse über die Regulation von pro11 und Smmob3 während des Lebenszyklus von S. macrospora. Beide Gene werden nur schwach exprimiert, so dass die Transkripte in Northern-Analysen nicht nachgewiesen werden konnten (Pöggeler und Kück 2004, Bernhards 2005). Im Rahmen dieser Arbeit sollte daher zur Untersuchung der transkriptionellen Expression von pro11 und Smmob3 die Real-Time Analyse zum Einsatz kommen, die eine sehr sensitive Erfassung von Transkriptmengen erlaubt (Valasek und Repa 2005).

Um zu untersuchen, ob SmMOB3 genauso wie PRO11 einen Einfluss auf die sexuelle Entwicklung ausübt, sollte das Smmob3-Gen in dem S. macrospora $\Delta$ ku70-Stamm mittels 
homologer Rekombination durch eine Hygromycin-Resistenz-Kassette ersetzt und so funktionell ausgeschaltet werden.

Transformierte DNA integriert in S. macrospora während der nicht-homologen Reparatur von DNA-Doppelstrangbrüchen durch den NHEJ-Komplex (,non-homologous end joining“) vornehmlich ektopisch in das Genom (Pöggeler und Kück 2006). An der Ausbildung des NHEJ-Komplexes sind unter anderem die Proteine Ku70 und Ku80 beteiligt (Walker et al. 2001). In dem $\Delta$ ku70-Stamm wurde das $k u 70$-Gen durch eine Nourseothricin-Resistenzkassette ersetzt. Nicht-homologe DNA-Integrationsereignisse werden daher unterbunden und in den $\Delta \mathrm{ku} 70$-Stamm transformierte DNA wird zu mehr als $85 \%$ homolog in das Genom integriert (Pöggeler und Kück 2006).

Wie beschrieben, ist die pro11-Punktmutante auf der Entwicklungsstufe der Protoperithezienbildung arretiert. Ein großer Teil des PRO11-Proteins (545 AS) wird in der Mutante noch gebildet. Es sollte daher die Auswirkung einer gesamten Deletion des pro11-Gens auf die sexuelle Entwicklung durch die Erstellung eines pro11-Knockout-Stamms untersucht werden. Weiterhin sollten die erstellten Knockout-Stämme in Komplementationsstudien für die Expression verschiedener Smmob3- und pro11-Verkürzungskonstrukte eingesetzt werden, um Aufschluss über funktionell wichtige Bereiche der korrespondierenden SmMOB3- und PRO11Proteine $\mathrm{zu}$ gewinnen. Es sollte außerdem mit Hilfe von Kreuzungsexperimenten eine Smmob3/pro11-Doppeldeletionsmutante generiert werden und eine morphologische Untersuchung des Phänotyps erfolgen.

In Säugern existieren verschiedene durch alternatives Spleißen hervorgebrachte Versionen von Striatin-Proteinen, welche in unterschiedlichen Geweben und auch $\mathrm{zu}$ unterschiedlichen Zeitpunkten der Entwicklung eine Funktion erfüllen. Es sollte daher analysiert werden, ob pro11 ebenfalls alternativ gespleißt wird und wie sich eine solche Variante funktionell auf die Entwicklung von S. macrospora auswirken könnte.

Ein anderer Teil der Arbeit sollte sich mit der Identifizierung weiterer Interaktionspartner von PRO11 und SmMOB3 beschäftigen. Hierzu sollten beide Proteine in einem Hefe Two-Hybrid „Screen“ einer S. macrospora und N. crassa cDNA-Bank als Köderproteine eingesetzt werden. Von den identifizierten Interaktionspartnern sollte ein Protein ausgewählt und in weiterführenden Analysen wie z. B. durch die Erstellung einer Deletionsmutante, funktionell näher charakterisiert werden.

Abschließend sollte eine Analyse der intrazellulären Lokalisierung von PRO11 und SmMOB3 erfolgen Dazu sollten die Proteine mit dem rot fluoreszierenden Protein (DsRed) oder dem grün fluoreszierenden Protein (GFP) fusioniert und die Lokalisierung in S. macrospora mittels Fluoreszenzmikroskopie untersucht werden. 


\section{MATERIAL UND METHODEN}

\section{Material}

\subsection{Stämme}

In Tabelle 1 sind die in dieser Arbeit verwendeten und konstruierten Stämme und deren geno- bzw. phänotypische Charakteristika aufgelistet.

Tab. 1: Übersicht der verwendeten Stämme

\begin{tabular}{|c|c|c|}
\hline Bezeichnung & Charakteristika & Referenz \\
\hline \multicolumn{3}{|l|}{ ESCHERICHIA COLI } \\
\hline SURE & $\begin{array}{l}\text { e14 }\left(\mathrm{McrA}^{-}\right) \Delta(\text { mcrCB-hsdSMR-mrr }) 171, \\
\text { endA1 supE44 thi-1 gyrA96 relA1 lac recB } \\
\text { recJ sbcC umuC::Tn5 }\left(\operatorname{Kan}^{\mathrm{r}}\right) \text { uvrC }\left[\mathrm{F}^{\prime},\right. \\
\left.\text { proAB, } \operatorname{lacI}^{\mathrm{q}} \mathrm{Z} \Delta \mathrm{M} 15 \operatorname{Tn} 10\left(\mathrm{Tet}^{\mathrm{r}}\right)\right]^{\mathrm{c}}\end{array}$ & Agilent (Santa Clara, USA) \\
\hline MACH1 & $\begin{array}{l}\Delta \mathrm{rec} A 1398 \text { endA1 tonA } \Phi 80 \Delta \text { lacM15 } \\
\Delta \text { lacX74 hsdR( }\left(\mathrm{r}_{\mathrm{K}}^{-} \mathrm{m}_{\mathrm{K}}^{+}\right)\end{array}$ & Invitrogen (Carlsbad, USA) \\
\hline \multicolumn{3}{|c|}{ SACCHAROMYCES CEREVISIAE } \\
\hline PJ69-4A & $\begin{array}{l}\text { MATa, trp1-901, leu2-3, 112, ura3-52, his3- } \\
\text { 200, gal4 } \Delta, \text { gal } 80 \Delta, \text { LYS2::GAL1-HIS3, } \\
\text { GAL2-ADE2, met2::GAL7-lacZ }\end{array}$ & (James et al. 1996) \\
\hline PJ69-4 $\alpha$ & 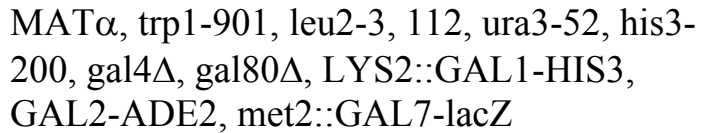 & (James et al. 1996) \\
\hline AH109 & 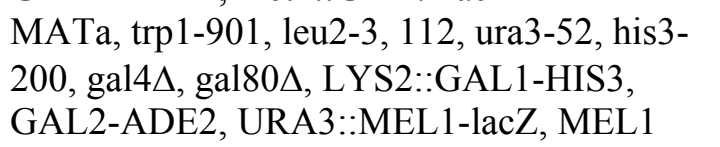 & (James et al. 1996) \\
\hline AH109-Nc & $\begin{array}{l}\text { AH109 transformiert mit der N. crassa } \\
\text { cDNA-Bank }\end{array}$ & (Seiler, unveröfftl.) \\
\hline \multicolumn{3}{|l|}{ SORDARIA MACROSPORA } \\
\hline wt & S17736, Wildtyp k-hell & Stammsammlung $^{1}$ \\
\hline fus-1 & $\begin{array}{l}\text { S23442, Mutation im Gen fus, braune } \\
\text { Ascosporen }\end{array}$ & Stammsammlung $^{1}$ \\
\hline $\mathrm{r} 2$ & $\begin{array}{l}\text { S67813, Mutation im Gen } r \text {, rosa } \\
\text { Ascosporen }\end{array}$ & Stammsammlung $^{1}$ \\
\hline$\Delta \mathrm{ku} 70$ & S66001, $\Delta k u 70:: n a t ;$ nat $^{\mathrm{R}}$, fertil & (Pöggeler und Kück 2006) \\
\hline pro11 & S24117, Mutation im Gen prol1, steril & (Pöggeler und Kück 2004) \\
\hline pro11/r2 & ESI aus Kreuzung pro 11 x r2, steril & Stammsammlung $^{1}$ \\
\hline pro1 & M8871, Mutation im Gen pro1, steril & (Masloff et al. 1999) \\
\hline$\Delta$ Smmob3 & $\Delta$ Smmob3 $:: h p h$, ESI; hyg ${ }^{\mathrm{R}}$, steril & (Bernhards und Pöggeler ${ }^{*}$ ) \\
\hline$\Delta$ Smmob3/fus-1 & $\begin{array}{l}\triangle S m m o b 3:: h p h / f u s, \text { ESI aus Kreuzung } \\
\Delta \text { Smmob3 } \times \text { fus- } 1 ; \text { hyg }^{\mathrm{R}} \text {, steril }\end{array}$ & (Bernhards und Pöggeler ${ }^{*}$ ) \\
\hline$\Delta$ Smmob3_MOB3FL ${ }^{\text {ect }}$ & $\Delta$ Smmob3 + pMob3FL $;$ hyg $^{R}$, nat ${ }^{R}$, fertil & (Bernhards und Pöggeler ${ }^{*}$ ) \\
\hline$\Delta$ Smmob3_MOB3N $\mathrm{N}^{\mathrm{ect}}$ & $\Delta$ Smmob3 + pMob3N; hyg $^{\mathrm{R}}$, nat $^{\mathrm{R}}$, fertil & (Bernhards und Pöggeler ${ }^{*}$ ) \\
\hline$\Delta$ Smmob3_MOB3C $C^{\text {ect }}$ & $\Delta$ Smmob3 + pMob3C; hyg $^{\mathrm{R}}$, nat ${ }^{\mathrm{R}}$, steril & (Bernhards und Pöggeler ${ }^{*}$ ) \\
\hline $\begin{array}{l}\Delta \text { Smmob3_MOB3MmFL } \\
\text { wt trpC-PRO11 } \text { si }^{\text {ect }}\end{array}$ & $\begin{array}{l}\Delta \text { Smmob3 }+ \text { pMob3MmFL; } \text { hyg }^{\mathrm{R}}, \text { nat }^{\mathrm{R}} \text {, steril } \\
\text { wt }+ \text { p11si; nat }\end{array}$ & $\begin{array}{l}\text { (Bernhards und Pöggeler*) } \\
\text { (Bernhards und Pöggeler*) }\end{array}$ \\
\hline wt_trpC-MOB3si $\mathrm{e}^{\mathrm{ect}}$ & $\mathrm{wt}+$ pMob3si; nat $^{\mathrm{R}}$, steril & (Bernhards und Pöggeler*) \\
\hline pro11_trpC-MOB3siect & pro11 + pMob3si; nat ${ }^{\mathrm{R}}$, steril & (Bernhards und Pöggeler*) \\
\hline$\Delta$ Smmob3_trpC-PRO11 si ${ }^{\text {ect }}$ & $\Delta$ Smmob3 + pPro11si; hyg $^{\mathrm{R}}$, nat ${ }^{\mathrm{R}}$, steril & (Bernhards und Pöggeler ${ }^{*}$ ) \\
\hline
\end{tabular}




\begin{tabular}{|c|c|c|}
\hline Bezeichnung & Charakteristika & Referenz \\
\hline \multicolumn{3}{|l|}{ SORDARIA MACROSPORA } \\
\hline $\begin{array}{l}\Delta \text { Smmob3_gpd-MOB3 }{ }^{\text {ect }} \\
\text { wt_gpd-MOB3 } \\
\text { ect }\end{array}$ & $\begin{array}{l}\Delta \text { Smmob3 }+ \text { pMob3oex; } \text { hyg }^{\mathrm{R}}, \text { nat }^{\mathrm{R}}, \text { fertil } \\
\text { wt }+ \text { pMob3oex; hyg }{ }^{\mathrm{R}}, \text { nat }^{\mathrm{R}}, \text { fertil }\end{array}$ & $\begin{array}{l}\text { (Bernhards und Pöggeler*) } \\
\text { (Bernhards und Pöggeler') }\end{array}$ \\
\hline $\begin{array}{l}\triangle \text { Smmob3_gpd- } \\
\text { MOB3:DsRED }\end{array}$ & $\Delta$ Smmob3 + pMob3DsRed; hyg $^{\mathrm{R}}$, nat $^{\mathrm{R}}$, fertil & diese Arbeit \\
\hline$\Delta$ pro11 & Aprol1::hph, ESI; hyg ${ }^{\mathrm{R}}$, steril & $\left(\right.$ Bloemendal et al. $\left.^{* *}\right)$ \\
\hline$\Delta$ pro11/fus-1 & $\begin{array}{l}\text { Aprol1::hph/fus, ESI aus Kreuzung } \Delta \text { pro } 11 \\
\text { x fus- } 1 ; \text { hyg }^{\mathrm{R}} \text {, steril }\end{array}$ & diese Arbeit \\
\hline$\Delta$ pro11_PRO11FL ${ }^{\text {ect }}$ & $\Delta$ pro11 + p11FL; hyg ${ }^{\mathrm{R}}$, nat $^{\mathrm{R}}$, fertil & $\left(\right.$ Bloemendal et al. $\left.{ }^{* *}\right)$ \\
\hline$\Delta$ pro11_PRO11mut ${ }^{\text {ect }}$ & $\Delta$ pro11 + p11mut; hyg $^{\mathrm{R}}$, nat ${ }^{\mathrm{R}}$, steril & $\left(\right.$ Bloemendal et al. $\left.{ }^{* *}\right)$ \\
\hline$\Delta$ pro11_PRO11N1 $1^{\text {ect }}$ & $\Delta$ pro11 + p11N1; hyg ${ }^{\mathrm{R}}$, nat $^{\mathrm{R}}$, steril & (Bloemendal et al. $^{* *}$ ) \\
\hline$\Delta$ pro11_PRO11N2 $2^{\text {ect }}$ & $\Delta$ pro11 + p11N2; hyg $^{\mathrm{R}}$, nat $^{\mathrm{R}}$, steril & $\left(\right.$ Bloemendal et al. $\left.^{* *}\right)$ \\
\hline$\Delta$ pro11_PRO11N3 ${ }^{\text {ect }}$ & $\Delta$ pro11 + p11N3; hyg $^{\mathrm{R}}$, nat $^{\mathrm{R}}$, steril & $\left(\right.$ Bloemendal et al. ${ }^{* *}$ ) \\
\hline$\Delta$ pro11_PRO11N4 $4^{\text {ect }}$ & $\Delta$ pro11 + p11N4; hyg $^{\mathrm{R}}$, nat ${ }^{\mathrm{R}}$, steril & (Bloemendal et al. $^{* *}$ ) \\
\hline $\begin{array}{l}\Delta \text { pro11_gpd-PRO11 } \\
\text { wt gpd-PRO11 }\end{array}$ & $\begin{array}{l}\Delta \text { pro11 }+ \text { p11oex; } \text { hyg }^{\mathrm{R}}, \text { nat }^{\mathrm{R}}, \text { fertil } \\
\text { wt + p11oex; hyg }{ }^{\mathrm{R}}, \text { nat }^{\mathrm{R}}, \text { fertil }\end{array}$ & $\begin{array}{l}\text { diese Arbeit } \\
\text { diese Arbeit }\end{array}$ \\
\hline$\Delta$ pro11_PRO11cDNA ${ }^{\text {ect }}$ & $\Delta$ pro11 + p11cDNA; hyg $^{\mathrm{R}}$, nat $^{\mathrm{R}}$, fertil & diese Arbeit \\
\hline$\Delta$ pro11_PRO11:DsRed ${ }^{\text {ect }}$ & $\Delta$ pro11 + p11DsRed; hyg $^{\mathrm{R}}$, nat $^{\mathrm{R}}$, fertil & diese Arbeit \\
\hline$\Delta \operatorname{Sm} 93 \overline{7} 5$ & $\Delta S m 9375: \because h p h$, ESI, hyg ${ }^{\mathrm{R}}$, fertil & diese Arbeit \\
\hline$\Delta \mathrm{Sm} 9375 / \mathrm{r} 2$ & $\begin{array}{l}\triangle S m 9375:: h p h / r 2, \text { ESI aus Kreuzung } \\
\Delta \text { Sm9375 x r2; } \text { hyg }^{\mathrm{R}} \text {, fertil }\end{array}$ & diese Arbeit \\
\hline$\Delta \operatorname{Sm} 9375 / \Delta$ pro 11 & $\begin{array}{l}\text { Aprol1::hph/4Sm9375::hph, ESI; hyg }{ }^{\mathrm{R}} \text {, } \\
\text { fertil }\end{array}$ & diese Arbeit \\
\hline$\Delta \operatorname{Sm} 9375 / \Delta$ Smmob3 & $\begin{array}{l}\Delta S m m o b 3:: h p h / \Delta S m 9375:: h p h, \text { ESI; hyg }{ }^{\mathrm{R}} \text {, } \\
\text { fertil }\end{array}$ & diese Arbeit \\
\hline wt_gpd-DsRed ${ }^{\text {ect }}$ & $\mathrm{wt}+$ pRHN1; nat ${ }^{\mathrm{R}}$ & diese Arbeit \\
\hline wt_gpd-DsRed:SKL ${ }^{\text {ect }}$ & $\mathrm{wt}+\mathrm{pDsRed-SKL} ;$ nat $^{\mathrm{R}}$ & $\begin{array}{l}\text { (Elleuche und Pöggeler } \\
\text { 2008) }\end{array}$ \\
\hline wt_gpd-Cas:DsRed ${ }^{\text {ect }}$ & wt + pMito-DsRed; nat ${ }^{\mathrm{R}}$ & $\begin{array}{l}\text { (Elleuche und Pöggeler } \\
\text { 2009) }\end{array}$ \\
\hline wt_ccg1-Lifeact:TagRFP ${ }^{\text {ect }}$ & $\mathrm{wt}+\mathrm{pAL} 4$-Lifeact & diese Arbeit \\
\hline
\end{tabular}

NEUROSPORA CRASSA

wt

wt

$\triangle m o b 3$

$\triangle m o b 3 \_M O B 3 F L^{e c t}$

$\triangle m o b 3 M O B 3 N^{e c t}$

$\triangle m o b 3-M O B 3 C^{e c t}$
Wildtyp; 74-OR23-1 Mat A

Wildtyp; ORS-SL6 Mat a

hph::mob-3A

$\Delta$ mob3 + pMob3FL; hyg ${ }^{\mathrm{R}}$, nat ${ }^{\mathrm{R}}$

$\Delta$ mob3 + pMob3N; hyg ${ }^{\mathrm{R}}$, nat ${ }^{\mathrm{R}}$

$\Delta$ mob3 + pMob3C; hyg $^{\mathrm{R}}$, nat ${ }^{\mathrm{R}}$
(Maerz et al. 2009)

(Maerz et al. 2009)

(Maerz et al. 2009)

(Seiler, unveröfftl.)

(Seiler, unveröfftl.)

(Seiler, unveröfftl.)

${ }^{1}$ Stammsammlung des Lehrstuhls Allgemeine und Molekulare Botanik, Ruhr-Universität Bochum.

*Manuskript eingereicht zur Veröffentlichung.

** Manuskript in Vorbereitung.

+ transformiert mit dem angegebenen Plasmid.

Die verwendeten Abkürzungen und Symbole sind dem Abkürzungsverzeichnis zu entnehmen. 


\subsection{Plasmide}

Tabelle 2 zeigt die verwendeten und konstruierten Plasmide mit den jeweiligen Charakteristika. Die zur Plasmid-Konstruktion verwendeten Ausgangsvektoren sind in Fett-Druck dargestellt. Darunter sind die mit dem jeweiligen Ausgangsvektor hergestellten Plasmide aufgelistet. Es ist zusätzlich angegeben, für welche Experimente die Plasmide verwendet worden sind.

Tab. 2: Auflistung der verwendeten und konstruierten Plasmide

\begin{tabular}{lll}
\hline \hline \multicolumn{1}{c}{ Plasmid } & \multicolumn{1}{c}{ Charakteristika/Insert } & \multicolumn{1}{c}{ Referenz } \\
\hline \hline \multicolumn{2}{l}{ SUBKLONIERUNG/SEQUENZIERUNG } & \\
pDrive & $\begin{array}{l}\text { lacZ } \alpha \text { zur Blau/Weiß-Selektion von } \\
\text { pJet1.2/blunt }\end{array}$ & Qiagen (Hilden, Deutschland) \\
& $\begin{array}{l}\text { Transformanten, } \operatorname{amp}^{\mathrm{R}}, \mathrm{kan}^{\mathrm{R}} \\
\text { letales Gen } e c o 47 I R \text { zur Selektion von } \\
\text { Transformanten, amp }\end{array}$ & $\begin{array}{l}\text { Fermentas (St. Leon-Rot, } \\
\text { Deutschland) }\end{array}$ \\
\hline \hline
\end{tabular}

\section{HEFE TWO-HYBRID}

\begin{tabular}{|c|c|c|}
\hline pAD-GAL4-2.1 & $L E U 2, G A L 4-A D, \mathrm{amp}^{\mathrm{R}}$ & Stratagene \\
\hline pGADT7 & $L E U 2, G A L 4-A D, \mathrm{amp}^{\mathrm{R}}$ & $\begin{array}{l}\text { Clontech (Mountain View, } \\
\text { USA) }\end{array}$ \\
\hline $\mathrm{pAK} 2$ & 857 bp pro11 5'-cDNA in pQE31 & (Pöggeler und Kück 2004) \\
\hline $\mathrm{pB}-\mathrm{a} 1$ & ges. Sm Smta- 1 cDNA in pGBDU-C1 & (Jacobsen et al. 2002) \\
\hline $\mathrm{pA}-\mathrm{A} 1$ & ges. Sm SmtA-1 cDNA in pGAD-C1 & (Jacobsen et al. 2002) \\
\hline pGBDU-C3 & $U R A 2, G A L 4-B D, \mathrm{amp}^{\mathrm{R}}$ & (James et al. 1996) \\
\hline pB11-aa1-110 & 5'-Bereich der proll cDNA (»AS 1-110) & $\left(\right.$ Bloemendal et al. $\left.^{* *}\right)$ \\
\hline pGBDU-C1 & $U R A 2, G A L 4-B D, \mathrm{amp}^{\mathrm{R}}$ & (James et al. 1996) \\
\hline pB11-aa1-215 & 5'-Bereich der proll cDNA (»AS 1-215) & (Bloemendal et al. $^{* *}$ ) \\
\hline pB11-aa1-281 & 5'-Bereich der proll cDNA (»AS 1-281) & $\left(\right.$ Bloemendal et al. $\left.{ }^{* *}\right)$ \\
\hline pB11-aa282-845 & 3'-Bereich der pro11 cDNA (»AS 282-845) & $\left(\right.$ Bloemendal et al. $\left.^{* *}\right)$ \\
\hline pBMob3-aa1-144 & 5'-Bereich der Smmob3 cDNA (»AS 1-144) & $\left(\right.$ Bloemendal et al. $\left.^{* *}\right)$ \\
\hline pBMob3-aa1-345 & 5'-Bereich der $S m m o b 3$ cDNA (»AS 1-345) & $\left(\right.$ Bloemendal et al. $\left.{ }^{* *}\right)$ \\
\hline pGAD-C1 & $L E U 2, G A L 4-A D, \mathrm{amp}^{\mathrm{R}}$ & (James et al. 1996) \\
\hline pA11-aa1-281 & 5'-Bereich der pro11 cDNA (»AS 1-281) & (Bloemendal et al. $^{* *}$ ) \\
\hline pA11-aa282-845 & 3'-Bereich der proll cDNA (»AS 282-845) & (Bloemendal et al. ${ }^{* *}$ ) \\
\hline pAMob3-aa1-345 & 5'-Bereich der Smmob3 cDNA (»AS 1-345) & (Bloemendal et al. $^{* *}$ ) \\
\hline
\end{tabular}

\section{KNOCKOUT}

\begin{tabular}{|c|c|c|}
\hline pCB1003 & $h p h, \mathrm{amp}^{\mathrm{R}}$ & (Carroll et al. 1994) \\
\hline pRS426 & $U R A 2, \mathrm{amp}^{\mathrm{R}}$ & (Christianson et al. 1992) \\
\hline pMob3ko & $\begin{array}{l}671 \text { bp Smmob3 5'-Bereich inkl. UTR und } 930 \\
\text { bp Smmob3 3'-Bereich getrennt durch } h p h\end{array}$ & (Bernhards und Pöggeler ${ }^{*}$ ) \\
\hline p11ko & $\begin{array}{l}704 \text { bp pro11 } 5^{\prime}-\text { und } 735 \text { bp pro11 } 3^{\prime} \text {-UTR } \\
\text { getrennt durch } h p h\end{array}$ & $\left(\right.$ Bloemendal et al. $\left.^{* *}\right)$ \\
\hline p9375ko & $\begin{array}{l}985 \text { bp Sm9375 5'-UTR und } 680 \text { bp Sm9375 3'- } \\
\text { Bereich inkl. UTR getrennt durch hph }\end{array}$ & diese Arbeit \\
\hline
\end{tabular}

\section{KOMPLEMENTATION/ÜBEREXPRESSION}

\begin{tabular}{|c|c|c|}
\hline p1783-1 & Pgpd, TtrpC, hph, egfp, amp ${ }^{\mathrm{R}}$ & (Pöggeler et al. 2003) \\
\hline pEHN1-nat & $\mathrm{P} g p d, \mathrm{~T} t r p C$, nat, $\mathrm{amp}^{\mathrm{R}}$ & Kück, unveröfftl. \\
\hline pMob3MmFL & ges. $M m$ Mob3 cDNA ORF (»AS 1-225) & (Bernhards und Pöggeler ${ }^{*}$ ) \\
\hline pRSnat & URA2, nat, $\mathrm{amp}^{\mathrm{R}}$ & (Klix et al. 2010) \\
\hline pMob3FL & $\begin{array}{l}\text { ges. Smmob3 gDNA ORF (»AS 1-663) inkl. } 663 \\
\text { bp 5'-UTR }\end{array}$ & (Bernhards und Pöggeler ${ }^{*}$ ) \\
\hline
\end{tabular}




\begin{tabular}{|c|c|c|}
\hline Plasmid & Charakteristika/Insert & Referenz \\
\hline \multicolumn{3}{|c|}{ KOMPLEMENTATION/ÜBEREXPRESSION } \\
\hline pMob3N & $\begin{array}{l}\text { Smmob3 gDNA ORF 5'-Bereich (»AS 1-264) } \\
\text { inkl. } 663 \text { bp 5'-UTR }\end{array}$ & (Bernhards und Pöggeler ${ }^{*}$ ) \\
\hline pMob3C & $\begin{array}{l}\text { Smmob3 3'-Bereich (»AS 324-663) reguliert } \\
\text { durch } 663 \text { bp Smmob3 5'-UTR }\end{array}$ & (Bernhards und Pöggeler ${ }^{*}$ ) \\
\hline pMob3oex & $\begin{array}{l}\text { ges. Smmob3 gDNA ORF (»AS 1-663) reguliert } \\
\text { durch Pgpd und TtrpC }\end{array}$ & (Bernhards und Pöggeler ${ }^{*}$ ) \\
\hline p11FL & $\begin{array}{l}\text { ges. prol1 gDNA ORF (»AS 1-845) inkl. } 704 \text { bp } \\
5^{\prime} \text {-UTR und } 735 \text { bp 3' UTR }\end{array}$ & $\left(\right.$ Bloemendal et al. ${ }^{* *}$ ) \\
\hline p11mut & $\begin{array}{l}\text { pro } 11 \text { gDNA ORF 5'-Bereich (»AS 1-545) inkl. } \\
704 \text { bp 5'-UTR }\end{array}$ & $\left(\right.$ Bloemendal et al. ${ }^{* *}$ ) \\
\hline p11N1 & $\begin{array}{l}\text { prol1 gDNA ORF 5'-Bereich (»AS 1-414) inkl. } \\
704 \text { bp 5'-UTR }\end{array}$ & $\left(\right.$ Bloemendal et al. ${ }^{* *}$ ) \\
\hline $\mathrm{p} 11 \mathrm{~N} 2$ & $\begin{array}{l}\text { prol1 gDNA ORF 5'-Bereich (»AS 1-281) inkl. } \\
704 \text { bp 5'-UTR }\end{array}$ & $\left(\right.$ Bloemendal et al. ${ }^{* *}$ ) \\
\hline $\mathrm{p} 11 \mathrm{~N} 3$ & $\begin{array}{l}\text { prol1 gDNA ORF 5'-Bereich (»AS 1-180) inkl. } \\
704 \text { bp 5'-UTR }\end{array}$ & $\left(\right.$ Bloemendal et al. ${ }^{* *}$ ) \\
\hline p11N4 & $\begin{array}{l}\text { prol1 gDNA ORF 5'-Bereich (»AS 1-120) inkl. } \\
704 \text { bp 5'-UTR }\end{array}$ & $\left(\right.$ Bloemendal et al. $^{* *}$ ) \\
\hline p11oex & $\begin{array}{l}\text { ges. pro11 gDNA ORF (»AS 1-845) reguliert } \\
\text { durch. Pgpd und TtrpC }\end{array}$ & diese Arbeit \\
\hline p11cDNA & $\begin{array}{l}\text { ges. pro } 11 \text { cDNA ORF (»AS 1-845) inkl. } 704 \text { bp } \\
5^{\prime} \text {-UTR und } 735 \text { bp 3' UTR }\end{array}$ & diese Arbeit \\
\hline \multicolumn{3}{|c|}{ LOKALISIERUNG } \\
\hline pRHN1 & gpd, $\operatorname{trp} C$, nat, DsRed, $\mathrm{amp}^{\mathrm{R}}$ & (Janus et al. 2007) \\
\hline pMito-DsRed & $\begin{array}{l}\text { cas } 2 \text { MTS fusioniert mit DsRed, reguliert durch } \\
\text { Pgpd und TtrpC }\end{array}$ & (Elleuche und Pöggeler 2009) \\
\hline pDsRed-SKL & $\begin{array}{l}\text { DsRed fusioniert mit } S K L \text {, reguliert durch Pgpd } \\
\text { und TtrpC }\end{array}$ & (Elleuche und Pöggeler 2008) \\
\hline pAL4-Lifeact & 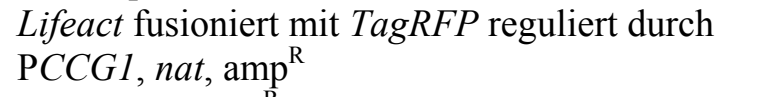 & (Berepiki et al. 2010) \\
\hline pRSnat & $U R A 2$, nat, $\mathrm{amp}^{\mathrm{R}}$ & (Klix et al. 2010) \\
\hline pMob3DsRed & $\begin{array}{l}\text { ges. Smmob3 gDNA ORF (»AS 1-663) fusioniert } \\
\text { mit } D s R e d \text {, reguliert durch Pgpd und TtrpC }\end{array}$ & diese Arbeit \\
\hline p11natDsRed & $\begin{array}{l}\text { ges. pro } 11 \text { gDNA ORF (»AS 1-845) fusioniert } \\
\text { mit DsRed, reguliert durch } 704 \text { bp pro11 5'-UTR }\end{array}$ & diese Arbeit \\
\hline \multicolumn{3}{|l|}{ RNAi } \\
\hline pS-NAT1 & $\begin{array}{l}\text { PtrpC und TtrpC, Mo cutinase Intron 2, nat 1- } \\
\text { Gen reguliert durch Pgpd, amp }\end{array}$ & (Janus et al. 2007) \\
\hline pPro11si & 471 bp des proll gDNA ORFs & (Bernhards und Pöggeler*) \\
\hline pMob3si & 500 bp des Smmob3 gDNA ORFs & (Bernhards und Pöggeler ${ }^{*}$ ) \\
\hline
\end{tabular}

Die verwendeten Abkürzungen und Symbole sind dem Abkürzungsverzeichnis zu entnehmen. 


\subsection{Oligonukleotide (Primer)}

In Tabelle 3 sind die Primer aufgeführt, die als PCR- oder Sequenzierungsstartermoleküle eingesetzt wurden. Es ist jeweils die Primer-Sequenz in $5^{\prime}-3^{\prime}$-Richtung und die spezifischen DNA-Positionen an welche die Primer binden, angegeben. Es wird zusätzlich benannt bei welchen Experimenten die Primer eingesetzt wurden.

Tab. 3: Übersicht der verwendeten Oligonukleotide

\begin{tabular}{|c|c|c|}
\hline Bezeichnung & Sequenz (5'-3') & Position \\
\hline \multicolumn{3}{|c|}{ SEQUENZIERUNG } \\
\hline Smpho1-14 & GGCAGTGCCCTGACTACTGTT & Smmob3 1101 bis 1121 \\
\hline GAL4-T7 & AATACGACTCACTATAGGGCTCTA & pAD-GAL4-2.1922 bis 899 \\
\hline Smpho1_Orf-r & GGAGAGCTTAGAGGAAGCGACAT & Smmob3 23 bis 1 \\
\hline NCU11371_r & GAGCATCGTCGTCGTAGTCCAT & NCU1137122 bis 1 \\
\hline Nc9375-f & ATGCCGGTTGAAACAGCGAGGG & NCU09375 136 bis 157 \\
\hline Nc9375-r & GGTTGTGGCGGTCATAGAGCACAT & NCU09375 690 bis 667 \\
\hline Nc9376C-f & CCAACAGCTCTCTTACGGCTT & NCU09376 1117 bis 1137 \\
\hline Sm9375Nr2 & ACATACTTTACAGGACAGCAGGC & SMU09375 290 bis 268 \\
\hline Sm9375Cf2 & TTCGTGATCTGGAGCCGGACGTGTCGC & SMU09375 743 bis 769 \\
\hline $\mathrm{Nc} 9374 \mathrm{Nr}$ & AGGAGTGCGCGTATGCCACCAGCAATG & NCU09374 2520 bis 2494 \\
\hline Sm9375-cDNAf2 & ATGGCAAGCCTTTGTGCTTTCC & SMU09375-10 bis 13 \\
\hline Sm9375-cDNAr & AATCAGAGAAGACCTGACACCG & SMU09375 982 bis 961 \\
\hline
\end{tabular}

\section{HEFE TWO-HYBRID}

\begin{tabular}{|c|c|c|}
\hline pro11-24 & ATCGCTGGTAAGACTGCTCCAG & prol 1770 bis 749 \\
\hline pro11-31 & $\begin{array}{l}\text { CGTCGACATGGGCACCAACGGCGTTCATG } \\
\mathrm{T}\end{array}$ & proll 1 bis 23 \\
\hline pro11-132 & GTCGACAACTCCCTTCTCTTTACCACC & proll 400 bis 380 \\
\hline pro11-34 & CGTCGACCCCATGGAGCGTTCGTCTAGA & prol1 947 bis 967 \\
\hline pro11-35 & $\begin{array}{l}\text { CCTGCAGCTACCTCGCATACACCTTGACC } \\
\text { AT }\end{array}$ & prol1 2717 bis 2694 \\
\hline Smpho1-11 & GTCGACTCGCTTCCTCTAAGCTCTCCT & Smmob3 4 bis 24 \\
\hline Smpho1-13 & GTCGACAACAGTAGTCAGGGGACTGCC & Smmob3 1121 bis 1101 \\
\hline \multicolumn{3}{|c|}{ KNOCKOUT } \\
\hline pho1-5f & 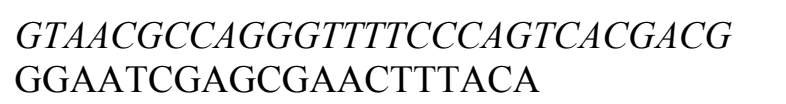 & $\begin{array}{l}\text { ÜH pRS426 } 1920 \text { bis } 1948 \\
\text { Smmob3 - } 177 \text { bis- } 158\end{array}$ \\
\hline pho1-5r & $\begin{array}{l}\text { CCAAAAATGCTCCTTCAATATCAGTTAAC } \\
\text { CCCAACAATGAGGTTATTGC }\end{array}$ & $\begin{array}{l}\text { ÜH } h p h 29 \text { bis } 1 \\
\text { Smmob3 } 494 \text { bis } 475\end{array}$ \\
\hline pho1-3f & $\begin{array}{l}\text { GAGTAGATGCCGACCGGGAACCAGTTAAC } \\
\text { AGCACAGCGAACACAAGAGG }\end{array}$ & $\begin{array}{l}\text { ÜH hph } 1386 \text { bis } 1414 \\
\text { Smmob3 } 2748 \text { bis } 2762\end{array}$ \\
\hline pho1-3r & 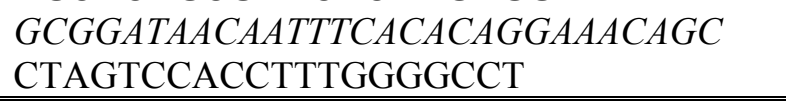 & $\begin{array}{l}\text { ÜH pRS426 } 2197 \text { bis } 2169 \\
\text { Smmob3 } 2078 \text { bis } 2059\end{array}$ \\
\hline \multicolumn{3}{|c|}{ KNOCKOUT } \\
\hline pho1-14f & CCCCGACATATCGAATCCAGC & Smmob3 -225 bis -205 \\
\hline pho1-2r & CCСCTAATGATGCCTCTACGC & Smmob3 2166 bis 2146 \\
\hline pho1-15f & AGGACCAACACGAGGCGGCAT & Smmob3 1059 bis 1079 \\
\hline pro11-5f & 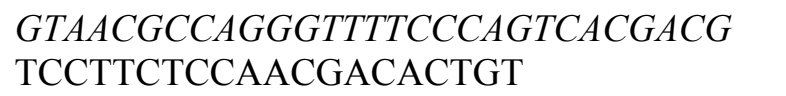 & $\begin{array}{l}\text { ÜH pRS426 } 1920 \text { bis } 1948 \\
\text { proll }-704 \text { bis }-685\end{array}$ \\
\hline pro11-5r & $\begin{array}{l}\text { CCAAAAATGCTCCTTCAATATCAGTTAAC } \\
\text { AGTTGTGCGGTTGTCGTTGG }\end{array}$ & $\begin{array}{l}\text { ÜH } h p h 29 \text { bis } 1 \\
\text { proll }-1 \text { bis }-20\end{array}$ \\
\hline
\end{tabular}




\begin{tabular}{|c|c|c|}
\hline Bezeichnung & Sequenz (5'-3') & Position \\
\hline \multicolumn{3}{|l|}{ KNOCKOUT } \\
\hline pro11-3f & $\begin{array}{l}\text { GAGTAGATGCCGACCGGGAACCAGTTAAC } \\
\text { ACGCTTCGAGAGGATGGGGA }\end{array}$ & ÜH hph 1386 bis 1414 \\
\hline pro11-3r & 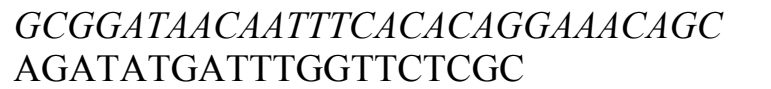 & $\begin{array}{l}\text { ÜH pRS426 } 2197 \text { bis } 2169 \\
\text { proll } 3467 \text { bis } 3448\end{array}$ \\
\hline pro11-21 & AAGCGCGCTTGCCAGTCGCTGC & proll -783 bis -762 \\
\hline pro11-kor & ACGATCAGCCTCGGAAAGACCGC & proll 3586 bis 3564 \\
\hline pro11-28 & CCCGCCATCGACCGACCACCTC & proll 2331 bis 2310 \\
\hline ko9375_5f & 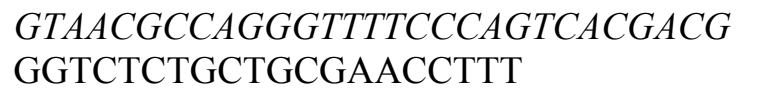 & $\begin{array}{l}\text { ÜH pRS426 } 1920 \text { bis } 1948 \\
\text { Sm } 9375-986 \text { bis }-967\end{array}$ \\
\hline ko9375_5r & $\begin{array}{l}\text { CCAAAAATGCTCCTTCAATATCAGTTAAC } \\
\text { GACGGCAAATCTGTATTGCTT }\end{array}$ & $\begin{array}{l}\text { ÜH } h p h 29 \text { bis } 1 \\
\text { Sm9375 -1 bis }-21\end{array}$ \\
\hline ko9375_3f & $\begin{array}{l}\text { GAGTAGATGCCGACCGGGAACCAGTTAAC } \\
\text { ACGGCCACAGCCGCCAGCGG }\end{array}$ & $\begin{array}{l}\text { ÜH } h p h 1386 \text { bis } 1414 \\
\text { Sm9375 } 855 \text { bis } 874\end{array}$ \\
\hline ko9375_3r & $\begin{array}{l}\text { GCGGATAACAATTTCACACAGGAAACAGC } \\
\text { TTCGTTGTCAGTCTAGATGG }\end{array}$ & $\begin{array}{l}\text { ÜH pRS426 } 2197 \text { bis } 2169 \\
\text { Sm } 93751535 \text { bis } 1516\end{array}$ \\
\hline ko9375_4f & AGGTACAAGTAGTCGGCGTGC & Sm9375 -1123 bis -1103 \\
\hline ko9375_2r & AAAAGAAGTAATGGGGAGCTAGC & Sm9375 1627 bis 1605 \\
\hline $\mathrm{Sm} 9375 \mathrm{Nr}$ & GTTGATGCTAATTGCCCTCGC & Sm9375 129 bis 109 \\
\hline hph-f & GTTAACTGATATTGAAGGAGCATTTTTGG & hph 1 bis 29 \\
\hline hph-r & GTTAACTGGTTCCCGGTCGGCATCTACTC & hph 1414 bis 1386 \\
\hline $\operatorname{trpC} 1$ & GATCCGCCTGGACGACTAAACC & hph 94 bis 73 \\
\hline hph3 & ACTCGTCCGAGGGCAAAGGAATAG & hph 1363 bis 1386 \\
\hline
\end{tabular}

\section{KOMPLEMENTATION/ÜBEREXPRESSION/LOKALISIERUNG}

pho5f_2

pho5r_2

phodom2_r

phodom3_f

Mmpho-f

Mmpho-r

phoORF-f

phocDNA-2r

phocDNA-3f

phoORF-r

pRSGPDf2

phorevGPD

phofGFP

phofDsRed

pRSGFPrev

pro11domplus-r

pro11dom-r
GTAACGCCAGGGTTTTCCCAGTCACGACG GTCGTGGATCACACAAACGT

GATGGTTCTTCGCTCTCTGAGC

CCAAAAATGCTCCTTCAATATCAGTTAAC

AGGAAGCTGGAAGTTCTCGT

GCATCGCGCTCAGAGAGCGAAGAACCATC

ATGAGGACCAACACGAGGCG

CCATGGTCATGGCGGAGGGGACGGC

GGATCCTCATGCTTCACTTTCCCC

ATGTCGCTTCCTCTAAGCTCTC

AGGAAGCTGGAAGTTCTCGT

ATGAGGACCAACACGAGGCG

GTCCACCTTTGGGGCCTGCT

GTAACGCCAGGGTTTTCCCAGTCACGACG

GTACAGTGACCGGTGACTCT

AGCCGAGGAGAGCTTAGAGGAAGCGACAT

TAGCTGTTAGTCAAGCTGCG

CTGTCGCTGAGCAGGCCCCAAAGGTGGAC

ATGGTGAGCAAGGGCGAGGA

CTGTCGCTGAGCAGGCCCCAAAGGTGGAC

ATGGCCTCCTCCGAGGACGT

GCGGATAACAATTTCACACAGGAAACAGC

TCGAGTGGAGATGTGGAGTG

GCGGATAACAATTTCACACAGGAAACAGC

TTATCATGCCTTCTGTTGAA

GCGGATAACAATTTCACACAGGAAACAGC

TTACTATCTAGACGAACGCT
ÜH pRS426 1920 bis 1948

Smmob3 -664 bis -645

Smmob3 -1 bis -22

ÜH pRS426 2197 bis 2169

Smmob3 878 bis 859

ÜH Smmob3 -29 bis -1

Smmob3 1056 bis 1075

Mm mob3 1 bis 17

Mm mob3 672 bis 655

Smmob3 1 bis 22

Smmob3 878 bis 859

Smmob3 1056 bis 1075

Smmob3 2075 bis 2056

ÜH pRS426 1920 bis 1948

Pgpd/p1783-1 2748 bis 2767

ÜH Smmob3 29 bis 1

Pgpd/p1783-1 3604 bis 3585

Smmob3 2047 bis 2075

egfp/p1783-1 3627 bis 3646

ÜH Smmob3 2047 bis 2075

DsRed/pRHN1 2913 bis 2932

ÜH pRS426 2197 bis 2169

TtrpC/p1783-1 5137 bis 5118

ÜH pRS426 2197 bis 2169

pro11 1366 bis 1353

ÜH pRS426 2197 bis 2169

proll 967 bis 954 


\begin{tabular}{|c|c|c|}
\hline Bezeichnung & Sequenz (5'-3') & Position \\
\hline \multicolumn{3}{|c|}{ KOMPLEMENTATION/ÜBEREXPRESSION/LOKALISIERUNG } \\
\hline pro11dom1-r & $\begin{array}{l}G C G G A T A A C A A T T T C A C A C A G G A A A C A G C \\
\text { TTACTATGTAACCATCAAAT }\end{array}$ & $\begin{array}{l}\text { ÜH pRS426 } 2197 \text { bis } 2169 \\
\text { prol1 } 664 \text { bis } 651\end{array}$ \\
\hline pro11dom1-1-r & $\begin{array}{l}G C G G A T A A C A A T T T C A C A C A G G A A A C A G C \\
\text { TTACTACTTGTTATCC }\end{array}$ & $\begin{array}{l}\text { ÜH pRS426 } 2197 \text { bis } 2169 \\
\text { proll } 430 \text { bis } 421\end{array}$ \\
\hline pro11-ORF-f & ATGGGCACCAACGGCGTTCATGT & pro 111 bis 23 \\
\hline pro11cDNA-r-mut & GACAGCGTCAGTATGGCCATCTAGG & prol1 1759 bis 1735 \\
\hline $\begin{array}{l}\text { pro11cDNA-plus- } \\
\mathrm{r}\end{array}$ & TGCCTTCTGTTGAAGAGACCC & proll 1366 bis 1346 \\
\hline pro11cDNA-r & TCTAGACGAACGCTCCATGGG & prol1 967 bis 947 \\
\hline pro11cDNA-1r & $\begin{array}{l}\text { TGTAACCATCAAATAAGTAAACTCAGCTT } \\
\text { GGC }\end{array}$ & prol1 664 bis 633 \\
\hline pro11cDNA-1-1r & CTTGTTATCCTCCGCCTCGGC & prol1 430 bis 410 \\
\hline pro11-ORF-r & CCTCGCATACACCTTGACCATGC & pro11 2714 bis 2692 \\
\hline pro11-ORF-r2 & CTACCTCGCATACACCTTGAC & pro11 2717 bis 2697 \\
\hline pRS42611GPDr2 & $\begin{array}{l}\text { AATGAGACATGAACGCCGTTGGTGCCCAT } \\
\text { TAGCTGTTAGTCAAGCTGCG }\end{array}$ & $\begin{array}{l}\text { ÜH pro11 } 29 \text { bis } 1 \\
\mathrm{Pgpd} / \mathrm{p} 1783-13604 \text { bis } 3585\end{array}$ \\
\hline pro11TrpC_r & $\begin{array}{l}\text { TTGATGATTTCAGTAACGTTAAGTGGATC } \\
\text { CTACCTCGCATACACCTTGA }\end{array}$ & $\begin{array}{l}\text { ÜH TtrpC/p1783-1 } 4397 \text { bis } 4369 \\
\text { pro11 } 2717 \text { bis } 2698\end{array}$ \\
\hline TtrpC_F & $\begin{array}{l}\text { GATCCACTTAACGTTACTGAAATCATCAA } \\
\text { A }\end{array}$ & TtrpC/p1783-1 4369 bis 4398 \\
\hline pro11-5r2 & AATGAGACATGAACGCCGTTGGTGCCCAT & prol1 29 bis 1 \\
\hline pro11-3f2 & $\begin{array}{l}\text { ACGGCATGGTCAAGGTGTATGCGAGGTA } \\
\text { G }\end{array}$ & prol1 2689 bis 2717 \\
\hline pro113fDsRed & $\begin{array}{l}\text { GAGACGGCATGGTCAAGGTGTATGCGAGG } \\
\text { ATGGCCTCCTCCGAGGACGT }\end{array}$ & $\begin{array}{l}\text { ÜH prol1 } 2686 \text { bis } 2714 \\
\text { DsRed/pRHN1 } 2913 \text { bis } 2932\end{array}$ \\
\hline
\end{tabular}

INTRONANALYSE

\begin{tabular}{|c|c|c|}
\hline pro11I2r & AGACAGGATAACAAAGTTGTGC & prol1 499 bis 478 \\
\hline \multicolumn{3}{|l|}{ RNAi } \\
\hline pho-sense-f & CTCGAGAGGACCAACACGAGGC & Smmob3 1058 bis 1074 \\
\hline pho-sense-r & AAGCTTGTTGCCTGGCTGTATTAC & Smmob3 1559 bis 1542 \\
\hline pho-antisense-f & GGGCCCAGGACCAACACGAGGC & Smmob3 1059 bis 1074 \\
\hline pho-antisense-r & AGATCTGTTGCCTGGCTGTATTAC & Smmob3 1559 bis 1542 \\
\hline 11-sense-f2 & $\underline{\text { CTCGAGGGAGCCCCTAACGAAGCT }}$ & prol1 545 bis 562 \\
\hline 11-sense-r & 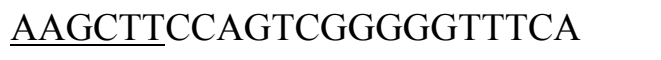 & prol1 1015 bis 1000 \\
\hline 11-antisense-f2 & $\underline{\text { GGGCCCGGAGCCCCTAACGAAGCT }}$ & proll 545 bis 562 \\
\hline 11-antisense-r & AGATCTCCAGTCGGGGGTTTCA & proll 1015 bis 1000 \\
\hline
\end{tabular}

\section{REAL-TIME PCR}

pholfrodo-f

pholfrodo-r

pro11frodo-f

pro11frodo-r

SSU-f

SSU-r
CTTCTGGGTCTGCCAATGAT

CTCTTGGGCGGTGTTTGTAT

GTTCTGGTCCCTCGAAACAA

ACCTCGCATACACCTTGACC

ATCCAAGGAAGGCAGCAGGC

TGGAGCTGGAATTACCGCG
Smmob3 1678 bis 1697

Smmob3 1910 bis 1891

pro11 2564 bis 2583

proll 2715 bis 2696

$N c$ gDNA SC8 93867 bis 93886

$N c$ gDNA SC8 94028 bis 94046

Erkennungssequenzen für Restriktionsendonukleasen sind unterstrichen. In Fett-Druck sind zusätzlich eingefügte Nukleotide gekennzeichnet. In Kursiv-Druck sind Primer-Überhänge (ÜH) für die homologe Rekombination in Hefe gekennzeichnet.

Verwendete Abkürzungen und Symbole sind dem Abkürzungsverzeichnis zu entnehmen. 


\subsection{Chemikalien und Verbrauchsmaterial}

Adenin (MP Biomedicals, Solon, USA), Agar-Agar (Roth, Karlsruhe, Deutschland), Agar-Agar SERVA high gel-strength (Serva, Heidelberg, Deutschland), Agarose (Biozym, Hessisch Oldendorf, Deutschland), Ameisensäure (Merck, Darmstadt, Deutschland), Amicon Ultra (Millipore, Billerica, USA), 3Aminotriazol (Merck), Ammoniumchlorid (VWR International, Darmstadt, Deutschland), Ampicillin (AppliChem, Darmstadt, Deutschland), Arginin (AppliChem), Biotin (Sigma-Aldrich, St. Louis, USA), Borsäure (Roth), Bromphenolblau (Merck), BSA Pentax Fraction V (Serva), Calciumchlorid (J. T. Baker, Deventer, Niederlande), CDTA (1,2-Diaminocyclohexantetra-Säure) (Sigma-Aldrich), Chloroform (Merck), Citronensäure (Roth), CSM-ADE-HIS-LEU-URA (MP Biomedicals), DAPI (4'-6-Diamidino-2phenylindol) (AppliChem), Desoxynukleotidtriphosphate (dNTPs) (Fermentas), Dextranblau (SigmaAldrich), Dimethylformamid (Merck), DTT (1,4-Dithiothreitol) (AppliChem), EDTA (Ethylendiamintetraessigsäure) (Roth), Eisen(II)-ammoniumsulfat (Riedel-de Haën, Seelze, Deutschland), Eisen(II)-chlorid (Roth), Elektroporationsküvetten (VWR International), Ethanol (VWR International), Ethidiumbromid (Sigma-Aldrich), Essigsäure (Roth), Ficoll (GE Healthcare, Solingen Deutschland), Formaldehyd (Roth), Formamid (VWR International), Gene Ruler DNA Ladder Mix (Fermentas), GeneScreen Hybridization Transfer Membrane (PerkinElmer Lifesciences, Wellesley, USA), Glasperlen 0,25-0,5 mm (Roth), Glukose (AppliChem), Glycerin (VWR International), Hefeextrakt (Oxoid, Cambridge, UK), Hefe-Stickstoffbasis ohne Aminosäuren (BD Biosciences, San Jose, USA), HEPES (4(2-hydroxyethyl)-1-piperazineethansulfonsäure) (Roth), Histidin (MP Biomedicals), Hygromycin B (Calbiochem, San Diego, USA), IPTG (Isopropyl- $\beta$-D-galaktopyranosid) (AppliChem), Isopropanol (AppliChem), Kaliumacetat (Merck), Kaliumchlorid (AppliChem), Kaliumnitrat (Merck), Kaliumdihydrogenphosphat (Merck), Kaliumhydroxid (Roth), Kupfersulfat (Roth), Leucin (MP Biomedicals), Lithiumacetat (Roth), LP Strip Tubes 0,2 ml (Biozym), Magnesiumsulfat-7-hydrat (Roth), Maismehl (Mühle Levers Bochum, Deutschland), Malzextrakt (Brau-Partner Kling, Heilbronn, Deutschland), Mangan(II)-chlorid-Tetrahydrat (Roth), Mangansulfat (Roth), MOPS (3Morpholinopropansulfonsäure) (AppliChem), Natriumacetat (Roth), Natriumchlorid (AppliChem), Natriumdihydrogenphosphat (Merck), Natriumhydrogenphosphat (J. T. Baker), Natriumhydroxid (SigmaAldrich), Natriummolybdat-2-hydrat (Riedel-de Haën), Nitrozellulose-Membranfilter (Schleicher \& Schuell, Dassel, Deutschland; Millipore), Nourseothricin (clonNat) (Werner-BioAgents, Jena, Deutschland), Optical Flat Cap Strips (Biozym), PEG (Polyethylenglycol) 6000 (Sigma-Aldrich), Phenol (AppliChem), Polyvinylpyrrolidon (Serva), RNA Loading Dye (2x) (Fermentas), Röntgenfilme (Fujifilm, Tokio, Japan), Saccharose (VWR International), Salzsäure 37\% (Roth), SDS (Natriumdodecylsulfat) (Roth), Sephadex G50 (GE Healthcare), Sorbitol (Roth), Sterilfilter 0,45 $\mu \mathrm{m}$ (VWR International), Tetrazyklin (Sigma-Aldrich), Tris (Tris-Hydroxy-methyl-Aminomethan) (Roth), Tris/HCl (Roth), Trizol (Invitrogen), Trypton/Pepton aus Casein (Roth), Uracil (MP Biomedicals), Verstärkerfolie (Kodak Xomatic Regular) (Sigma-Aldrich), Wasserstoffperoxid 30\% $\left(\mathrm{H}_{2} \mathrm{O}_{2}\right)$ (Merck), Whatmanpapier (Schleicher \& Schuell) X-Gal (5-Bromo-5-chloro-3-indolyl- $\beta$-D-galactopyranosid) (AppliChem), Zinkchlorid (Riedel-de Haën), Zinksulfat-Heptahydrat (Roth)

\subsubsection{Radiochemikalien}

$\left(\alpha^{32} \mathrm{P}\right) \mathrm{dCTP}$ spez. Aktivität $110 \mathrm{~Tb}_{\mathrm{q}} / \mathrm{mmol}(=3000 \mathrm{Ci} / \mathrm{mmol})$ (GE Healthcare)

\subsubsection{Kits}

CloneJET PCR Cloning Kit (Fermentas), DECAprime ${ }^{\mathrm{TM} I I}$ Random Priming DNA Labeling Kit (Ambion, Foster City, USA), GeneJET Plasmid Miniprep Kit (Fermentas), HiSpeed Plasmid Midi Kit (Qiagen), HotStarTaq Master Mix Kit (Qiagen), Omniscrip RT Kit (Qiagen), QIAGEN PCR Cloning Kit (Qiagen), QIAGEN Plasmid Plus Midi Kit (Qiagen), QIAprep Spin Miniprep Kit (Qiagen), QIAquick Gel Extraction Kit (Qiagen), QIAquick PCR Purification Kit (Qiagen), qPCR Mastermix for SYBR GreenI (Eurogentec, Lüttich, Belgien), Silica Bead DNA Gel Extraction Kit (Fermentas), Transcriptor High Fidelity cDNA Synthesis Kit (Roche, Basel, Schweiz) 


\subsubsection{Enzyme}

Calf Intestine Alkaline Phosphatase (Fermentas), DNAse I (Fermentas), Glucanex (Schliessmann, Schwäbisch Hall, Deutschland), Klenow-Fragment (Roche), Lysozym (Serva), MolTaq DNA Polymerase (Molzym, Bremen, Deutschland), Phusion ${ }^{\circledR}$ Hot Start High-Fidelity DNA Polymerase (Finnzymes, Espoo, Finnland), Restriktionsendonukleasen (Fermentas), Ribonuklease A (Roth), T4 DNA Ligase (Fermentas)

\subsection{Nährmedien}

E. coli

LB $1 \%$ Trypton, $0,5 \%$ Hefeextrakt, $0,5 \% \mathrm{NaCl}$, pH 7,2; Festmedium mit 1,5\% Agar-Agar

Zur Selektion Zusatz von Ampicillin $(100 \mu \mathrm{g} / \mathrm{ml})$

Für die „Blau/Weiß“-Selektion Zugabe von 0,2 mM IPTG (Stock-Lsg. 0,1 M in A. dest) und 0,004 $\%$ X-Gal (Stock-Lsg. $2 \%$ in Dimethylformamid)

SOC $20 \mathrm{mM}$ Glukose, $2 \%$ Trypton, $0,5 \%$ Hefeextrakt, $10 \mathrm{mM} \mathrm{NaCl}, 2,5 \mathrm{mM} \mathrm{KCl}, 10 \mathrm{mM} \mathrm{MgCl} 2,10$ $\mathrm{mM} \mathrm{MgSO}_{4}, \mathrm{pH} 7,5$

\section{S. cerevisiae}

YPD $2 \%$ Trypton, $1 \%$ Hefeextrakt, $2 \%$ Glukose, pH 5,8; Festmedium mit $2 \%$ Serva-Agar

YPDA YEPD + 0,003\% Adenin, pH 6,5

SD $\quad 0,67 \%$ Hefe-Stickstoffbasis ohne Aminosäuren, $2 \%$ Glukose, 0,064 \% CSM-ADE-HIS-LEUURA $(0,002 \%$ L-Methionin, je $0,005 \%$ L-Arginin $\mathrm{HCl}$, L-Isoleucin, L-Lysin $\mathrm{HCl}$, LPhenylalanin, L-Tryptophan, L-Tyrosin, 0,008 \% L-Asparaginsäure, 0,01 \% L-Leucin, L-Threonin, $0,014 \%$ L-Valin), pH 5,8; Festmedium mit $2 \%$ Serva-Agar

Selektion von Transformanten auf Medium ohne Uracil und/oder ohne L-Leucin

Reportergenanalyse auf Medium ohne Uracil, ohne L-Leucin und ohne L-Histidin zuzüglich 20 $\mathrm{mM}$ bzw. $50 \mathrm{mM}$ 3-AT, auf Medium ohne Uracil, ohne L-Leucin und ohne Adenin und auf Medium ohne Uracil, ohne L-Leucin, ohne L-Histidin und ohne Adenin

\section{S. macrospora}

BMM 0,8 \% Malzextrakt in Maismehlextrakt (25g/l), pH 6,5; Festmedium mit 1,5\% Agar-Agar

Zur Selektion von Transformanten Zugabe von $110 \mathrm{U} / \mathrm{ml}$ Hygromycin B und/oder $50 \mu \mathrm{g} / \mathrm{ml}$ Nourseothricin, zur Förderung der Keimung Zugabe von 0,5\% Natriumacetat

SWG 1x Westergaard's $\left(0,1 \% \mathrm{KNO}_{3}, 0,1 \% \mathrm{KH}_{2} \mathrm{PO}_{4}, 0,05 \% \mathrm{MgSO}_{4} \times 7 \mathrm{H}_{2} \mathrm{O}, 0,01 \% \mathrm{NaCl}, 0,01 \%\right.$ $\mathrm{CaCl}_{2}, 0,01 \%$ Spurenelemente-Stammlösung $\left(5 \% \mathrm{C}_{6} \mathrm{H}_{8} \mathrm{O}_{7} \times \mathrm{H}_{2} \mathrm{O}, 5 \% \mathrm{ZnSO}_{4} \times 7 \mathrm{H}_{2} \mathrm{O}, 1 \%\right.$ $\mathrm{Fe}\left(\mathrm{NH}_{4}\right)_{2}\left(\mathrm{SO}_{4}\right) 2 \times 6 \mathrm{H}_{2} \mathrm{O}, 0,25 \% \mathrm{CuSO}_{4}$ × $5 \mathrm{H}_{2} \mathrm{O}, 0,05 \% \mathrm{MnSO}_{4} \times \mathrm{H}_{2} \mathrm{O}, 0,05 \% \mathrm{H}_{3} \mathrm{BO}_{3}, 0,05 \%$ $\mathrm{Na}_{2} \mathrm{MoO}_{4} \times 2 \mathrm{H}_{2} \mathrm{O}, 1 \%$ Chloroform) $0,02 \%$ Chloroform), $2 \%$ Glukose, $0,1 \%$ Arginin, $0,1 \%$ Biotin-Stammlösung $(0,01 \%$ in $50 \% \mathrm{EtOH}), \mathrm{pH} 6,5$; Festmedium mit 1,5\% Agar-Agar, zur Selektion von Transformanten siehe BMM

CMS $1 \%$ Glukose, $0,2 \%$ Trypton, 0,2 \% Hefeextrakt, $0,15 \% \mathrm{KH}_{2} \mathrm{PO}_{4}, 0,05 \% \mathrm{KCl}, 0,05 \% \mathrm{MgSO}_{4}$, $0,37 \% \mathrm{NH}_{4} \mathrm{Cl}, 10,8 \%$ Saccharose, $0,01 \%$ Spurenelemente-Lösung $(10 \mathrm{mg} / 1 \mathrm{ZnSO}, 10 \mathrm{mg} / \mathrm{l}$ $\mathrm{Fe}(\mathrm{II}) \mathrm{Cl}_{2}, 10 \mathrm{mg} / 1 \mathrm{MnCl}_{2}$ ), $\mathrm{pH} 6,5$; Festmedium mit $2 \%$ Agar

\subsection{Nährmedien}

\author{
Adenin-Stammlösung \\ BD1 \\ BD2 \\ BD3 \\ Denaturierungspuffer \\ Denhardt's (50x) \\ DNA-Stopperlösung (5x) \\ dNTP-Mix (10 mM) \\ EtBr-Stammlösung \\ Histidin-Stammlösung \\ Leucin-Stammlösung
}

$0,002 \%$ Adenin in A. dest

$50 \mathrm{mM}$ Glukose, $10 \mathrm{mM}$ CDTA, $25 \mathrm{mM}$ Tris/HCl, 0,2 \% Lysozym

$0,4 \mathrm{M} \mathrm{NaOH}+2 \% \operatorname{SDS}(1: 1)$

$3 \mathrm{M}$ Kaliumacetat, 1,8 M Ameisensäure

$0,5 \mathrm{M} \mathrm{NaOH}, 1,5 \mathrm{M} \mathrm{NaCl}, \mathrm{pH} 12-13$

$10 \mathrm{mg} / \mathrm{ml}$ Ficoll, $10 \mathrm{mg} / \mathrm{ml}$ Polyvinylpyrrolidon, $10 \mathrm{mg} / \mathrm{ml}$ BSA

20 mM EDTA, 0,25\% Bromphenolblau, 50 \% Glycerin

jeweils $10 \mathrm{mM}$ dATP, dCTP, dGTP, dTTP in A. dest

$10 \mathrm{mg} / \mathrm{ml}$ Ethidiumbromid in A. dest

$0,002 \%$ Histidin in A. dest

$0,003 \%$ Leucin in A. dest 


\author{
S. $m$. Lysepuffer \\ MOPS-Puffer (10x) \\ Neutralisierungspuffer \\ Protoplastenpuffer (PPP) \\ Sonden-Stopperlösung \\ SSPE (20x) \\ TBE (10x) \\ TE(D) \\ TPS \\ Uracil-Stammlösung \\ Vorhybridisierungspuffer \\ Waschpuffer
}

$10 \mathrm{mM}$ Tris/HCl, $1 \mathrm{mM}$ EDTA, $100 \mathrm{mM} \mathrm{NaCl}, 2 \%$ SDS, pH 8,0

0,2 M MOPS, $50 \mathrm{mM} \mathrm{NaAc}, 10 \mathrm{mM}$ EDTA, $\mathrm{pH}$ 7,0

$2 \mathrm{M} \mathrm{NaCl}, 1 \mathrm{M}$ Tris/HCl, $\mathrm{pH} 5,5$

$13 \mathrm{mM} \mathrm{Na}_{2} \mathrm{HPO}_{4}, 45 \mathrm{mM} \mathrm{KH}_{2} \mathrm{PO}_{4}, 0,6 \mathrm{M} \mathrm{KCl}, \mathrm{pH} 6,0$

Dextranblau in $0,2 \%$ SDS, 0,2 M EDTA

3,6 M NaCl, $20 \mathrm{mM}$ Natriumphosphat, $20 \mathrm{mM}$ EDTA, pH 7,4

$1 \mathrm{M}$ Tris/HCl, $1 \mathrm{M}$ Borsäure, $20 \mathrm{mM}$ EDTA, $\mathrm{pH}$ 8,3

$10 \mathrm{mM}$ Tris, $1 \mathrm{mM}$ EDTA, $\mathrm{pH}$ 7,5

$1 \mathrm{M}$ Sorbit, $80 \mathrm{mM} \mathrm{CaCl}_{2}, \mathrm{pH} \mathrm{7,4}$

$0,002 \%$ Uracil in A. dest

5 x Denhardt's, $50 \%$ Formamid, $5 \times$ SSPE, 0, $6 \%$ SDS

$25 \% 20 \times$ SSPE, $0,2 \%$ SDS

\section{Methoden}

Im Folgenden nicht näher aufgeführte, grundlegende molekularbiologische Methoden wurden nach Sambrook et al. (2001) durchgeführt.

\subsection{Kulturbedingungen von $E$. coli, $S$. cerevisiae und $S$. macrospora-Stämmen}

Für die Klonierung und Vermehrung rekombinanter Plasmide wurden die E. coli Stämme SURE und MACH1 verwendet und nach Standard-Anzuchtbedingungen bei $37^{\circ} \mathrm{C}$ auf LB-Festmedien oder in LBSchüttelkulturen bei $200 \mathrm{rpm}$ inkubiert (Sambrook et al. 2001).

Für die Two-Hybrid-Experimente wurden die $S$. cerevisiae-Stämme PJ-69-4A und PJ-69-4 $\alpha$ genutzt und bei $30^{\circ} \mathrm{C}$ auf YEPD- und SD-Festmedien oder in YEPD- und SD-Schüttelkulturen $(180 \mathrm{rpm})$ kultiviert (James et al. 1996). Der $S$. cerevisiae Stamm AH109, welcher mit der N. crassa cDNA-Bank transformiert worden war, wurde im Rahmen des Two-Hybrid-,,Screens“, wie unter II Material und Methoden, 2.23.2 beschrieben, kultiviert.

Für die Anzucht von S. macrospora Stämmen wurde festes oder flüssiges Maismehl-Medium (BMM) oder Fruktifikationsmedium (SWG) verwendet (Esser 1982, Elleuche und Pöggeler 2008). Die Inkubation erfolgte bei $27^{\circ} \mathrm{C}$ unter Dauerlicht. Für die Isolierung von gDNA wurden die S. macrospora-Stämme in Petrischalen mit flüssigem BMM-Medium, dem ggf. entsprechende Antibiotika zugefügt waren, für 3-4 d kultiviert. Zur Isolierung von RNA wurden die S. macrospora-Stämme für 3-7 d entweder in Petrischalen mit $30 \mathrm{ml}$ flüssigem BMM (Induzierung der sexuellen Entwicklung) oder in Erlenmeyerkolben mit $100 \mathrm{ml}$ flüssigem BMM, welche bei $130 \mathrm{rpm}$ geschüttelt wurden (Induzierung des vegetativen Wachstums), angezogen. Eine Auflistung aller in dieser Arbeit verwendeten und konstruierten Stämme ist in Tabelle 1 aufgeführt.

\subsection{Kreuzung von $S$. macrospora-Stämmen}

Zur Kreuzung wurden jeweils zwei ca. $0,25 \mathrm{~cm}^{2}$ große mit $S$. macrospora-Stämmen überwachsene AgarBlöckchen einander gegenüberliegend auf BMM- oder SWG-Festmedium in Petrischalen angeimpft und 7$21 \mathrm{~d}$ inkubiert. Nach ca. $4 \mathrm{~d}$ waren die beiden Myzelien bis zur Mitte der Petrischale gewachsen und bildeten Hyphenanastomosen aus. Im weiteren Verlauf der sexuellen Entwicklung wurden vermehrt in dieser Kontaktzone Kreuzungsperithezien ausgebildet. Zur Isolierung von Einzelsporen wurden die Kreuzungsperithezien auf Präparationsagar (6 \% Agar-Agar in A. dest) geöffnet und zur Förderung der Keimung mit einer sterilen Nadel auf BMM+Natriumacetat-Medium überführt.

\subsection{Vorbereitung und Transformation von $E$. coli und $S$. cerevisiae}

Zur Herstellung elektrokompetenter $E$. coli SURE-Zellen wurde eine mit Tetrazyklin $(12,5 \mu \mathrm{g} / \mathrm{ml})$ versetzte $100 \mathrm{ml}$ LB-Hauptkultur (HK) bis zu einer $\mathrm{OD}_{600}$ von 0,5-0,6 angezogen. Nach 30 min Inkubation auf Eis wurden die Zellen geerntet (ه $15 \mathrm{~min}, 4500 \mathrm{rpm}, 4^{\circ} \mathrm{C}$ ) und das Zellpellet 2x mit kaltem A. dest $(100 \mathrm{ml}$ und $50 \mathrm{ml})$ und $1 \mathrm{x}$ mit $20 \mathrm{ml}$ kaltem $10 \%$ Glycerin gewaschen. Das Zellpellet wurde in 0,2 ml $10 \%$ Glycerin resuspendiert und jeweils in $40 \mu \mathrm{l}$ Aliquots in flüssigem Stickstoff schockgefroren und 
anschließend bei $-80^{\circ} \mathrm{C}$ gelagert. Die Transformation mittels Elektroporation erfolgte in $0,2 \mathrm{~cm}$ Küvetten in dem „Eppendorf Electroporator 2510“ (Eppendorf, Hamburg, Deutschland) bei 2,5 kV (Song et al. 1993). Die transformierten E. coli-Zellen wurden in $1 \mathrm{ml}$ SOC aufgenommen und auf LB-Festmedium mit den entsprechenden Antibiotika selektioniert.

Für die Herstellung chemisch kompetenter E. coli SURE-Zellen wurde der Stamm wie oben beschrieben

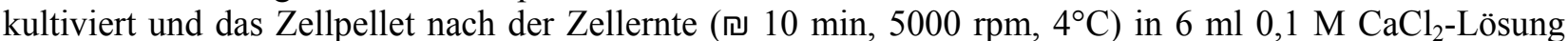

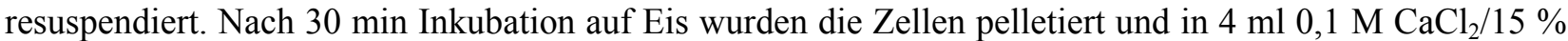
Glycerin-Lösung gelöst. Anschließend wurden die Zellen in Aliquots von $200 \mu 1$ schockgefroren und bei $-80^{\circ} \mathrm{C}$ gelagert. Die Herstellung chemisch kompetenter E. coli MACH1-Zellen erfolgte nach dem Protokoll von Hanahan et al. (1991). Für die Transformation der chemisch kompetenten E. coli-Zellen wurden die Aliquots 10 min auf Eis aufgetaut und dann 20 min mit der zu transformierenden DNA auf Eis inkubiert. Nach einem Hitzeschock bei $42^{\circ} \mathrm{C}$ für 90 sek wurden die Zellen 1 min auf Eis gekühlt, mit $600 \mu \mathrm{LB}$ versetzt und anschließend $45 \mathrm{~min}$ bei $750 \mathrm{rpm}$ und $37^{\circ} \mathrm{C}$ inkubiert. Die Selektion von Transformanten erfolgte auf LB-Festmedium mit den entsprechenden Antibiotika.

Zur Herstellung elektrokompetenter $S$. cerevisiae PJ-69-4A oder PJ-69-4 $\alpha$-Zellen wurde eine $100 \mathrm{ml}$ YEPD- oder SD-HK bis zu einer $\mathrm{OD}_{600}$ von 1,3-1,6 angezogen. Nach der Zellernte (ه $10 \mathrm{~min}, 5000 \mathrm{rpm}$, $4^{\circ} \mathrm{C}$ ) wurde das Zellpellet in $16 \mathrm{ml} \mathrm{A}$. dest, $2 \mathrm{ml} \mathrm{TE}(\mathrm{D})$ und $2 \mathrm{ml} \mathrm{0,1} \mathrm{M}$ Lithiumacetat gelöst und $45 \mathrm{~min}$ bei $100 \mathrm{rpm}$ und $30^{\circ} \mathrm{C}$ inkubiert. Nach Zugabe von $0,5 \mathrm{ml} 1 \mathrm{M}$ DTT erfolgte eine Inkubation von $15 \mathrm{~min}$ bei $100 \mathrm{rpm}$ und $30^{\circ} \mathrm{C}$. Anschließend wurden die Zellen 2x mit A. dest $(100 \mathrm{ml}, 50 \mathrm{ml})$ und 1x mit $5 \mathrm{ml}$ 1 M Sorbitol gewaschen und in 50-100 $\mu 11$ M Sorbitol aufgenommen. Die Zellen wurden zu $40 \mu 1$ aliquotiert und sofort für die Transformation verwendet. Die Transformation mittels Elektroporation erfolgte in 0,2 cm Küvetten in dem „Eppendorf Electroporator 2510“ (Eppendorf) bei 1,5 kV (Becker und Lundblad 2001). Die transformierten S. cerevisiae-Zellen wurden in $800 \mu 11$ M Sorbitol aufgenommen und auf SD-Medium mit den entsprechenden Zusätzen selektioniert.

Es wurden jeweils 100 ng Plasmid-DNA für die Transformationen von E. coli und S. cerevisiae eingesetzt.

\subsection{Protoplastierung und Transformation von $S$. macrospora}

Die Protoplastierung von S. macrospora wurde verändert nach Pöggeler et al. (1997) durchgeführt. $S$. macrospora-Kulturen wurden $3 \mathrm{~d}$ in flüssigem $\mathrm{BMM}$ angezogen und das geerntete Pilzmyzel in Glucanex-Lösung (20 mg/ml PPP) mind. $90 \mathrm{~min}$ bei $100 \mathrm{rpm}$ und $27^{\circ} \mathrm{C}$ protoplastiert. Die Protoplasten wurden mittels einer Fritte (Porengröße 1) auf Eis von den Myzelresten getrennt, 1x mit PPP gewaschen (ㄴ) $3 \mathrm{~min}, 4400 \mathrm{rpm}, 4^{\circ} \mathrm{C}$ ) und der Protoplasten-Titer auf $2 \times 10^{8}$ Zellen/ml TPS eingestellt. Die Transformation erfolgte verändert nach Skatrud et al. (1987). $100 \mu 1$ Protoplasten-Suspension wurden mit $20 \mu \mathrm{g}$ DNA für 10 min auf Eis inkubiert. Nach Zugabe von $200 \mu 1$ PEG 6000-Lösung (25\% in TPS) und einer Inkubation von $20 \mathrm{~min}$ bei RTmp wurde der Transformationsansatz auf CMS-Festmedium ausplattiert.

Die Selektion erfolgte nach 4-24 h durch Überschichten des CMS-Mediums mit Topagar $(0,8 \mathrm{M} \mathrm{NaCl}$, $0,8 \%$ Agar-Agar), welcher Hygromycin B $(550 \mathrm{U} / \mathrm{ml})$ und/oder Nourseothricin $(250 \mu \mathrm{g} / \mathrm{ml})$ enthielt.

Nach mehrtägiger Inkubation wurden die Transformanten auf BMM mit Hygromycin B und/oder Nourseothricin überführt.

\subsection{Präparation von Nukleinsäuren}

\subsubsection{Isolierung von Plasmid-DNA aus $E$. coli und $S$. cerevisiae}

Plasmid-DNA wurde mittels Mini- und Midi-Präparation aus E. coli-Zellen isoliert. Mini-Präparationen erfolgten mit dem QIAprep Spin Miniprep Kit und dem GeneJET Plasmid Miniprep Kit nach Angaben der Hersteller oder nach einer modifizierter Vorschrift von Birnboim und Doly (1979). Hierbei wurde eine E. coli $5 \mathrm{ml}$ LB-Übernachtkultur geerntet (匹 $5 \mathrm{~min}, 5000 \mathrm{rpm}$, RTmp), aufeinanderfolgend mit je $200 \mu 1$ der Lösungen BD1, BD2 und BD3 versetzt und der anschließend gewonnene Überstand ( 10 min, $\left.13.000 \mathrm{rpm}, 4^{\circ} \mathrm{C}\right)$ mit Ribonuklease A $(10 \mu \mathrm{g} / \mathrm{ml})$ für $10 \mathrm{~min}$ bei $37^{\circ} \mathrm{C}$ inkubiert. Es wurden dann $750 \mu 1$ kaltes Isopropanol hinzugegeben und die DNA für mind. 20 min bei $-20^{\circ} \mathrm{C}$ gefällt. Die DNA wurde pelletiert, mit 70\% EtOH gewaschen und nach dem Trocknen unter dem Abzug oder in dem ,eppendorf 
Concentrator 5301“ (Eppendorf) in $30 \mu \mathrm{l}$ A. dest aufgenommen. Midi-Präparationen erfolgten mit dem HiSpeed Plasmid Midi Kit und dem QIAGEN Plasmid Plus Midi Kit nach Vorschrift des Herstellers.

Die Isolierung von Plasmid-DNA aus S. cerevisiae erfolgte mit dem QIAprep Spin Miniprep Kit und dem GeneJET Plasmid Miniprep Kit nach veränderter Vorschrift der Hersteller. Zur Isolierung homolog rekombinierter Plasmide wurden die entsprechenden Hefe-Transformanten mit A. dest von dem Selektionsmedium gewaschen, vereinigt und geerntet (ه $5 \mathrm{~min}, 12.000 \mathrm{rpm}$ RTmp). Zur Isolierung der S. macrospora cDNA-Bank pAD-GAL4-2.1 und N. crassa cDNA-Bank pGADT7 Plasmid-DNA aus den Hefe-Transformanten wurden diese in einer $10 \mathrm{ml}$ SD-Übernachtkultur angezogen und 1,5 $\mathrm{ml}$ von dieser Kultur geerntet (ه 5 min, $12.000 \mathrm{rpm}, \mathrm{RTmp}$ ). Die Zellpellets wurden mit $250 \mu$ l Puffer P1 (QIAprep Spin Miniprep Kit) bzw. $250 \mu 1$ Resuspension Solution (GeneJET Plasmid Miniprep Kit) und dem gleichen Volumen Glasperlen $(0,25-0,5 \mathrm{~mm})$ versetzt und 5 min gevortext, um die Zellwand zu zerstören. Weiterfolgend wurde nach der Vorschrift der Hersteller verfahren.

\subsubsection{Isolierung von genomischer DNA und RNA aus $S$. macrospora}

Die Isolierung von genomischer DNA aus S. macrospora-Stämmen erfolgte mittels Phenol/ChloroformExtraktion nach einer Vorschrift von Lecellier und Silar (1994) oder abgewandelt mit Hilfe einer Natriumacetat/Isopropanol-Fällung. Hierzu wurde das geerntete Pilzmyzel mit $600 \mu 1$ Lysepuffer versetzt und $3 x$ jeweils 30 sek gevortext und 30 sek in flüssigen Stickstoff getaucht. Nachfolgend wurde der Ansatz $30 \mathrm{~min}$ bei $70^{\circ} \mathrm{C}$ inkubiert und 2 min gevortext. Anschließend wurden $400 \mu 1$ einer $3 \mathrm{M}$ NatriumacetatLösung hinzugegeben und nach 10 min Inkubation bei $-20^{\circ} \mathrm{C}$ der Überstand gewonnen (ه 10 min, $13.000 \mathrm{rpm}, \mathrm{RTmp}$ ). Dieser wurde mit dem gleichen Volumen Isopropanol versetzt und die DNA nach einer Inkubation von 10 min bei RTmp pelletiert und mit $70 \%$ EtOH gewaschen. Die genomische DNA wurde anschließend unter dem Abzug getrocknet und in 40-60 $\mu \mathrm{l}$ A. dest gelöst.

Die Isolierung von RNA wurde verändert nach Elleuche und Pöggeler (2009) durchgeführt. Das Pilzmyzel wurde nach der Ernte in flüssigem Stickstoff zu Pulver gemörsert und mit $1 \mathrm{ml}$ Trizol versetzt. Der durch Zentrifugation ( $10 \mathrm{~min}, 13.000 \mathrm{rpm}, 4^{\circ} \mathrm{C}$ ) gewonnene Überstand wurde mit 0,2 ml Chloroform gemischt und zu $500 \mu 1$ des erneut gewonnenen Überstandes, das gleiche Volumen Isopropanol hinzugegeben. Nach einer Inkubation von 10 min bei RTmp wurde die RNA pelletiert, mit $75 \%$ EtOH gewaschen, unter dem Abzug getrocknet und in $120 \mu \mathrm{l} \mathrm{A}$. dest für $30 \mathrm{~min}$ bei $1000 \mathrm{rpm}$ und $60^{\circ} \mathrm{C}$ gelöst.

\subsection{Hydrolyse und Ligation von Nukleinsäuren}

DNA wurde mit Restriktionsendonukleasen in Ansätzen mit einem Volumen von 10-80 $\mu 1$ nach HerstellerAngaben hydrolysiert. Für die Ligation von Nukleinsäuren wurde T4 DNA Ligase, das QIAGEN PCR Cloning Kit und das CloneJET PCR Cloning Kit nach Angaben der Hersteller verwendet. Zur Vermeidung von Selbstligationen wurden Plasmide nach der Hydrolyse und vor der Ligationsreaktion ggf. mit Calf Intestine Alkaline Phosphatase nach Hersteller-Angaben dephosphoryliert.

\subsection{Natriumacetat-Fällung und Mikrodialyse}

Zur Fällung von DNA aus wässrigen Lösungen, wurde die Probe mit 1/10 Volumen 3 M NatriumacetatLösung und dem 3-fachen Volumen Ethanol versetzt. Nach Inkubation für 10 min bei $-70^{\circ} \mathrm{C}$ wurde die DNA pelletiert ( ( $10 \mathrm{~min}, 13.000 \mathrm{rpm}, 4^{\circ} \mathrm{C}$ ), mit $70 \% \mathrm{EtOH}$ gewaschen und nach dem Trocknen unter dem Abzug in dem gewünschten Volumen A. dest aufgenommen. Die Entfernung von Salzen aus Reaktionsansätzen (z.B. nach einer Ligation) erfolgte durch Mikrodialyse. Dazu wurde die Probe für 30 min auf einem Mikrodialysefilter $(0,02 \mu \mathrm{m}$ Porengröße) gegen A. dest inkubiert.

\subsection{Gelelektrophorese von Nukleinsäuren und Gelextraktion}

\subsubsection{DNA}

DNA-Fragmente wurden mit 1x DNA-Stopperlösung versetzt und in $1 \% 1 \mathrm{x}$ TBE-Agarosegelen in horizontalen Elektrophorese-Apparaturen (Gibco, Karlsruhe, Deutschland; Mupid, Tokio, Japan) bei einer elektrischen Spannung von 5-15 V/cm aufgetrennt. Als Elektrophoresepuffer diente 1x TBE (GibcoApparatur) oder 0,5x TBE (Mupid-Kammer). Als Größenstandard wurde der Gene Ruler DNA Ladder Mix verwendet. Die DNA wurde nach 10-20 min Inkubation in Ethidiumbromid $(1 \mu \mathrm{g} / \mathrm{ml})$ unter UV-Licht 
sichtbar gemacht. Zur Isolierung von DNA aus Agarosegelen wurde das QIAquick Gel Extraction Kit oder das Silica Bead DNA Gel Extraction Kit verwendet.

\subsubsection{RNA}

RNA-Fragmente wurden in 1,2\% 1x MOPS-Agarosegelen mit $5 \%$ Formaldehyd in horizontalen Elektrophorese-Apparaturen (Gibco, Mupid) bei 80-100 V aufgetrennt. Als Elektrophoresepuffer diente 1x MOPS. Vor der Auftragung auf das Gel wurde die RNA 1:1 mit Ethidiumbromid-haltigem 2x RNA Loading Dye versetzt und für 10 min bei $65^{\circ} \mathrm{C}$ inkubiert. Nach Beendigung der Gelelektrophorese wurde die RNA unter UV-Licht sichtbar gemacht.

\subsection{Radioaktive Markierung von Nukleinsäuren}

Zur Herstellung von radioaktiven Sonden wurden DNA-Fragmente entweder nach Feinberg und Vogelstein (1983) mit Klenow-Polymerase und unspezifischen Startermolekülen oder nach Vorschrift des Herstellers mit dem DECAprime ${ }^{\mathrm{TM} I I}$ Random Priming DNA Labeling Kit mit $\left[\alpha^{32} \mathrm{P}\right] \mathrm{dCTP}$ markiert. Nach der enzymatischen Reaktion wurden überschüssige Nukleotide durch Gelfiltration über Sephadex G-50Säulen abgetrennt.

\subsection{Southern-Blotverfahren und Hybridisierung}

Hydrolysierte und gelelektrophoretisch aufgetrennte DNA wurde nach jeweils 30 min Inkubation des Agarosegels in Denaturierungs- und Neutralisierungspuffer mittels Kapillarblot auf eine GeneScreen Hybridization Transfer Membrane übertragen und durch UV-Bestrahlung im „Bio-Link ${ }^{\circledR}$ BLX“ (Biometra, Göttingen, Deutschland) nach Herstellerangaben an die Membran fixiert. Nach $1 \mathrm{~h}$ Inkubation der Membran bei $37^{\circ} \mathrm{C}$ in Vorhybridisierungspuffer erfolgte die Hybridisierung mit der ${ }^{32} \mathrm{P}$-markierten DNASonde über Nacht bei $37^{\circ} \mathrm{C}$. Unspezifisch gebundene DNA wurde durch Waschpuffer bei $40-60^{\circ} \mathrm{C}$ entfernt. Nach dem Trocknen der Membran folgte die Exposition von Röntgenfilmen mit Verstärkerfolie für $1 \mathrm{~d}$ bis 3 Wochen.

\subsection{Oligonukleotidsynthese und Sequenzierung}

Die Synthese von Oligonukleotiden wurde als Auftragsarbeit von der Firma Eurofins MWG Operon (Ebersberg, Deutschland) durchgeführt. Alle in dieser Arbeit verwendeten Primer sind in Tabelle 3 zusammengefasst. DNA-Sequenzierungen wurden von der Firma Eurofins MWG Operon (Ebersberg) oder dem Göttinger Genom Labor (Georg-August Universität Göttingen, Deutschland) durchgeführt.

\subsection{PCR und Kolonie-PCR}

Die PCR wurde zur Vervielfältigung von definierten DNA und cDNA-Abschnitten genutzt (Mullis und Faloona 1987). Die Amplifikationen wurden in den ,eppendorf Mastercycler epgradient $\mathrm{S}_{\text {“ (Eppendorf) }}$ oder „iCycler“ (BioRad, Hercules, USA) PCR-Maschinen unter Verwendung der Phusion ${ }^{\circledR}$ Hot Start HighFidelity DNA Polymerase, MolTaq DNA Polymerase und des HotStarTaq Master Mix Kit nach HerstellerAngaben verwendet. Die Kolonie-PCR wurde zur Detektion rekombinanter Vektorkonstrukte nach Ligation und Transformation in E. coli-Zellen eingesetzt. Für die Kolonie-PCR wurde ausschließlich die MolTaq DNA Polymerase nach modifizierter Herstellerangabe verwendet. Ein Reaktionsansatz $(12,5 \mu 1$ Gesamtvolumen) enthielt: $10,47 \mu 1 \mathrm{~A}$. dest, $1,25 \mu 1$ 10x PCR reaction buffer, $0,25 \mu 1 \mathrm{dNTPs}(10 \mathrm{mM})$, $0,25 \mu$ l Primer $1(10 \mathrm{mM}), 0,25 \mu$ l Primer $2(10 \mathrm{mM}), 0,03 \mu 1$ Taq-Polymerase $(0,15 \mathrm{U})$.

Als Matrize wurde anstelle von DNA eine transformierte E. coli-Kolonie mit einem sterilen Zahnstocher direkt in den Reaktionsansatz gegeben.

\subsection{3 cDNA Synthese und quantitative Real-Time PCR}

Zum Abbau enthaltener gDNA wurde die aufgearbeitete RNA aus den S. macrospora-Stämmen (III Material und Methoden, 2.5.2) zunächst nach Angaben des Herstellers mit DNAse I behandelt. Die reverse Transkription erfolgte danach mit dem Omniscript RT Kit oder dem Transcriptor High Fidelity cDNA Synthesis Kit nach Hersteller-Vorschrift. Es wurden $2 \mu \mathrm{g}$ RNA als Matrize eingesetzt. Die quantitativen Real-Time PCR-Experimente wurden mind. $2 \mathrm{x}$ in Triplikaten mit 2 biologisch unabhängigen 
Proben in einem „Mastercycler ${ }^{\circledR}$ ep realplex“ (Eppendorf) unter Verwendung des qPCR Mastermix for SYBR GreenI durchgeführt (Pöggeler et al. 2006b). Mit der Primer-Kombination pho1 frodo-f/pholfrodo-r wurde ein 233 bp Fragment des Smmob3 Gens und mit pro11frodo-f/pro11frodo-r 152 bp des pro11 Gens amplifiziert. Die Amplifikation eines 180 bp Fragments kodierend für die kleine rRNA Untereinheit mit den Primern SSU-f and SSU-r diente als Referenz für die Normalisierung der Ct-Werte. Die Signifikanz wurde mit der Anwendung „REST“ermittelt (Pfaffl et al. 2002).

\subsection{Analyse von Nukleotid- und Aminosäuresequenzen}

Zur Planung von Plasmid-Klonierungsstrategien und Restriktionen wurde das Programm „Clone Manager 7“ verwendet. Aus Sequenzierungen erhaltene DNA-Sequenzen wurden mit dem Programm „Chromas“ (Version 1.42) analysiert. Revers-komplementäre Sequenzen wurden mit dem Programm „Reverse Complement“ (http://www.ualberta.ca/ stothard/javascript/rev_comp.html) erstellt (Stothard 2000). Promotor-Sequenzen wurden mit dem "Promoter Predictor" (http://www.fruitfly.org/seq tools/ promoter.html) vorhergesagt (Reese 2001). AS-Sequenzen wurden mit dem Programm „Translate“ des „ExPASy Proteomics Server“ (http://www.expasy.org.html) aus cDNA-Sequenzen abgeleitet. Das putative Molekulargewicht, der isoelektrische Punkt, die AS-Zusammensetzung, sowie Phosphorylierungs-Stellen von SmMOB3, PRO11 und Sm9375 wurden mit den Programmen „ProtParam” und „NetPhos” des „ExPASy Proteomics Server“ bestimmt (Gasteiger et al. 2005, Blom et al. 1999). SekundärstrukturVorhersagen erfolgten über den „PSIPRED Server“ (http://bioinf.cs.ucl.ac.uk/psipred/) (Bryson et al. 2005). Nukleotid- und Proteinsequenzen von SmMOB3-, PRO11- und Sm9375-Homologen aus anderen Organismen wurden aus den Datenbanken des „NCBI“ (http://www.ncbi.nlm.nih.gov/entrez/) oder durch BLAST-Suche der beim „Broad Institute“ (http://www.broad.mit.edu/annotation/fungi/fgi/) hinterlegten sequenzierten Pilz-Genome bezogen (Altschul et al. 1997). Multiple Protein-Sequenzvergleiche wurden mit dem Programm „ClustalX“ erstellt (Thompson et al. 1997) und mit der Anwendung "GeneDoc“ grafisch dargestellt. Der Grad der Identität zwischen zwei Sequenzen wurde mit dem Programm „LALIGN“ berechnet (http://www.ch.embnet.org) (Huang und Miller 1991). N-terminale konservierte „,coiled-coil"-Motive und Calmodulin-Bindedomänen von Striatin-Proteinen aus verschiedenen Organismen wurden mit dem Programm „Paircoil“ (ExPASy) und unter zu Hilfenahme der „Calmodulin Target Database“ (http://calcium.uhnres.utoronto.ca/ctdb) vorhergesagt (Berger et al. 1995, Yap et al. 2000). Die Caveolin-Bindedomänen wurden durch eine manuelle Sequenzanalyse im Vergleich zu der experimentell bestätigten Caveolin-Bindedomäne des Säuger-Striatins bestimmt (Gaillard et al. 2001). Mit den Programmen „SignalP“ und „big-PI Predictor“ des „ExPASy Proteomics Server“ wurde eine putative Signalsequenz und eine GPI-Ankerstelle im Sm9375 Protein vorhergesagt (Bendtsen et al. 2004, Eisenhaber et al. 1998). Informationen zu den in den Two-Hybrid "Screens“ identifizierten Interaktionspartnern wurden durch BLAST-Suche in den Datenbanken des „NCBI“ oder in der „Saccharomyces Genome Database“ (http://www.yeastgenome.org) bezogen.

\subsection{Isolierung und Sequenzierung der Gene $S m m o b 3$ und $S m 9375$}

Das Smmob3-Gen wurde in einem Hochdurchsatz-PCR-,,Screening” einer geordneten S. macrospora Cosmid-Bank und einem PCR-,,Screen“ einer S. macrospora cDNA-Bank mit den Primern Smpho1-14 und GAL4T7 amplifiziert (Nolting und Pöggeler 2006b, Pöggeler et al. 1997). Die Subklonierung der erhaltenen Fragmente in pDrive und anschließende Sequenzierung ergab eine Smmob3 ORF-Länge von 2078 bp und eine 212 bp 3'-UTR. Eine 716 bp Smmob3 5'-UTR wurde unter Verwendung von S. macrospora gDNA als Matrize in einer PCR mit den Primern NCU11371_Orf-r und Smpho1_Orf-r amplifiziert und nach Subklonierung in pDrive sequenziert. Die Primer-Sequenz NCU11371_Orf-r wurde aus einem konservierten Sequenz-Bereich des N. crassa ORFs NCU11371 abgeleitet. Die S. macrospora Smmob3 Nukleotid-Sequenz wurde unter der „Accession“ Nummer FN995002 in der EMBL-Datenbank hinterlegt.

Zur Isolierung des Gens Sm9375 wurde zunächst ein 710 bp Sm9375-Fragment aus S. macrospora gDNA mit den aus dem N. crassa ORF NCU09375 abgeleiteten Primern Nc9375-f und Nc9375-r amplifiziert. Nach Subklonierung des Fragments in pDrive und Sequenzierung wurden mit den erhaltenen Sequenzdaten die Sm9375-spezifischen Primer Sm9375Nr2 und Sm9375Cf2 generiert. Diese wurden in PCR-Reaktionen zusammen mit den aus den N. crassa ORFs NCU09376 und NCU09374 abgeleiteten Primern Nc9376C-f und Nc9374Nr genutzt, um ein jeweils 1630 bp (Nc9376C-f/Sm9375Nr2) und 1850 
bp (Sm9375Cf2/Nc9374Nr) Fragment des Sm9375-Lokus zu amplifizieren. Beide Fragmente wurden nach der Subklonierung in den pDrive Vektor sequenziert. Zusammengefasst konnten mit den erhaltenen Sequenzdaten eine Sm9375 ORF-Länge von 980 bp und eine 1123 bp Sm9375 5'-UTR und 647 bp 3'-UTR bestimmt werden.

\subsection{Herstellung von $S$. macrospora Knockout-Stämmen}

Alle in dieser Arbeit hergestellten Gen-Deletionskonstrukte basieren auf Plasmiden, welche mittels homologer Rekombination in S. cerevisiae konstruiert wurden (Colot et al. 2006). Hierbei wurde ein Teil des 5'- und 3'-Bereiches des jeweiligen Gens mit Primern amplifiziert, welche jeweils 29 bp-Überhänge zu dem Plasmid pRS426 und zu der $h p h$-Kassette aufwiesen (Christianson et al. 1992). Der mit EcoRI/XhoIlinearisierte pRS426 Vektor wurde zusammen mit dem jeweils amplifizierten 5'-Genbereich, 3'Genbereich und der amplifizierten $h p h$-Kassette in den S. cerevisiae-Stamm PJ69-4A eingebracht und hier durch homologe Rekombination zu einem Fusionskonstrukt, bestehend aus dem 5'- und 3'-Bereich des jeweiligen Gens getrennt durch die $h p h$-Kassette, zusammengefügt. Die Selektion der HefeTransformanten erfolgte auf SD-Medium ohne Uracil.

Für die Erstellung des Plasmids pMob3ko wurden die Primerkombinationen pho1-5f/pho1-5r und pho13f/pho1-3r zur Amplifikation eines 671 bp 5'- und 930 bp 3'-Bereiches des Smmob3-Gens verwendet. Analog hierzu wurde für das Plasmid p11ko ein 704 bp 5'- und 735 bp 3'-flankierender Bereich des pro11ORFs mit den Primerkombinationen pro11-5f/pro11-5r und pro11-3f/pro11-3r amplifiziert. Für das Plasmid p9375ko wurde ein flankierender 986 bp 5'- und ein 681 bp 3'-Sm9375-Bereich mit den Primern ko9375 5f/ko9375 5r und ko9375 3f/ko9375 3r amplifiziert. Als Matrize in diesen PCR-Reaktionen diente $\bar{S}$. macrospora wt gDNA. Die für die homologen Rekombinationen jeweils verwendete 1414 bp $h p h$-Kassette wurde mit der Primerkombination hph-f/hph-r aus dem Plasmid pCB1003 amplifiziert (Carroll et al. 1994).

Die Plasmide pMob3ko, p11ko und p9375ko wurden nach der homologen Rekombination aus S. cerevisiae isoliert (II Material und Methoden, 2.5.1) und dienten jeweils als Matrize zur Amplifikation der 3015 bp Smmob3-, 2853 bp pro11- und 3081 bp Sm9375-Deletionskassette mit den Primerkombinationen pho15f/pho1-3r, pro11-5f/pro11-3r und ko9375_5f/ko9375_3r. Die Deletionskassetten wurden jeweils in den S. macrospora-Stamm $\Delta \mathrm{ku} 70$ transformiert (Pöggeler und Kück 2006).

Die erfolgreiche homologe Integration der Deletionskassetten in den Smmob3-, pro11- und Sm9375-Lokus der nach der Transformation erhaltenen Primärtransformanten wurde durch PCR-Analyse mit den Primerkombinationen pho1-14f/pho1-2r, pro11-21/pro11-kor und ko9375_4f/ko9375_2r verifiziert. Von den experimentell bestätigten fertilen Primärtransformanten wurden homokaryotische ESIs gewonnen, deren Wachstum auf Hygromycin- und Nourseothricin-haltigem BMM-Medium getestet wurde. Nur solche ESIs, die auf dem Selektionsmedium wachsen konnten, wiesen den jeweils gesuchten

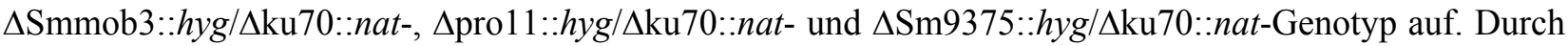
eine anschließende Kreuzung der ESIs mit der Farbspor-Mutante fus-1 oder r2 wurde der $\Delta \mathrm{ku} 70:: n a t-$ Genhintergrund ausgekreuzt und die resultierenden Knockout-Stämme $\Delta$ Smmob3::hyg, $\Delta$ pro11::hyg und $\Delta$ Sm9375::hyg abschließend durch eine PCR-Analyse bestätigt. Der $\Delta$ Smmob3-Stamm wurde zusätzlich durch Southern Blot Analyse verifiziert.

\subsection{Herstellung von $S$. macrospora RNAi- und Doppel-Knockout-Stämmen}

Für die Klonierung der RNAi-Vektoren pMob3si und pPro11si wurde zunächst jeweils ein 500 bp „sense“und ,antisense"-Fragment des Smmob3 und des proll ORFs mit den Primerkombinationen pho-sensef/pho-sense-r, pho-antisense-f/pho-antisense-r und 11-sense-f2/11-sense-r, 11-antisense-f2/11-antisense-r unter Verwendung von wt gDNA als Matrize amplifiziert. Durch die Primer-Überhänge wurden in der PCR-Reaktion XhoI/HindIII-Restriktionsschnittstellen an die "sense“-Fragmente und ApaI/BglIIRestriktionsschnittstellen an die ,antisense"-Fragmente angefügt. Die Amplifikate wurden zur Sequenzierung in pDrive subkloniert und nach Exzision mit XhoI/HindIII und $A p a \mathrm{I} / B g l \mathrm{II}$ in „sense“- und „antisense“-Orientierung in den Vektor pS-NAT1 kloniert (Janus et al. 2007). Die Vektoren pMob3si und pPro11si wurden anschließend in den S. macrospora wt transformiert. Vektor pPro11si wurde zusätzlich in den $\Delta$ Smmob3-Stamm und Vektor pMob3si in die pro11-Mutante transformiert. Die Selektion der erhaltenen Transformanten wt_trpC-MOB3 $\mathrm{si}^{\mathrm{ect}}$, wt trpC-PRO11si ${ }^{\mathrm{ect}}, \Delta \mathrm{Smmob} 3$ trpC-PRO11si ${ }^{\mathrm{ect}}$ und pro11_trpC-MOB3si ${ }^{\text {ect }}$ erfolgte auf Nourseothricin-haltigem BMM-Medium. Zür Überprüfung einer 
erfolgreichen Herunterregulierung der Smmob3- und prol1-Transkriptmengen wurden die Expressionslevel beider Gene in den Transformanten durch quantitative Real-Time PCR analysiert.

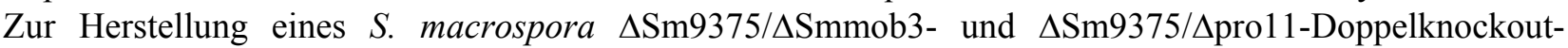
Stamms wurde der $\Delta$ Sm9375-Stamm jeweils mit dem $\Delta$ Smmob3-fus-1- und $\Delta$ pro11-fus-1-Stamm gekreuzt. Anschließend wurden ESIs aus den rekombinanten Kreuzungs-Perithezien isoliert und deren Wachstum auf Hygromycin-haltigem-Medium getestet. Hygromycin-resistente ESIs wurden durch PCRAnalyse mit den Primerkombinationen pho1-14f/pho1-2r und ko9375_4f/ko9375_2r auf den gesuchten $\Delta$ Sm9375/ASmmob3 und mit den Primern pro11-21/pro11-kor und ko9375_4f/ko9375_2r auf den gesuchten $\Delta \mathrm{Sm} 9375 / \Delta$ pro11 Doppelknockout-Genotyp überprüft.

\subsection{Komplementationsanalyse}

Mit Ausnahme des Plasmids pMob3MmFL wurden alle Komplementationsvektoren basierend auf dem Vektor pRSnat mittels homologer Rekombination in S. cerevisiae konstruiert (Colot et al. 2006). Der Vektor pRSnat ist ein Derivat des Plasmids pRS426. Er enthält das Nourseothricin-Resistenz vermittelnde nat 1 Gen unter der Kontrolle des $\operatorname{trpC}$ Promotors aus A. nidulans (Klix et al. 2010). Alle zur Konstruktion der Komplementationsvektoren verwendeten DNA-Fragmente wurden mit der Phusion ${ }^{\circledR}$ Hot Start HighFidelity DNA Polymerase amplifiziert. Durch die in den PCR-Reaktionen verwendeten Primern erhielten einige Amplifikate für die homologe Rekombination benötigte 29 bp Überhänge, deren Spezifitäten in Tabelle 3 angegeben sind. Die Amplifikate wurden zusammen mit dem XhoI-linearisierten pRSnat-Vektor in den PJ69-4A-Stamm eingebracht. Die Selektion der Hefetransformanten und Isolierung der homolog rekombinierten Komplementationsvektoren erfolgte wie bereits beschrieben. Nach der Transformation der Komplementationsvektoren in $S$. macrospora und $N$. crassa wurden alle Transformanten auf Nourseothricin-haltigem BMM-Medium selektioniert und einer morphologischen Analyse unterzogen (II Material und Methoden, 2.19).

\subsubsection{Herstellung von Smmob3-Komplementationskonstrukten}

Zur Konstruktion des Plasmids pMob3MmFL wurde der Ausgangsvektor pEHN1-nat verwendet, welcher das natl Gen unter der Kontrolle des gpd-Promotors und trpC-Terminators aus A. nidulans trägt (Kück, unveröfftl.). Die für das Maus Voll-Längen Phocein (AS 1-225) kodierende cDNA wurde mit den Primern Mmpho-f/Mmpho-r, welche jeweils eine NcoI- und BamHI-Restriktionsschnittstelle aufwiesen, amplifiziert und nach Subklonierung in pJet1.2/blunt sequenziert. Anschließend wurde das Fragment mit NcoI/BamHI aus pJet1.2/blunt geschnitten und in den pEHN1-nat Vektor kloniert. Die Maus cDNA wurde freundlicherweise von Prof. Dr. H. Hahn (Abtl. Molekulare Entwicklungsgenetik, Georg-August Universität Göttingen) zur Verfügung gestellt.

Für die Herstellung der Vektoren pMob3FL und pMob3N wurde das Voll-Längen Smmob3 und eine Cterminal verkürzte Version des Gens inklusive der putativen Smmob3 Promotor-Region in einer PCR mit den Primer-Paaren pho5f_2/pho1-3r and pho5f_2/phodom2_r unter Verwendung von $S$. macrospora wt gDNA als Matrize amplifiziert. Vektor pMob3FL kodiert für das gesamte SmMOB3 (AS 1-663) und pMob3N für die ersten 264 Aminosäuren des Proteins. Für die Konstruktion von pMob3C wurden die putative Smmob3 Promotor-Region und der für den C-Terminus des Proteins kodierende Bereich (AS 324663) unabhängig voneinander mit den Primerkombinationen pho5f_2/pho5r_2 und phodom 3 f $/$ pho1-3r aus $S$. macrospora wt gDNA amplifiziert. Nach der Transformation der Vektoren in $\Delta$ Smmob3 wurde die korrekte Expression der Plasmide in den resultierenden Transformanten-Stämmen $\Delta$ Smmob3_MOB3FL ${ }^{\text {ect }}$, $\Delta$ Smmob3_MOB3 $N^{\text {ect }}, \Delta$ Smmob3_MOB3C ${ }^{\text {ect }}$ und $\Delta$ Smmob3_MOB3MmFL ${ }^{\text {ect }}$ überprüft. Hierzu wurde die Gesamt-RNA aus den Transformanten isoliert und nach der reversen Transkription die jeweils synthetisierte cDNA als Matrize in einer PCR-Analyse eingesetzt. Dabei wurden die Primerkombinationen phoORF-f/phoORF-r für die cDNA-Präparation aus $\triangle$ Smmob3_MOB3FL ${ }^{\text {ect }}$, phoORF-f/phocDNA_2r für $\triangle$ Smmob3_MOB3N ${ }^{\text {ect }}$, phocDNA_3f/phoORF-r für $\Delta$ Smmob3_MOB3C ${ }^{\text {ect }}$ und Mmpho-f/Mmpho-r für $\triangle$ Smmob3_MOB3MmFL ${ }^{\text {ect }}$ verwendet. Die Plasmide pMob3FL, pMob3N and pMob3C wurden außerdem in den $N$. crassa-Stamm $\triangle m o b-3$ transformiert. Hieraus resultierten die Transformanten $\Delta m o b-$ 3_MOB3FL ${ }^{e c t}, \triangle m o b-3 \_M O B 3 N^{e c t}$ und $\triangle m o b-3 \_M O B 3 C^{e c t}$. Die Transformation und Analyse der N. crassa Stämme wurden von Herrn Dr. S. Seiler (Abtl. Molekulare Mikrobiologie und Genetik, Georg-August Universität Göttingen) durchgeführt. 
Um die Auswirkung einer Überexpression des Smmob3-Gens zu testen wurde der Vektor pMob3oex konstruiert, in welchem das Voll-Längen Smmob3 unter Kontrolle des konstitutiv exprimierten gpdPromotors und $\operatorname{trpC}$-Terminators aus A. nidulans steht. Der Smmob3-ORF wurde aus S. macrospora wt gDNA mit den Primern phoORF-f/phoORF-r amplifiziert. Die gpd- und trpC-Fragmente wurden unter Verwendung des Plasmids p1783-1 als Matrize mit den Primern pRSGPDf2/phorevGPD und phofGFP/pRSGFPrev in einer PCR-Reaktion hergestellt. Die Transformation von pMob3oex in $\Delta$ Smmob3 und den WT resultierte in der Transformante $\Delta$ Smmob3_gpd-MOB ${ }^{\text {ect }}$ und den wt_gpd-MOB $3^{\text {ect }}$.

\subsubsection{Herstellung von pro11-Komplementationskonstrukten}

Für die Herstellung der Vektoren p11FL, p11N1, p11N2, p11N3 und p11N4 wurde das Voll-Längen pro11 und verschiedene C-terminal verkürzte Versionen des Gens inklusive der putativen proll PromotorRegion in einer PCR mit wt gDNA als Matrize mit den Primer-Paaren pro11-5f/pro11-3r, pro115f/pro11domplus-r, pro11-5f/pro11dom-r, pro11-5f/pro11dom1-r und pro11-5f/pro11dom1-1-r amplifiziert. Die Vektoren kodieren in der angegebenen Reihenfolge für die AS 1-845, 1-414, 1-281, 1-180 und 1-120 des PRO11-Proteins. Nach der Transformation der Plasmide in $\Delta$ pro11 wurden die Stämme

$\Delta$ pro11_PRO11FL ${ }^{\text {ect }}, \quad \Delta$ pro11_PRO11N1 ${ }^{\text {ect }}, \quad \Delta$ pro11_PRO11N2 $2^{\text {ect }}, \quad \Delta$ pro11_PRO11N3 ${ }^{\text {ect }}$ und $\Delta$ pro11_PRO11N4 ${ }^{\text {ect }}$ erhalten. Für die Herstellung des Vektors p11mut wurde gDNA der pro11-Mutante als Matrize in einer PCR-Reaktion mit den Primern pro11-5f/pro11-3r eingesetzt. Durch die im pro11-Gen enthaltene Punktmutation kodiert der resultierende Vektor p11mut für AS 1-545 des PRO11-Proteins. Die Transformation von p11mut in $\Delta$ pro11 resultierte in der Transformante $\Delta$ pro11_PRO11mut ${ }^{\text {ect }}$. Nach der Transformation wurde die korrekte Expression der Plasmide wie für die SmMOB3Komplementationsstämme beschrieben überprüft. Hierzu wurden die Primer-Kombinationen pro11-ORF-f/pro11-ORF-r2 (Dpro11_PRO11FL $\left.{ }^{\text {ect }}\right)$, pro11-ORF-f/pro11cDNA-r-mut ( PRO11 mut $\left.^{\text {ect }}\right)$, pro11-ORF-f/pro11cDNA-plus-r ( $\left(\right.$ pro11_PRO11N1 $\left.{ }^{\text {ect }}\right), \quad$ pro11-ORF-f/pro11cDNA-r $\left(\Delta\right.$ pro11_PRO11N2 $\left.2^{\text {ect }}\right), \quad$ pro11-ORF-f/pro11cDNA-1r $\quad\left(\Delta\right.$ pro11_PRO11N3 $\left.{ }^{\text {ect }}\right)$ und pro11-ORFf/pro11cDNA-1-1-r ( $\Delta$ pro11_PRO11N4 $\left.{ }^{\mathrm{ect}}\right)$ verwendet.

Um die Auswirkung einer Überexpression des pro11-Gens zu testen wurde der Vektor p11oex konstruiert, in welchem das Voll-Längen proll unter Kontrolle des gpd-Promotors und des trpC-Terminators aus $A$. nidulans steht. Der proll-ORF wurde aus $S$. macrospora wt gDNA mit den Primern pro11-ORF-f/pro11TrpC_r amplifiziert. Die gpd- und trpC-Fragmente wurden unter Verwendung des Plasmids p1783-1 als Matrize mit den Primern pRSGPDf2/pRS42611GPDr2 und TrpC_F/pRSGFPrev in einer PCR-Reaktion hergestellt. Das p1loex-Plasmid wurde in den wt und den spro11-Stamm transformiert, woraus die Stämme wt_gpd-PRO1 ${ }^{\text {ect }}$ und $\Delta$ pro11_gpd-PRO11 ${ }^{\text {ect }}$ resultierten.

Zur Überprüfung des Einflusses einer alternativ gespleißten PRO11-Variante auf die sexuelle Entwicklung wurde der Vektor p11cDNA generiert. Dieser enthält den gesamten pro11 cDNA-ORF, welcher mit den Primern pro11-ORF-f/pro11-ORF-r2 aus wt cDNA amplifiziert wurde, unter Kontrolle der putativen pro11 Promotor- und Terminator-Sequenz. Diese wurden mit den Primer-Paaren pro11-5f/pro11-5r2 und pro113f2/pro11-3r aus wt gDNA amplifiziert. Die Transformation von p11cDNA in $\Delta$ pro11 resultierte in dem Stamm $\Delta$ pro11_PRO11cDNA ${ }^{\text {ect }}$.

\subsection{Morphologische Analyse von S. macrospora-Stämmen}

Phänotypische Übersichtsaufnahmen von S. macrospora-Stämmen erfolgten mit einer „Canon PowerShot A 620 " Digitalkamera nach $7 \mathrm{~d}$ Inkubation auf SWG-Festmedium. Alle Aufnahmen von Perithezien wurden nach 7-10 d Inkubation der S. macrospora-Stämme auf SWG-Festmedium mit dem „Keyence Digital Mikroskop VHX-500F“ mit dem Objektiv „VH-Z20R RZx20-x150“ (Keyence, Osaka, Japan) gemacht. Für die Dokumentation der verschiedenen sexuellen Entwicklungsstadien wurden die S. macrospora-Stämme für 3-7 d auf Objektträgern kultiviert, welche mit einer dünnen Schicht SWGFestmedium überzogen waren und anschließend unter dem Lichtmikroskop analysiert (II Material und Methoden, 2.22).

Für die phänotypische Charakterisierung des $N$. crassa wt und $4 m o b-3$ wurden die Stämme wie bereits beschrieben kultiviert und analysiert (Maerz et al. 2009). Die sexuelle Entwicklung der $N$. crassa Komplementationsstämme wurde 3 Wochen nach der Fertilisierung mit wt Konidien analysiert und dokumentiert. 
Alle nachfolgend beschriebenen Experimente wurden mind. zweifach mit mind. zwei biologisch unabhängigen Proben durchgeführt. Für die Bestimmung der Ascogon- und Protoperithezien-Anzahl wurden die S. macrospora-Stämme $5 \mathrm{~d}$ auf mit SWG-Festmedium beschichteten Objektträgern angezogen. Von jedem Objektträger wurden $4 \times 0,25 \mathrm{~cm}^{2}$ große Bereiche ca. 1-2 cm hinter der Wuchsfront herausgeschnitten und die Ascogon- bzw. Protoperithezien-Anzahl unter dem Lichtmikroskop ausgezählt. Zur Bestimmung der Perithezien-Anzahl wurden die S. macrospora-Stämme $7 \mathrm{~d}$ in Petrischalen mit SWGFestmedium kultiviert und die sich auf $1 / 8$ der Fläche $\left(\sim 8 \mathrm{~cm}^{2}\right)$ befindenden Perithezien ausgezählt.

Die Bestimmung der Wachstumsgeschwindigkeit und des Trockengewichts wurden wie zuvor beschrieben durchgeführt (Nowrousian und Cebula 2005, Nolting und Pöggeler 2006a).

Das Wachstum von $S$. macrospora-Stämmen unter Stress-induzierenden Bedingungen wurde auf SWGFestmedium mit Zusatz von $0,1 \mathrm{M} \mathrm{NaCl}$ oder $\mathrm{KCl}, 0,4 \mathrm{M}$ Sorbitol, $0,01 \%$ oder $0,03 \% \mathrm{H}_{2} \mathrm{O}_{2}$ und $0,003 \%$ SDS getestet. Die fototechnische Dokumentation der morphologischen Phänotypen der S. macrosporaStämme auf dem Stress-induzierenden Medium erfolgte mit einer „Canon PowerShot A260“ Digitalkamera nach 7-10 d.

\subsection{Analyse von Hyphenfusionen}

Für die Untersuchung der Fusionsfähigkeit wurden jeweils zwei der zu testenden S. macrospora-Stämme gekreuzt (II Material und Methoden, 2.2). Die entstandene Kreuzungsfront wurde ausgeschnitten, alle sich darauf befindenden Perithezien geöffnet und die Anzahl der Kreuzungsperithezien unter einem „Stemi 2000-C“ Binokular (Zeiss, Jena, Deutschland) bestimmt. Als Kreuzungsfront wurde ein Bereich von $0,5 \mathrm{~cm}$ jeweils rechts und links der Kreuzungslinie der beiden $S$. macrospora-Stämme definiert. Die Versuche wurden zweifach mit zwei biologisch unabhängigen Proben durchgeführt.

\subsection{Lokalisierungsstudie von SmMOB3 und PRO11}

Die für die Lokalisierungsstudie eingesetzten Plasmide pMob3DsRed und p11natDsRed basieren auf dem Vektor pRSnat und wurden mittels homologer Rekombination in Hefe hergestellt (II Material und Methoden, 2.16 und 2.18). Der Vektor pMob3DsRed enthält das Smmob3-DsRed-Fusionsgen unter der Kontrolle des gpd-Promotors und trpC-Terminators aus A. nidulans. Zur Konstruktion des Plasmids wurde der $g p d$-Promotor mit der Primerkombination pRSGPDf2/phorevGPD und das DsRed-Gen zusammen mit dem trpC-Terminator mit den Primern phofDsRed/pRSGFPrev unter Verwendung von pRHN1 PlasmidDNA als Template amplifiziert. Der gesamte Smmob3-ORF ohne Stopp-Codon wurde in einer PCRReaktion mit den Primern phoORF-f/phoORF-r aus wt gDNA amplifiziert.

Das Plasmid p11natDsRed enthält das pro11-DsRed-Fusionsgen unter der Kontrolle der putativen pro11 Promotor-Region. Zur Amplifikation des pro11-Fragments aus wt gDNA wurde die Primerkombination pro11-5f/pro11-ORF-r und für das DsRed-Fragment pro113fDsRed/pRSGFPrev unter Verwendung von pRHN1 als Matrize verwendet. Die Plasmide pMob3DsRed und p11natDsRed wurden in $\Delta$ Smmob3 bzw. $\Delta$ pro11 transformiert, woraus die Stämme $\Delta$ Smmob3_gpd-MOB3:DsRED ${ }^{\text {ect }}$ und $\Delta$ pro11_PRO11:DsRed ${ }^{\text {ect }}$ resultierten. Die Stämme $\Delta$ Smmob3_gpd-MOB3:DsRED ${ }^{\text {ect }}$ und $\Delta$ pro11_PRO11:DsRed ${ }^{\text {ect }}$ waren fertil, daraus konnte auf eine korrekte Expression der transformierten Plasmide geschlossen werden. Um die Lokalisierung der Fusionsproteine näher eingrenzen zu können wurden Zellorganellen unterschiedlich sichtbar gemacht. Die Zellkerne wurden mit DAPI nach Hersteller-Angaben angefärbt. Die Peroxisomen wurden in dem Stamm wt_gpd-DsRed:SKL ${ }^{\text {ect }}$ durch die Expression eines DsRed-SKL Fusionsproteins spezifisch angefärbt. Das SKL (Serin/Lysin/Leucin)-Tripeptid ist eine peroxisomale Zielsequenz (Elleuche und Pöggeler 2008). In dem Stamm wt_gpd-Mito:DsRed ${ }^{\text {ect }}$ wurden die Mitochondrien durch die Expression des DsRed-Gens fusioniert mit der mitochondrialen Zielsequenz des cas2-Gens sichtbar gemacht (Elleuche und Pöggeler 2009). Die Fusionsproteine bzw. die mit DAPI gefärbten Zellkerne wurden durch geeignete Fluoreszenz-Anregung unter dem Mikroskop sichtbar gemacht (II Material und Methoden, 2.22).

\subsection{Licht- und Fluoreszenzmikroskopie}

Durchlicht- und fluoreszenzmikroskopische Aufnahmen wurden mit einem „AxioImager M1“ Mikroskop (Zeiss) unter Verwendung einer „Photometrics CoolSNAP ${ }_{\mathrm{HQ}}^{2 ،}$ "Kamera (Roper Scientific, Tucson, USA) aufgenommen. Zur Detektion der Fluorophor-Fusionsproteine wurden die Chroma-Filtersätze 49000 
(DAPI; Anregungs-/Emittionsfilter D350/50/ET460/50, Strahlteiler T400lp) und 49005 (DsRed; Anregungs-/Emittionsfilter ET545/30/ET620/60, Strahlteiler T570lp) und eine „X-cite 120 PC“-Lampe (EXFO, Ontario, Kanada) verwendet. Die fotografischen Aufnahmen wurden mit der „MetaMorph Software“ (VisitronSystems, Puchheim, Deutschland) und „Adobe Photoshop CS2“ bearbeitet.

\subsection{Analyse von Protein-Protein-Interaktionen}

\subsubsection{Hefe Two-Hybrid-Analyse der Proteine PRO11 und SmMOB3}

Die Hefe Two-Hybrid Experimente wurden mit dem pGBDU/pGAD-Vektorsystem und dem S. cerevisiaeStamm PJ69-4A durchgeführt (James et al. 1996). Zur Konstruktion der Vektoren pB11-aa1-281 und pA11-aa1-281 wurde ein 857 bp pro11-5' cDNA-Fragment mit SalI/PstI aus dem Vektor pAK2 geschnitten und in die mit SalI/PstI-linearisierten Vektoren pGBDU-C1 and pGAD-C1 kloniert (Pöggeler und Kück 2004). Die resultierenden Vektoren kodieren jeweils für AS 1-281 des PRO11 Proteins. Ein 3'verkürztes 653 bp pro11-5' cDNA-Fragment wurde mit der Primerkombination pro11-31 und pro11-24 unter Verwendung des Vektors pB11-aa1-281 als Matrize amplifiziert und in pDrive zur Sequenzierung subkloniert. Anschließend wurde das Fragment aus pDrive mit SalI/PstI freigesetzt und in den mit SalI/PstI-restringierten Vektor pGBDU-C1 inseriert. Der resultierende Vektor pB11-aa1-215 kodiert für AS 1-215 des PRO11-Proteins. Für eine weitere 3'-Verkürzung des pro11-5' cDNA-Fragments wurde ein 349 bp Amplifikat mit SalI-Überhängen in einer PCR-Reaktion mit den Primern pro11-31/pro1 1-132 unter Verwendung von cDNA aus einer wt-Präparation als Matrize generiert. Nach Subklonierung und Sequenzierung wurde das Fragment mit SalI aus pDrive geschnitten und in den SalI-linearisierten pGBDUC3 kloniert. Der resultierende Vektor pB11-aa1-110 kodiert für PRO11 AS 1-110.

Für die Herstellung der Vektoren pB11-aa282-845 und pA11-aa282-845 wurde ein 1728 bp pro11-3' cDNA-Fragment mit SalI/PstI-Überhängen durch die Verwendung der Primer pro11-34 und pro11-35 amplifiziert. Nach Subklonierung und Sequenzierung wurde das SalI/PstI-freigesetzte Fragment in die SalI/PstI-restringierten pGBDU-C1 und pGAD-C1 Vektoren kloniert. Die resultierenden Vektoren kodieren für AS 282-845 des PRO11 Proteins.

Für die Konstruktion der Smmob3 Two-Hybrid Plasmide wurde ein 1038 bp 5'-Smmob3 cDNA-Fragment mit der Primerkombination Smpho1-11/Smpho1-13 (jeweils Sall-Überhang) aus wt cDNA amplifiziert. Nach Subklonierung in pDrive und Sequenzierung wurde das SalI-restringierte Fragment in die SalIlinearisierten pGBDU-C1 und pGAD-C1 Vektoren kloniert. Die entstandenen Plasmide pBMob3-aa1-345 und pAMob3-aa1-345 kodieren für AS 1-345 des SmMOB3 Proteins. Vektor pBMob3-aa1-144, welcher ein 3'-verkürztes 435 bp 5'-Smmob3 cDNA-Fragment enthält, wurde durch PstI-Hydrolyse des Vektors pBMob3-aa1-345 und anschließender Selbstligation generiert. Die Selektion, der Test auf Transaktivierung und die Two-Hybrid-Analyse mit den nach der Transformation der Two-Hybrid Vektoren erhaltenen HefeStämmen wurden wie von Jacobsen et al. (2002) beschrieben durchgeführt.

\subsubsection{Hefe Two-Hybrid-Screen einer $S$. macrospora und $N$. crassa cDNA-Bank mit PRO11 und SmMOB3 als Köderprotein}

Zur Identifizierung von Interaktionspartnern der Proteine PRO11 und SmMOB3 wurde eine Hefe TwoHybrid-Analyse mit einer S. macrospora cDNA-Bank, wie von Nolting und Pöggeler (2006b) beschrieben, durchgeführt. Als Köder wurden die Vektoren pB11-aa1-110, pB11-aa282-845 und pBMob3-aa1-144, welche für die unter II Material und Methoden, 2.23.1 angegebenen PRO11- und SmMOB3 ProteinTeilstücke kodieren, jeweils zusammen mit der cDNA-Bank in PJ69-4A transformiert. Die cDNA-Bank Plasmide, welche für die identifizierten Interaktionspartner kodierten, wurden isoliert, zur Vermehrung in E. coli transformiert und nach Birnboim und Doly (1979) aufgearbeitet. Zur eindeutigen Identifizierung der S. macrospora cDNA-Bank Plasmide wurde eine Restriktionsanalyse durchgeführt. Hierbei wurden die aufgearbeitete Plasmid-DNA und die eingesetzten Köder-Plasmide mit den Restriktionsendonukleasen EcoRI und XhoI hydrolysiert und gelelektrophoretisch aufgetrennt. Alle Ansätze, die ein anderes Bandenmuster aufwiesen als die restringierten Köderplasmide, wurden sequenziert und die erhaltenen Sequenzdaten einem BLAST-Sequenzvergleich unterzogen.

Es wurde zusätzlich eine artübergreifende Two-Hybrid Analyse mit den oben genannten S. macrospora Ködern und einer $N$. crassa cDNA-Bank durchgeführt, welche freundlicherweise von Dr. S. Seiler (Abtl. Molekulare Mikrobiologie und Genetik, Georg-August Universität Göttingen) zur Verfügung gestellt 
wurde. Die N. crassa cDNA-Bank wurde mit dem „Matchmaker Library Construction \& Screening Kit“ (Clontech) konstruiert und lag bereits in dem S. cerevisiae-Stamm AH109 (AH109-Nc) vor. Die KöderPlasmide wurden in den S. cerevisiae-Stamm PJ69-4 $\alpha$ transformiert und die resultierenden Hefestämme durch Paarung („Mating“) mit AH109-Nc mit der N. crassa cDNA-Bank zusammengebracht. Für das Mating der Hefestämme wurde jeweils eine $5 \mathrm{ml}$ Kultur der Köder-Stämme $\left(1 \times 10^{9}\right.$ Zellen $\left./ \mathrm{ml}\right)$ mit einer $1 \mathrm{ml} \mathrm{Kultur}$ von AH109-Nc $\left(2 \times 10^{7}\right.$ Zellen/ml) in $45 \mathrm{ml} 2 \mathrm{x}$ YPDA für $20-24 \mathrm{~h}$ bei $30-50 \mathrm{rpm}$ und $30^{\circ} \mathrm{C}$ inkubiert. Anschließend wurden die Zellen pelletiert (ه $10 \mathrm{~min}, 4500 \mathrm{rpm}, \mathrm{RTmp}$ ), in $10 \mathrm{ml}$ 0,5x YPDA resuspendiert und in Aliquots von je $200 \mu \mathrm{l}$ auf SD-Festmedium ohne Uracil, Leucin, Histidin und Adenin selektioniert. Die Identifizierung der Genbank-Plasmide aus den Hefe-Transformanten erfolgte durch Restriktionsanalyse mit EcoRI/XhoI und die Plasmide wurden anschließend wie oben beschrieben sequenziert und analysiert.

\subsection{Sicherheitsmaßnahmen}

Gentechnische Experimente der Sicherheitsstufe 1 wurden nach den Richtlinien des Gentechnikgesetzes (GenTG) vom 16.12.1993 (zuletzt geändert durch Art. 12 G v. 29.7.2009 I 2542) durchgeführt. 


\section{ERGEBNISSE}

\section{$1 \quad$ Funktionelle Charakterisierung des $S$. macrospora Proteins SmMOB3}

\subsection{S. macrospora kodiert für ein Phocein/Mob3-Homolog}

Wie in der Einführung beschrieben interagieren die Proteine der Striatin-Familie aus Säugern mit dem Protein Phocein. Um eine Interaktion der homologen Proteine aus S. macrospora zu analysieren, wurde zunächst das zu phocein homologe Gen Smmob3 aus S. macrospora isoliert. In N. crassa kodiert NCU07674 für das Phocein/Mob3 Homolog MOB3, welches an der vegetativen Zellfusion, der Fruchtkörperbildung und Ascosporogenese beteiligt ist (Maerz et al. 2009). Die Genome der beiden filamentösen Ascomyceten N. crassa und S. macrospora weisen einen hohen Grad an Syntenie auf. Die durchschnittliche Nukleinsäure-Identität innerhalb der Exons beträgt 89,5 \% (Nowrousian et al. 2004). Der 2078 bp Smmob3-ORF und 212 bp der zugehörigen 3'-UTR wurden daher wie beschrieben (II Material und Methoden, 2.15), mit von N. crassa NCU07674 abgeleiteten Primern unter Verwendung einer geordneten S. macrospora Cosmid-Bank und einer S. macrospora cDNA-Bank als Matrize in einer PCR-Reaktion amplifiziert (Daten nicht gezeigt) (Nolting und Pöggeler 2006b, Pöggeler et al. 1997). Darüber hinaus konnte eine 716 bp Smmob3 5'-UTR unter Verwendung von S. macrospora gDNA aus dem Wildtyp-Stamm (wt) als Matrize amplifiziert und anschließend sequenziert werden. Mit dem „Promotor Prediction program” wurde ein Transkriptionsstart 336 Nukleotide stromaufwärts des putativen Smmob3 ATG-Start-Codons vorhergesagt (Reese 2001). Die flankierenden Sequenzbereiche des putativen Start-Codons zeigen eine starke Ähnlichkeit zu Translationsinitiations-Stellen anderer S. macrospora Gene (Pöggeler 1997). Der Smmob3 cDNA-ORF wurde mit den Primern phoOFR-f/phoORF-r aus einer S. macrospora cDNA-Bank amplifiziert und sequenziert. Durch den Vergleich der genomischen und der cDNA-Sequenz konnte ein 86 bp Intron zwischen den Nukleotid-Positionen 217 und 302 des Smmob3 ORFs identifiziert werden (Daten nicht gezeigt). Das abgeleitete SmMOB3 Protein besteht aus 663 Aminosäuren (AS). Das Molekulargewicht wurde mit $72 \mathrm{kDa}$ und der putative isoelektrische Punkt mit 4,6 vorhergesagt.

Eine BLAST-Datenbank-Suche ergab, dass nah verwandte Organismen von S. macrospora wie z. B. der filamentöse Ascomycet Chaetomium globosum und entfernter verwandte filamentöse Pilze wie Magnaporthe grisea und F. graminearum, sowie Tiere in ihren Genomen ein homologes Mob3-Protein kodieren. Dagegen weisen hemiascomycetische Hefen kein Mob3Protein auf. 
Die Mob3 Proteine der in dem multiplen Proteinalignment verglichenen Organismen (Abb. 6A) weisen die höchste Identität in der AS-Sequenz der konservierten Mob-Domäne auf, welche ca. 180-200 AS umfasst (Abb. 6B).

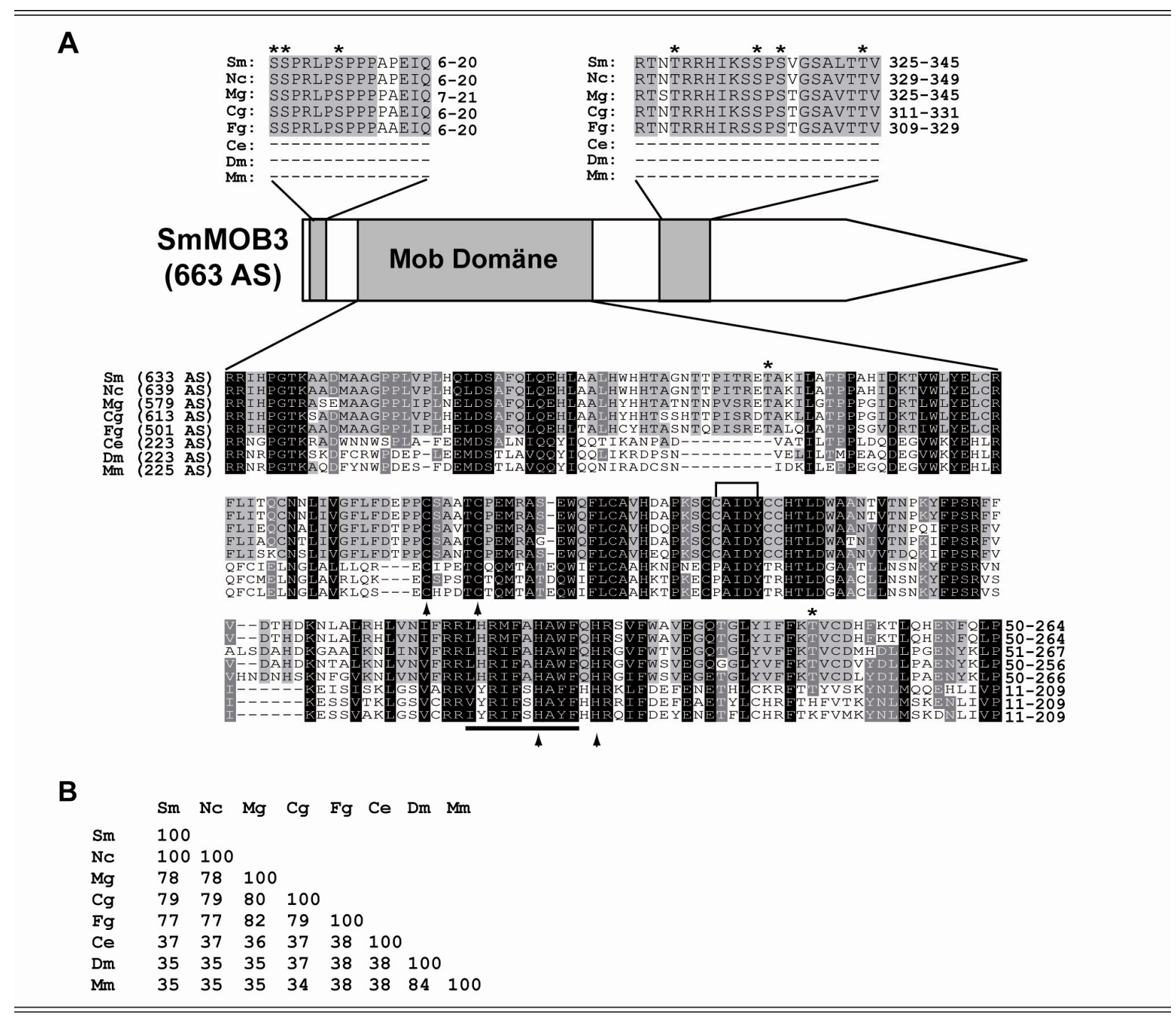

Abb. 6 Multipler Sequenzvergleich von Mob3 Proteinen aus filamentösen Ascomyceten und Tieren. (A) Der weiße Pfeil repräsentiert das S. macrospora SmMOB3 Protein mit der konservierten MobDomäne und den beiden konservierten Ascomyceten-spezifischen N- und C-terminalen Domänen (graue Boxen). Das Sequenz-Alignment wurde mit dem Programm ClustalX berechnet und mit der Anwendung GeneDoc dargestellt. Schwarz hinterlegte AS sind in allen verglichenen Protein-Sequenzen konserviert, AS, die in mind. sieben Sequenzen konserviert sind, sind dunkelgrau markiert und in hellgrau hinterlegt sind AS, welche in mind. fünf Sequenzen konserviert sind. Striche symbolisieren, dass die angegebenen AS anderer Organismen in dieser Sequenz nicht enthalten sind. Die AS Region, die für das Alignment verwendet wurde ist jeweils auf der rechten Seite angegeben. Sterne über dem Alignment kennzeichnen die vorhergesagten, in $S$. macrospora, $N$. crassa und M. grisea konservierten Serin- und Threonin Phosphorylierungsstellen. Die putative SH3-Bindedomäne ist durch eine Klammer und die SequenzRegion mit Homologie zu der $\sigma$-Untereinheit des Clathrin Adaptor Komplexes durch schwarze Linien in Fettdruck markiert. Die konservierten Cys2-His2 Zn Bindestellen sind durch schwarze Pfeilspitzen gekennzeichnet. Abkürzungen und Accession-Nummern: Sm-Sordaria macrospora (FN995002), NcNeurospora crassa (XP_328380.1), Mg-Magnaporthe grisea (MG07095.4), Cg-Chaetomium globosum 


\section{(weiter zu Abb. 6A)}

(XP_001223910.1), Fg-Fusarium graminearum (FGSG_05101.2), Ce-Caenorhabditis elegans (NP_498798.2), Dm-Drosophila melanogaster (NP_610229.1), Mm-Mus musculus (NP_079559.2). (B) Die Mob-Domänen aller in (A) dargestellten Sequenzen wurden paarweise verglichen und die resultierenden AS-Identitäten in \% angegeben.

Interessanterweise sind die AS-Sequenzen der MOB3 Proteine der filamentösen Pilze im Vergleich zu denen der Tiere fast dreimal länger, da sie zusätzliche $\mathrm{N}$ - und C-terminale Sequenzbereiche aufweisen. Innerhalb dieser zusätzlichen Sequenzen konnten zwei konservierte, Ascomyceten-spezifische Domänen identifiziert werden (Abb. 6A). Abgesehen von diesen Bereichen ist die Sequenzähnlichkeit zwischen den pilzlichen MOB3-Proteinen in den zusätzlichen N- und C-terminalen Bereichen mit 46-96 \% bzw. 19-65 \% gering. Da Mob3Proteine wie beschrieben vermutlich eine Funktion in großen Proteinkomplexen mit Serin/Threonin Protein Phosphatasen und Kinasen einnehmen (Goudreault et al. 2009), wurden mögliche Phosphorylierungsstellen in dem SmMOB3 Protein mit dem Programm „Netphos“ bestimmt (Blom et al. 1999). Es wurden 36 von 52 Serin- und 21 von 57 Threonin-Resten in SmMOB3 als putative Phosphorylierungsstellen vorhergesagt, von welchen die meisten in der konservierten N- bzw. C-terminalen Domäne lagen (Daten nicht gezeigt).

Es wurden zusätzlich die putativen Phosphorylierungsstellen für die MOB3 Proteine aus $N$. crassa und $M$. grisea vorhergesagt und mit denen von SmMOB3 verglichen. Es stellte sich heraus, dass sieben putativ phosphorylierte Serin- und fünf Threonin-Reste in allen drei Organismen konserviert waren und sich vornehmlich in der konservierten N- und C-terminalen Region und der Mob-Domäne befanden (Abb. 6A).

Wie Abb. 6A zeigt, weisen die pilzlichen MOB3-Proteine eine putative Cys2-His2 ZnBindestelle auf, welche in den Proteinen der Mob-Familie konserviert ist (Stavridi et al. 2003, Vitulo et al. 2007). Darüber hinaus zeigen auch alle pilzlichen MOB3-Proteine, wie für das homologe Protein aus Säugern beschrieben, einen Sequenzabschnitt mit Ähnlichkeit zu der $\sigma$ Untereinheit des Clathrin-Adaptor Komplexes [(I, L, V, M) (I, L, V, M) YRxxxxLYF] und zu einer SH3-Bindedomäne des Typs „PxxDY“. Beide Sequenzmotive finden sich typischerweise in Proteinen, welche an der Endozytose und an vesikulären Transportprozessen beteiligt sind (Baillat et al. 2001). 


\subsection{Expressionsanalyse der beiden $S$. macrospora Gene Smmob3 und pro11}

Das Expressionsmuster der beiden Gene Smmob3 und proll während des Lebenszyklus von $S$. macrospora wurde mit Hilfe von quantitativen Real-Time PCR Experimenten analysiert. Unter den gegebenen Laborbedingungen begann die sexuelle Entwicklung drei Tage nach dem Animpfen einer S. macrospora-Kultur mit der Bildung der Ascogone. Diese entwickelten sich nach vier bis fünf Tagen zu den Vorfruchtkörpern (Protoperithezien) und nach sieben Tagen zu reifen Fruchtkörpern (Perithezien), aus welchen die Ascosporen geschleudert wurden.

Die Transkript-Level von Smmob3 und pro11 im Wildtyp unter vegetativen Wachstumsbedingungen wurden mit der Expression beider Gene unter sexuellen Wachstumsbedingungen am 3., 4., 5., 6. und 7. Tag der Entwicklung bestimmt (Abb. 7).

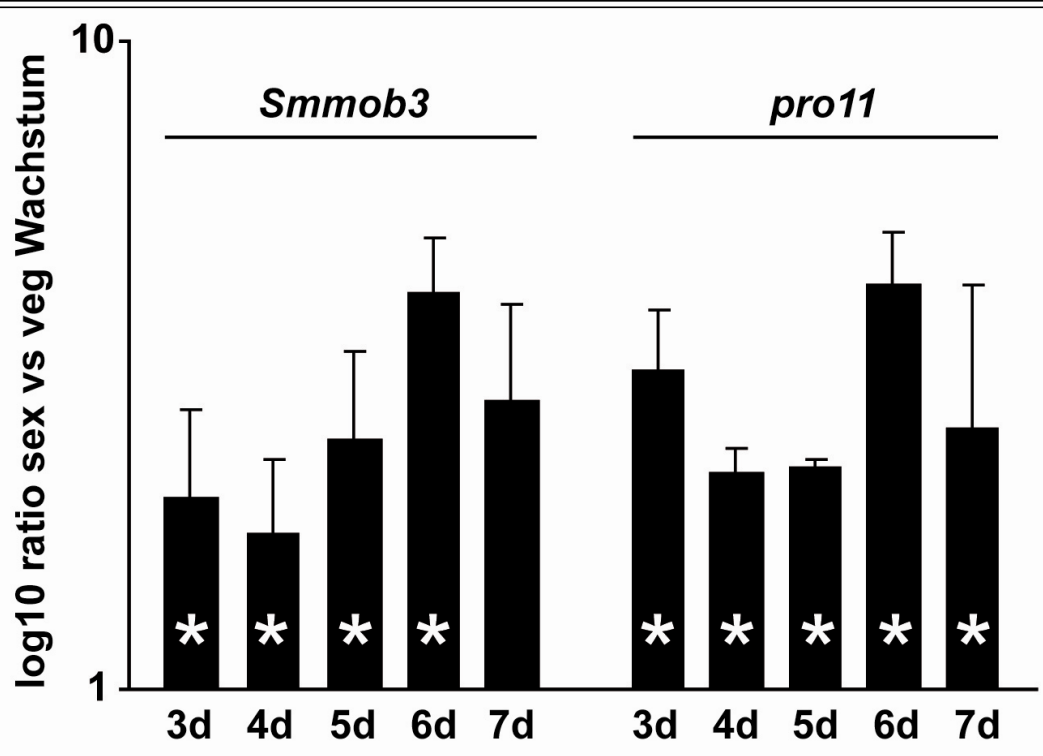

Abb. 7 Quantitative Real-Time PCR Analyse der Gene Smmob3 und pro11. Die Expression der Gene Smmob3 und pro11 wurde im wt unter sexuellen und vegetativen Wachstumsbedingungen $(\log 10$ ratio sex vs veg Wachstum) zu den angegebenen Zeitpunkten der sexuellen Entwicklung (3-7d) verglichen. Die gezeigten Expressionsraten sind Mittelwerte aus mind. zwei biologisch unabhängigen Proben, welche jeweils dreifach gemessen wurden. Die Sterne kennzeichnen die mit der Anwendung „REST“ ermittelte Signifikanz der erhaltenen Werte (Pfaffl et al. 2002). Die Standardabweichungen sind als Fehlerbalken angegeben.

Wie Abb. 7 zeigt, war die Expression der Gene Smmob3 und pro11 während der sexuellen Entwicklung ähnlich reguliert. Die Expression beider Gene war an allen sieben Tagen hochreguliert, insbesondere jedoch in der späten Phase (6. Tag) der sexuellen Differenzierung. Für prol1 konnte darüber hinaus auch in der frühen Phase (3. Tag) der sexuellen Entwicklung eine signifikante Hochregulierung des Transkripts bestimmt werden. 


\subsection{Two-Hybrid Studie der Proteine SmMOB3 und PRO11 aus $S$. macrospora}

In einem Hefe Two-Hybrid „Screen“ mit dem R. norwegicus Striatin Protein als Köder wurde Phocein als Interaktionspartner identifiziert (Baillat et al. 2001).

Im Rahmen dieser Arbeit wurde daher eine Two-Hybrid Analyse durchgeführt, um eine Interaktion der homologen Proteine SmMOB3 und PRO11 aus S. macrospora nachzuweisen (siehe II Material und Methoden, 2.23.1).

In der Hefe Two-Hybrid Analyse wird das eine auf Interaktion zu untersuchende Protein (Köder) an die Bindedomäne des GAL4-Transkriptionsfaktors aus der Hefe S. cerevisiae fusioniert und das andere (Beute) an die GAL4-Aktivierungsdomäne. Beide Domänen sind getrennt voneinander nicht in der Lage, die Transkription zu aktivieren (Keegan et al. 1986). Köder und Beute werden in einen S. cerevisiae-Stamm eingebracht, welcher mehrere Reportergene (z.B. lacZ, his3, ade2) unter der Kontrolle verschiedener galPromotoren enthält. Ein funktionelles gal4-Gen ist in dem Stamm nicht vorhanden. Bei einer Interaktion zwischen Köder- und Beuteprotein, wird der GAL4Transkriptionsfaktor funktionell rekonstruiert, so dass die Transkription der Reportergene aktiviert wird. Der Nachweis der Interaktion kann auf entsprechenden Selektionsmedien, die z. B. kein Adenin enthalten erbracht werden (James et al. 1996).

Für die Analyse wurden verschiedene SmMOB3- und PRO11-Two-Hybrid Konstrukte eingesetzt, um die für die Interaktion wichtigen Protein-Domänen zu bestimmen (Abb. 8).

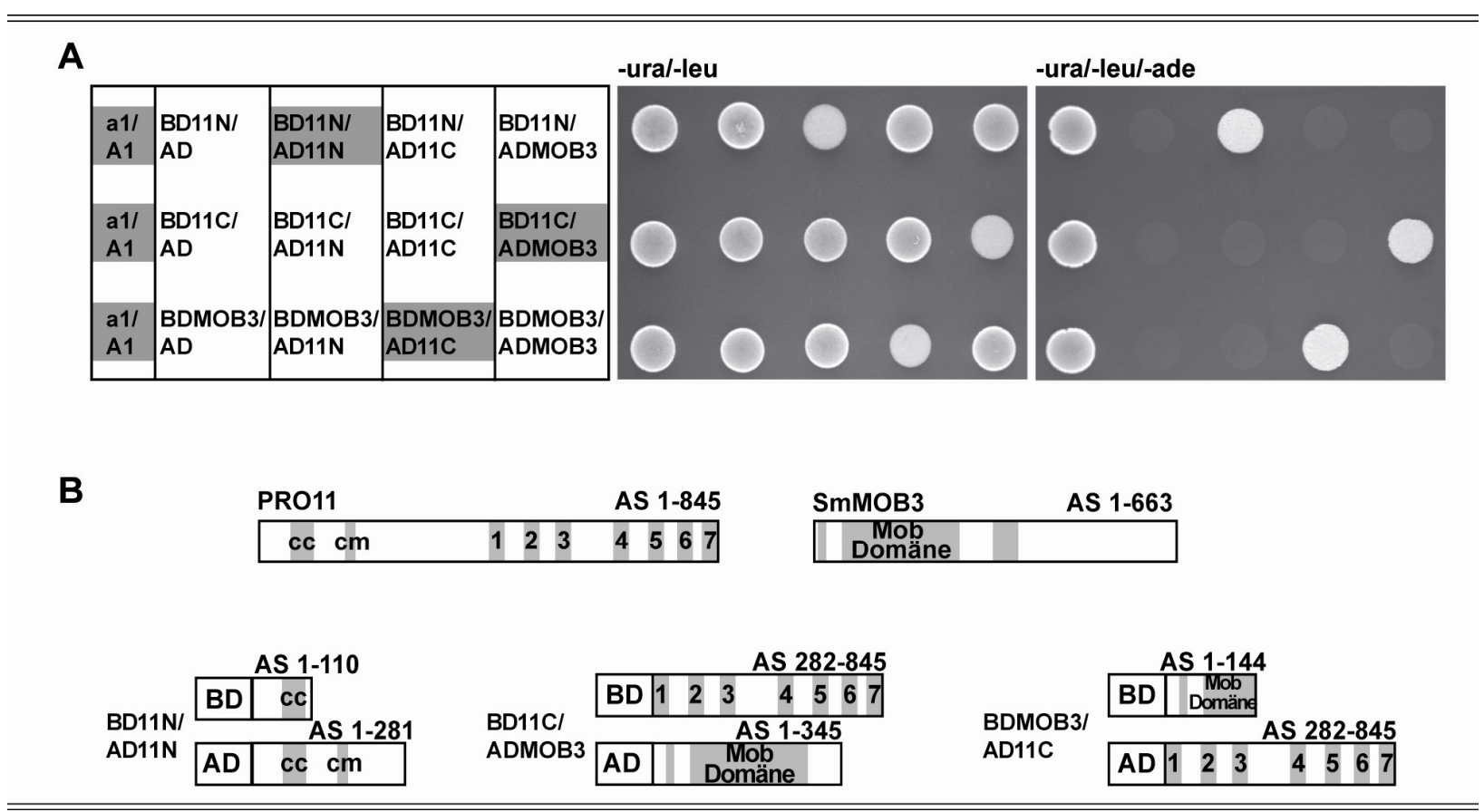

Abb. 8 Interaktion der Proteine SmMOB3 und PRO11 aus S. macrospora. (A) Hefe Two-Hybrid Analyse der Proteine SmMOB3 und PRO11. Die eingesetzten Plasmid-Kombinationen sind im Schema links dargestellt. Obere Zeilen: GAL4-BD-Fusionsproteine (BD11N, BD11C, BDMOB3), untere Zeilen: GAL4-AD-Fusionsproteine (AD11N, AD11C, ADMOB3). Grau hinterlegte Plasmid-Kombinationen führten in den Transformanten zur Reportergen-Aktivierung. Wachstumstest der Hefe-Transformanten für den Nachweis der erfolgreichen Transformation der jeweiligen pB-/ pA-Derivat-Kombination auf 


\section{(weiter zu Abb. 8A)}

Medium ohne Uracil und Leucin (-ura/-leu; Mitte) und für die Reportergenanalyse auf Medium ohne Uracil, Leucin und Adenin (-ura/-leu/-ade; rechts). Positivkontrolle: Wachstum einer Hefe-Transformante mit Plasmid-Kombination pB-a1 und pA-A1 (a1/A1). Negativkontrollen: Wachstum von HefeTransformanten mit dem jeweiligen Smmob3 bzw. pro11 pB-Derivat und dem pA-,,Leervektor“ (AD). Abkürzungen: a1: pB-a1; A1: pA-A1; AD: pGAD-C1; BD11N: pB11-aa1-110; BD11C: pB11-aa282845; BDMOB3: pBMob3-aa1-144; AD11N: pA11-aa1-281; AD11C: pA11-aa282-845; ADMOB3: pAMob3-aa1-345. (B) Schematische Darstellung der im Two-Hybrid System detektierten Interaktionen. Die obere Illustration zeigt die Voll-Längen Proteine SmMOB3 und PRO11. Die putative „,coiled-coil“Domäne (cc) und Calmodulin-Bindedomäne ( $\mathrm{cm}$ ) im N-Terminus, sowie die Positionen der sieben „WDrepeats" im C-Terminus von PRO11 sind durch graue Boxen markiert. Für die Beschreibung der Domänen von SmMOB3 siehe Abb. 6. Das untere Schema zeigt die SmMOB3- und PRO11-ProteinVersionen, die miteinander interagierten.

Die zwei N-terminalen SmMOB3-Köderproteine beinhalteten die AS 1-345 (pBMob3-aa1-345) und 1-144 (pBMob3-aa1-144) und die drei N-terminalen PRO11-Köderproteine bestanden aus AS 1-281 (pB11-aa1-281), 1-215 (pB11-aa1-215) und 1-110 (pB11-aa1-110). Es wurde zusätzlich eine C-terminale Version des PRO11-Köderproteins mit AS 282-845 (pB11-aa282845 ) konstruiert. Die Konstrukte wurden vor ihrer Verwendung in der Two-Hybrid Analyse auf Transaktivierungsaktivität getestet. Die für die Köder-Proteine kodierenden Plasmide pBMob3aa1-345, pB11-aa1-281 und pB11-aa1-215 zeigten Selbstaktivierung in der Reportergen-Analyse und wurden daher für die Experimente nicht eingesetzt (Daten nicht gezeigt).

Wie aus Abb. 8A und 8B hervorgeht, konnte eine Interaktion des C-Terminus von PRO11, welcher das „WD-repeat“"-Motiv umfasst, mit dem N-terminalen Teil von SmMOB3 (AS 1-345), welcher die konservierte N-terminale Ascomyceten-spezifische Domäne und die Mob-Domäne beinhaltet, nachgewiesen werden. Ebenso interagierte eine verkürzte N-terminale Version von SmMOB3 (AS 1-144) mit dem C-Terminus von PRO11.

Darüber hinaus zeigte sich eine Homodimerisierung der N-terminalen Region des PRO11Proteins, welche die putative „,coiled-coil““-Domäne enthielt.

Als Positivkontrolle wurde in der Two-Hybrid Analyse die bereits beschriebene Interaktion der Kreuzungstyp-Proteine SMTA-1 und SMTa-1 genutzt (Jacobsen et al. 2002). 


\subsection{Konstruktion eines $S$. macrospora Smmob3 Knockout-Stamms}

Um die Funktion von SmMOB3 in dem homothallischen Ascomycet S. macrospora aufzuklären, wurde der Stamm $\Delta$ Smmob3 generiert, in welchem das Smmob3 Gen größtenteils durch eine Hygromycin-Resistenz-Kassette (hph-Kassette) ausgetauscht und somit funktionsunfähig gemacht wurde (II Material und Methoden, 2.16). Die resultierende Deletion umfasst ein 654 bp Fragment des Smmob3 Gens, welches für mehr als die Hälfte der konservierten Mob-Domäne und für die konservierte Ascomyceten-spezifische C-terminale Domäne kodiert (Abb. 9A).

Nach der Transformation der Smmob3-Deletionskassette in den $\Delta$ ku70 Stamm konnten vier heterokaryotische fertile Hygromycin- und Nourseothricin-resistente Primärtransformanten

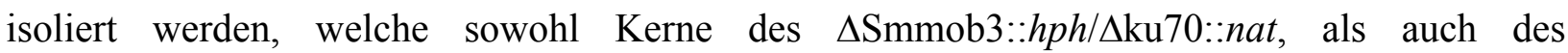
Smmob3/Aku70::nat Genotyps enthielten. Die homologe Integration der Smmob3Deletionskassette in den Primärtransformanten wurde durch PCR-Analyse bestätigt (Daten nicht

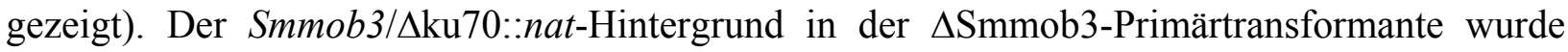
durch die Kreuzung mit der Farbspormutante fus-1 und durch die anschließende Isolierung von Einzelsporen entfernt und der resultierende homokaryotische $\Delta$ Smmob3::hph Stamm ( $\Delta$ Smmob3), welcher einen sterilen Phänotyp aufwies, einer klassischen genetischen Analyse unterzogen. Hierbei zeigte die Analyse von 15 geordneten Tetraden eine Mendelsche 4:4 Segregation des sterilen Phänotyps von $\Delta$ Smmob3. Darüber hinaus war die Segregation der Sterilität gleichzeitig mit der Hygromycin-Resistenz verbunden, was darauf hindeutete, dass die Deletion des Smmob3-Gens ursächlich für den sterilen Phänotyp war.

Der $\Delta$ Smmob3-Stamm wurde außerdem durch PCR- und Southern Blot-Analyse bestätigt (Abb. 9B und 9C). In der PCR-Analyse wurden Primer-Kombinationen gewählt, welche entweder spezifisch aus $\Delta$ Smmob3 gDNA den Smmob3 5'- oder 3'-flankierenden Sequenzbereich zusammen mit einem Teil der integrierten $h p h$-Kassette (pho1-14f/trpC1 und hph3/pho1-2r) oder ein spezifisches Smmob3 Fragment aus wt gDNA (pho1-15f/pho1-2r) amplifizierten. Mit dem Primer-Paar pho1-14f/pho1-2r wurde außerdem der Smmob3 Lokus aus wt gDNA und die 760 bp größere Smmob3-Deletionskassette aus $\Delta$ Smmob3 gDNA amplifiziert.

Mit dem als Sonde in der Southern Blot Analyse eingesetzten ${ }^{32}$ P-markierten Smmob3 3'Bereich wurde das intakte Smmob3-Gen im wt und die Smmob3-Deletionskassette im $\Delta$ Smmob3 als 5,5 kb und 6,2 kb Fragmente nachgewiesen. 


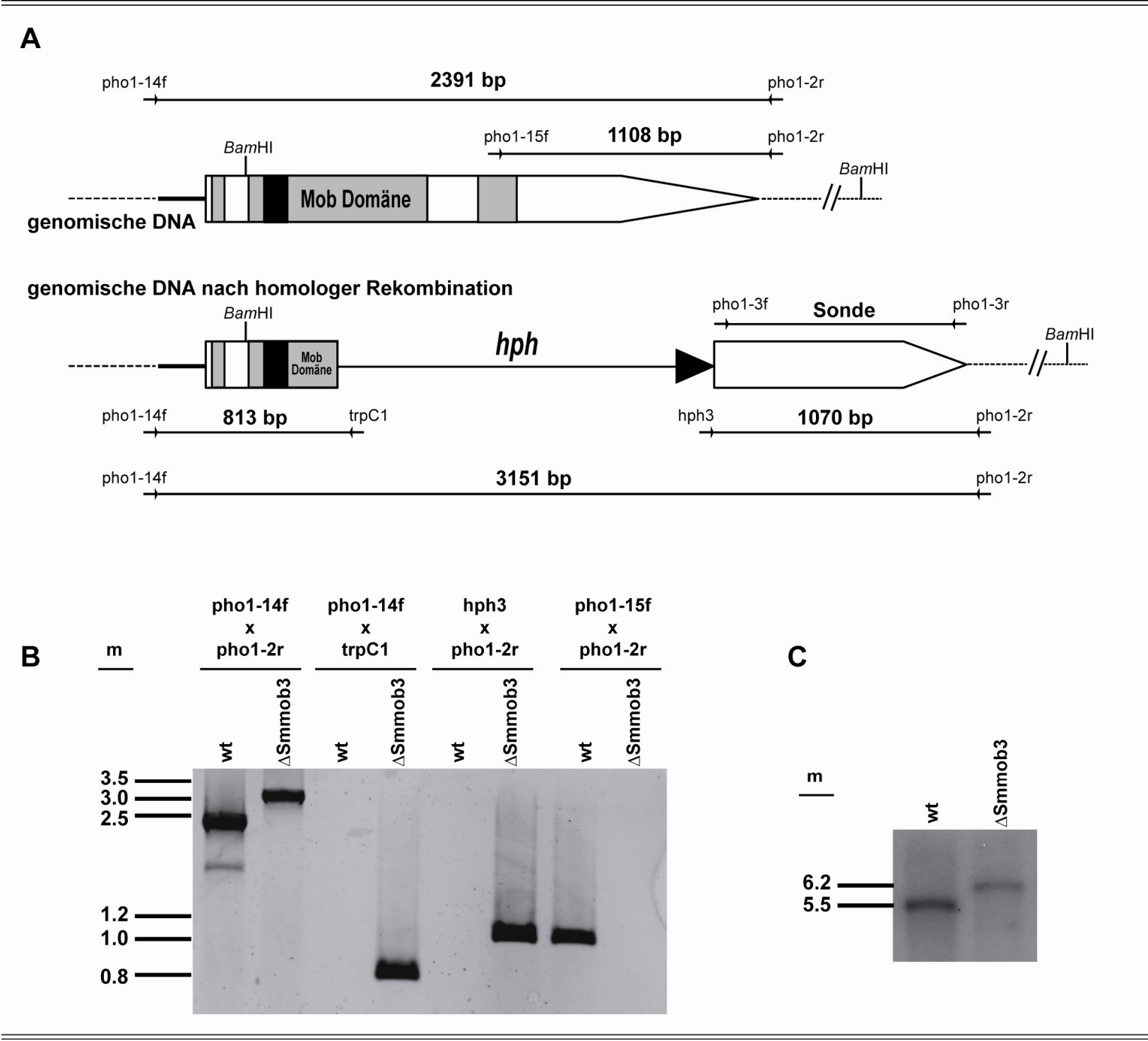

Abb. 9 Smmob3 Gendeletion durch homologe Rekombination. (A) Schematische Illustration des Smmob3-ORFs (weißer Pfeil) mit den kodierten konservierten Domänen (graue Boxen), dem Intron (schwarze Box) und den flankierenden Sequenzbereichen (durchgehende und gestrichelte Linien) vor (oben) und nach (unten) der homologen Integration der $h p h$-Kassette (schwarzer Pfeil). Die Position der verwendeten Primer (schwarze Pfeile) und die resultierenden Amplifikat-Größen in der PCR-Analyse sind angegeben. Das als Sonde in der Southern Blot Analyse verwendete Smmob3-Fragment ist entsprechend markiert. (B) PCR Analyse zur Bestätigung der homologen Integration der Smmob3Deletionskassette in den Smmob3-Lokus mit wt und $\triangle$ Smmob3 gDNA als Matrize und den angegebenen Primer-Kombinationen. Aliquots der PCR-Reaktionen wurden gelelektrophoretisch aufgetrennt. MarkerGrößen (m) sind in kb angegeben. Primerpaar pho1-14f/pho1-2r ergab ein 2391 bp Smmob3 Amplifikat aus wt gDNA und ein 3151 bp Fragment für $\Delta$ Smmob3 gDNA. Die Primer Paare pho1-14f/trpC1 und hph3/pho1-2r amplifizierten die Smmob3 5'- oder 3'-flankierenden Sequenzbereiche zusammen mit einem Teil der integrierten $h p h$-Kassette. Für den wt ergaben sich mit diesen Primerkombinationen keine Amplifikate. Der Primer pho1-15f bindet spezifisch im Smmob3-Gen und generierte in Kombination mit pho1-2r ein 1108 bp Fragment unter Verwendung von wt gDNA, jedoch kein Fragment für $\Delta$ Smmob3. (C) Bestätigung des $\Delta$ Smmob3 Stamms durch Southern Blot Analyse. Die gDNA von wt und $\Delta$ Smmob3 wurde über die BamHI Restriktionsschnittstellen (siehe A) hydrolysiert und das Smmob3 Fragment im wt bzw. die Smmob3-Deletionskassette im $\Delta$ Smmob3 als 5,5 und 6,2 kb Fragmente mit der ${ }^{32} \mathrm{P}$-markierten Sonde detektiert. 
Im Anschluss wurde der Phänotyp des hergestellten und durch PCR- und Southern-Blot Analyse bestätigten $\Delta$ Smmob3-Stamms morphologisch charakterisiert.

\subsection{Morphologische Charakterisierung des $S$. macrospora $\Delta$ Smmob3-Stamms}

Für eine makroskopische Analyse des $\Delta$ Smmob3-Phänotyps im Vergleich zu dem wt und der pro11-Mutante wurden die drei Stämme für zehn Tage auf SWG-Festmedium kultiviert (Abb. 10A). Im Vergleich zum wt war das vegetative Wachstum des $\Delta$ Smmob3-Stamms reduziert und es wurden keine Fruchtkörper ausgebildet. Darüber hinaus wurde vermehrt Luftmyzel produziert, wodurch das Myzel „watteartig“ erschien. Auch die pro11-Mutante bildete vermehrt Luftmyzel aus (Abb. 10A) (Pöggeler und Kück 2004). Das vegetative Wachstum von $\Delta$ Smmob3 wurde durch die Bestimmung der Wachstumsgeschwindigkeit in Rennrohren und durch die Bestimmung der produzierten Myzelmasse (Trockengewicht) analysiert. Die tägliche Wuchsrate des $\Delta$ Smmob3-Stamms $(8 \pm 3 \mathrm{~mm} / \mathrm{d})$ war im Vergleich zum wt $(23 \pm 4 \mathrm{~mm} / \mathrm{d})$ stark reduziert. Es wurde außerdem mit $1( \pm 0,4) \mathrm{mg}$ Myzel/ml SWG $83 \%$ weniger Biomasse von dem $\Delta$ Smmob3Stamm produziert als vom wt $(6 \pm 0,5 \mathrm{mg} / \mathrm{ml})$.

Um die Auswirkung der Smmob3-Deletion auf die sexuelle Entwicklung zu untersuchen, wurde die Fähigkeit des $\Delta$ Smmob3-Stamms zur Ausbildung sexueller Strukturen unter dem Mikroskop analysiert. Ähnlich wie der wt und die pro11-Mutante, produzierte der $\Delta$ Smmob3-Stamm Ascogone und pigmentierte Protoperithezien (Abb. 10B). Die Ausbildung fertiler Fruchtkörper und Ascosporen konnte dagegen jedoch auch nach verlängerter Inkubationszeit nicht beobachtet werden. Der $\Delta$ Smmob3-Stamm war somit, wie die pro11-Mutante steril. Interessanterweise war die Zahl der von $\Delta$ Smmob3 gebildeten pigmentierten Protoperithezien pro $\mathrm{cm}^{2}$ Medium stark reduziert (Abb. 10C). Wie bereits beschrieben wurde (Pöggeler und Kück 2004), weist auch die prol1-Mutante mit $153( \pm 6)$ Protoperithezien $/ \mathrm{cm}^{2}$ im Vergleich zum wt $(240 \pm 34$ Protoperithezien $/ \mathrm{cm}^{2}$ ) eine reduzierte Protoperithezien-Anzahl auf. Dieser Effekt war allerdings in $\Delta$ Smmob3 mit $7( \pm 1)$ Protoperithezien $/ \mathrm{cm}^{2}$ drastisch verstärkt.

Ein möglicher Einfluss von Stress-induzierenden Agenzien auf den $\Delta$ Smmob3-Phänotyp wurde mittels Kultivierung des $\Delta$ Smmob3-Stamms und des wt auf SWG-Festmedium mit Zusatz verschiedener Konzentrationen $\mathrm{H}_{2} \mathrm{O}_{2}$, SDS, NaCl, $\mathrm{KCl}$ oder Sorbitol getestet. Hierbei konnte kein Unterschied im Wachstum zwischen dem wt und $\Delta$ Smmob3-Stamm festgestellt werden (Daten nicht gezeigt). 


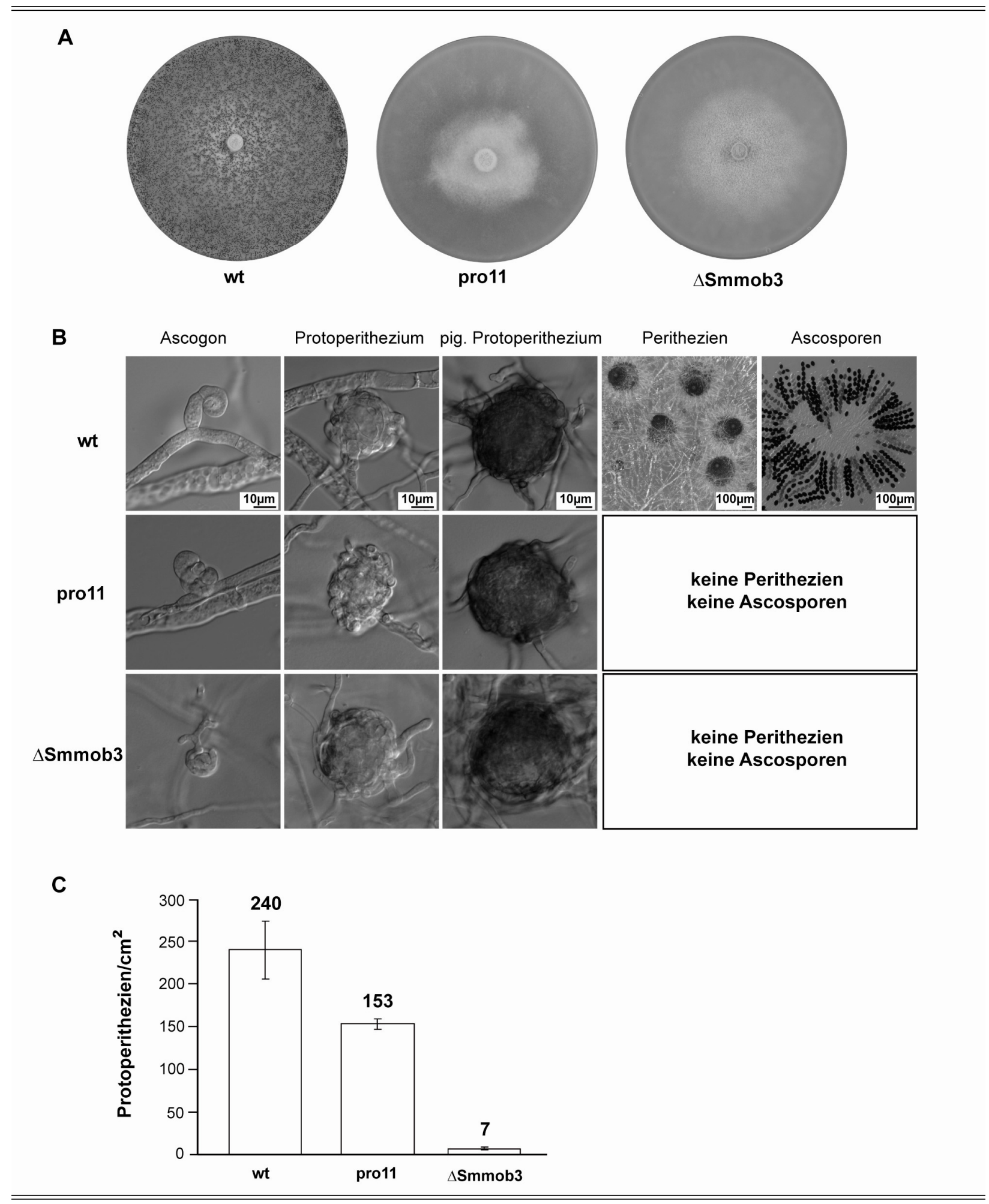

Abb. 10 Makroskopische und mikroskopische Analyse der Fruchtkörper- und AscosporenEntwicklung des $S$. macrospora $\Delta$ Smmob3-Stamms. (A) Übersichtsaufnahme der Phänotypen von wt, pro11-Mutante und $\Delta$ Smmob3 nach Kultivierung auf SWG-Festmedium. (B) Mikroskopische Aufnahmen der gebildeten sexuellen Strukturen von wt, pro11 und $\Delta$ Smmob3. Abkürzung: pig.-pigmentiert. (C) Die von den Stämmen wt, pro11 und $\Delta$ Smmob3 gebildeten 40-200 $\mu \mathrm{m}$ großen Protoperithezien wurden nach sieben Tagen Inkubation auf mit SWG-Festmedium beschichteten Objektträgern pro $\mathrm{cm}^{2}$ unter dem Mikroskop ausgezählt. Die Standardabweichungen sind als Fehlerbalken angegeben. 


\subsection{SmMOB3-Komplementationsanalyse in S. macrospora und $N$. crassa}

Um die für die sexuelle Entwicklung funktionell wichtigen SmMOB3-Domänen zu charakterisieren wurden verschiedene Smmob3-Komplementationskonstrukte hergestellt (II Material und Methoden, 2.18.1). Die Plasmide pMob3FL, pMob3N und pMob3C kodieren für das Voll-Längen Protein und für N- bzw. C-terminale SmMOB3-Teilstücke. Das Plasmid pMob3MmFL enthält die für das M. musculus Mob3/Phocein-Protein kodierende cDNA unter der Kontrolle des konstitutiv exprimierten $g p d$-Promotors und $\operatorname{trpC}$-Terminators aus $A$. nidulans (Abb. 11A). Die Plasmide wurden in $\Delta \mathrm{Smmob} 3$ transformiert und die korrekte Expression der ektopisch integrierten Plasmide in den resultierenden Stämmen $\Delta$ Smmob3_MOB3FL ${ }^{\text {ect }}$, $\Delta$ Smmob3_MOB3 $\mathrm{N}^{\mathrm{ect}}, \quad \Delta$ Smmob3_MOB3 $\mathrm{C}^{\mathrm{ect}}$ und $\Delta$ Smmob3_MOB3MmFL $^{\text {ect }}$ mittels qualitativer RT-PCR nachgewiesen (Daten nicht gezeigt). Anschließend wurden die Stämme auf die Fähigkeit zur Perithezienbildung untersucht (Abb. 11B). Das Voll-Längen SmMOB3 (pMob3FL) komplementierte den sterilen Phänotyp, es konnten Perithezien und reife Ascosporen gebildet werden. Interessanterweise war auch das N-terminale SmMOB3-Teilstück $($ pMob3N), welches die N-terminale Ascomyceten-spezifische Domäne und die Mob-Domäne umfasste, für eine vollständige Komplementation des $\Delta$ Smmob3 Entwicklungsdefekts ausreichend. Das C-terminale SmMOB3-Teilstück hingegen führte nicht zu einer Komplementation, der $\Delta$ Smmob3_MOB3C ${ }^{\text {ect }}$ Stamm blieb steril.

Um eine konservierte Funktion von MOB3-Proteinen verschiedener filamentöser Ascomyceten zu zeigen, wurden die Plasmide pMob3FL, pMob3N und pMob3C auch in den N. crassa $\Delta m o b-3$ Stamm transformiert. Wie in $S$. macrospora komplementierte das Voll-Längen und das N-terminale Teilstück des SmMOB3-Proteins den sterilen $\Delta m o b-3$ Phänotyp ( $\Delta m o b$ 3_MOB3FL $L^{e c t}, \Delta m o b-3 \_M O B 3 N^{e c t}$ ) während der $\Delta m o b-3$ nach der Transformation mit pMob3C $\left(\triangle m o b-3 \_M O B 3 C^{e c t}\right)$ steril blieb (Abb. 11C).

Frühere Studien zeigten, dass eine striatin-cDNA aus M. musculus den Entwicklungsdefekt der pro11-Mutante teilweise komplementierte (Pöggeler und Kück 2004). Es wurde daher getestet, ob neben der funktionellen Konservierung von MOB3-Proteinen aus Pilzen auch eine Konservierung der Funktion von Mob3-Proteinen zwischen Pilzen und Säugern vorliegt. Hierzu wurde das Plasmid pMob3MmFL in $\triangle \mathrm{Smmob3}$ transformiert und die korrekte Expression des Plasmids mittels qualitativer RT-PCR nachgewiesen (Daten nicht gezeigt). Es konnte jedoch keine Komplementation des $\Delta$ Smmob3 Entwicklungsdefekts beobachtet werden (Abb. 11B). 
A

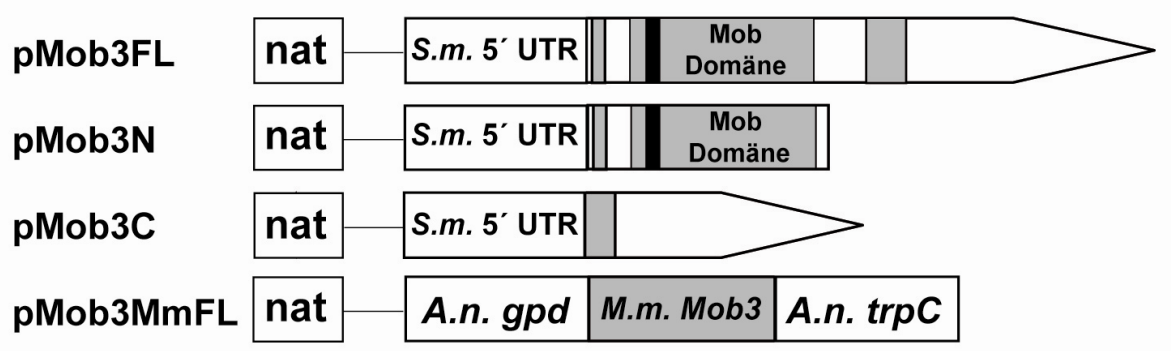

B

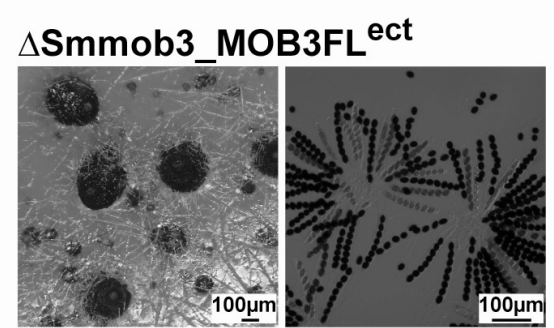

$\triangle$ Smmob3_MOB3N ${ }^{\text {ect }}$

$\Delta$ Smmob3_MOB3C ect $^{\text {ect }}$
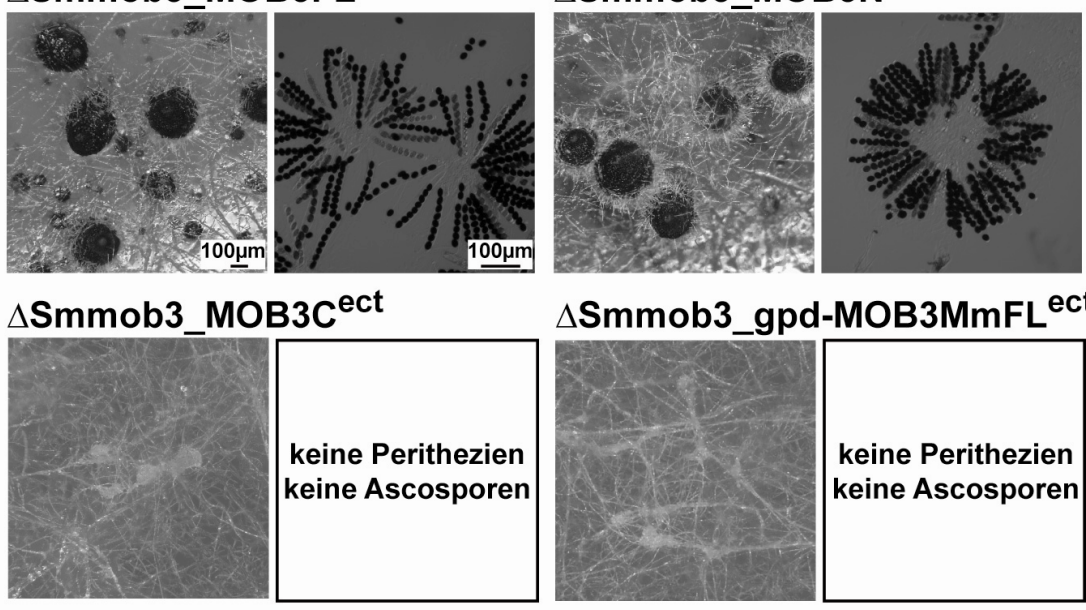

$\triangle$ Smmob3_gpd-MOB3MmFL ${ }^{\text {ect }}$

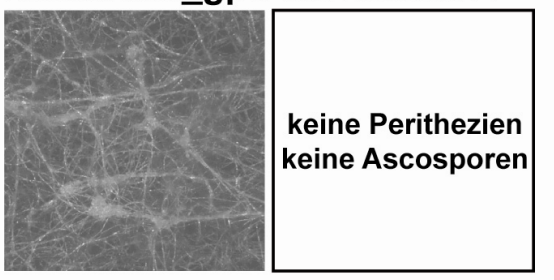

C

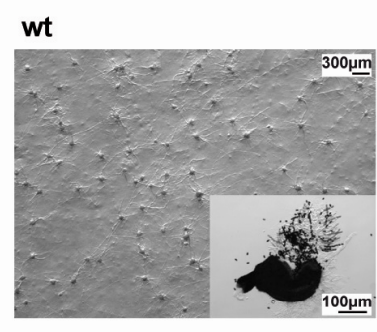

$\triangle$ mob-3_MOB3FL ${ }^{e c t}$

$\triangle$ mob-3 MOB3N $N^{e c t}$

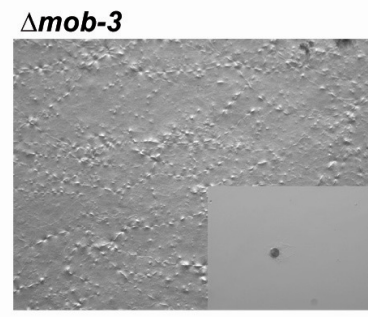

$\Delta$ mob-3_MOB3C ${ }^{e c t}$

Abb. 11 SmMOB3-Komplementationsanalyse in $S$. macrospora und $N$. crassa. (A) Schematische Abb. der eingesetzten Plasmide. Das Voll-Längen Smmob3 und die Teilstücke stehen unter der Kontrolle der putativen Smmob3-Promotor-Region (S. m. 5' UTR). Das Smmob3-Intron ist gekennzeichnet (schwarze Box). Die M. musculus phocein/Mob3 cDNA (M. m. Mob3) wird unter dem gpd Promotor und $\operatorname{trp} C$ Terminator aus $A$. nidulans $(A$. $n . g p d, A$. $n$. $\operatorname{trp} C$ ) exprimiert. Alle Plasmide tragen die nat-Kassette (nat) für die Selektion von Transformanten. (B) Untersuchung der Perithezien- und Ascosporenbildung der S. macrospora Stämme $\Delta \mathrm{Smmob3} \mathrm{MOB}_{\mathrm{FL}}{ }^{\mathrm{ect}}, \Delta \mathrm{Smmob} 3 \mathrm{SOB}_{-} \mathrm{N}^{\mathrm{ect}}, \Delta \mathrm{Smmob} 3 \mathrm{SOB}_{3} \mathrm{C}^{\mathrm{ect}}$ und $\triangle$ Smmob3_gpd-MOB3MmFL ${ }^{\text {ect }}$ nach zehn Tagen Inkubation auf SWG-Festmedium. (C) Untersuchung der Perithezien- und Ascosporenbildung der N. crassa Stämme wt, $\triangle m o b-3, \triangle m o b-3 \_M O B 3 F L^{e c t}, \triangle m o b-$ 3_MOB3N $N^{e c t}$ und $\triangle m o b-3 \_M O B 3 C^{e c t}$. Die großen Bilder zeigen eine phänotypische Übersicht der Stämme nach zehn Tagen Inkubation auf BMM. Die inserierten kleinen Bilder stellen die erreichten Entwicklungsstufen der Stämme drei Wochen nach der Fertilisierung mit wt Konidien dar. 
Abschließend wurde der Einfluss einer Smmob3-Überexpression auf $\Delta$ Smmob3 und den wt untersucht. Die Transformation von $\Delta$ Smmob3 mit dem konstruierten Überexpressionsplasmid pMob3oex restaurierte den sterilen Phänotyp des Knockout-Stamms, wodurch die Funktionalität des Plasmids nachgewiesen war. Die aus der Transformation mit pMob3oex resultierenden Stämme $\Delta$ Smmob3_gpd-MOB3 ${ }^{\text {ect }}$ und wt_gpd-MOB3 ${ }^{\text {ect }}$ zeigten jedoch keinen Unterschied im vegetativen Wachstum und/oder der sexuellen Entwicklung im Vergleich zum wt Stamm (Daten nicht gezeigt).

\subsection{Ausbildung von Hyphen-Fusionen der Stämme $\Delta$ Smmob3 und pro11}

Es wurde versucht eine pro11/ $\Delta$ Smmob3-Doppelmutante durch Kreuzung zu generieren. In keiner der Kreuzungen wurden jedoch rekombinante Perithezien gebildet, da vermutlich beide Stämme keine Hyphen-Fusionen ausbilden konnten. Um diesen offensichtlichen Fusionsdefekt im Detail zu untersuchen, wurden die gebildeten rekombinanten Perithezien in Kreuzungen zwischen dem wt und den Mutanten ausgezählt (Abb. 12).

Der homothallische Ascomycet S. macrospora ist selbst-fertil, d. h. der Organismus benötigt keinen Kreuzungspartner für die sexuelle Entwicklung und die Bildung von Perithezien, welche Asci mit jeweils 8 schwarz gefärbten Ascosporen enthalten. Trotzdem ist es möglich, zwei $S$. macrospora-Stämme miteinander zu kreuzen. Werden zwei Wildtyp-Stämme miteinander gekreuzt, kann morphologisch jedoch nicht zwischen den selbst-fertilen Perithezien und den Kreuzungsperithezien unterschieden werden. Es werden daher für $S$. macrospora Kreuzungen Farbspor-Mutanten oder sterile Stämme verwendet. Die Kreuzung zwischen einem wt-Stamm und einer Farbspor-Mutante, welche z. B. braune Ascosporen bildet, resultiert in Kreuzungsperithezien, deren Asci eine Mischung aus 4 schwarzen und 4 braunen Ascosporen enthalten. Werden zwei sterile Stämme miteinander gekreuzt, sind alle gebildeten Perithezien Kreuzungsperithezien.

Die Kreuzungen wt x fus-1 $(n=4)$ ergaben im Durchschnitt $105( \pm 29)$ rekombinante von insgesamt 1269 ( \pm 111) pro Kreuzungsfront gebildeten Perithezien (= $8 \%$ \%). In den Kreuzungsfronten der Kreuzungen pro11 x fus-1 $(649 \pm 37)$ und $\Delta$ Smmob3 x fus-1 (307 \pm 86$)$ wurden auf Grund der Sterilität von pro11 und $\Delta$ Smmob3 insgesamt weniger Perithezien gebildet, von denen aber im Vergleich zu wt x fus-1 mehr Perithezien rekombinante Asci enthielten (21\% für pro11 x fus-1 und $24 \%$ für $\Delta$ Smmob3 x fus-1). In Kreuzungen zwischen $\Delta$ Smmob3/fus-1 und pro11 wurden wie bereits erwähnt keine Perithezien gebildet. Um dieses Ergebnis zu bestätigen wurden $\mathrm{n}=80 \Delta$ Smmob3/fus-1 x pro11 Kreuzungsplatten untersucht, aber auch nach verlängerter Inkubationszeit wurden keine Perithezien ausgebildet. 


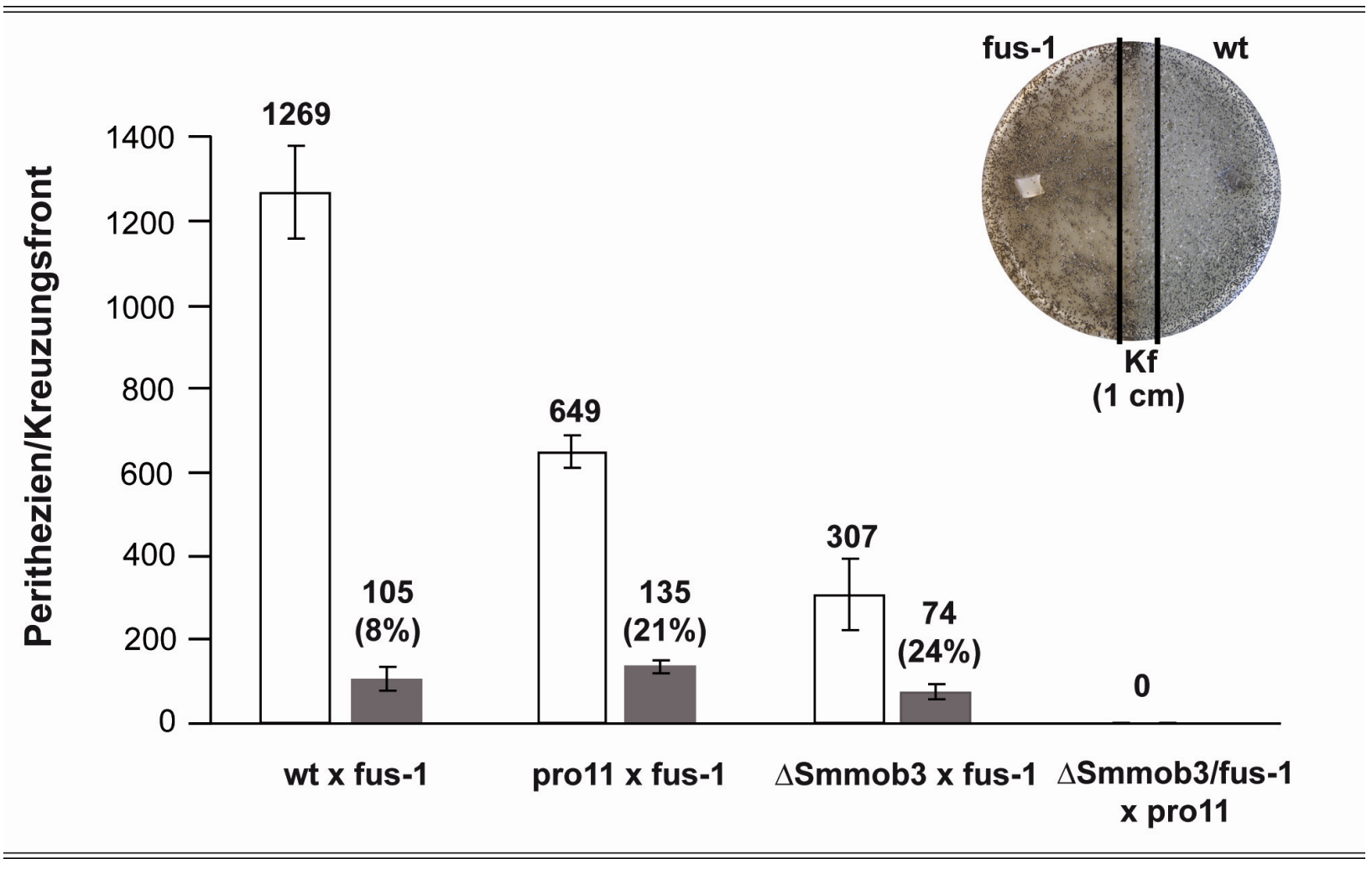

Abb. 12 Analyse von Hyphen-Fusionen der Stämme $\Delta$ Smmob3 und pro11. Die Anzahl aller Perithezien pro Kreuzungsfront der Kreuzungen wt $\mathrm{x}$ fus-1, pro11 $\mathrm{x}$ fus-1, $\Delta$ Smmob3 $\mathrm{x}$ fus-1 und $\Delta$ Smmob3/fus-1 x pro11 wurde bestimmt (weiße Säulen). Die Perithezien wurden geöffnet und die Perithezien, welche rekombinante Asci enthielten, ausgezählt (graue Säulen; Angaben in \%). Die Standardabweichungen sind in Form von Fehlerbalken angegeben. Die Teilabb. oben rechts verdeutlicht die experimentelle Vorgehensweise. Es ist eine typische Kreuzungsplatte (in diesem Fall wt $\mathrm{x}$ fus-1) dargestellt. Die $1 \mathrm{~cm}$ breite Kreuzungsfront (Kf, gekennzeichnet durch schwarze Linien) wurde mit dem Skalpell ausgeschnitten und die sich darauf befindlichen Perithezien wie beschrieben analysiert.

Um auszuschließen, dass die Sterilität von $\Delta$ Smmob3 und pro11 für den Fusionsdefekt verantwortlich war, wurden außerdem Kreuzungen zwischen pro11:r2 oder $\Delta$ Smmob3:fus-1 und der sterilen Mutante pro1 untersucht, in welcher das für einen C6-Zink-Finger Transkriptionsfaktor kodierende prol-Gen deletiert ist (Masloff et al. 1999). Diese Kreuzungen ergaben durchschnittlich $63 \%$ (67 von 105 für pro11:r2 x pro1) und 67\% (6 von 9 für $\Delta$ Smmob3/fus-1 x pro1) rekombinante Perithezien, was darauf hinweist, dass der beobachtete Fusionsdefekt spezifisch für die pro11- und Smmob3-Genmutationen der beiden entsprechenden Mutanten ist.

\subsection{Herunterregulierung der Gene pro11 und Smmob3 mittels RNAi}

Da die Herstellung einer pro11/ $\Delta$ Smmob3-Doppelmutante durch Kreuzung nicht möglich war, wurde das Smmob3-Gen in der pro11-Mutante und das prol1-Gen in dem $\Delta$ Smmob3-Stamm in einem RNAi-Experiment herunterreguliert (Abb. 13). 


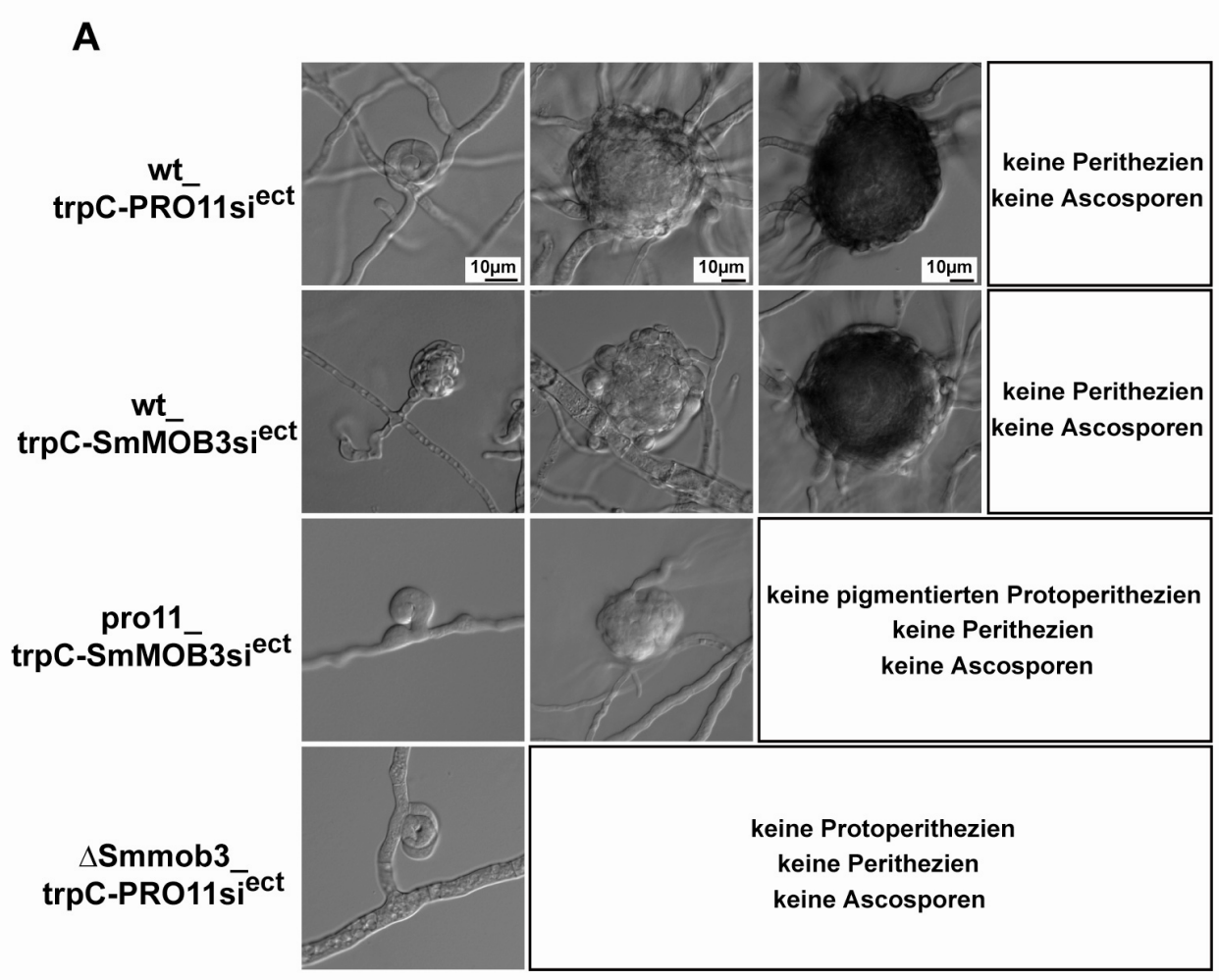

B

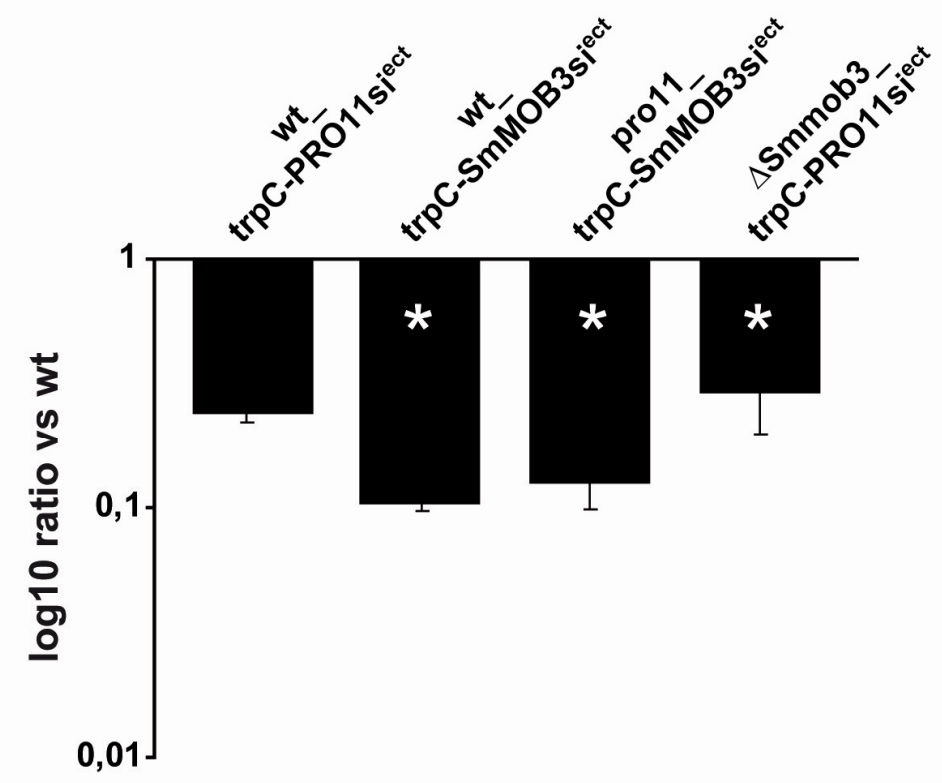

Abb. 13 Herunterregulierung der Gene pro11 und Smmob3 mittels RNAi. (A) Mikroskopische Analyse der sexuellen Strukturen bei den RNAi-Transformanten wt_trpC-PRO11si ${ }^{\text {ect }}$, wt_trpCMOB3sisi ${ }^{\text {ect }}$, pro11_trpC-MOB3si ${ }^{\text {ect }}$ und $\triangle$ Smmob3_trpC-PRO11 si ${ }^{\text {ect }}$. (B) Quantitative Real-Time PCR der RNAi-Stämme. Es wurde die Expression der Gene pro11 und Smmob3 in den RNAi-Transformanten und dem wt verglichen ( $\log 10$ ratio vs wt). Die gezeigten Expressionsraten sind Mittelwerte aus mind. zwei biologisch unabhängigen Proben, welche jeweils dreifach gemessen wurden. Die Sterne kennzeichnen die mit der Anwendung REST ermittelte Signifikanz der erhaltenen Werte (Pfaffl et al. 2002). 
Hierzu wurden die RNAi-Plasmide pMob3si und pPro11si konstruiert und in die entsprechenden Mutanten transformiert (II Material und Methoden, 2.17).

Um sicherzustellen, dass die transformierten Plasmide die transkriptionelle Expression von Smmob3 und pro11 tatsächlich herunterregulierten, wurden beide Plasmide jeweils zusätzlich in den wt transformiert. Die resultierenden Stämme wt_trpC-MOB3si ${ }^{\text {ect }}$ und wt_trpC-PRO11si ${ }^{\text {ect }}$ zeigten den gleichen Phänotyp wie der $\Delta$ Smmob3-Stamm bzw. die pro11-Mutante. Ähnlich wie die beiden Mutanten entwickelten die RNAi-Transformanten nur noch pigmentierte Protoperithezien aber keine Perithezien und keine Ascosporen (Abb. 13A).

Die Mutanten, welche das jeweilige RNAi-Plasmid trugen (pro11_trpC-MOB3si ${ }^{\text {ect }}$ und $\Delta$ Smmob3_trpC-PRO11 si $^{\text {ect }}$ ) zeigten stärkere Entwicklungsdefekte als die Einzelmutanten pro11 und $\Delta$ Smmob3. Während die RNAi-Transformante pro11_trpC-MOB3si ${ }^{\text {ect }}$ nur noch unpigmentierte Protoperithezien entwickelte, führte die Herunterregulierung von proll in dem $\Delta$ Smmob3 Stamm zu einer Arretierung in einer sehr frühen Phase der sexuellen Entwicklung. Die $\Delta$ Smmob3_trpC-PRO11si ${ }^{\text {ect }}$ Transformante produzierte nur noch sehr wenige Ascogone (Abb. 13A). Mittels quantitativer Real-Time PCR wurde eine signifikante Herunterregulierung der Gene in den RNAi-Transformanten nachgewiesen (Abb. 13B).

\section{Funktionelle Charakterisierung des $S$. macrospora Proteins PRO11}

\subsection{In silico Strukturanalyse des PRO11 N-Terminus}

Die in der Two-Hybrid Analyse festgestellte Fähigkeit zur Homodimerisierung des PRO11 NTerminus deutet darauf hin, dass dieser Proteinbereich eine besondere funktionelle Rolle einnimmt und soll daher im Folgenden ausführlich beschrieben werden. Zhu et al. (2001) zeigten, dass der N-Terminus von Striatin-Proteinen aus Säugern neben dem Domänen-,Cluster“ bestehend aus „,coiled-coil“-Motiv und Caveolin- und Calmodulin-Bindedomänen weitere charakteristische Strukturmerkmale aufweist. So sind z. B. die ca. ersten 60 AS der Proteine sehr Glycin- und Prolin-reich. Darüber hinaus ist der Proteinabschnitt zwischen dem Domänen„Cluster“ und dem „WD-repeat"-Motiv durch das überwiegende Vorkommen der sauren bzw. negativ geladenen AS Asparaginsäure und Glutaminsäure geprägt.

Für den PRO11 N-Terminus wurden ebenfalls ein putatives ,coiled-coil“-Motiv und eine Calmodulin-Bindedomäne vorhergesagt (Pöggeler und Kück 2004). Um, wie bei den SäugerStriatinen, über weitere Strukturmerkmale Aufschluss zu gewinnen, wurde der N-Terminus des PRO11-Proteins daher im Vergleich zu PRO11-Homologen aus anderen filamentösen 
Ascomyceten und Striatin-Proteinen aus Säugern einer erweiterten in silico Analyse unterzogen (Abb. 14).

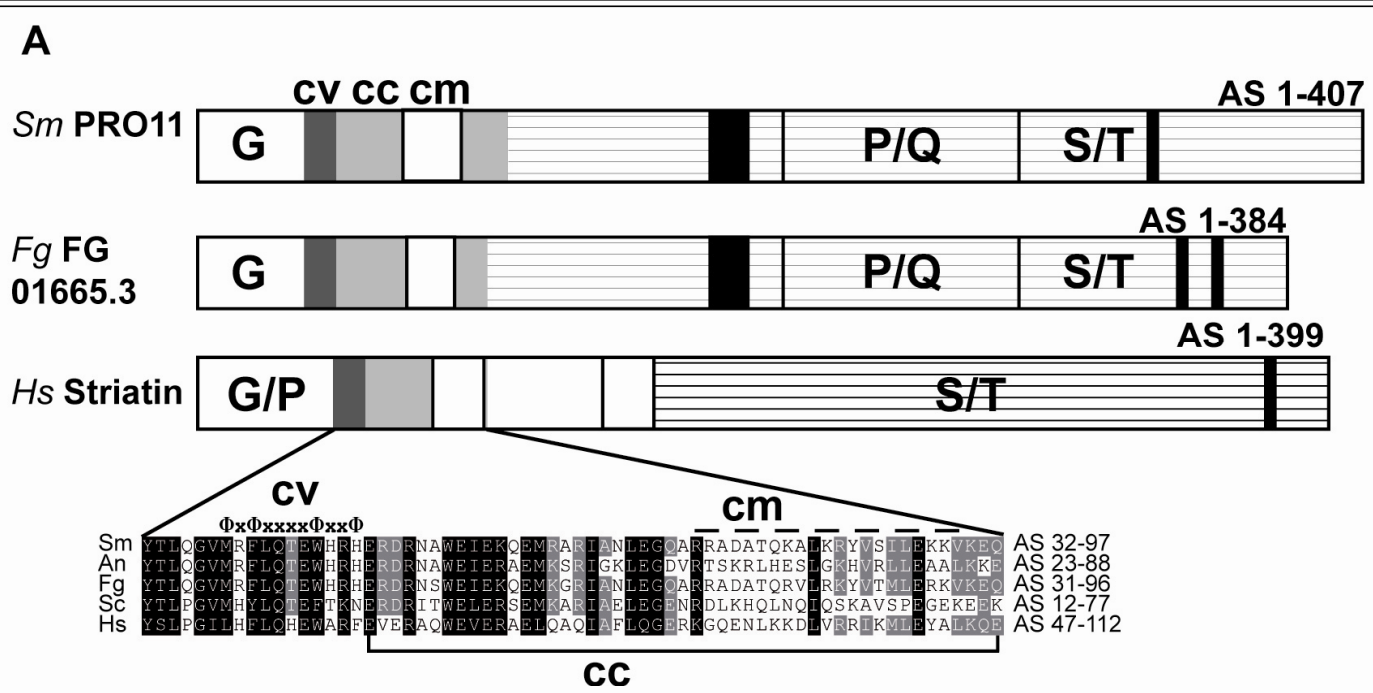

B

\begin{tabular}{l|c|c}
\multicolumn{1}{c|}{ Protein } & AS & G/P-Gehalt (\%) \\
\hline Hs SG2NA & $1-62$ & $32 / 16$ \\
Hs Zinedin & $1-66$ & $25 / 19$ \\
Hs Striatin & $1-46$ & $21 / 8$ \\
Sm PRO11 & $1-31$ & $27 / 5$ \\
An AN08071.2 & $1-22$ & $39 / 7$ \\
Fg FG01665.3 & $1-30$ & $25 / 8$
\end{tabular}

\begin{tabular}{l|r|r|r|r|r|r|r}
\multicolumn{1}{c}{ AS-Zusammensetzung (\%) } \\
\hline Protein & \multicolumn{1}{|c|}{ AS } & E & D & P & Q & S & T \\
\hline Hs SG2NA & $149-418$ & 12 & 10 & 3 & 3 & 7 & 5 \\
Hs Striatin & $167-399$ & 11 & 13 & 3 & 3 & 10 & 5 \\
Sm PRO11 & $109-407$ & 8 & 6 & 10 & 11 & 10 & 5 \\
Fg FG01665.3 & $96-384$ & 9 & 6 & 11 & 11 & 7 & 5 \\
\hline
\end{tabular}

Abb. 14 Strukturvergleich von Striatin-Proteinen aus Ascomyceten und dem Mensch. (A) Schematische Darstellung der N-Terminalen Bereiche von Striatin-Proteinen aus S. macrospora, $F$. graminearum und $H$. sapiens (oberer Teil). Die Längen der verglichenen $\mathrm{N}$-terminalen Bereiche sind rechts angegeben. Farblegende: dunkelgrau-Caveolin-Bindedomäne (cv), hellgrau-,,coiled-coil“-Motiv $(\mathrm{cc})$, weiß mit schwarzer Umrandung-Calmodulin-Bindedomäne $(\mathrm{cm})$, schwarz-SH3-Bindemotiv, Längsstriche-negativ geladene Proteinbereiche (dickere Striche markieren stärkere negative Ladung). Der untere Abb.-Teil zeigt ein Sequenz-Alignment der N-terminalen Domänengruppe von Striatin-Proteinen aus Ascomyceten und dem Mensch. Schwarz markierte AS: konserviert in allen Sequenzen, grau markierte AS: konserviert in mind. vier Sequenzen. Die für das Alignment verwendeten AS-Regionen sind rechts angegeben. Die Konsensus-Sequenz der Caveolin-Bindedomänen ist an der entsprechenden Position über dem Alignment notiert, wobei „, $\Phi^{“}$ aromatische und „x“ beliebige AS darstellen. Die Lage der „coiled-coil“-Motive ist durch eine Klammer und der Calmodulin-Bindedomänen durch eine gestrichelte Linie gekennzeichnet. Abkürzungen und Accession-Nummern: Sm-Sordaria macrospora PRO11 (AJ564211), An-Aspergillus nidulans AN08071.2 (XP_681340.1), Fg-Fusarium graminearum FG01665.3 (XP_381841.1), Sc-Saccharomyces cerevisiae Far8p (NP_013742.1), Hs-Homo sapiens Striatin (NP_003153.2). (B) Glycin/Prolin-(G/P)-Gehalt der vorderen Sequenzbereiche von StriatinProteinen aus verschiedenen Organismen. Die jeweils für die prozentuale Berechnung verwendeten ASBereiche sind angegeben. AS-Abkürzungen in (A) und (B): G-Glycin, P-Prolin, Q-Glutamin, S-Serin, TThreonin, E-Glutaminsäure, D-Asparaginsäure.

Der obere Teil von Abb. 14A zeigt den strukturellen Aufbau des N-terminalen Sequenzbereichs von PRO11 aus S. macrospora, dem homologen Protein FG01665.3 aus F. graminearum und von Striatin aus $H$. sapiens. Die jeweils nachfolgenden „WD-repeat"-Motive sind nicht 
dargestellt. Die Sequenzen der N-terminale Domänengruppen wurden in einem Proteinalignment miteinander verglichen (Abb. 14A unterer Teil).

Interessanterweise konnte in den Striatin-Proteinen der einbezogenen filamentösen Ascomyceten jeweils ein stark konserviertes Caveolin-Bindemotiv identifiziert werden.

Die pilzlichen Caveolin-Bindedomänen sind vom gleichen Typ $(\Phi x \Phi x \operatorname{xx} \Phi \times x \Phi)$ wie die der menschlichen Striatin-Proteine und die Sequenzähnlichkeit dieser Domäne zwischen Pilz und Mensch beträgt 64 \% (Couet et al. 1997). Dieses Ergebnis ist überraschend, da die Genome von Pilzen für kein homologes Caveolin-Protein, welches spezifisch an die Caveolin-Bindedomäne bindet, kodiert.

Neben der Caveolin-Bindedomäne ist auch die Region, welche das „,coiled-coil“-Motiv enthält innerhalb der verschiedenen Organismen stark konserviert, wohingegen die Sequenzen der vorhergesagten Calmodulin-Bindedomänen nur zum Teil Sequenz-Homologien untereinander aufweisen.

Die in die Analyse einbezogenen Striatin-Proteine weisen bis auf das H. sapiens Striatin (21\%) und das A. nidulans AN08071.2 (39\%) mit 25-32\% einen ähnlichen Glycin-Gehalt in den ersten 22-66 AS auf, dagegen ist der Prolin-Gehalt in der gleichen Sequenzregion bei den menschlichen Striatin-Proteinen (16-19\%) mit Ausnahme von Striatin (8\%) höher als bei den pilzlichen (5-8 \%) (Abb. 14B, links). Der auf die N-terminale Domänen-Gruppe folgende Sequenzbereich ist bei den Säuger-Striatinen mit einem Anteil von 22-24 \% Asparaginsäure- und GlutaminsäureResten deutlich negativer geladen als bei den pilzlichen Proteinen (14-15 \%) (Abb. 14B, rechts). Der weitere strukturelle Aufbau dieser Regionen unterscheidet sich zwischen Pilz und Mensch (Abb. 14A). Die beiden Striatin-Homologe aus S. macrospora und F. graminearum beinhalten in dem negativ geladenen Sequenzbereich mehrere putative SH3-Bindedomänen. Interessanterweise liegen die beiden ersten Motive des Typs „PxxP“ und „RxxPxxP“ nur durch drei AS getrennt direkt hintereinander und sind bei beiden Pilzen zu $100 \%$ konserviert. Darauf folgt bei beiden Proteinen eine Prolin-/Glutamin-reiche Region (21-22 \%). Im hinteren Teil der Proteine sind vermehrt Serin-/Threonin-Reste und im Fall des $S$. macrospora PRO11 eine und in F. graminearum FG01665.3 zwei weitere „PxxP“ SH3Bindedomänen enthalten. Im Gegensatz dazu weist das H. sapiens Striatin in dem Sequenzbereich nach der N-terminalen Domänengruppe vermehrt Serin- und Threonin-Reste auf. Ein P/Q-reiches Motiv hingegen fehlt. Das Striatin-Protein enthält nur ein putatives SH3Bindemotiv des Typs „PxxP“ an den AS-Positionen 377-380.

Eine Sonderstellung bei dem Struktur-Vergleich der Striatin-Proteine nimmt das Far8p Homolog aus $S$. cerevisiae ein. Wie das Alignment zeigt ist lediglich der Sequenzbereich von AS 12-54 
konserviert. In diesem Bereich kann, ähnlich wie für die anderen Striatin-Proteine beschrieben, eine Caveolin-Bindedomäne des Typs $Ф x \Phi \operatorname{xxx} \Phi$ und ein „coiled-coil“-Motiv identifiziert werden. Ein G/P-reiches Motiv am Beginn des Proteins fehlt jedoch und auch der weitere Aufbau des Far8p Proteins inklusive des C-Terminus zeigt keine signifikante Homologie zu den Striatin-Proteinen aus anderen Organismen (Daten nicht gezeigt).

Da Striatin Proteine zusammen mit Mob3-Proteinen wie beschrieben vermutlich in großen Proteinkomplexen mit Serin/Threonin Protein Phosphatasen und Kinasen wirken (Goudreault et al. 2009), wurden mögliche Phosphorylierungsstellen in dem N-terminalen Teil des $S$. macrospora PRO11-Proteins bestimmt. Es wurden 21 von 36 Serin- und 3 von 19 ThreoninResten in PRO11 als putative Phosphorylierungsstellen vorhergesagt (Daten nicht gezeigt).

Zum Vergleich wurden zusätzlich die putativen Phosphorylierungsstellen für die StriatinProteine aus $F$. graminearum und $H$. sapiens vorhergesagt und mit denen von PRO11 verglichen. Es stellte sich heraus, dass sechs putativ phosphorylierte Serin- und ein ThreoninReste in S. macrospora und F. graminearum konserviert waren. Vier der konservierten SerinReste befanden sich relativ dicht aufeinanderfolgend am Ende des jeweiligen N-Terminus (S. m. ab Position 379, F. g. ab Position 358).

Bei dem Vergleich der putativen Phosphorylierungsstellen aller drei Organismen stellte sich heraus, dass einer der Serin-Reste, welcher jeweils am Ende der N-terminalen Bereiche von $S$. macrospora und F. graminearum lag, konserviert war (S. m. AS 379, F. g. AS 358, H. s. AS 259).

\subsection{Identifizierung einer alternativ gespleißten pro11 Variante}

Die besondere Bedeutung des N-terminalen Bereichs von Striatin-Proteinen wird weiterhin durch die Tatsache unterstrichen, dass in Säugern durch alternative Spleißprozesse verschiedene SG2NA-Varianten entstehen, welche gewebespezifisch und $\mathrm{zu}$ unterschiedlichen Entwicklungszeitpunkten exprimiert werden (Sanghamitra et al. 2008). Eine dieser Spleißvarianten kodiert nur für den N-terminalen Teil von SG2NA, welcher wie die Voll-Längen Version die konservierte Caveolin-Bindedomäne, das „coiled-coil““-Motiv und die CalmodulinBindedomäne enthält. Durch ein alternativ gespleißtes Intron folgt auf die konservierten Nterminalen Motive eine 19 AS lange „neue“ Sequenz. Das „WD-repeat“-Motiv hingegen fehlt (Sanghamitra et al. 2008). Wie Abbildung 15A zeigt, kann durch alternatives Spleißen eine zu der N-terminalen SG2NA Version homologe N-terminale PRO11-Variante entstehen, welche neben den konservierten Domänen einen 13 AS langen zusätzlichen Sequenzbereich aufweist. 
Ein Sequenzvergleich ergab, dass die 13 und 19 zusätzlichen AS in den alternativen PRO11 und SG2NA Versionen nicht konserviert sind (Daten nicht gezeigt).

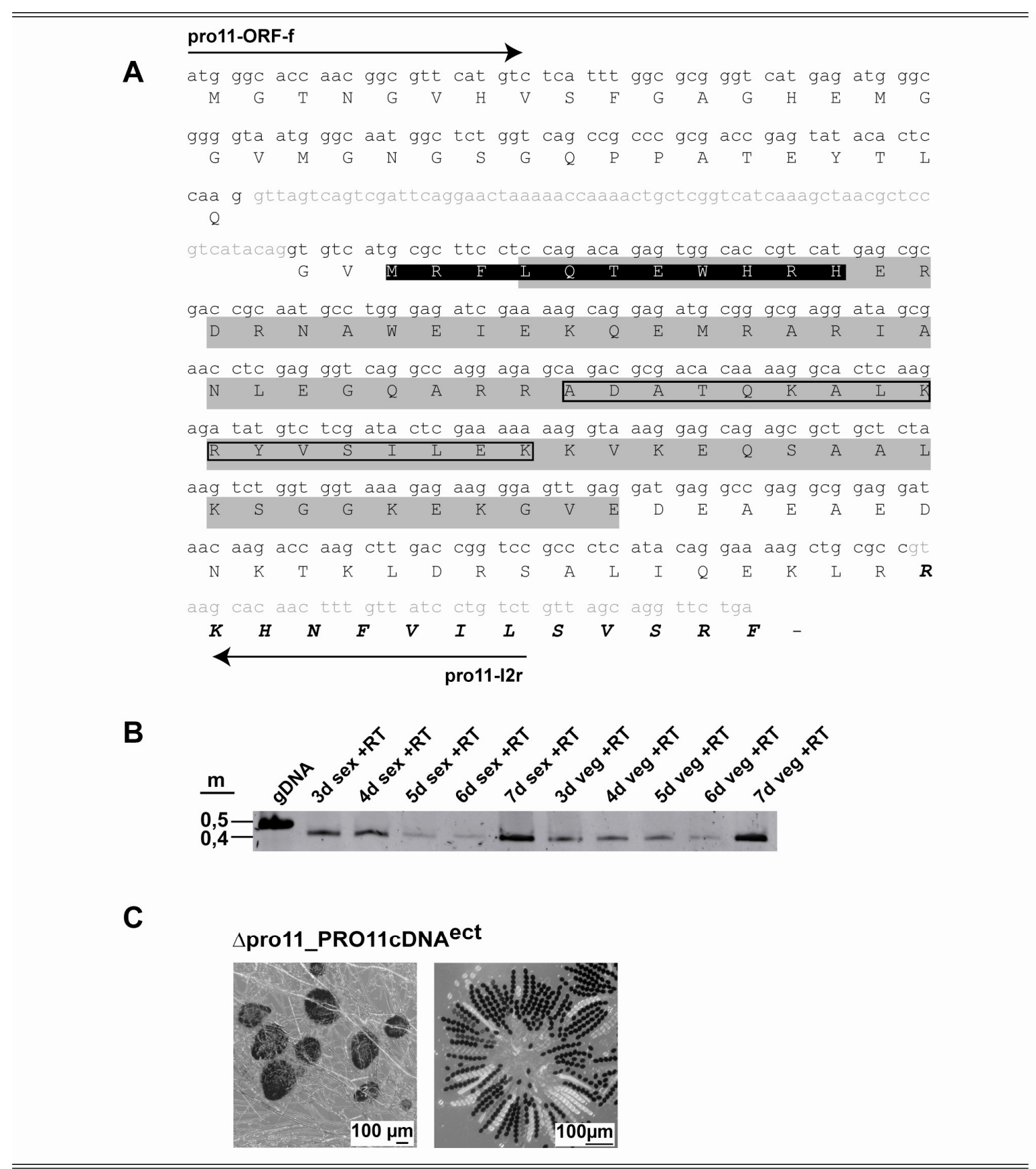

Abb. 15 Analyse der alternativen pro11 Spleißvariante. (A) Darstellung der alternativen PRO11 Sequenz. Die Caveolin-Bindedomäne ist schwarz und das „,coiled-coil“-Motiv grau hinterlegt. Die Calmodulin-Bindedomäne ist schwarz umrandet. Die beiden Introns im pro11 5'-Bereich sind grau hervorgehoben. Das alternative Spleißen des 2. Introns führt bei der Translation zu der Synthese von 13 „,neuen“ AS (kursiv und fettgedruckt). (B) Expressionsanalyse der alternativ gespleißten pro11 Variante mittels RT-PCR. Die mit der Primerkombination pro11-ORF-f/pro11I2r generierten 499 bp und 429 bp Amplifikate aus wt gDNA und cDNA (+RT) wurden gelelektrophoretisch aufgetrennt. Die cDNA stammte aus RNA-Präparationen, welche vom 3.-7. Tag (d) der Entwicklung unter sexuellen (sex) oder vegetativen (veg) Kulturbedingungen gewonnen wurde. Die Größen des Markers (m) sind in kb angegeben. (D) Analyse der Transformante $\Delta$ pro11_PRO11cDNA ${ }^{\text {ect }}$ hinsichtlich der Perithezien- und Ascosporenentwicklung. 
Die alternative PRO11 Variante entsteht, wenn das 2. Intron des pro11 Transkripts nicht wie bei der Reifung des Voll-Längen Transkripts herausgespleißt, sondern unter Beibehaltung des selben Leserahmens transkribiert wird, wobei das Stop-Codon an Nukleotid-Position 1760-1762 in der nachfolgenden Proteinbiosynthese $\mathrm{zu}$ der verkürzten PRO11-Version führt. Die Expression der alternativ gespleißten prol1 Variante wurde experimentell durch eine RTPCR-Analyse bestätigt (Abb. 15B). Hierzu wurde der wt unter vegetativen und sexuellen Wachstumsbedingungen kultiviert und eine cDNA Synthese der jeweils am 3., 4., 5., 6., und 7. Tag isolierten gesamt-RNA durchgeführt. Mit den Primern pro11-ORF-f und pro11I2r, welcher spezifisch in der 2. Intronsequenz bindet, wurde ein 429 bp Fragment aus allen cDNA Präparationen amplifiziert, woraus geschlossen werden konnte, dass die alternative pro11 Variante während des gesamten Lebenszyklus von S. macrospora exprimiert wird. Zur Kontrolle wurde eine PCR Reaktion mit der gleichen Primerkombination unter Verwendung von wt gDNA als Matrize durchgeführt. Das Amplifikat besitzt durch die Sequenzen der beiden im 5'-Bereich enthaltenen proll-Introns eine Größe von 499 bp. Als Negativ-Kontrolle in der RT-PCRAnalyse dienten die oben genannten RNA-Präparationen, welche bei der cDNA-Synthese nicht mit reverser Transkriptase versetzt worden waren. Die Kontrollen wiesen nach der PCRReaktion wie erwartet keine Amplifikate auf (Daten nicht gezeigt).

Anschließend wurde der Einfluss der alternativen PRO11 Variante auf die sexuelle Entwicklung von $S$. macrospora untersucht. Hierzu wurde das Plasmid p11cDNA hergestellt, welches den gesamten pro11 cDNA-ORF unter der Kontrolle der putativen pro11 Promotor- und TerminatorSequenzen enthält und in den $\Delta$ pro11-Stamm transformiert (für die Herstellung und Analyse von $\Delta$ pro11 siehe III Ergebnisse, 2.3 und 2.4). Eine alternativ gespleißte prol1-Variante kann in der resultierenden Transformante $\Delta$ pro11_PRO11cDNA ${ }^{\text {ect }}$ durch die in der pro11-cDNA fehlenden Introns nicht generiert werden. Wie Abbildung 15C zeigt komplementierte das p11cDNA Konstrukt den sterilen $\Delta$ pro11 Phänotyp vollständig. Das alternative pro11 Spleißprodukt war demnach nicht essentiell für die sexuelle Differenzierung. 


\subsection{Konstruktion eines $S$. macrospora pro11 Knockout-Stamms}

Wie in der Problemstellung beschrieben kodiert das pro11-Gen der pro11-Mutante für ein bis zum 2. „WD-repeat“ intaktes PRO11-Protein. Pöggeler und Kück (2004) zeigten auf, dass die sterile pro11-Mutante keine reifen Perithezien ausbildet, die Entwicklung ist auf der Stufe der Protoperithezien-Entwicklung arretiert. Um die Auswirkung der Deletion des gesamten pro11Gens auf die Fruchtkörperentwicklung zu untersuchen, wurde ein $\Delta$ pro11 Knockout-Stamm generiert, in welchem das prol1-Gen durch die hph-Kassette ersetzt wurde (II Material und Methoden, 2.16). Abbildung 16A zeigt schematisch die Situation des proll-Lokus im S. macrospora wt und im $\Delta$ pro11-Stamm nach der Integration der pro11-Deletionskassette. Nach der Transformation der proll-Deletionskassette in den $\Delta$ ku70 Stamm wurden zwei heterokaryotische fertile Hygromycin- und Nourseothricin-resistente Primärtransformanten isoliert und durch PCR-Analyse verifiziert (Daten nicht gezeigt). Ein homokaryotischer, von dem $\Delta$ ku70::nat Hintergrund entkoppelter $\Delta$ pro11::hph Stamm, welcher einen sterilen Phänotyp zeigte, wurde nach der für $\Delta$ Smmob3 beschriebenen Vorgehensweise isoliert. In einer klassischen genetischen Analyse wurde der $\Delta$ pro11-Stamm mit der Farbspormutante fus-1 gekreuzt und 15 geordnete Tetraden aus dieser Kreuzung analysiert. Der sterile $\Delta$ pro11 Phänotyp segregierte verbunden mit der Hygromycin-Resistenz 4:4 nach Mendel, was darauf hinwies, dass die Deletion des pro11 Gens den sterilen Phänotyp verursachte.

Zur Bestätigung der erfolgreichen Integration der pro11-Deletionskassette in den $\Delta$ pro11-Stamm wurde, analog zu der Verifikation des $\Delta$ Smmob3 Knockout-Stamms, eine PCR-Analyse durchgeführt (Abb. 16B). Mit den Primer-Kombinationen pro11-21/trpC1 und hph3/pro11-kor wurde spezifisch der prol1 5'- und 3'-flankierende Sequenzbereich zusammen mit einem Teil der integrierten $h p h$-Kassette aus der $\Delta$ pro11 gDNA amplifiziert, wohingegen das Primer-Paar pro11-21/pro11-28r ein spezifisches pro11-Fragment aus wt gDNA generierte. Mit den beiden Primern pro11-21/pro11-kor wurde außerdem der pro11 Lokus aus wt gDNA und die 1318 bp kleinere pro11-Deletionskassette aus $\Delta$ pro11 gDNA amplifiziert.

Im Anschluss an die PCR-Analyse wurde der $\Delta$ pro11 Knockout-Stamm morphologisch analysiert 
A
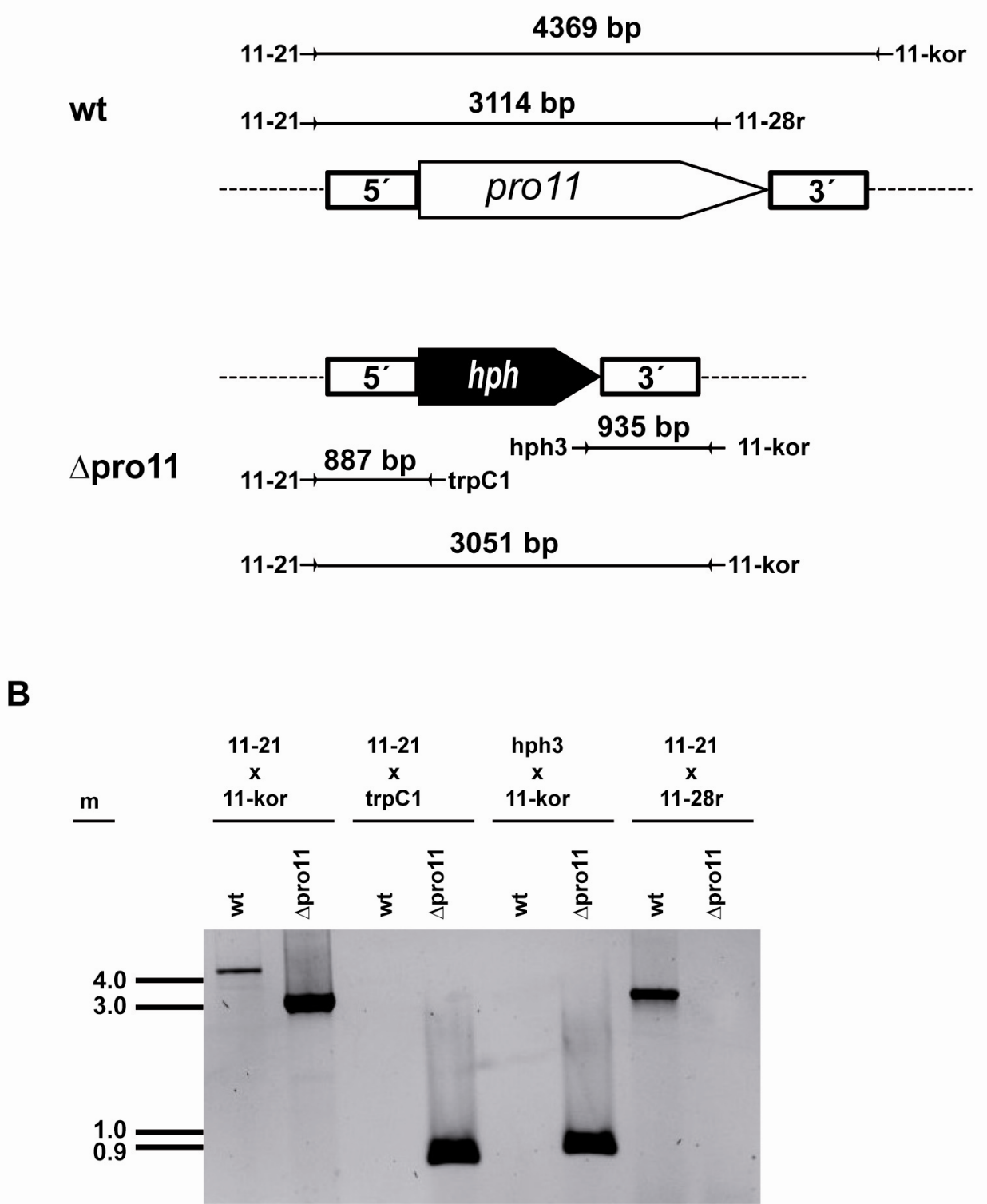

\begin{abstract}
Abb. 16 Herstellung und Bestätigung eines $\Delta$ pro11 Knockout-Stamms. (A) Schematische Darstellung des proll-Lokus im wt und im $\Delta$ prol1-Stamm nach der homologen Integration der $h p h$-Kassette (schwarzer Pfeil). Der prol1-ORF ist als weißer Pfeil und die für die homologe Integration der $h p h-$ Kassette verwendeten 5'- und 3'-flankierenden prol1-Sequenzbereiche als schwarz umrandete Boxen gekennzeichnet. Angrenzende Sequenzbereiche sind durch gestrichelte Linien dargestellt. Die Bezeichnung und Position der verwendeten Primer (kleine schwarze Pfeile) und die Größen in bp der resultierenden Amplifikate in der PCR-Analyse sind angegeben. (B) Verifikation des $\Delta$ pro11-Stamms durch PCR und Gelelektrophorese der PCR-Fragmente. Angabe der Marker-Größen (m) in kb. Primerkombination pro11-21/pro11-kor ergibt ein 4369 bp (wt) und ein 3051 bp (Apro11) pro11 Amplifikat. Primer Paare pro11-21/trpC1 und hph3/pro11-kor generieren für $\Delta$ pro11 Fragmente bestehend aus den 5'- (887 bp) und 3'- (935 bp) flankierenden Sequenzbereichen und einem Teil der integrierten $h p h$-Kassette und ergeben keine Fragmente für den wt. Der prol 1 -spezifisch bindende Primer pro11-28r ergibt mit pro11-21 ein 3114 bp Amplifikat für den wt und kein Amplifikat für $\Delta$ pro11.
\end{abstract}




\subsection{Morphologische Charakterisierung des $S$. macrospora $\Delta$ pro11 Stamms}

Für den phänotypischen Vergleich des $\Delta$ pro11 Knockout-Stamms und der pro11-Mutante wurden die beiden Stämme für zehn Tage auf SWG-Festmedium kultiviert. Der wt wurde zur Kontrolle ebenfalls unter den gleichen Kulturbedingungen angezogen (Abb. 17A). Die Übersichtsaufnahme zeigt, dass im Vergleich zu dem wt und zu der pro11-Mutante der $\Delta$ pro11Stamm im vegetativen Wachstum eingeschränkt ist. Im Gegensatz zu der pro11-Mutante weist $\Delta$ pro11 außerdem keine verstärkte Bildung von Luftmyzel auf.

Das eingeschränkte vegetative Wachstum von $\Delta$ pro11 wurde in Rennrohrtests und durch die Bestimmung des Trockengewichts bestätigt. Das tägliche Wachstum von $\Delta$ pro11 betrug mit $8( \pm 3) \mathrm{mm} / \mathrm{d}$ nur die Hälfte der durchschnittlichen Wuchsrate der pro11-Mutante $(16 \pm 4 \mathrm{~mm} / \mathrm{d})$. Im Vergleich zu dem wt-Stamm $(27 \pm 6 \mathrm{~mm} / \mathrm{d})$ war die Wuchsrate von $\Delta$ pro11 um $70 \%$ und von der pro11-Mutante um $41 \%$ reduziert. Die Bestimmung des Trockengewichts ergab, dass sowohl die pro11-Mutante mit 1,2 $( \pm 0,3) \mathrm{mg}$ Myzel/ml SWG als auch der $\Delta$ pro11-Stamm $(1 \pm 0,2 \mathrm{mg} / \mathrm{ml}) 78-82 \%$ weniger Biomasse produzierten als der wt $(5,5 \pm 0,5 \mathrm{mg} / \mathrm{ml})$.

In der Ausbildung der sexuellen Strukturen während der Entwicklung ließen sich deutliche Unterschiede zwischen dem $\Delta$ pro11 Knockout-Stamm und der pro11-Mutante feststellen (Abb. 17B). Während die pro11-Mutante noch die Fähigkeit zur Ausbildung pigmentierter Protoperithezien besaß, war der $\Delta$ pro11-Stamm in der sehr frühen entwicklungsphysiologischen Phase der Ascogonenbildung blockiert. Es wurden zwar Ascogone ausgebildet, diese befanden sich jedoch am Beginn der Entwicklung, welche durch die sich einrollende Hyphe charakterisiert ist. Darüber hinaus konnte die Bildung von nur sehr wenigen Ascogonen an dem Myzel des $\Delta$ pro11-Stamms beobachtet werden.

Um dieses Ergebnis zu bekräftigen wurden die vom wt, der pro11-Mutante und des $\Delta$ pro11Stamms produzierten Ascogone pro $\mathrm{cm}^{2}$ Kulturmedium ausgezählt (II Material und Methoden, 2.19). Aus Abbildung 17C geht hervor, dass die von der pro11-Mutante produzierte AscogonenAnzahl $\left(83 \pm 12\right.$ Ascogone $\left./ \mathrm{cm}^{2} \mathrm{SWG}\right)$ im Vergleich $\mathrm{zu}$ dem wt-Stamm $(151 \pm 19$ Ascogone $/ \mathrm{cm}^{2}$ ) um $40 \%$ reduziert war. Im Gegensatz dazu war die Bildung von Ascogonen im $\Delta$ pro11-Stamm mit $2( \pm 0,8)$ Ascogonen/ $\left.\mathrm{cm}^{2} \mathrm{SWG}\right)$ drastisch eingeschränkt. Dies enstpricht im Vergleich zu dem wt-Stamm einer Reduktion der Ascogonen-Anzahl um 99 \%. 


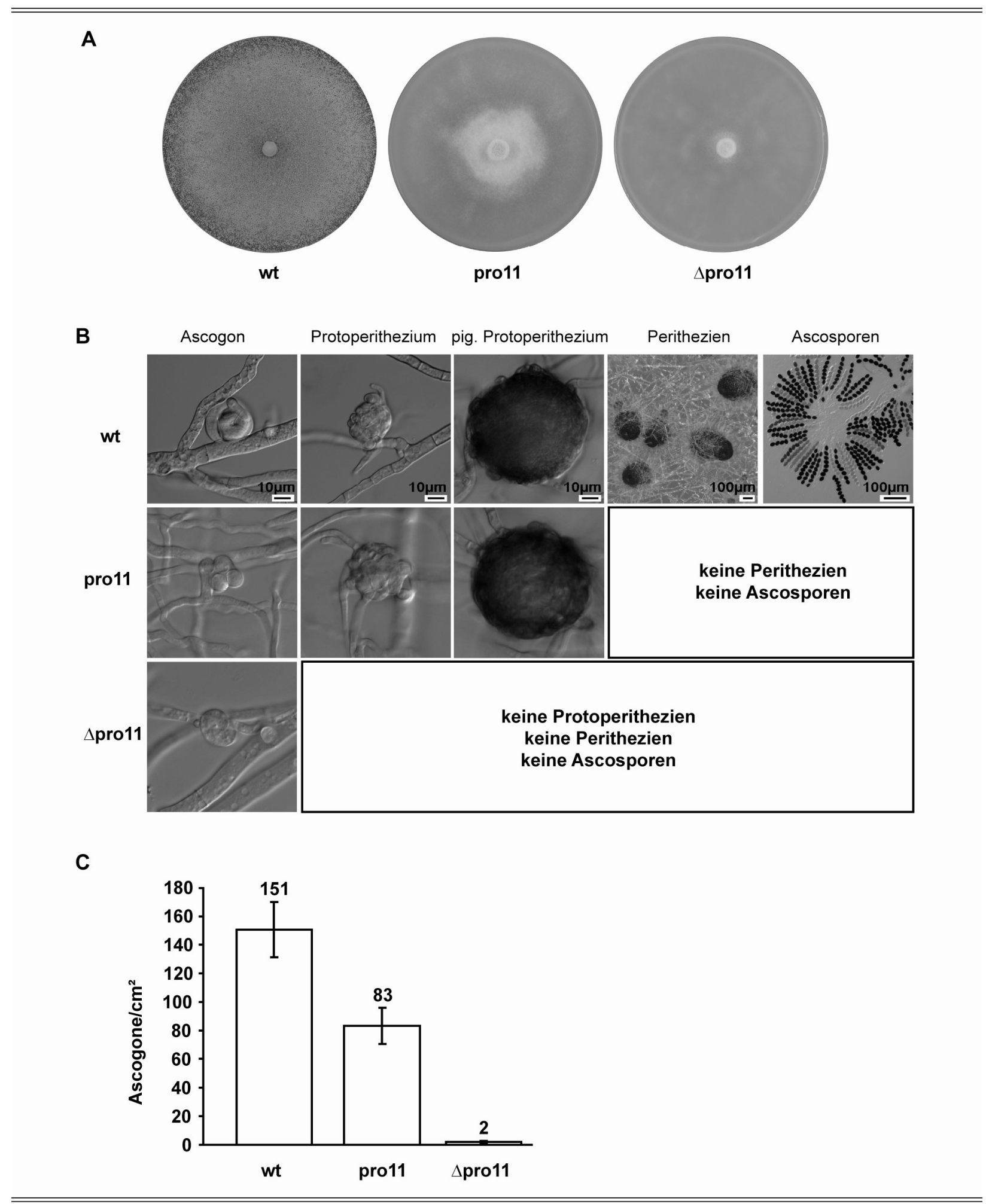

Abb. 17 Makroskopische und mikroskopische Analyse des $S$. macrospora $\Delta$ pro11 Phänotyps. (A) Übersichtsaufnahme der Phänotypen von wt, der pro11-Mutante und dem Apro11-Stamm nach Kultivierung auf SWG. (B) Mikroskopische Aufnahmen der gebildeten sexuellen Strukturen von wt, pro11 und $\Delta$ pro11. Abk.: pig.-pigmentiert. (C) Die von den Stämmen gebildeten Ascogone wurden nach fünf Tagen Inkubation auf mit SWG-Festmedium beschichteten Objektträgern pro $\mathrm{cm}^{2}$ unter dem Mikroskop ausgezählt. Die Standardabweichungen sind als Fehlerbalken angegeben. 


\subsection{PRO11-Komplementationsstudie}

Da der $\Delta$ pro11 Knockout-Stamm einen Defekt in einer viel früheren Phase der sexuellen Entwicklung zeigte als die pro11-Mutante, sollte die Auswirkung der Expression unterschiedlicher PRO11-Teilstücke auf die sexuelle Entwicklung in einer Komplementationsanalyse getestet werden. Hierzu wurden die Plasmide p11FL, p11mut, p11N1, p11N2, p11N3 und p11N4 konstruiert (II Material und Methoden, 2.18.2) (Abb. 18A). Nach der Transformation der Plasmide in den $\Delta$ pro11-Stamm wurde die korrekte Expression der verschiedenen proll-Versionen in den erhaltenen Stämmen $\Delta$ pro11_PRO11FL ${ }^{\text {ect }}$, $\Delta$ pro11_PRO11mut ${ }^{\text {ect }}, \Delta$ pro11_PRO11N1 $1^{\text {ect }}, \Delta$ pro11_PRO11N2 ${ }^{\text {ect }}, \Delta$ pro11_PRO11N3 ${ }^{\text {ect }}$ und $\Delta$ pro11_PRO11N4 ${ }^{\text {ect }}$ mittels qualitativer RT-PCR nachgewiesen (Daten nicht gezeigt).

Anschließend wurde mikroskopisch untersucht, welche sexuellen Strukturen die Transformanten ausbilden konnten (Abb. 18B).

Das Voll-Längen PRO11 (p11FL) komplementierte den sterilen Phänotyp vollständig, es konnten wieder Perithezien und reife Ascosporen gebildet werden. Interessanterweise führte die Transformation der Plasmide p11mut, p11N1-p11N4, welche für schrittweise verkürzte PRO11Proteine kodierten, zu einer sukzessiven Einschränkung der sexuellen Strukturen, die noch ausgebildet werden konnten. So konnten von der Transformante $\Delta$ pro11_PRO11mut ${ }^{\mathrm{ect}}$, welche analog $\mathrm{zu}$ der pro11 Mutante eine 567 AS PRO11-Version exprimierte und von der Transformante $\Delta$ pro11_PRO11N1 ${ }^{\text {ect }}$, in welcher der 414 AS PRO11 N-Terminus gebildet wurde, noch pigmentierte Protoperithezien generiert werden. Die Transformanten $\Delta$ pro11_PRO11N2 ${ }^{\text {ect }}$, $\Delta$ pro11_PRO11N3 ${ }^{\text {ect }}$ und $\Delta$ pro11_PRO11N4 ${ }^{\text {ect }}$, welche eine 281 AS, 180 AS und 120 AS PRO11-Version beinhalteten, produzierten im Gegensatz dazu nur noch Ascogone. Diese waren jedoch im Vergleich zu den von $\Delta$ pro11 gebildeten Ascogonen weiter entwickelt und vielzählig vorhanden. 


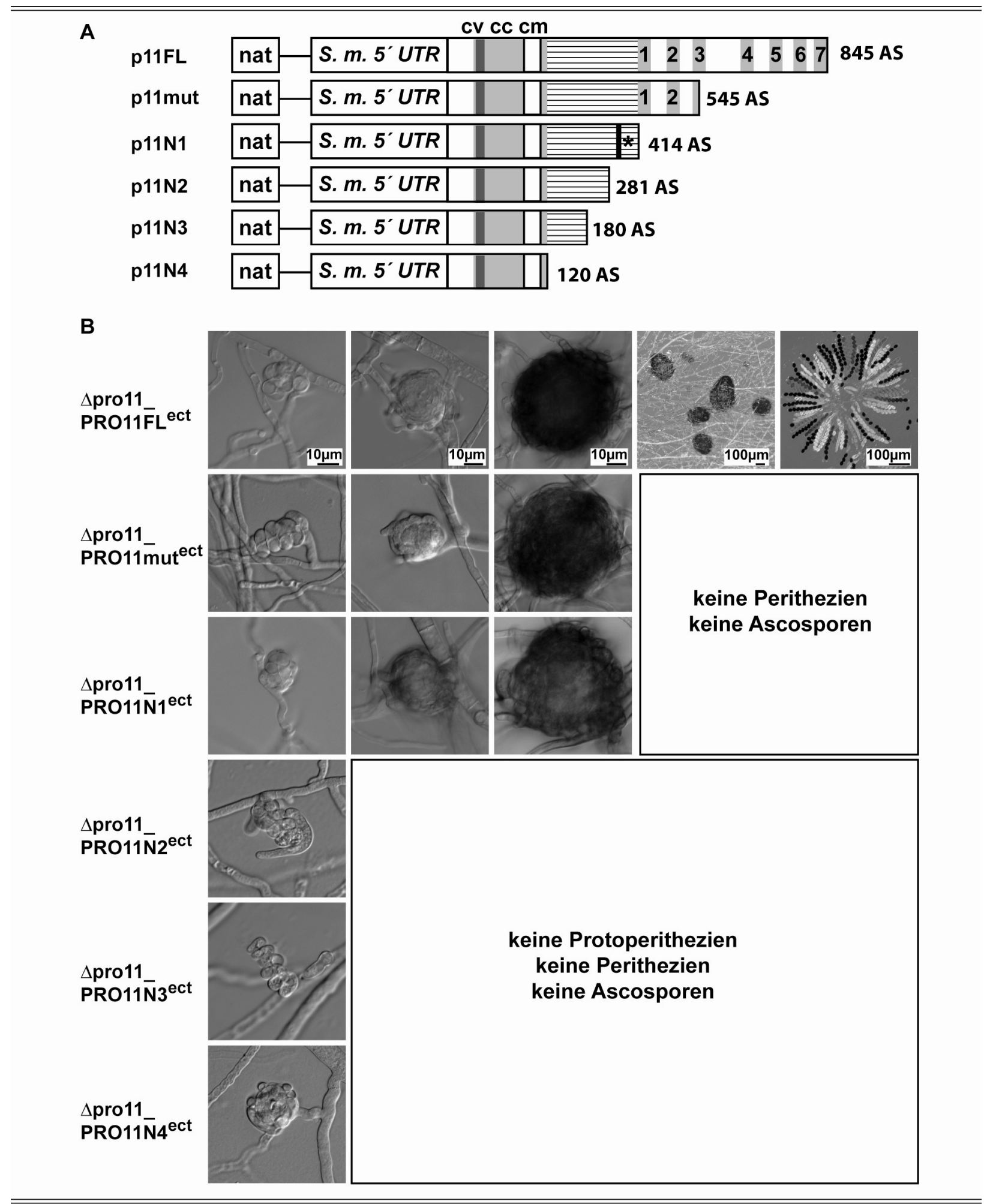

Abb. 18 PRO11-Komplementationsanalyse. (A) Schematische Abbildung der transformierten Plasmide. Das Voll-Längen prol1 und die Teilstücke stehen unter der Kontrolle des putativen pro11Promotors (S. m. 5' UTR). Alle Plasmide tragen die nat-Kassette (nat) für die Selektion von Transformanten. Das „PxxP“-Motiv ist als schwarze Box, die Serin-Reste als Stern gekennzeichnet. Zur Erklärung der markierten PRO11-Domänen siehe Abb. 14. (B) Mikroskopische Untersuchung der Ausbildung sexueller Strukturen der S. macrospora Stämme $\Delta$ pro11_PRO11FL ${ }^{\text {ect }}, \Delta$ pro11_PRO11mut ${ }^{\text {ect }}$, $\Delta$ pro11_PRO11N1 ${ }^{\text {ect }}, \Delta$ pro11_PRO11N2 $2^{\text {ect }}, \Delta$ pro11_PRO11N3 ${ }^{\text {ect }} \bar{u}^{-} \Delta$ pro11_PRO11N4 ${ }^{\text {ect }}$ nach der Inkubation auf SWG. 
Ein möglicher Einfluss von Stress-induzierenden Agenzien wurde mittels Kultivierung des pro11- und $\Delta$ pro11-Stamms auf SWG-Festmedium mit Zusatz verschiedener Konzentrationen $\mathrm{H}_{2} \mathrm{O}_{2}$, SDS, NaCl, $\mathrm{KCl}$ oder Sorbitol getestet. Aus Abbildung 19 geht hervor, dass sowohl die pro11-Mutante als auch der $\Delta$ pro11 Knockout-Stamm eine erhöhte Sensitivität gegenüber der Induzierung von osmotischem Stress aufwiesen. Auf SWG-Medium, welchem 0,1 M NaCl oder $0,1 \mathrm{M} \mathrm{KCl}$ zugesetzt worden war, zeigten beide Stämme ein deutlich eingeschränktes Wachstum im Vergleich zu der Kultivierung auf SWG-Medium.

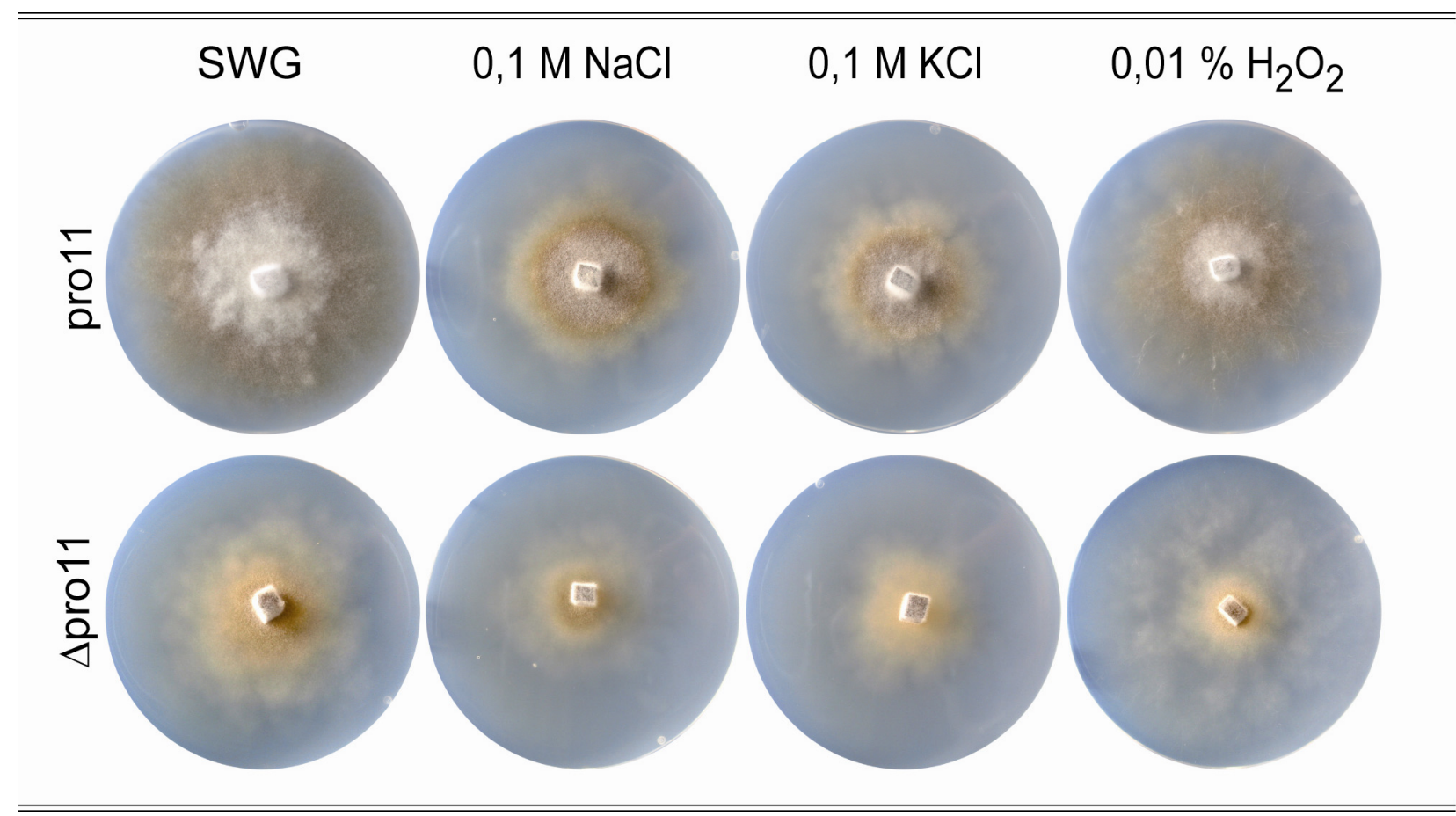

Abb. 19 Kultivierung der Stämme pro11 und $\Delta$ pro11 auf Stress-induzierendem Medium. Übersichtsaufnahmen der pro11-Mutante und des $\Delta$ pro11-Stamms nach der Inkubation auf SWGMedium ohne und mit Stress-induzierenden Zusätzen (SWG, SWG $+\mathrm{NaCl}$, SWG $+\mathrm{KCl}$ oder SWG + $\mathrm{H}_{2} \mathrm{O}_{2}$ ).

Eine Induzierung von oxidativem Stress löste bei der pro11-Mutante und dem $\Delta$ pro11-Stamm ein unterschiedliches Wachstumsverhalten aus. Während die Kultivierung der pro11-Mutante auf SWG mit 0,01\% $\mathrm{H}_{2} \mathrm{O}_{2} \mathrm{zu}$ einer leichten Reduzierung des Wachstums führte, war bei dem $\Delta$ pro11-Stamm eine leichte Verbesserung des Wachstums zu beobachten. Zur Kontrolle wurde der wt ebenfalls auf den genannten Medien angezogen. Der wt-Stamm zeigte auf den Stressinduzierenden Medien kein verändertes Wachstum im Vergleich zu der Kultivierung auf SWG (Daten nicht gezeigt).

Es wurde außerdem der Einfluss einer pro 11-Überexpression auf $\Delta$ pro11 und den wt untersucht. Die mit dem Plasmid p11oex transformierten Stämme $\Delta$ pro11_gpd-PRO11 ${ }^{\text {ect }}$ und wt_gpd- 
PRO11 ${ }^{\text {ect }}$ zeigten jedoch keinen Unterschied bezüglich des vegetativen Wachstums oder der Anzahl und Form der gebildeten Perithezien und Ascosporen im Vergleich zum wt-Stamm (Daten nicht gezeigt). Das Überexpressionsplasmid komplementierte den sterilen Phänotyp des $\Delta$ pro11-Stamms, wodurch die Funktionalität des Plasmids bestätigt wurde.

\subsection{Expression von $S m m o b 3$ in $\Delta$ pro11 und pro11 in $\Delta$ Smmob3}

Es wurde mittels quantitativer Real-Time PCR untersucht, ob sich die Expression des Smmob3Gens in dem Knockout-Stamm $\Delta$ pro11 und die des prol1-Gens in $\Delta$ Smmob3 von der Expression im wt-Stamm unterschied. Dazu wurden die Transkript-Level von Smmob3 und pro11 im wt und in den Knockout-Stämmen unter sexuellen Wachstumsbedingungen verglichen. Wie Abbildung 20 zeigt ist das Smmob3 Transkript in dem $\Delta$ pro11-Stamm im Vergleich zum wt 5-fach hochreguliert. Im Gegensatz dazu unterscheidet sich die Expression von proll in $\Delta$ Smmob3 nicht signifikant von der Expression im wt.

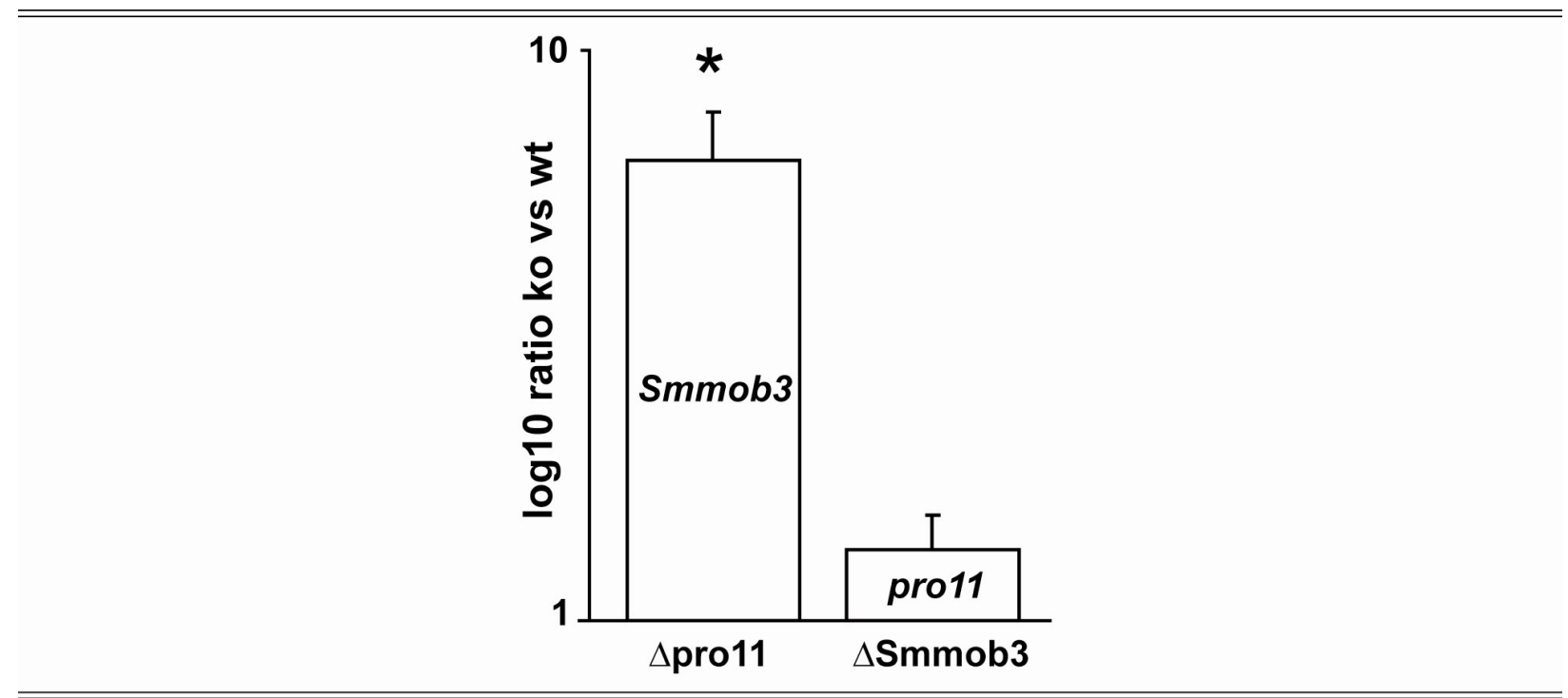

Abb. 20 Smmob3- und pro11-Expressionsanalyse in $\Delta$ pro11 und $\Delta$ Smmob3. Die Transkript-Level der Gene Smmob3 und prol1 in $\Delta$ pro11 und $\Delta$ Smmob3 wurden mit denen im wt unter sexuellen Wachstumsbedingungen $(\log 10$ ratio ko vs wt) nach $5 \mathrm{~d}$ der Entwicklung verglichen. Die gezeigten Expressionsraten sind Mittelwerte aus mind. zwei biologisch unabhängigen Proben, welche jeweils dreifach gemessen wurden. Der Stern kennzeichnet die mit der Anwendung REST ermittelte Signifikanz $(\mathrm{P}=0,004)$ der erhaltenen Werte (Pfaffl et al. 2002). 


\section{Identifizierung und Charakterisierung weiterer Interaktionspartner von SmMOB3 und PRO11}

\subsection{Hefe Two-Hybrid „Screen” mit einer $S$. macrospora und $N$. crassa cDNA-Bank}

Neben den Interaktionsstudien mit den Proteinen SmMOB3 und PRO11 wurde eine $S$. macrospora und eine $N$. crassa cDNA-Bank nach weiteren Interaktionspartnern von SmMOB3 und PRO11 durchsucht (II Material und Methoden, 2.23.2). Als Köder wurden die in der Interaktionsstudie eingesetzten Plasmide pBMob3-aa1-144, pB11-aa1-110 und pB11-aa282845 verwendet, welche für die AS 1-144 des SmMOB3-Proteins (SmMOB3N), AS 1-110 des PRO11-Proteins (PRO11N) und AS 282-845 des PRO11-Proteins (PRO11C) kodieren (IV Ergebnisse, 1.3). Aus dem S. macrospora cDNA-Bank „Screen“ ergaben sich für SmMOB3N zwölf, für PRO11N fünf und für PRO11C keine Interaktionen mit den von den Genbankplasmiden kodierten Proteinen. Der artübergreifende „Screen“ mit der N. crassa cDNABank resultierte in 19 Interaktionen für SmMOB3N, 55 für PRO11N und 34 für PRO11C. Die Genbankplasmide wurden aus den Hefekolonien aufgearbeitet und sequenziert. Die Sequenzdaten wurden anschließend einem „BLAST“-Vergleich mit den Datenbanken des „NCBI“ oder der „Saccharomyces Genome Database“ unterzogen, um Informationen über die Funktionalität der identifizierten Interaktionspartner zu erhalten.

Tabelle 4 zeigt die Auswertung der erhaltenen Sequenzdaten putativer Interaktionspartner von SmMOB3N, PRO11N und PRO11C aus dem „Screen“ der S. macrospora und N. crassa cDNA Bank.

Tab. 4: Übersicht identifizierter Interaktionspartner in den Hefe Two-Hybrid „Screens“ Köderprotein: SmMOB3

Screen $S$. macrospora cDNA Bank

\begin{tabular}{|c|c|c|c|c|}
\hline Anz. & N. c. & S. c. & E-Wert & Funktion $N . c . ; S . c$. \\
\hline $2 \mathrm{x}$ & NCU02003 & $T E F 2$ & $1 \mathrm{e}^{-204}$ & $\begin{array}{l}\text { Elongationsfaktor } 1 \alpha \text {, Translation } \\
\text { (Ichi-ishi und Inoue 1995, Schirmaier und Philippsen 1984) }\end{array}$ \\
\hline $1 x$ & NCU00493 & RET2 & $5,2 \mathrm{e}^{-76}$ & $\begin{array}{l}\text { Coatomare (COPI) UE } \delta \text {; Golgi-Vesikel Hülle-Protein, retrograder Transport } \\
\text { von Golgi zu ER (Kasuga und Glass 2008, Cosson et al. 1996) }\end{array}$ \\
\hline $1 \mathrm{x}$ & NCU01548 & PBI2 & $2,1 \mathrm{e}^{-07}$ & $\begin{array}{l}\text { unbekannt; Inhibitor der vakuolären Proteinase B (Prb1p), mit Thioredoxin } \\
\text { beteiligt an SNARE-Bindung und vakuolärer Fusion (Slusarewicz et al. 1997) }\end{array}$ \\
\hline $1 x$ & NCU04528 & FET5 & $3 e^{-38}$ & $\begin{array}{l}\text { Multi-Kupfer Oxidase, Oxidation phenolischer Verbindungen; integrales } \\
\text { Membranprotein, Eisentransport (Germann et al. 1988, Spizzo et al. 1997) }\end{array}$ \\
\hline $1 x$ & NCU05259 & OLE1 & $8,6 \mathrm{e}^{-121}$ & $\begin{array}{l}\text { Fettsäure-Desaturase, Synthese einfach ungesättigter Fettsäuren } \\
\text { (Xie et al. 2004, Stukey et al. 1989) }\end{array}$ \\
\hline $1 x$ & NCU05319 & MDM35 & 0,79 & $\begin{array}{l}\text { unbekannt; mitochondriales Intermembranraum Protein, Form und } \\
\text { Verteilung von Mitochondrien (Gabriel et al. 2007) }\end{array}$ \\
\hline $1 \mathrm{x}$ & NCU05804 & $R P L 19 B$ & $1,5 \mathrm{e}^{-43}$ & 60S rib. Protein L19, Translation (Tian et al. 2009, Planta und Mager 1998) \\
\hline $1 \mathrm{x}$ & NCU08374 & YFR016C & $1,1 \mathrm{e}^{-13}$ & unbekannt; interagiert mit Proteinen derAktin-Organisation (Sheu et al. 1998) \\
\hline
\end{tabular}




\section{Köderprotein: SmMOB3}

Screen $S$. macrospora cDNA Bank

\begin{tabular}{|c|c|c|c|c|}
\hline Anz. & N. $c$. & S. c. & E-Wert & Funktion $N . c . ; S . c$. \\
\hline $1 x$ & NCU09290 & PRE3 & $3,1 \mathrm{e}^{-68}$ & $\begin{array}{l}\beta 1 \text { UE des 20S-Proteasoms, Peptidspaltung nach sauren AS-Resten } \\
\text { (Jager et al. 1999) }\end{array}$ \\
\hline $1 x$ & NCU11263 & $M A G 2$ & $8,1 \mathrm{e}^{-44}$ & $\begin{array}{l}\text { unbekannt; ähnlich zu humanem RING-Finger Protein RNF10 } \\
\text { (Samanta und Liang 2003) }\end{array}$ \\
\hline $1 x$ & NCU03150 & $R P L 24 A$ & $6,1 \mathrm{e}^{-40}$ & $\begin{array}{l}\text { 60S rib. Protein L24; 60S rib. Protein L30, Translation } \\
\text { (Mannhaupt et al. 2003, Baronas-Lowell und Warner 1990) }\end{array}$ \\
\hline
\end{tabular}

Screen $N$. crassa cDNA Bank

\begin{tabular}{|c|c|c|c|c|}
\hline Anz. & N. $c$. & S. $c$. & E-Wert & Funktion $N . c . ; S . c$. \\
\hline $9 x$ & NCU09375 & YJL020W-A & 0,88 & unbekannt \\
\hline $2 \mathrm{x}$ & NCU00200 & TRP3 & $1 \mathrm{e}^{-157}$ & $\begin{array}{l}\text { Anthranilat Synthase, Tryptophan Biosynthese } \\
\text { (Chalmers und Seale 1971, Paluh und Zalkin 1983) }\end{array}$ \\
\hline $1 x$ & NCU00995 & THI6 & 0,99 & $\begin{array}{l}\text { unbekannt; Thiamin-Phosphat Pyrophosphorylase, Thiamin-Biosynthese } \\
\text { (Nosaka et al. 1994) }\end{array}$ \\
\hline $1 \mathrm{x}$ & NCU02733 & TVP23 & $2,1 \mathrm{e}^{-23}$ & $\begin{array}{l}\text { unbekannt; Golgi-Membranprotein, retrograder Transport von Endosom zu } \\
\text { Golgi (Stein et al. 2009) }\end{array}$ \\
\hline $1 x$ & NCU03194 & $A D E 2$ & $9,5 \mathrm{e}^{-121}$ & $\begin{array}{l}\text { Phosphoribosylaminoimidazol Carboxylase, Nukleotidsynthese } \\
\text { (Newcombe und Griffiths 1973, Stotz et al. 1993) }\end{array}$ \\
\hline $1 x$ & NCU05498 & $B U D 9$ & 0,56 & $\begin{array}{l}\text { unbekannt; Beteiligung bei Determination der Hefe Knospungs-Stellen } \\
\text { (Ni und Snyder 2001) }\end{array}$ \\
\hline $1 x$ & NCU06226 & $R P L 25$ & $6,5 \mathrm{e}^{-36}$ & 60S rib. Protein L25, Translation (Tian et al. 2009, Kooi et al. 1994) \\
\hline $1 x$ & NCU06727 & SPE3 & $3,2 \mathrm{e}^{-114}$ & $\begin{array}{l}\text { Spermidin Synthase, Spermidin Biosynthese } \\
\text { (Katagiri et al. 1998, Hamasaki-Katagiri et al. 1997) }\end{array}$ \\
\hline $1 \mathrm{x}$ & NCU07826 & RPS19A & $6,9 \mathrm{e}^{-48}$ & 40S rib. Protein S19, Translation (Tian et al. 2009, Planta und Mager 1998) \\
\hline $1 \mathrm{x}$ & NCU08091 & $O G G 1$ & 0,14 & $\begin{array}{l}\text { unbekannt; mitochondriale Glycosylase/Lyase, Reparatur oxidativ } \\
\text { geschädigter DNA (Nash et al. 1996) }\end{array}$ \\
\hline
\end{tabular}

\section{Köderprotein: PRO11N}

\section{Screen $S$. macrospora cDNA Bank}

\begin{tabular}{|c|c|c|c|c|}
\hline Anz. & N. $c$. & S. $c$. & E-Wert & Funktion $N . c . ; S . c$. \\
\hline $2 \mathrm{x}$ & NCU10058 & $P G M 2$ & $2,3 \mathrm{e}^{-184}$ & $\begin{array}{l}\text { Phosphoglucomutase; } \mathrm{Ca}^{2+} \text {-Homöostase } \\
\text { (Borkovich et al. 2004, Aiello et al. 2004) }\end{array}$ \\
\hline $1 \mathrm{x}$ & NCU00635 & $E G D 2$ & $1,4 \mathrm{e}^{-25}$ & $\begin{array}{l}\alpha \text { UE des heterotrimeren "nascent polypeptide-associated complex" (NAC), } \\
\text { Protein-Sortierung und-Translokation zu den Mitochondrien } \\
\text { (George et al. 1998) }\end{array}$ \\
\hline $1 \mathrm{x}$ & NCU03905 & $Y A P 1$ & $1,4 \mathrm{e}^{-13}$ & $\begin{array}{l}\text { unbekannt; bZIP-Transkriptionsfaktor, oxidative Stress-Toleranz, Transition } \\
\text { von Cytoplasma in den Nukleus (Kuge et al. 1997) }\end{array}$ \\
\hline $1 \mathrm{x}$ & NCU06550 & SNZ3 & $2,5 \mathrm{e}^{-82}$ & $\begin{array}{l}\text { Pyridoxin; Induziert u.a. bei Abwesenheit von Thiamin } \\
\text { (Bean et al. 2001, Padilla et al. 1998) }\end{array}$ \\
\hline
\end{tabular}

\section{Screen $N$. crassa cDNA Bank}

$\begin{array}{llll}\text { Anz. } & \text { N. } c . & \text { S. } c . & \text { E-Wert } \\ 37 \mathrm{x} & \text { NCU09375 } & \text { YJL020W-A } & 0,88 \\ 3 \mathrm{x} & \text { NCU00995 } & \text { THI6 } & 0,99 \\ & & & \\ 2 \mathrm{x} & \text { NCU06727 } & \text { SPE3 } & 3,2 \mathrm{e}^{-114} \\ & & & \\ 2 \mathrm{x} & \text { NCU07947 } & \text { FTH1 } & 0,98\end{array}$

\section{Funktion N. c. ; S. $c$.}

unbekannt

unbekannt; Thiamin-Phosphat Pyrophosphorylase, Thiamin-Biosynthese (Tian et al. 2009, Nosaka et al. 1994)

Spermidin Synthase, Spermidin Biosynthese (Katagiri et al. 1998, Hamasaki-Katagiri et al. 1997)

Glycolipid-Transferprotein; vakuolärer Eisentransporter, interagiert mit Fet5p, indirekte Funktion in Endocytose (Videira et al. 2009, Urbanowski und Piper 1999) 


\begin{tabular}{|c|c|c|c|c|}
\hline \multicolumn{5}{|c|}{ Köderprotein: PRO11N } \\
\hline \multicolumn{5}{|c|}{ Screen $N$. crassa cDNA Bank } \\
\hline Anz. & N. c. & S. $c$. & E-Wert & Funktion $N$. c. ; S. $c$. \\
\hline $1 \mathrm{x}$ & NCU01353 & TIR4 & 0,91 & Glucanase; Zellwand-Mannoprotein (Maddi et al. 2009, Abramova et al. 2001) \\
\hline $1 \mathrm{x}$ & NCU02410 & ECM22 & 1 & $\begin{array}{l}\text { unbekannt; Transkriptionsfaktor von Sterol-Biosynthese Genen } \\
\text { (Marie et al. 2008) }\end{array}$ \\
\hline $1 \mathrm{x}$ & NCU02499 & ZIM17 & $1,7 \mathrm{e}^{-19}$ & $\begin{array}{l}\text { unbekannt; Hitzeschock-Protein mit Zink-Finger Motiv, essentiell für } \\
\text { Proteinimport in Mitochondrien (Burri et al. 2004) }\end{array}$ \\
\hline $1 \mathrm{x}$ & NCU03194 & $A D E 2$ & $9,5 \mathrm{e}^{-121}$ & $\begin{array}{l}\text { Phosphoribosylaminoimidazol Carboxylase, Nukleotidsynthese } \\
\text { (Newcombe und Griffiths 1973, Stotz et al. 1993) }\end{array}$ \\
\hline $1 \mathrm{x}$ & NCU04552 & $R P S 26 B$ & $4,4 \mathrm{e}^{-30}$ & 40S rib. Protein S26E (Wang et al. 1993, Planta und Mager 1998) \\
\hline $1 \mathrm{x}$ & NCU05252 & $L I A 1$ & $5,3 \mathrm{e}^{-57}$ & Deoxyhypusin Hydroxylase; “HEAT-repeat"-Motiv (Park et al. 2006) \\
\hline $1 \mathrm{x}$ & NCU05274 & $H Y P 2$ & $3,4 \mathrm{e}^{-55}$ & Translationsinitiationsfaktor 5A (Tao und Chen 1994, Zanelli et al. 2006) \\
\hline $1 \mathrm{x}$ & NCU07112 & $\operatorname{COX} 9$ & 0,96 & $\begin{array}{l}\text { unbekannt; UE VIIa der Cytochrom-C Oxidase, mitochondrialer } \\
\text { Elektronentransport (Wright et al. 1986) }\end{array}$ \\
\hline $1 \mathrm{x}$ & NCU07826 & RPS19A & $6,9 \mathrm{e}^{-48}$ & 40S rib. Protein S19, Translation (Tian et al. 2009, Planta und Mager 1998) \\
\hline $1 \mathrm{x}$ & NCU09109 & $R P L 33 A$ & $9,7 \mathrm{e}^{-26}$ & $\begin{array}{l}\text { 60S rib. Protein L33; 60S rib. Protein L37 } \\
\text { (Tian et al. 2009, Planta und Mager 1998) }\end{array}$ \\
\hline $1 \mathrm{x}$ & NCU09498 & $\begin{array}{l}Y D R 183 C- \\
A\end{array}$ & 0,89 & unbekannt \\
\hline
\end{tabular}

\section{Köderprotein: PRO11C}

Screen S. macrospora cDNA Bank

\section{Screen $N$. crassa cDNA Bank}

\begin{tabular}{|c|c|c|c|c|}
\hline Anz. & N. c. & S. c. & E-Wert & Funktion $N . c . ; S . c$. \\
\hline $22 \mathrm{x}$ & NCU09375 & YJL020W-A & 0,88 & unbekannt \\
\hline $3 x$ & NCU03194 & $A D E 2$ & $9,5 \mathrm{e}^{-121}$ & $\begin{array}{l}\text { Phosphoribosylaminoimidazol Carboxylase, Nukleotidsynthese } \\
\text { (Newcombe und Griffiths 1973, Stotz et al. 1993) }\end{array}$ \\
\hline $2 \mathrm{x}$ & NCU02733 & TVP23 & $2,1 \mathrm{e}^{-23}$ & $\begin{array}{l}\text { unbekannt; Golgi-Membranprotein, retrograder Transport von Endosom zu } \\
\text { Golgi (Stein et al. 2009) }\end{array}$ \\
\hline $1 \mathrm{x}$ & NCU00200 & TRP3 & $1 \mathrm{e}^{-157}$ & $\begin{array}{l}\text { Anthranilat Synthase, Tryptophan Biosynthese } \\
\text { (Chalmers und Seale 1971, Paluh und Zalkin 1983) }\end{array}$ \\
\hline $1 \mathrm{x}$ & NCU00716 & $C D C 123$ & 0,23 & $\begin{array}{l}\text { Nicht-geankertes Zellwandprotein 5; Zellzyklus-Kontrolle durch Regulation } \\
\text { des Translationsinitiationsfaktors eIF2 } \\
\text { (Maddi et al. 2009, Bieganowski et al. 2004) }\end{array}$ \\
\hline $1 \mathrm{x}$ & NCU02621 & $S F P 1$ & $6,8 \mathrm{e}^{-51}$ & $\begin{array}{l}\text { unbekannt; Transkriptionsfaktor, Nährstoff- und Stress-abhängige } \\
\text { Regulation der Expression von Ribosom Biogenese Genen (Marion et al. 2004) }\end{array}$ \\
\hline $1 \mathrm{x}$ & NCU06727 & SPE3 & $3,2 \mathrm{e}^{-114}$ & $\begin{array}{l}\text { Spermidin Synthase, Spermidin Biosynthese } \\
\text { (Katagiri et al. 1998, Hamasaki-Katagiri et al. 1997) }\end{array}$ \\
\hline $1 \mathrm{x}$ & NCU07826 & RPS19A & $6,9 \mathrm{e}^{-48}$ & 40S rib. Protein S19, Translation (Tian et al. 2009, Planta und Mager 1998) \\
\hline $1 x$ & NCU08693 & PMRI & $3,8 \mathrm{e}^{-237}$ & $\begin{array}{l}\text { Hitzeschock-Protein 70-5; ATPase für } \mathrm{Ca}^{2+} \text { und } \mathrm{Mn}^{2+} \text { Transport in Golgi, } \\
\mathrm{Ca}^{2+} \text {-abhängige Protein-Sortierung und -Prozessierung } \\
\text { (Seiler und Plamann 2003, Durr et al. 1998) }\end{array}$ \\
\hline $1 \mathrm{x}$ & NCU09498 & $\begin{array}{l}Y D R 183 C- \\
A\end{array}$ & 0,89 & unbekannt \\
\hline
\end{tabular}

Es konnten keine Interaktionspartner identifiziert werden

Anz.: Anzahl; Häufigkeit des gefundenen Interaktionspartners

N. c.: Angabe der Gene aus N. crassa mit der höchsten Homologie zu den identifizierten Interaktionspartnern S. c.: Angabe der homologen Gene aus $S$. cerevisiae.

E-Wert: Angabe des Homologie-Wertes zwischen den kodierten N. crassa und S. cerevisiae Proteinsequenzen grau: E-Werte über dem Wert null

N. $c$; S. c.: Funktionen kodierter Proteine aus N. crassa und S. cerevisiae; die entprechende Literatur ist angegeben 
Wie aus Tabelle 4 hervorgeht, ergab der $S$. macrospora und $N$. crassa "Screen“ keine übereinstimmenden Interaktionspartner. Für SmMOB3N wurden in beiden „Screens“ insgesamt 21, für PRO11N 19 und für PRO11C zehn unterschiedliche Interaktionspartner identifiziert. In dem S. macrospora cDNA-Bank „Screen“ wurde der Elongationsfaktor $1 \alpha$ und die Phosphoglucomutase jeweils 2x als Interaktionspartner von SmMOB3 bzw. PRO11N gefunden, alle anderen Proteine interagierten nur jeweils 1x mit SmMOB3 oder PRO11N. Interessanterweise wurde in dem N. crassa cDNA-Bank „Screen“ das von NCU09375 kodierte Protein mit unbekannter Funktion insgesamt 68x als Interaktionspartner von SmMOB3, PRO11N und PRO11C identifiziert. Auch andere Proteine wurden häufiger als Interaktionspartner gefunden, wie z. B. NCU06727 (SmMOB3, PRO11N, PRO11C), NCU00200 (SmMOB3, PRO11C), NCU00995 (SmMOB3, PRO11N), NCU02733 (SmMOB3. PRO11C) oder NCU09498 (PRO11N, PRO11C), jedoch mit 2-4x längst nicht so häufig wie NCU09375. Da das von NCU09375 kodierte Protein sowohl mit SmMOB3 als auch mit PRO11N und PRO11C interagierte und von allen identifizierten Interaktionspartnern am häufigsten gefunden wurde, wurde das homologe Protein Sm9375 aus S. macrospora in weiteren Studien funktionell näher charakterisiert. 


\subsection{Charakterisierung des Gens $S m 9375$ aus $S$. macrospora}

Der 980 bp Sm9375 ORF, sowie 1123 bp der zugehörigen 5'-UTR und 1404 bp der 3'-UTR wurden wie unter II Material und Methoden, 2.15 beschrieben in PCR Reaktionen unter Verwendung von abgeleiteten Primern aus dem N. crassa NCU09375 und S. macrospora wt gDNA als Matrize amplifiziert und anschließend sequenziert (Abb 21).

5 UTR (-1123 bis -1$)$

AGGTACAAGTAGTCGGCGTGCCATCGAGCCCCACGAAGAACAACAAGCATGATAAATTCATATGAGAATACCGGCGGTGGGGTTCCAGCTGAAAAAAAGAAAC AAGGATCATGGGCAAGGGGATCTTGGACTCTTGTGGTCTCTGCTGCGAACCTTTCGAACGAAACCCTTTTGCTCATTAGTATGGGCGACAGGCAGCCTGGCAG GATATGGAGCGTATGGATCGTAAGGATCGTATGTATTTTACATACCCGCGGGGCGACCCCGTACTGTGTGTGTGGTGGTTGCTGTGGCAGCGGTGTTGAGTGC TTCACTGATTCGGCCAACAAATGACATCACTGAATGTTACACAAGTGGTGGAGATATAGGAGCTGTGAAGCTATCGTCTAGTTCAACCATTCCAGGTACCCTT ACACGAACCAGACAAATGCCTTTTTGAAGGCTTTTGTTACTACATTTCAACACCCGATCGGCTTTCAAGGACTGACAACGTACACTGAAAATTATGCTCACAC CTTTCAATTACTCACTTCACGCGATCCTTGCTGGCTCCATTCAATGCAGAGAACATTCAGCTCTGTTAGCTTACACACAAATATAGCCTGTATTAAAGACACA TCATTGGTCAGTACGGGC霍TTTCTCAGAAGCTCTTGTCCTACAAGTTTTCAGTGACAGTACGGGAATACCGACCGGTCTCGCGGGCACCAACAAGCGCTTGCT CGTAGCTGAGAAGATGTGCCAGCGCAACCAGCACCCAGTCAGCCCGCCCGCGATGGTGGGCTCGCCAAGTCCTATCACGCCGTACCAACCACGATTTCCAGCC TCCCGGGTTCTAAAATGCGCAGGGTTGCATCTCAGCTTTGCATATAGGCTTCCCACCTGGATGCTCTGGAACTCGTTCGCACTCCTCCTCAGAACTTTCATCT GTGGCTGATCTGAGCTGCTGCTGCTGCTGCTGCTGACCGACTTCATCCGGAAAGCCTCATAAAAAAAAAGATCGGACGACGGGGGCTGGTACCAGACTCATCC CAGGCTCAGCTCTTATCAAACCATTTCTAACCGCATTCTTCTTACCGACTTTTACAGTTTGGTTCACCTTCCAAGCAATACAGATTTGCCGTC ORF

ATGGATAATCAGCAGTCGCATTCCCGTTTTGAGACATGGCAAGCCTTTGTGCTTTCCTTCCTGGTCTTGTCC $\begin{array}{llllllllllllllllllllllllllllllllll}M & D & N & Q & Q & S & H & S & R & F & E & T & W & Q & A & F & V & I & S & F & I & V & I & S\end{array}$ GTCCACGCTCAACAACCGTTCCTGCCCGTTGAAACAGTGAGGGCAATTAGCATCAACGACGGCAGCAGCAAC

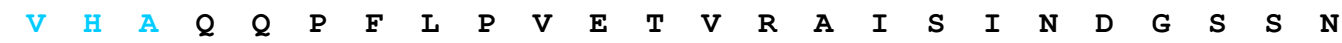
GTACTCGAAAAGCGGCAGGGATGCATCTCCAACTTCTTCAGCTGCTCAGGAGTGGGAGCTGCCTTCAGCGAC $\begin{array}{llllllllllllllllllllllll}\mathrm{V} & \mathrm{L} & \mathrm{E} & \mathrm{K} & \mathrm{R} & \mathrm{Q} & \mathrm{G} & \mathrm{C} & \mathrm{I} & \mathrm{S} & \mathrm{N} & \mathrm{F} & \mathrm{F} & \mathrm{S} & \mathrm{C} & \mathrm{S} & \mathrm{G} & \mathrm{V} & \mathrm{G} & \mathrm{A} & \mathrm{A} & \mathrm{F} & \mathrm{S} & \mathrm{D}\end{array}$ GTATGTTGCCAGTACGGCTACACCTGCGCCCTTGATCAGAGCAACCAGCCGGCCTGCTGTCCTGTAAAGTAT $\begin{array}{llllllllllllllllllllllll}\text { V } & C & C & Q & Y & G & Y & T & C & A & L & D & Q & S & N & Q & P & A & C & C & P & V\end{array}$ GTAAACAACAATATTATAGTCATACCGAACTCACTTCAAGGTTGAGTGATGAACACCTCATGTCGAAGTCCT САСТАACACCTCCCGCCCAGTGCCGTCTGCACCGGCACCGCCCCCGCCGGCTTCGCCGCCCCAAGCCCGACT $\begin{array}{llllllllllllllllll}\mathbf{N} & \mathbf{A} & \mathbf{V} & \mathbf{C} & \mathbf{T} & \mathbf{G} & \mathbf{T} & \mathbf{A} & \mathbf{P} & \mathbf{A} & \mathbf{G} & \mathbf{F} & \mathbf{A} & \mathbf{A} & \mathbf{P} & \mathbf{S} & \mathbf{P} & \mathbf{T}\end{array}$ GGTCAGTACGGCGTCACGATTGTGGTACCCGGCGGCGAGGGAACGACCGTGGGTGCTAATGTCGGGACTACG

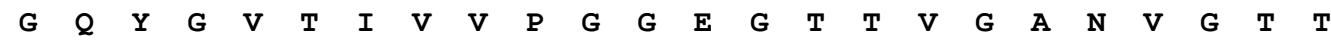
GTCGGGCCTGAGAGTGCTTCTAGGATTTGTAAGTCTCACCTGGCTCTCACCTCCCCTGCTGGTCTTCGGACA $\begin{array}{lllllllllllllll}V & G & P & E & S & A & S & R & I\end{array}$ AAAAAACTTTTAATTCATTTTCTTCGTGATCTGGAGCCGGACGTGTCGCTGACTGTTTCTTTTTTTTCAACG TCAAAGGCAGCAGCTTGTCAAGCGTAGCTTGCCACGGTCTAGAGAACAACATGTGCTCAATGACGGCCACA $\begin{array}{llllllllllllllllllllll}C & S & S & L & S & S & V & A & C & H & G & L & E & N & N & M & C & S & M & T & A & T\end{array}$ GCCGCCGCGGCTTCTACTTTGGCACGGGTGCGCCTAACCGCGCGTCCTCGAAGAGAGGCTATTACCGGTCTT $\begin{array}{lllllllllllllllllllllllll}\mathbf{A} & \mathbf{A} & \mathbf{S} & \mathbf{G} & \mathbf{F} & \mathbf{Y} & \mathbf{F} & \mathbf{G} & \mathbf{T} & \mathbf{G} & \mathbf{A} & \mathbf{P} & \mathbf{N} & \mathbf{R} & \mathbf{A} & \mathrm{S} & \mathrm{S} & \mathbb{K} & \mathbf{R} & \mathrm{G} & \mathbf{F} & \mathbf{T} & \mathrm{G} & \mathrm{L}\end{array}$ CTGGTTGCTGCTGTTGTGGTAGCGACGGTGTCAGGTCTTCTCTGA

3'UTR (981 bis 2384)

TTCTGCACTCTCGGGAAGGCGCTTCCCCCTATCGGTATTGAGATGATCGGTGATGGACACTTGAGAGGGAAAGTAACGAACGAATGGAGTGATGATGAGGAAG TGCGAAAGAGGTGCCTTCAACGAGGCCAGTACCTTTCTTTTCTCATTTTGTGGGTTACGATATCAACGAAGTCATGAATAAATCCAAGGAGTCATGAGATCAG ATACTTTACTACCTTCATCTGTACGTATGCAATCATGATTAGCAAGATTTCAAAGTTTGTACAAAAAACGATCACAAAATGCGAAGGTGATGGAGACGTTAAG TGAATGCCAAGTCAAAGCGCAAGTTCACGTAAAGATGAAGAGTGAGTGACCAAAACTGGATGGGCGAAAAGACATATATATATCGCAAGGCACAAAATCAAAG CCAGCAAGGAAAAGAGGGACATTATGAAATCTCCAAAACATAGCAGATTTTTGTAGCCGCTTGTGTACGCCATCGCTAAAACTCTCAGAACCCCAAGTAAGCT ATATAACCGTTTTCCGATATCCATCTAGACTGACAACGAAAAGGGCAACAAAACCACATACAAAAAAAAAAAAGAGCAAAAGGTAACAAAGGGAACTTGTTAT ACCCGAGCTAGCTCCCCATTACTTCTTTTCCTTTTCATTTCACATCCCTGAGTACCTGGAGGTGTTTCCCGTTTGACTGCTGCCTCGGGATGTCACGACCATA GTCCAGCCTCCGCCACGCTTCCTAACAATCAGCTCGTGCCCTGCTCACCTATTTACGTCCCCTATCACGACCCGTACTTCGTCACCCCGATCCGTCTGATCGG TTAGCGTCCGAACTCGATCTCGCTACCCATTGAGGACTAGAGTCCTTTGCATATGCTTCAGCAGCTGCACCGCCAGATAGCGCTGGCTGGTCCGGTGCTGTTG TTGTTGTTGTTGTTGCGGGCCCCCGGATTCTAGGACTGGCAGACCCGGCGGTGGTGTGTTACTAATAGGGCCGGAGCCGCTGCGTGTGTGATGGTAAGAATTG CGCTTGGAACTTCTCCGCGGCGGCGAAAGAAGAGGGGACGGATCGTTGTCGGCCTCATTCGAAGTCCGGTTACCGCGGCGGGTCACTGTCTGAGCCCTACTTG ACTGGCTAACTGTTGCGAGGCCCGGTTCAGCAGGCAAATTTTCCGAATCGTGGTATGCTTCCGTTTCGTCTCGTGCGTCATCGTTGGTACCCTCTGCTGCCCT AAGAGGCACCGCTTCTGCTGCTGCACGATCTGCTGTGTCCCGGTCTGCATTGGTCTGTCGCACATTATCCTCTTCGTCGGATTCAATCGGCCCATTACGGATC ACGCCCATCGCCACTGGTATCCCTTCTGGCGGCGACTCATCCTCATAGTCGACCGCTCCGGTACG

Abb. 21: Nukleotid- und Aminosäuresequenz des Sm9375 Gens aus Sordaria macrospora.

Der Bereich stromaufwärts des gelb markierten ATG-Start-Kodons (5'-UTR) umfasst 1123 bp und der Bereich stromabwärts des ebenfalls gelb markierten TGA-Stop-Kodons 1404 bp (3'-UTR). Der putative Transkriptionsstart an Position -487 ist schwarz hinterlegt. 


\section{(weiter zu Abb. 21)}

Der ORF weist eine Länge von 980 bp und die abgeleitete Proteinsequenz (Fettdruck) 253 AS auf. Die beiden Intronsequenzen sind grau hinterlegt. Die putative Signalsequenz und der vorhergesagte Sequenzbereich, welcher post-translational durch den GPI-Anker ersetzt wird, sind jeweils blau markiert. Die GPI-Ankerstelle ( $\omega$-,,site“) ist rot markiert.

Mit dem „Promotor Prediction program” wurde ein Transkriptionsstart 487 Nukleotide stromaufwärts des putativen Sm9375 ATG-Start-Codons vorhergesagt (Reese 2001). Die Expression des Sm9375-Gens wurde durch die Amplifikation des gesamten Sm9375 cDNAORFs aus der S. macrospora cDNA-Bank mit den Primern Sm9375-cDNAf2 und Sm9375cDNAr nachgewiesen. Ein Vergleich der genomischen und der cDNA-Sequenz bestätigte ein 96 bp Intron von Nukleotid-Position 285 bis 380 und ein 122 bp Intron von Position 677 bis 798 (Daten nicht gezeigt).

Die aus dem Sm9375 cDNA-ORF abgeleitete Sm9375-Proteinsequenz ist 253 AS lang. Das putative Molekulargewicht beträgt $26 \mathrm{kDa}$ und der vorhergesagte isoelektrische Punkt 5.

Interessanterweise ergab die Untersuchung der Sm9375-Proteinsequenz mit den Programmen „SignalP“ und „big-PI Predictor“ die Vorhersage einer putativen Signalsequenz, welche die Aminosäuren 1-27 umfasst und eine GPI-Ankerstelle an AS Position 228 (Bendtsen et al. 2004, Eisenhaber et al. 1998). Beide Sequenzstrukturen charakterisieren Sm9375 als putatives GPIgeankertes Protein.

Eine BLAST-Datenbank-Suche ergab, dass nah verwandte Organismen von S. macrospora wie z. B. N. crassa und C. globosum, sowie entfernter verwandte filamentöse Pilze wie Magnaporthe oryzae und F. graminearum in ihren Genomen ein homologes Sm9375-Protein kodieren. Diese Proteine weisen wie Sm9375 aus S. macrospora ebenfalls jeweils eine putative Signalsequenz und eine GPI-Ankerstelle auf (Daten nicht gezeigt). Hemiascomycetische Hefen, Basidiomyceten und höhere Eukaryoten kodieren dagegen kein homologes Sm9375-Protein.

Das Alignment in Abbildung 22A zeigt die am stärksten konservierten Sequenzbereiche von Sm9375 aus S. macrospora und den homologen Proteinen aus verwandten Ascomyceten. Wie der Vergleich in Abb. 22 B zeigt, betrug die AS-Identität der jeweiligen Sequenzen zueinander zwischen $37 \%$ und $91 \%$. Die Signalsequenzen und die Sequenzbereiche, welche posttranslational durch den GPI-Anker ersetzt werden, wurden nicht in das Alignment einbezogen, da diese untereinander nur eine geringe Sequenzidentität aufweisen (15-51 \% für die Signalsequenz und 13-88 \% für den GPI-Bereich). 


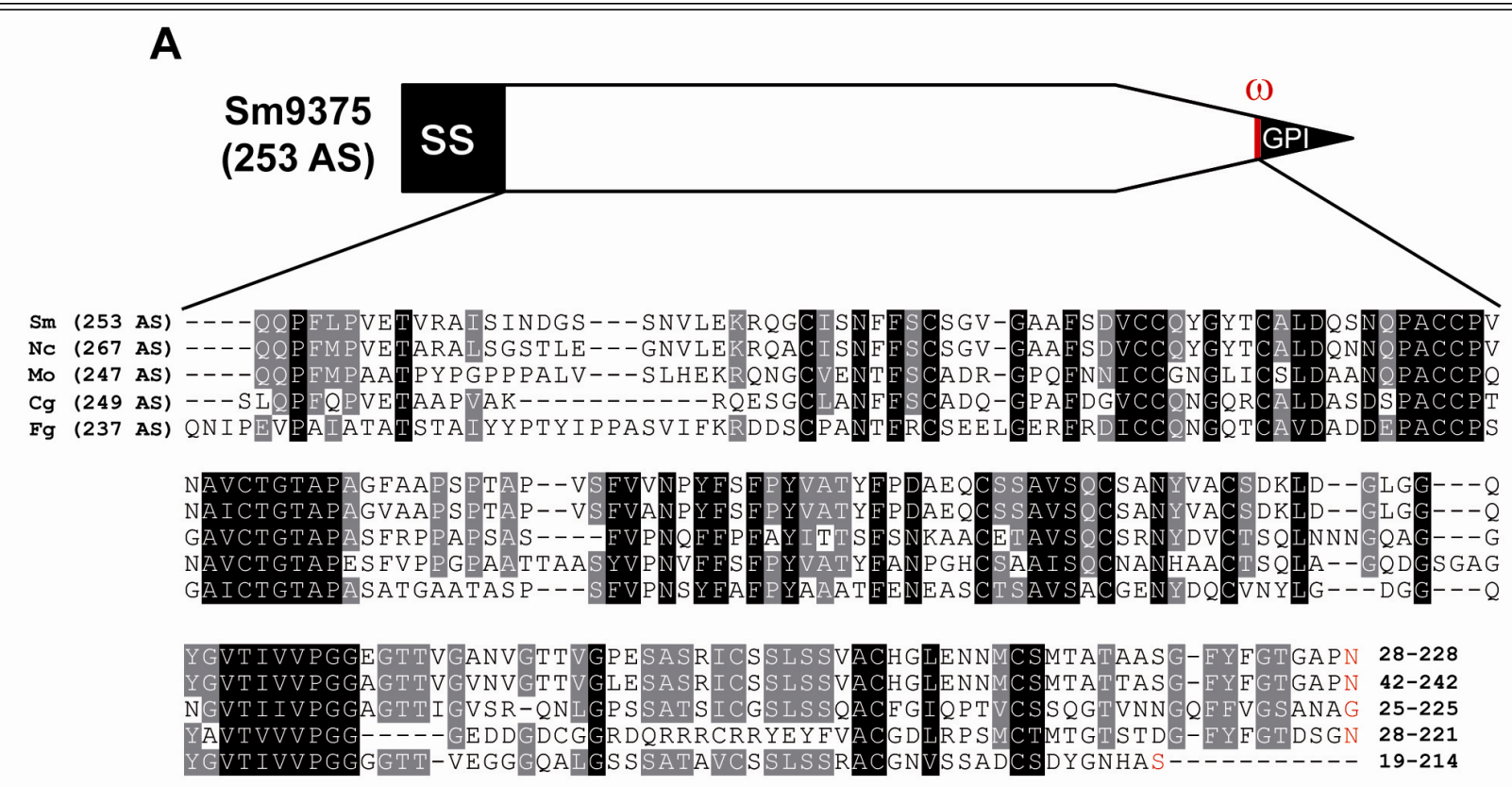

B

$\begin{array}{llllll} & \text { Sm } & \text { Nc } & \text { Mo } & \text { Cg } & \text { Fg } \\ \text { Sm } & 100 & & & & \\ \text { Nc } & 91 & 100 & & & \\ \text { Mo } & 46 & 46 & 100 & & \\ \text { Cg } & 48 & 47 & 41 & 100 & \\ \text { Fg } & 44 & 45 & 45 & 37 & 100\end{array}$

Abb. 22 Multipler Sequenzvergleich von Sm9375 aus $S$. macrospora und homologen Proteinen aus verwandten filamentösen Ascomyceten. (A) Der weiße Pfeil zeigt schematisch die S. macrospora Sm9375-Proteinstruktur. Die putative Signalsequenz (ss) und der durch den GPI-Anker ersetzte Sequenzbereich (GPI) sind schwarz eingefärbt. Die vorhergesagte GPI-Ankerstelle $(\omega)$ ist rot gekennzeichnet. Das Sequenz-Alignment wurde mit dem Programm „ClustalX“ berechnet und mit der Anwendung „GeneDoc“ dargestellt (Thompson et al. 1997). Die AS, welche als putative GPIAnkerstellen dienen, sind rot gekennzeichnet. Schwarz hinterlegte AS sind in allen verglichenen ProteinSequenzen konserviert, AS, die in vier Sequenzen konserviert sind, sind grau markiert. Striche symbolisieren, dass die angegebenen AS anderer Organismen in dieser Sequenz nicht enthalten sind. Die jeweilige AS-Region, die für das Alignment verwendet wurde ist auf der rechten Seite angegeben. Abkürzungen und Accession-Nummern: Sm-Sordaria macrospora (CBI52865), Nc-Neurospora crassa (XP_963746.2), Mo-Magnaporthe oryzae (XP_360261.1), Cg-Chaetomium globosum (XP_001229251.1), Fg-Fusarium graminearum (FGSG_01368.3). (B) Die in (A) gezeigten Sequenzen wurden paarweise verglichen und die AS-Identität in \% angegeben. 


\subsection{Konstruktion eines $S$. macrospora $S m 9375$ Knockout-Stamms und der Doppelknockout-Stämme $\Delta \mathrm{Sm} 9375 / \Delta$ pro11 und $\Delta \mathrm{Sm} 9375 / \Delta$ Smmob3}

Über die Funktion des Proteins Sm9375 aus S. macrospora und der dazu homologen Proteine aus anderen filamentösen Ascomyceten ist bislang nichts bekannt. Die in silico Untersuchung charakterisierte Sm9375 als putatives GPI-geankertes Protein. Die Interaktion des von NCU09375 kodierten Proteins aus N. crassa mit den S. macrospora Proteinen SmMOB3 und PRO11 ließ eine mögliche Funktion von Sm9375 bei der sexuellen Differenzierung vermuten. Um den Einfluss von Sm9375 auf die Fruchtkörperentwicklung zu analysieren wurde daher ein $\Delta$ Sm9375 Knockout-Stamm hergestellt (Abb. 23).

Der Sm9375-ORF wurde bis auf die Nukleotidsequenz von Position 855 bis 980 (AS 231-253) mittels homologer Rekombination durch die $h p h$-Kassette ersetzt (Abb. 23A). Nach der Transformation der Sm9375-Deletionskassette in den $\Delta$ ku70-Stamm konnten zwei heterokaryotische Hygromycin- und Nourseothricin-resistente Primärtransformanten isoliert und durch PCR-Analyse verifiziert werden (Daten nicht gezeigt). Der $\Delta$ ku70-Hintergrund in der Primärtransformante wurde, wie für die Herstellung des $\Delta$ Smmob3- und $\Delta$ pro11-KnockoutStamms beschrieben, ausgekreuzt und der resultierende homokaryotische $\Delta$ Sm9375-Stamm durch PCR bestätigt (Abb. 23B). Zur Herstellung der Doppelknockout-Stämme wurde der $\Delta$ Sm9375-Stamm jeweils mit dem $\Delta$ pro11- und dem $\Delta$ Smmob3-Stamm gekreuzt und Einzelsporen aus den rekombinanten Kreuzungsperithezien isoliert. Die aus den isolierten Einzelsporen gekeimten Myzelien wurden auf Hygromycin-haltigem Medium kultiviert und diejenigen Stämme, welche Hygromycin-Resistenz zeigten mittels einer PCR-Analyse auf den Doppelknockout-Genotyp getestet (Abb. 23C). Hierzu wurden spezifische $\Delta \operatorname{Sm} 9375, \Delta$ pro11 und $\Delta$ Smmob3 DNA-Fragmente mit den in Abbildung 23C angegebenen Primer-Kombinationen aus der gDNA der Doppelknockout-Stämme amplifiziert.

Im Anschluss wurden die Phänotypen der mittels PCR-Analyse bestätigten $\Delta$ Sm9375, $\Delta \mathrm{Sm} 9375 / \Delta$ pro1 1 und $\Delta \mathrm{Sm} 9375 / \Delta$ Smmob3 Stämme morphologisch untersucht. 


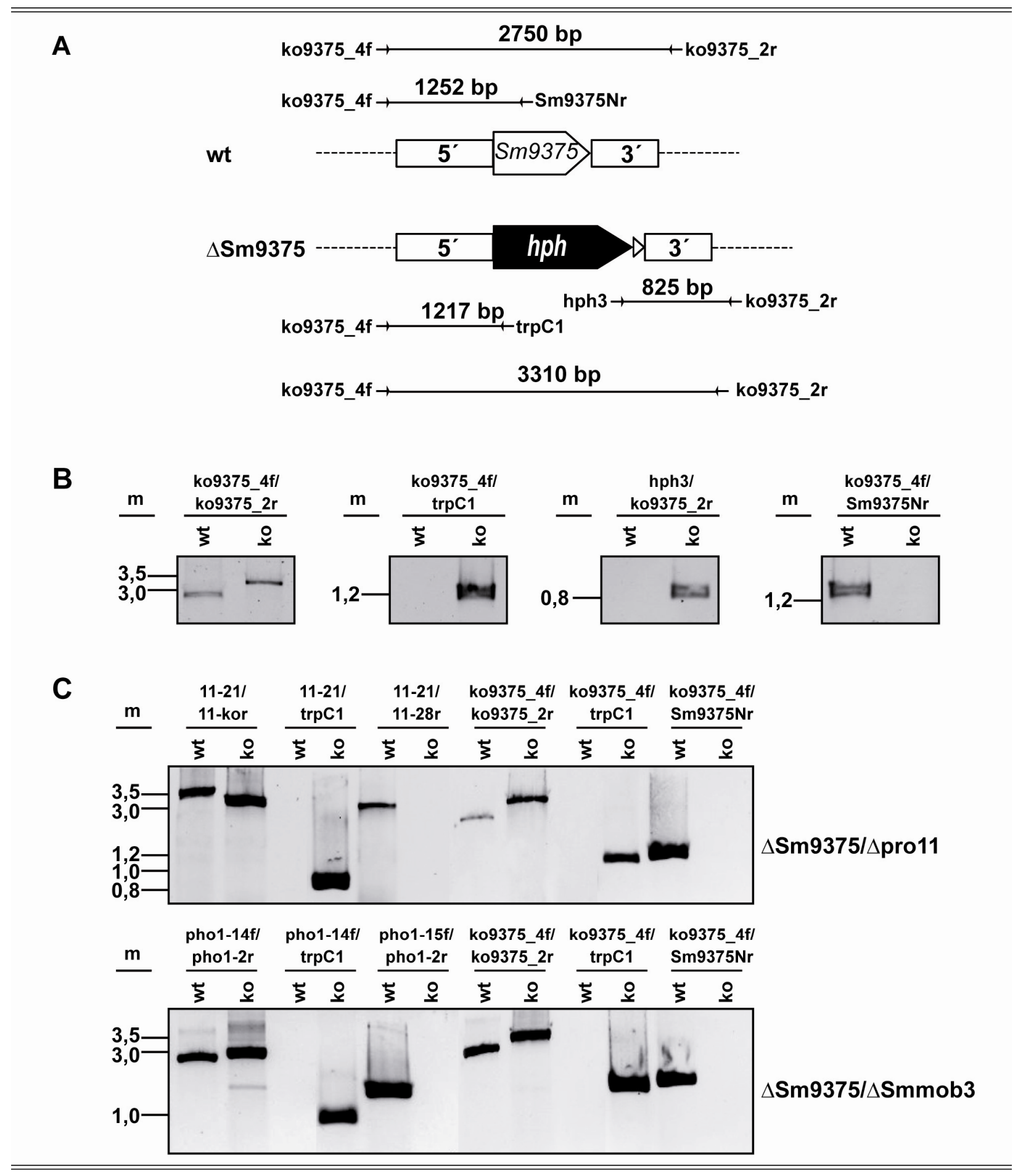

Abb. 23 Konstruktion eines $\Delta$ Sm9375 Knockout-Stamms und Herstellung der DoppelknockoutStämme $\Delta$ Sm9375/ $\Delta$ pro11 und $\Delta$ Sm9375/ $\Delta$ Smmob3. (A) Schema des $S m 9375$-Lokus im wt und im $\Delta$ Sm9375-Stamm nach der homologen Integration der hph-Kassette (schwarzer Pfeil). Es sind der Sm9375-ORF (weißer Pfeil), die 5'- und 3'-flankierenden Bereiche (schwarz umrandete Boxen) und die weiter außen liegenden genomischen Sequenzbereiche (gestrichelte Linien) dargestellt. Die Bezeichnung und Position der verwendeten Primer (kleine schwarze Pfeile) und die Größen in bp der resultierenden Amplifikate in der PCR-Analyse sind angegeben. (B) Verifikation des $\triangle$ Sm9375-Stamms durch PCR. Die Größen der mit den verwendeten Primern erhaltenen Fragmente sind in (A) angegeben. (C) Verifikation

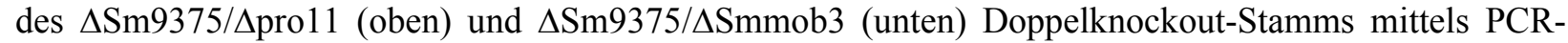
Analyse. Die Positionen der verwendeten $\Delta$ pro11- und $\Delta$ Smmob3-spezifischen Primer und die resultierenden Fragmentgrößen sind in Abb. 9 und Abb. 16 angegeben. 


\subsection{Morphologische Charakterisierung des $S$. macrospora $\Delta$ Sm9375 Stamms und der $\Delta$ Sm9375/ $\Delta$ pro11 und $\Delta$ Sm9375/ $\Delta$ Smmob3 Doppelknockout-Stämme}

Der Phänotyp des hergestellten $\Delta$ Sm9375-Stamms und der Doppelknockout-Stämme wurde makroskopisch analysiert (Abb. 24). Der $\Delta$ Sm9375-Stamm zeigte bezüglich der sexuellen Differenzierung eine leichte Beeinträchtigung. Es wurden zwar Fruchtkörper ausgebildet, die Anzahl der gebildeten Perithezien im Vergleich zu dem wt-Stamm war jedoch deutlich geringer (Abb. 24A). Diese Beobachtung wurde durch das Auszählen der produzierten Perithezien beider Stämme pro $\mathrm{cm}^{2}$ SWG-Medium verifiziert (Abb. 24B). Der wt produzierte durchschnittlich 330 ( \pm 109$)$ Perithezien $/ \mathrm{cm}^{2}$. Die Anzahl der gebildeten Perithezien war im Vergleich dazu im $\Delta$ Sm9375-Stamm um ca. die Hälfte reduziert $\left(168 \pm 15\right.$ Perithezien $\left./ \mathrm{cm}^{2}\right)$. Die Wuchsrate von $\Delta$ Sm9375 war nicht beeinträchtigt. Der Knockout-Stamm zeigte in der Rennrohr-Analyse mit $32( \pm 3) \mathrm{mm} / \mathrm{d}$ eine nahezu identische tägliche Wuchsrate wie der wt $(33 \pm 5 \mathrm{~mm} / \mathrm{d})$. Dagegen unterschied sich die Produktion der Biomasse des $\Delta$ Sm9375-Stamms deutlich von der des wt. Während der wt ein Trockengewicht von $7( \pm 1) \mathrm{mg}$ Myzel/ml SWG aufwies, produzierte der $\Delta \mathrm{Sm} 9375 \mathrm{Stamm} 2( \pm 0,4) \mathrm{mg}$ Myzel/ml, was einer Reduktion um $71 \%$ entspricht.

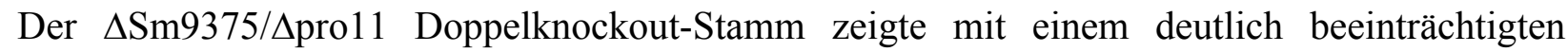
vegetativen Wachstum einen ähnlichen Phänotyp wie der $\Delta$ pro11-Stamm. Die Analyse der täglichen Wuchsrate $(12 \pm 3 \mathrm{~mm} / \mathrm{d})$ und der produzierten Biomasse $(1 \pm 0,8 \mathrm{mg} / \mathrm{ml})$ des $\Delta$ Sm9375/Dpro11-Stamms bestätigten diese Beobachtung. Diese Ergebnisse entsprachen in etwa den für den $\Delta$ prol1-Stamm ermittelten Daten $(8 \pm 3 \mathrm{~mm} / \mathrm{d}$ und $1 \pm 0,2 \mathrm{mg} / \mathrm{ml})$. Im Gegensatz zu

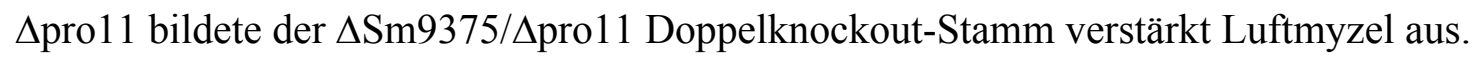

Bei dem $\Delta$ Sm9375/ $\Delta$ Smmob3 Doppelknockout-Stamm konnte die Bildung von Fruchtkörpern beobachtet werden. Die Anzahl der Fruchtkörper war jedoch mit $40( \pm 9)$ Perithezien/ $/ \mathrm{cm}^{2}$ im Vergleich zum wt und dem $\Delta$ Sm9375-Stamm deutlich reduziert (Abb. 24B). Darüber hinaus produzierte der Doppelknockout-Stamm ein ausgeprägtes Luftmyzel (Abb. 24A). Die Wuchsrate von $\Delta$ Sm9375/ $\Delta$ Smmob3 unterschied sich mit $29( \pm 5) \mathrm{mm} / \mathrm{d}$ nicht deutlich von der Wuchsrate des $\Delta$ Sm9375-Stamms und der Doppelknockout-Stamm zeigte darüber hinaus mit $3( \pm 0,7) \mathrm{mg} / \mathrm{ml}$ eine ähnliche Biomasse-Produktion wie $\Delta \mathrm{Sm} 9375$. 


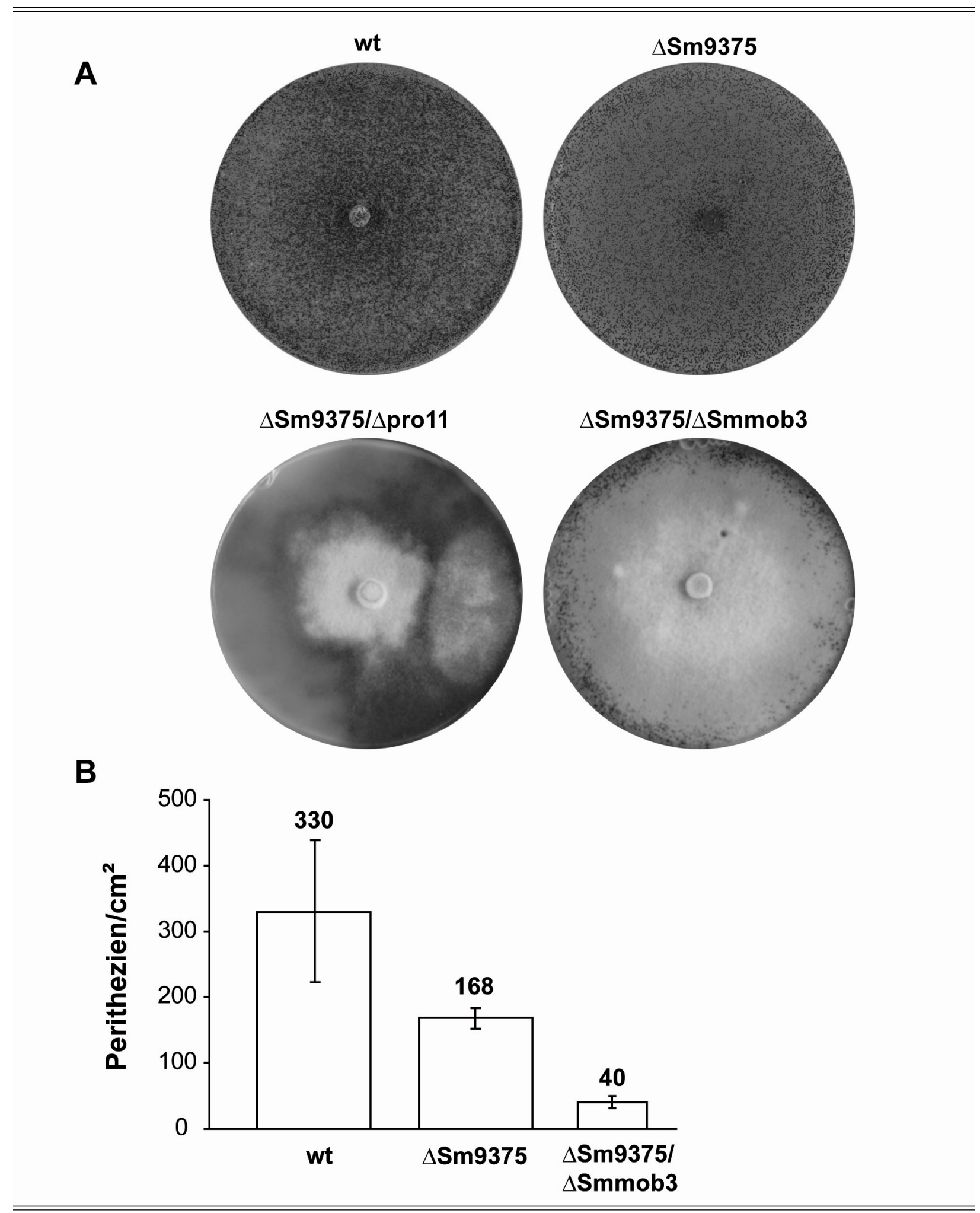

Abb. 24 Makroskopische Analyse der Fruchtkörper- und Ascosporen-Entwicklung der $S$. macrospora Stämme wt, $\Delta \mathrm{Sm} 9375, \Delta \mathrm{Sm} 9375 / \Delta$ pro11 und $\Delta \mathrm{Sm9375} / \Delta \operatorname{Smmob3}$. (A) Phänotypische Übersichtsaufnahme der Stämme wt, $\Delta$ Sm9375, $\Delta$ Sm9375/ pro11 und $\Delta$ Sm9375/ $\Delta$ Smmob3 nach zehn tägiger Kultivierung auf SWG-Festmedium. (B) Die von den Stämmen wt, $\Delta$ Sm9375 und $\Delta$ Sm9375/ $\Delta$ Smmob3 gebildeten Perithezien wurden nach sieben Tagen Inkubation auf SWG-Festmedium pro $\mathrm{cm}^{2}$ ausgezählt. Die Standardabweichungen sind als Fehlerbalken angegeben. 
Bei der mikroskopischen Analyse der gebildeten sexuellen Strukturen wurden keine Unterschiede zwischen dem wt und den Stämmen $\Delta$ Sm9375 und $\Delta$ Sm9375/ Smmob3

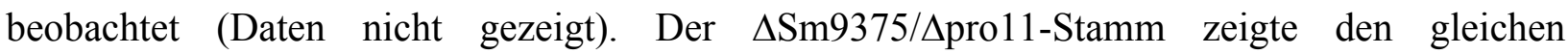
mikroskopischen Phänotyp wie $\Delta$ pro11 (Daten nicht gezeigt).

Ein möglicher Einfluss von Stress-induzierenden Agenzien wurde mittels Kultivierung des $\Delta$ Sm9375-Stamms und des wt auf SWG-Festmedium mit Zusatz verschiedener Konzentrationen $\mathrm{H}_{2} \mathrm{O}_{2}$, SDS, $\mathrm{NaCl}, \mathrm{KCl}$ oder Sorbitol getestet. Im Vergleich zum wt konnten bei dem $\Delta \mathrm{Sm} 9375$ Stamm jedoch keine Abweichungen im Hinblick auf die vegetative oder sexuelle Entwicklung beobachtet werden (Daten nicht gezeigt).

\section{$4 \quad$ Lokalisierung der Proteine SmMOB3 und PRO11}

Um einen erweiterten Einblick in die zelluläre Funktion der S. macrospora Proteine SmMOB3 und PRO11 zu gewinnen, wurden die Proteine wie unter II Material und Methoden, 2.21 beschrieben mit dem rot fluoreszierenden DsRed-Protein aus der Koralle Discosoma sp. fusioniert und die Lokalisierung der Fusionsproteine in den Hyphen mittels Fluoreszenzmikroskopie untersucht (Abb. 25).

Darüber hinaus wurden zum Vergleich verschiedene Zellkompartimente bzw. -organellen fluoreszenzmikroskopisch sichtbar gemacht. So wurde in der Transformante wt_gpd-DsRed ${ }^{\text {ect }}$, welche das DsRed-Protein überexprimierte, eine gleichmäßige cytoplasmatische Fluoreszenz in den Hyphen detektiert. Mit dem Fluoreszenzfarbstoff DAPI wurden im wt-Stamm spezifisch die Zellkerne angefärbt.

Zur Visualisierung der Mitochondrien und Peroxisomen wurden die Plasmide pMito-DsRed und pDsRed-SKL in den S. macrospora wt Stamm transformiert. Das Plasmid pMito-DsRed enthält die mitochondriale Zielsequenz des S. macrospora cas2-Gens fusioniert an DsRed. Die korrespondierende Transformante wt_gpd-Cas:DsRed ${ }^{\text {ect }}$ zeigte eine Fluoreszenz in tubulären und runden Strukturen, welche charakteristische Formen für die Mitochondrien in pilzlichen Hyphen sind (Elleuche und Pöggeler 2009). Das Plasmid pDsRed-SKL kodiert für eine Fusion bestehend aus dem DsRed-Protein und dem SKL (Serin/Lysin/Leucin)-Tripeptid, welches ein klassisches PTS1-Signal („Peroxisome Targeting Signal Type 1“) für den peroxisomalen Matrix-Import darstellt (Elleuche und Pöggeler 2008). Die Peroxisomen erschienen in der Transformante wt_gpd-DsRed:SKL als hell fluoreszierende Punkte. 


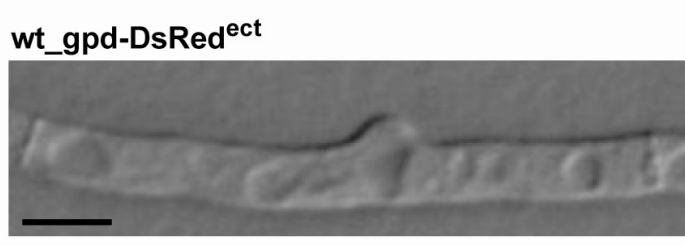

wt

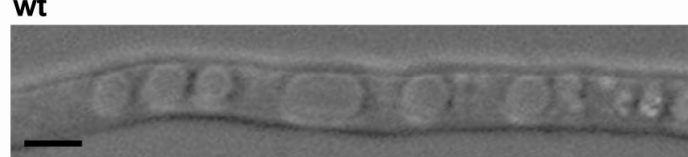

wt_gpd-Cas:DsRed ${ }^{\text {ect }}$

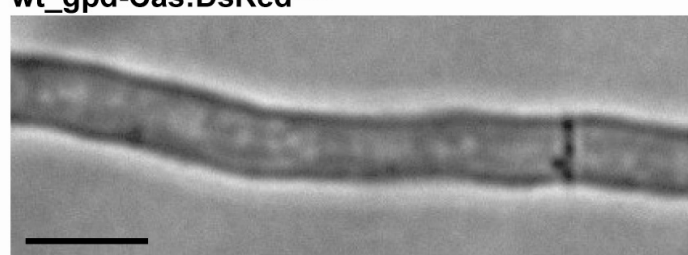

wt_gpd-SKL:DsRed ${ }^{\text {ect }}$

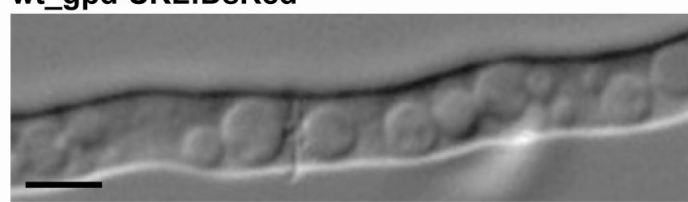

wt_ccg1-Lifeact:TagRFP ${ }^{\text {ect }}$

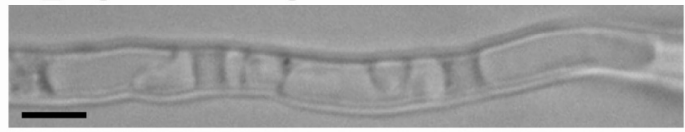

$\triangle$ Smmob3_gpd-SmMOB3:DsRed ${ }^{\text {ect }}$

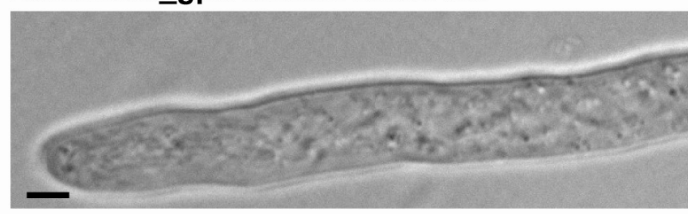

Apro11_PRO11:DsRed ${ }^{\text {ect }}$

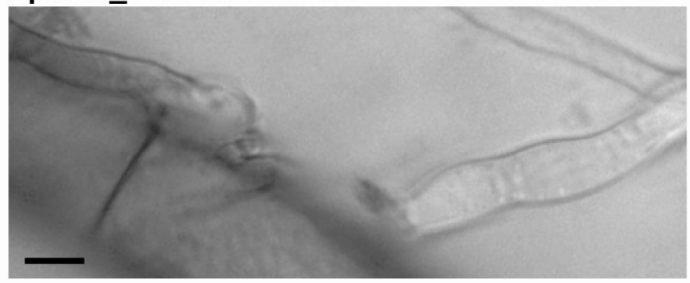

DsRed (Cytoplasma)

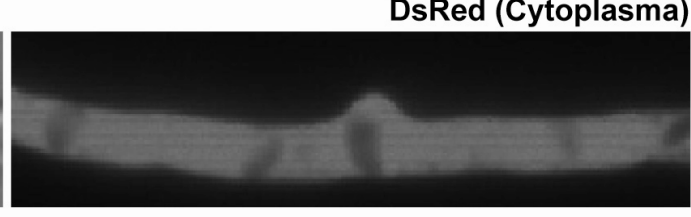

DAPI (Zellkerne)

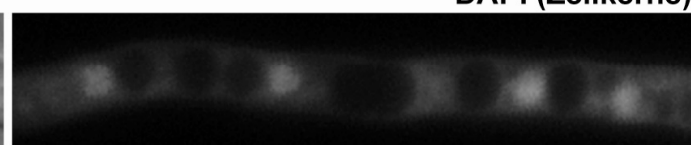

Cas:DsRed (Mitochondrien)

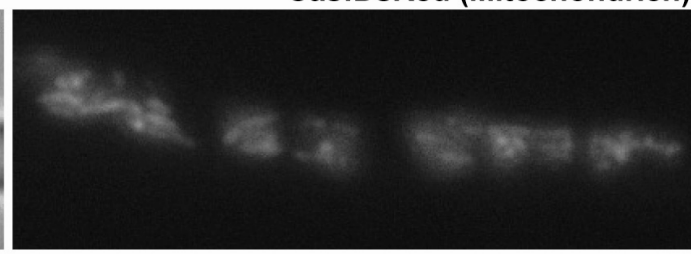

SKL:DsRed (Peroxisomen)

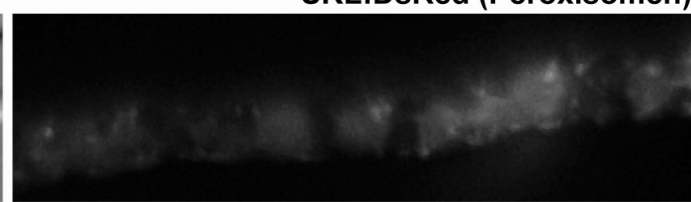

Lifeact:TagRFP (Aktin)

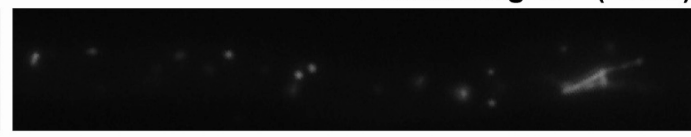

SmMOB3:DsRed

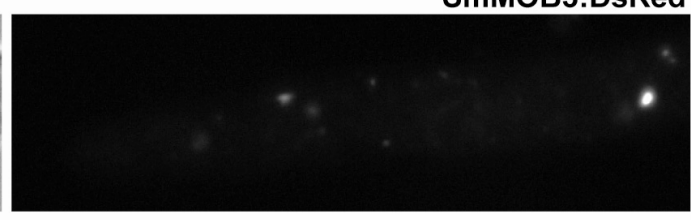

PRO11:DsRed

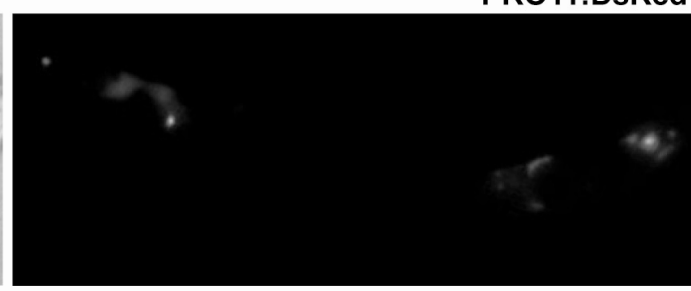

Abb. 25 Lokalisierung der Fusionsproteine SmMOB3-DsRed und PRO11-DsRed mittels Fluoreszenzmikroskopie. Links.: Aufnahmen von Hyphen unter differentiellem Interferenzkontrast. Rechts: Aufnahmen derselben Hyphen nach Anregung der DsRed-(Fusions-)Proteine mit Licht der Wellenlänge $558 \mathrm{~nm}$ bzw. des DAPI-Farbstoffs mit Licht der Wellenlänge 365 nm. Der jeweils angegebene Maßstab beträgt $5 \mu \mathrm{m}$.

Für die fluoreszenzmikroskopische Darstellung von F-Aktin wurde der S. macrospora wt-Stamm mit dem Plasmid pAL4-Lifeact transformiert. Das Plasmid kodiert für ein Lifeact-TagRFPFusionsprotein. Lifeact repräsentiert die ersten 17 AS des Abp140p Proteins, ein nicht essentielles S. cerevisiae Protein, welches spezifisch Aktin-Filamente bindet (Riedl et al. 2008). Das monomere rot-orange fluoreszierende TagRFP ist eine modifizierte Variante des 
ursprünglichen RFP-Proteins aus der See-Anemone Entacmaea quadricolor (Merzlyak et al. 2007, Shaner et al. 2008). Die Transformante wt_ccg1-Lifeact:TagRFP ${ }^{\text {ect }}$ zeigte Fluoreszenz in runden und filamentösen Aktin-Strukturen.

Die fluoreszenzmikroskopische Untersuchung der SmMOB3- und PRO11-DsRed Proteine in den Transformanten $\Delta$ Smmob3_gpd-SmMOB3:DsRed ${ }^{\text {ect }}$ und $\Delta$ pro11_PRO11:DsRed ${ }^{\text {ect }}$ ergab eine Lokalisierung der Fusionsproteine in vesikulären Strukturen. Die Anzahl und Größe dieser Vesikel in $\Delta$ Smmob3_gpd-SmMOB3:DsRed ${ }^{\text {ect }}$ entsprach etwa den runden Aktin-Strukturen, welche in der Transformante wt_ccg1-Lifeact:TagRFP ${ }^{\text {ect }}$ beobachtet werden konnten. In der Dpro11_PRO11:DsRed ${ }^{\text {ect }}$ Transformante waren die vesikulären Strukturen im Gegensatz dazu nicht so zahlreich vertreten. 


\section{DISKUSSION}

\section{Das S. macrospora Protein PRO11 interagiert mit SmMOB3, einem konservierten Protein aus der Mob-Familie}

\subsection{Das PRO11, „WD-repeat"-Motiv interagiert mit dem SmMOB3 N-Terminus}

Im Rahmen einer Hefe Two-Hybrid Analyse wurde eine Interaktion des N-terminalen Bereichs von SmMOB3 (AS 1-144) mit dem „WD-repeat“ des PRO11-Proteins (AS 282-845) gefunden.

Das SmMOB3-Protein aus S. macrospora kann auf Grund der in silico analysierten strukturellen Charakteristika eindeutig in die Gruppe der Mob3-Proteine eingeordnet werden (Vitulo et al. 2007). Die Mob-Domäne des SmMOB3-Proteins weist mit 24 \% eine ähnliche Homologie zu der Konsensus-Sequenz wie Mob3-Proteine aus anderen Organismen auf (21-26 \%) (I Einführung, $A b b$. 2). Die Cystein- und Histidin-Reste, welche die Zink-Bindestelle bilden sind auch in SmMOB3 konserviert und darüber hinaus zeigt ein Vergleich der Sekundärstrukturen von Mob1Proteinen mit SmMOB3 eine nahezu identische Anordnung der Globulärstruktur-bildenden Helices in der konservierten Mob-Domäne (Abb. 26).

\section{SmMOB3 (AS 50-281)}

HO

50

RRIHPGTKAADMAAGPPLVPLHQLDSAFQLQEHLAALHWHHTAGNTTP
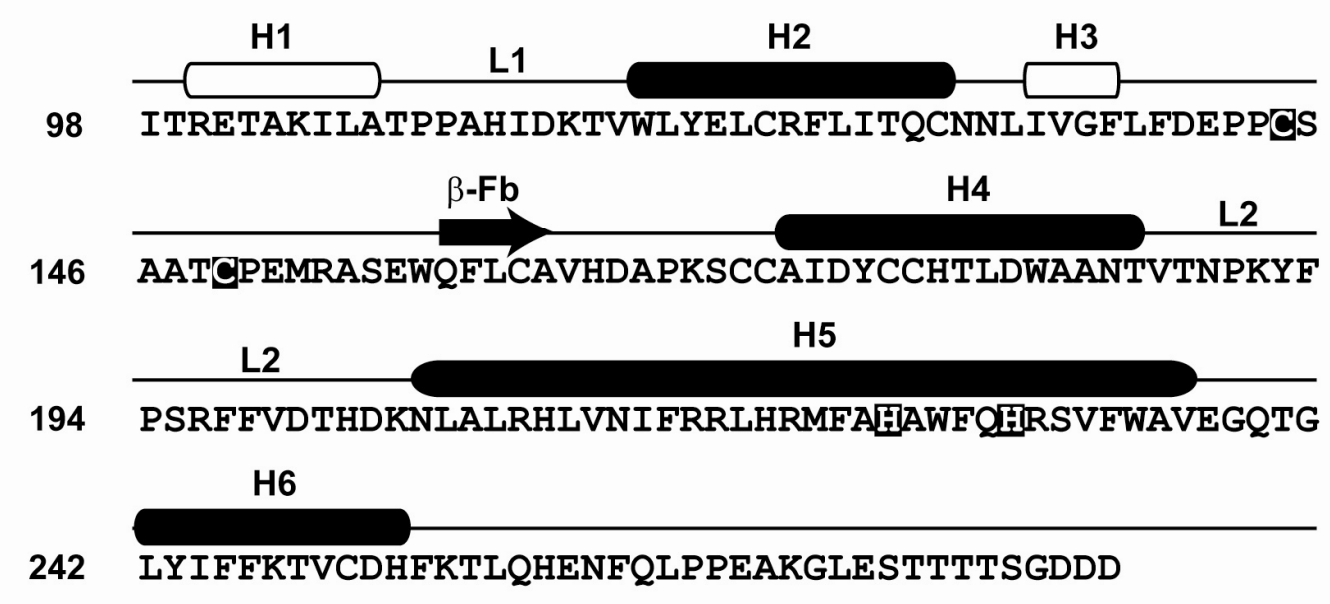

Abb. 26 Übersicht der putativen Sekundärstruktur von SmMOB3. Der AS-Sequenzausschnitt repräsentiert die konservierte Mob-Domäne von SmMOB3. Die mit dem Programm „PSIPRED“ vorhergesagten Sekundärstrukturelemente sind über der AS-Sequenz eingezeichnet (Bryson et al. 2005). Wie bei Mob1-Proteinen wird die globuläre Kernstruktur vermutlich aus den Helices H2, H4, H5 und H6 gebildet. Die zwei zusätzlichen Helices, wurden in Analogie zu H. sapiens und S. cerevisiae mit H0 und $\mathrm{H} 1$ bezeichnet. Die konservierten Cystein- und Histidin-Reste der Zink-Bindestelle sind schwarz unterlegt. Abkürzungen: L-,Loop“, $\beta$-Fb- $\beta$-Faltblatt. 
Dies lässt vermuten, dass die Mob-Domäne der Mob3-Proteine ebenfalls eine globuläre Tertiärstruktur einnimmt. Darüber hinaus werden für das $S$. macrospora SmMOB3-Protein zwei weitere $\alpha$-Helices vorhergesagt.

Auch das S. cerevisiae Mob1p-Protein und die Mob1-Proteine aus H. sapiens und X. laevis besitzen im N-terminalen Bereich weitere Strukturelemente, nämlich eine $\alpha$-Helix (H0) und zwei $\beta$-Stränge (S. cerevisiae) und eine $\alpha$-Helix H1 (H. sapiens und X. laevis) (Mrkobrada et al. 2006, Stavridi et al. 2003, Ponchon et al. 2004). Die $\alpha$-Helix H0 vermittelt in $S$. cerevisiae die Homodimerisierung des Moblp-Proteins (Mrkobrada et al. 2006).

Für SmMOB3 konnte in der Hefe Two-Hybrid Studie keine Homodimerisierung festgestellt werden. Es ist jedoch vorstellbar, dass die detektierte Interaktion von SmMOB3 und PRO11 über die beiden Helices $\mathrm{H} 0$ und $\mathrm{H} 1$ erfolgt, da das eingesetze Two-Hybrid Konstrukt für diesen Bereich des SmMOB3-Proteins kodiert. Allerdings kodiert das Konstrukt auch noch für die Strukturelemente L1, H2 und H3, so dass ein weiteres SmMOB3-Verkürzungskonstrukt, welches z. B. nur den AS-Bereich 1-110 umfasst, notwendig wäre, um diese Hypothese zu bestätigen.

Die Interaktion von SmMOB3 erfolgte mit dem „WD-repeat“ des PRO11-Proteins. Dieses Ergebnis ist plausibel, da das „WD-repeat“ von PRO11 mit hoher Wahrscheinlichkeit eine Propeller-ähnliche Struktur einnimmt, welche als Plattform für vielfältige gleichzeitige oder aufeinanderfolgende Protein-Protein-Interaktionen dienen kann ( $\mathrm{Li}$ und Roberts 2001). Das PRO11-Protein stellt daher vermutlich ein Gerüstprotein dar, welches die Bildung großer Proteinkomplexe vermitteln kann. Die Interaktion der homologen Proteine Mob3 und SG2NA aus Säugern erfolgt ebenfalls über das „WD-repeat“ von SG2NA. Gaillard et al. (2006) zeigten, dass eine N-terminal verkürzte Version von SG2NA ohne das „,coiled-coil“-Motiv dazu fähig war mit Mob3 zu interagieren.

Interessanterweise wurde mittels Ko-Immunopräzipitation gezeigt, dass die homologen Proteine HAM3 und MOB3 in $N$. crassa miteinander interagieren, woraus hervorgeht, dass die Komplexbildung von Striatin- und Mob3-Proteinen neben S. macrospora auch in einem weiteren filamentösen Ascomycet konserviert ist (Dettmann, pers. Mittlg.).

\subsection{Die Homodimerisierung von PRO11 und die besondere Rolle des N-Terminus}

Als weiteres Ergebnis brachte die Two-Hybrid Analyse hervor, dass PRO11 ein Homodimer bildet. Es ist anzunehmen, dass die Homodimerisierung über das ,coiled-coil“-Motiv erfolgt, da das in der Analyse eingesetzte Konstrukt für die ersten 110 AS des PRO11-Proteins kodiert und die daraus resultierende Protein-Version nur die Caveolin-Bindedomäne, das „coiled-coil“-Motiv und die putative Calmodulin-Bindedomäne enthält. Eine Homo- und Hetero-Oligomerisierung 
über das „,coiled-coil“"-Motiv wurde außerdem bereits für alle Proteine der Striatin-Familie aus Säugern beschrieben (Gaillard et al. 2006). Eine Funktion des PRO11-Homodimers könnte sein, dass die Bildung eines „Doppel“-Gerüstproteins eine noch größere und komplexere Formation von Protein-Protein-Interaktionsnetzwerken erlaubt.

Darüber hinaus gibt es mehrere Hinweise, dass das „,coiled-coil“-Motiv im N-terminalen Teil von Striatin-Proteinen weitere wichtige Funktionen übernimmt. So ist beispielsweise in Säugern die Oligomerisierung der Proteine über die „coiled-coil“-Domäne die entscheidende Voraussetzung für die Lokalisierung in den neuronalen dendritischen Dornen (Gaillard et al. 2006). In dem pflanzenpathogenen Pilz F. verticillioides vermittelt das ,coiled-coil“-Motiv die Virulenz zur Induzierung der Mais-Stielfäule (Yamamura und Shim 2008).

Neben dem „coiled-coil“-Motiv übernehmen auch die weiteren N-terminalen Domänen von Striatin-Proteinen wichtige Funktionen.

So dient in Säugern die Bindung von Caveolin über die Caveolin-Bindedomäne vermutlich der Assoziierung der Striatin-Komplexe an spezialisierte Mikrodomänen der Plasmamebran (Caveolae). An den Caveolae werden Signalmoleküle spezifisch zusammengeführt und sie bilden somit den Ursprung verschiedener zellulärer Prozesse wie z. B. der Endocytose oder der Signaltransduktion (Brazer et al. 2003, Murata et al. 2007, Pani und Singh 2009, Pike 2006).

Gaillard et al. (2001) zeigten, dass alle Proteine der Striatin-Familie über die CaveolinBindedomäne an das Caveolin-1 Protein binden. Ein Sequenzvergleich von Striatin-Proteinen ergab, dass auch in PRO11 aus S. macrospora eine putative Caveolin-Bindedomäne enthalten ist (III Ergebnisse, Abb 14). Die pilzliche Caveolin-Bindedomäne ist vom gleichen Typ wie die der Säuger-Proteine (ФхФххххФххФ) und ist darüber hinaus mit $64 \%$ Sequenzähnlichkeit stark konserviert. Dieses Ergebnis ist erstaunlich, da das Genom von S. macrospora für kein homologes Caveolin-1 Protein kodiert (Nowrousian et al. 2010). Um ein Protein zu identifizieren, welches möglicherweise mit der Caveolin-Bindedomäne von Pilzen interagieren könnte, wurde ein BLAST-Vergleich der Caveolin-1 Gerüstdomäne mit der N. crassa Datenbank durchgeführt. Interessanterweise zeigten mehrere Proteine (NCU02706, NCU08917, NCU05425, NCU11773) eine hohe Identität (42-58 \%) mit der Gerüstdomäne. Die aufgeführten Proteine beinhalten ein Protein unbekannter Funktion, ein integrales Membranprotein von Transportvesikeln (v-SNARE) und zwei mitochondrial assoziierte Proteine (McNew et al. 1998, Repetto und Tzagoloff 1989, Krause-Buchholz et al. 2006). Es kann daher in Betracht gezogen werden, dass im pilzlichen Organismus mehrere Proteine an den Membranen unterschiedlicher zellulärer Kompartimente eine Caveolin-ähnliche Funktion übernehmen. Dafür spricht auch, dass Einstülpungen der 
Plasmamebran, welche die charakteristische Caveolae-Struktur bewirken, bislang in Pilzen nicht beobachtet werden konnten.

Eine weitere N-terminale Domäne des PRO11-Proteins bildet die putative CalmodulinBindedomäne. Es wird angenommen, dass Striatin-Proteine durch die $\mathrm{Ca}^{2+}$-abhängige Bindung von CaM in Signaltransduktionsprozesse involviert sind (Benoist et al. 2006).

Für das Säuger-Striatin wurden ursprünglich zwei Calmodulin-Bindedomänen vorhergesagt: Nr. 1 an AS-Positionen 88-105 und Nr. 2 an den Positionen 149-166. Bartoli et al. (1998) wiesen durch Mutagenese-Experimente nach, das Nr. 2 die funktionell wichtige Domäne für die CaM-Bindung darstellt. Die in PRO11 vorhergesagte Calmodulin-Bindedomäne korreliert bezüglich der Position in der Proteinsequenz mit der nicht funktionellen Domäne Nr. 1 des Säuger-Striatins. Es ist daher nicht auszuschließen, dass der korrespondierende PRO11-Sequenzbereich keine funktionelle Calmodulin-Bindedomäne repräsentiert. Eine Beteiligung von PRO11-Komplexen in $\mathrm{Ca}^{2+} /$ Calmodulin-abhängigen Signalwegen könnte dennoch indirekt möglich sein. Einer der in dem S. macrospora Two-Hybrid „Screen“ identifizierten Interaktionspartner des PRO11 NTerminus ist die Phosphoglucomutase (NCU10058; Pgm2p), welche wiederum mit CaM interagiert. Die Phosphoglucomutase katalysiert im Hexose-Metabolismus die Konversion von Glukose-1- zu Glukose-6-Phosphat (Boles et al. 1994). Interessanterweise ist die zelluläre $\mathrm{Ca}^{2+}{ }_{-}$ Homöostase direkt von den relativen Mengen an Glukose-1- und Glukose-6-Phosphat abhängig (Aiello et al. 2002). PRO11 könnte daher über die Interaktion mit der Phosphoglucomutase die intrazelluläre $\mathrm{Ca}^{2+}$-Konzentration modulieren und gleichzeitig $\mathrm{Ca}^{2+} / \mathrm{CaM}$-abhängige Signalwege induzieren. Es bedarf weiterführender Studien, um die Funktionalität der PRO11 CalmodulinBindedomäne zu klären. Eine Möglichkeit hierzu wäre, die direkte Interaktion von PRO11 und $\mathrm{CaM}$ in einer Two-Hybrid Analyse zu überprüfen. Alternativ könnte eine CaM-Sepharose Immunopräzipitation durchgeführt werden, bei der die Bindung von PRO11 an CaM über eine Antikörper-Reaktion und -Detektion nachgewiesen wird (Moreno et al. 2000).

Zwei weitere interessante Strukturmerkmale im N-terminalen Teil des PRO11-Proteins sind die teilweise konservierten SH3-Bindedomänen (,Src Homology 3“) und die Akkumulation putativ phosphorylierter Serin-Reste. Die SH3-Bindedomäne ist ein Prolin-reiches Motiv, welches die Bindung an Proteine mit einer SH3-Domäne vermittelt (Mayer 2001). Eukaryotische Genome kodieren vielfältige SH3-Domänen Proteine (z. B. 20-30 in hemiascomycetischen Hefen und bis zu 300 im Mensch), welche an verschiedenen zellulären Prozessen, wie z. B. Signaltransduktion, Zell-Polarität, Zellteilung, Membran-Zytoskelett-Interaktionen, Hyphenwachstum und VakuolenMorphologie, beteiligt sind (Musacchio et al. 1992, Reijnst et al. 2010, Karkkainen et al. 2006). In den Hefe Two-Hybrid „Screens“ wurde kein SH3-Domänen Protein als Interaktionspartner 
identifiziert, da die eingesetzen Köderproteine auf Grund der starken Transaktivierungsaktivität des PRO11 N-Terminus den Bereich der SH3-Bindedomänen nicht inkludierten. In vielen eukaryotischen Transkriptionsaktivatoren korrelieren saure Proteinbereiche mit einer Transaktivierungsaktivität und auch der Sequenzbereich 110-407 des PRO11 N-Terminus ist durch einen hohen Anteil der sauren AS Glutaminsäure und Asparaginsäure geprägt (Ptashne 1988). Im N-Terminus des Säuger-Homologs SG2NA wurde ebenfalls ein saurer Proteinabschnitt identifiziert, welcher eine starke Transaktivierungsaktivität bewirkte (Zhu et al. 2001). Die Identifikation eines möglichen SH3-Domänen Interaktionspartners von PRO11 könnte in zukünftigen Studien durch die Anwendung der TAP-Tag Methode („Tandem Affinity Purification") erfolgen, eine in vivo Methode, die für pilzliche Organismen gut etabliert ist (Bayram et al. 2008, Busch et al. 2007).

Es ist wahrscheinlich, dass PRO11 mit Serin/Threonin-Kinasen und -Phosphatasen interagiert, da mehrere Serin-Phosphorylierungsstellen für das PRO11-Protein vorhergesagt wurden, die zum Teil auch in anderen pilzlichen Organismen konserviert sind. Interessanterweise konnte für das Säuger-Striatin bereits eine Wechselwirkung mit verschiedenen Kinasen und der Phosphatase PP2A in dem STRIPAK-Komplex nachgewiesen werden. Welche Kinasen und Phosphatasen mit PRO11 interagieren bildet einen Schwerpunkt weiterer Forschungen.

Ein eindrucksvoller Beleg dafür, dass auch der alleinige N-terminale Teil von Striatin-Proteinen in der Zelle für die Ausführung spezifischer Funktionen notwendig ist, ergibt sich aus der Existenz multipler Spleißvarianten, welchen das „WD-repeat“-Motiv teilweise oder gänzlich fehlt (Sanghamitra et al. 2008). Die kürzeste Variante umfasst nur die Caveolin-Bindedomäne, das „coiled-coil“-Motiv, die Calmodulin-Bindedomäne und eine zusätzliche 19 AS lange Sequenz (Sanghamitra et al. 2008). In S. macrospora konnte das PRO11-Homolog dieser SG2NA-Variante identifiziert werden. Es wurde gezeigt, dass die alternativ gespleißte PRO11-Version keinen Einfluss auf die sexuelle Entwicklung ausübt, da eine ausschließliche Expression des PRO11 Voll-Längen Proteins nicht zu einer Beeinträchtigung in der Fruchtkörperentwicklung führte. Es bedarf daher zukünftiger Studien, um die Funktion des alternativen PRO11-Proteins näher einzugrenzen. Aufschluss könnte hier beispielsweise die Auswirkung einer Überexpression oder die fluoreszenzmikroskopische Untersuchung der Lokalisierung eines GFP- oder DsRedFusionsproteins bringen. 


\section{Der PRO11/SmMOB3-Komplex reguliert in $S$. macrospora die sexuelle Differenzierung und die Hyphenfusion}

\subsection{Die Gene pro11 und Smmob3 werden während der sexuellen Entwicklung exprimiert}

In vorangegangenen Studien wurde gezeigt, dass die beiden Entwicklungsgene pro11 und Smmob3 nur schwach exprimiert sind (Bernhards 2005, Pöggeler und Kück 2004). Viele Entwicklungsgene weisen ein schwaches Expressionsprofil auf, da sie ihre Funktion nicht während des gesamten Zyklus, sondern nur in spezifischen Differenzierungsprozessen erfüllen.

Quantitative Real-Time Experimente zeigten, dass pro11 und Smmob3 während aller Phasen der sexuellen Entwicklung hochreguliert waren. Ein Anstieg der Expression wurde für beide Gene insbesondere in der späteren Phase (6. Tag) des Lebenszyklus beobachtet, woraus geschlossen wurde, dass prol1 und Smmob3 in diesem Entwicklungsstadium eine wichtige Funktion übernehmen. Der 5. bis 6. Tag markiert bei der Entwicklung von S. macrospora den Übergang von dem kugelig angelegten Protoperithezium zum flaschenförmigen Perithezium. Dazu muss ein schmaler Perithezienhals gerichtet an dem Protoperithezium entstehen. Gleichzeitig werden in einem aufwändigen Prozess die Zellwände umgestaltet: Zellen fusionieren miteinander und lagern Melanin ein, so dass eine feste äußere Peridie entsteht. Darüber hinaus findet auch im Inneren des sich entwickelnden Peritheziums ein umfassender Umbau statt, da sich die Zellen funktionell differenzieren: die Asci mit den reifen Ascosporen entstehen und die Zwischenräume werden mit den sterilen Paraphysen ausgekleidet.

Für prol1 konnte darüber hinaus auch eine erhöhte Expression am 3. Tag der Entwicklung festgestellt werden. Zu diesem Zeitpunkt wird die sexuelle Entwicklung durch die Ausbildung der Ascogone initiiert.

Das Expressionsmuster von Smmob3 korreliert mit den Ergebnissen der Deletionsstudie, da der $\Delta$ Smmob3-Stamm genau in der Übergangsphase vom Protoperithezium zum Perithezium arretiert war. Der $\Delta$ pro11-Stamm hingegen zeigte einen viel früheren Entwicklungsdefekt, da nur initiale Ascogon-Stadien ausgebildet werden konnten. Interessanterweise konnte in der $\Delta$ pro11Komplementationsstudie nachgewiesen werden, dass PRO11 sowohl für die frühe als auch für spätere Entwicklungsphasen wichtig ist. Verkürzte Versionen des PRO11 N-Terminus in $\Delta$ pro11 vermittelten die Ausbildung von normal entwickelten Ascogonen und der vollständige NTerminus oder der N-Terminus mit einem Teil des „WD-repeat“-Motivs führten zu der Ausbildung pigmentierter Protoperithezien. Dieses Ergebnis ist zu dem Expressionsmuster von pro11 konvergent, da eine erhöhte Expression am 3. und am 6. Tag festgestellt wurde. 
Auch in anderen $S$. macrospora Entwicklungsmutanten, wie z. B. dem pro1-, pro22- und pro40Stamm werden die korrespondierenden Gene nur schwach exprimiert und zeigen ein ähnliches Expressionsprofil wie Smmob3 (Masloff et al. 1999, Rech et al. 2007, Engh et al. 2007). Im Gegensatz dazu ist die Transkriptmenge des sip2-Gens, welches keinen direkten Einfluss auf die Fruchtkörperentwicklung ausübt, während der beschriebenen Entwicklungsphase herunterreguliert (Elleuche et al. 2010).

\subsection{Der $\Delta$ pro11-Stamm weist einen stärkeren Entwicklungsdefekt auf als die pro11- Mutante}

Über die zellulären Funktionen von Striatin-Proteinen in höheren Eukaryoten ist bislang auf Grund der technischen Anforderungen nur wenig bekannt. In vielen filamentösen Pilzen, wie z. B. S. macrospora, N. crassa, F. verticillioides oder $A$. nidulans hingegen können mit relativ geringem Aufwand Gendeletionen erzielt werden. Wie nachfolgend diskutiert, geben neben den hier präsentierten Daten mehrere neuere Studien Aufschluss über die zellulären Funktionen von Striatin-Homologen in diesen Organismen.

Wie bereits beschrieben, ist in S. macrospora eine Punktmutation in dem prol1-Gen ursächlich für den sterilen Phänotyp der pro11-Mutante. Wie alle pro-Mutanten weist dieser Stamm einen entwicklungsbiologischen Arrest auf der Stufe der Protoperithezienbildung auf (Pöggeler und Kück 2004). Im Rahmen dieser Arbeit wurde eine Deletion des gesamten pro11-ORFs erzielt und der resultierende Stamm $\Delta$ pro11 hinsichtlich des Phänotyps mit der pro11-Mutante verglichen. Erstaunlicherweise führte die Deletion des pro11-Gens zu einer drastischen Verschlechterung der vegetativen und sexuellen Entwicklung. In dem $\Delta$ pro11-Stamm war die durchschnittliche tägliche Wuchsrate im Vergleich zu pro11 um die Hälfte reduziert. Darüber hinaus zeigte der $\Delta$ pro11Stamm bereits einen Defekt bei der Ausbildung der Ascogone, Protoperithezien konnten nicht generiert werden. Bei dem $\Delta$ pro11-Stamm handelt es sich somit um eine asc-Mutante. Auffällig war die sehr geringe Anzahl und die Struktur der gebildeten Ascogone im Vergleich zu dem wtund dem pro11-Stamm. Es wurde nur die erste Vorstufe der Ascogone, die sich einrollende Hyphe ausgeformt, so dass der Stamm nahezu einen rein vegetativen Phänotyp aufwies. Weitere $S$. macrospora asc-Mutanten wurden bislang nicht charakterisiert, es wäre jedoch interessant zu vergleichen, ob asc-Mutanten generell diesen starken Entwicklungsdefekt zeigen, oder ob dieser Phänotyp spezifisch für den $\Delta$ pro11-Stamm ist.

In Studien über die sterilen pro-Punktmutanten pro40 und pro22 wurden ebenfalls die Phänotypen der Mutanten und der korrespondierenden Deletionsstämme $\Delta$ pro40 und $\Delta$ pro22 verglichen. Die pro40- und die pro22-Mutanten sind wie pro11 auf der Stufe der Protoperithezien-Entwicklung 
blockiert. In der Ausprägung der Phänotypen wurde zwischen der jeweiligen Mutante und dem Deletionsstamm jedoch kein Unterschied festgestellt (Engh et al. 2007) (Bloemendal, pers. Mittlg.).

Eine Erklärung für die Ursache der unterschiedlichen Entwicklungsdefekte von pro11 und $\Delta$ pro11 ergibt sich aus den Ergebnissen der $\Delta$ pro11-Komplementationsstudie. Es zeigte sich, dass die Verkürzungskonstrukte den sterilen Phänotyp unterschiedlich restaurierten. Dabei korrelierte die Länge der Konstrukte mit der Stufe der sexuellen Strukturen, die wieder ausgebildet werden konnten. Der PRO11-Proteinbereich von AS 1-281 bewirkte die Ausbildung normal geformter Ascogone. Interessanterweise war auch das kürzeste eingesetzte Konstrukt (AS 1-120), welches ausschließlich das „,coiled-coil“-Motiv und die Caveolin- und Calmodulin-Bindedomäne enthielt, dazu fähig, die Generierung von Ascogonen herbeizuführen. Die Hinzunahme weiterer Sequenzbereiche bis AS 414 resultierte in der Ausbildung von Protoperithezien. Der Sequenzbereich zwischen AS 281 und AS 414 enthält das dritte „PxxP“-Motiv des PRO11 NTerminus und die vier putativ phosphorylierten und konservierten Serin-Reste.

Ein mögliches Denkmodell wäre, dass durch eine Homo- oder Heterodimerisierung über das „coiled-coil"-Motiv das PRO11-Protein innerhalb der Zelle zunächst zu seinem Wirkungsort dirigiert und hier die sexuelle Entwicklung initiiert wird (Ascogonbildung). Die Aktivierung des PRO11-Proteins über die Phosphorylierung der Serin-Reste durch eine Kinase könnte anschließend dazu führen dass weitere Proteine an die C-terminale PRO11-Gerüstdomäne rekrutiert werden, welche die Differenzierung der nächsten Fruchtkörperstufen vorantreiben (Protoperithezien, Perithezien). Interessanterweise wurde in ersten Studien eine Phosphorylierung des homologen HAM3-Proteins aus N. crassa von der NDR-Kinase COT1 nachgewiesen (Dettmann, pers. Mittlg.), welche bei dem filamentösen Wachstum, der Hyphenfusion und der sexuellen Differenzierung eine wichtige Rolle spielt (Maerz et al. 2008).

Kürzlich wurden Deletionsstämme von prol1-Homologen in A. nidulans, N. crassa, F. verticillioides und $F$. graminearum beschrieben. Alle Stämme waren wie $\Delta$ pro11 im vegetativen Wachstum deutlich eingeschränkt. Bezüglich der sexuellen Entwicklung zeigte jedoch keiner dieser Stämme einen ähnlich starken Defekt wie $\Delta$ pro11. Die Deletion des homologen ham-3Gens in dem nah verwandten Organismus $N$. crassa resultierte zwar ebenfalls in einem sterilen Phänotyp, jedoch konnten mit einer leichten zeitlichen Verzögerung normal geformte Protoperithezien ausgebildet werden (Simonin et al. 2010). Der A. nidulans $\Delta$ strADeletionsstamm war sogar noch zu der Ausbildung von Cleistothezien, welche die analogen Strukturen zu den Perithezien darstellen, und zu der Produktion von Ascosporen fähig. Allerdings wurden weniger und kleinere Cleistothecien im Vergleich zum wt gebildet, welche einen hohen 
Anteil abnormal geformte Ascosporen enthielten (Wang et al. 2010). Für die beiden $F$. verticillioides und $F$. graminearum Deletionsstämme $\Delta \mathrm{fsr} 1$ und SJF01 wird beschrieben, dass sie keine Perithezien mehr hervorbringen können. Ob die Stämme dazu fähig sind Ascogone oder Protoperithezien zu formen wird nicht erwähnt (Shim et al. 2006).

\subsection{Der $\Delta$ Smmob3-Stamm ist auf der Stufe der Protoperithezien-Entwicklung arretiert}

Der $\Delta$ Smmob3-Stamm weist wie die pro11-Mutante und der $\Delta$ pro11-Stamm ebenfalls einen sterilen Phänotyp auf. Die sexuelle Differenzierung ist auf der Stufe der Protoperithezienbildung blockiert. Im Vergleich zu dem wt-Stamm fällt auf, dass die Anzahl der Protoperithezien in $\Delta$ Smmob3 stark herabgesetzt ist. Diese Ergebnisse decken sich mit dem kürzlich beschriebenen Phänotyp des N. crassa $\Delta m o b$-3-Stamms, in welchem das homologe mob-3-Gen deletiert wurde. In dem sterilen $\triangle m o b-3-S t a m m$ ist die Zahl der Protoperithezien im Vergleich zum wt um das 30-fache reduziert und die Protoperithezien waren zusätzlich kleiner und weniger gut entwickelt (Maerz et al. 2009). Die Zahl der gebildeten Protoperithezien ist innerhalb der Gruppe der S. macrospora pro-Mutanten nicht identisch. So ist z. B. die Anzahl in der pro40-Mutante um ca. $45 \%$ erhöht, während die pro11-Mutante eine Reduktion von $39 \%$ in der Produktion der Vorfruchtkörper aufweist (Engh et al. 2007, Pöggeler und Kück 2004). Der $\Delta$ Smmob3-Stamm hingegen zeigt von den charakterisierten pro-Mutanten und auch im Vergleich mit dem $N$. crassa Amob-3-Stamm die bisher stärkste Reduktion (97\%) in der Protoperithezien-Produktion.

Um funktionell wichtige Domänen in SmMOB3 zu identifizieren wurden der N- und der C-terminale Teilbereich des Proteins jeweils einzeln auf die Fähigkeit zur Komplementation des sterilen $\Delta$ Smmob3-Phänotyps getestet. Es zeigte sich, dass der SmMOB3 N-Terminus, welcher eine der Ascomyceten-spezifischen Domänen und die Mob-Domäne umfasste, für die Restaurierung des sterilen $\Delta$ Smmob3-Phänotyps ausreichend war. Dieses Ergebnis bestätigt die Vermutung, dass die SmMOB3 Mob-Domäne, genau wie bei Mob1-Proteinen, die zentrale Funktionseinheit darstellt. Für die Mob-Domäne der Mob1-Proteine wurde gezeigt, dass sie durch die Interaktion mit NDR-Kinasen deren Aktivität regulieren (Bichsel et al. 2004, Hergovich et al. 2005, Bao et al. 2009). Auch der Interaktionsmechanismus wurde aufgeklärt. In hMob1 aus H. sapiens bilden die Strukturelemente L1, H2, L2 und ein Teil von H4 auf Grund der enthaltenen Aminosäuren eine konservierte stark negativ geladene Oberfläche aus. NDR-Kinasen sind reich an positiv-geladenen AS und es wird angenommen, dass die Interaktion von hMob1 mit der NDRKinase über eine spezifische elektrostatische Wechselwirkung erfolgt (Stavridi et al. 2003). 
Es ist daher nicht abwegig, dass die essentielle Funktion von SmMOB3 während der Fruchtkörperentwicklung von der Interaktion des Proteins mit einer Kinase abhängt. Die Interaktion könnte dabei auf Grund der strukturellen Homologie von SmMOB3 und Mob1Proteinen analog zu dem beschriebenen Interaktionsmechanismus zwischen Mob1-Proteinen und NDR-Kinasen erfolgen. Dabei erweist sich insbesondere auch das N-terminal konservierte Ascomyceten-spezifische Motiv von SmMOB3 als interessant, da hier vermutlich mehrere der konservierten Serin-Reste phosphoryliert werden.

Für Mob3-Proteine aus Säugern wurde bereits gezeigt, dass sie in Komplexen mit verschiedenen Kinasen (NDPK, GCK), sowie der Phosphatase PP2A vorliegen (Baillat et al. 2002, Goudreault et al. 2009, Moreno et al. 2001).

Inwiefern die N-terminale Ascomyceten-spezifische Domäne zu der Funktion des SmMOB3Proteins bei der sexuellen Differenzierung beiträgt könnte in weiterführenden Komplementationsstudien durch die Verwendung einer SmMOB3-Version ohne diese Domäne getestet werden.

In früheren Studien wurde der Entwicklungsdefekt der pro11-Mutante durch eine striatin-cDNA aus M. musculus partiell restauriert, woraus geschlossen werden konnte, dass die Funktion zwischen Striatin und PRO11 zumindest teilweise evolutionär konserviert ist (Pöggeler und Kück 2004). Im Rahmen dieser Arbeit wurde getestet, ob auch eine Konservierung der Funktion von Mob3-Proteinen zwischen Pilzen und Säugern vorliegt. Der $\Delta$ Smmob3 Entwicklungsdefekt konnte jedoch durch die eingebrachte M. musculus mob3-cDNA nicht komplementiert werden.

In D. melanogaster hingegen wurde der Defekt der DMob4-Mutante durch das Homolog aus dem Mensch aufgehoben. Zwischen den Mob-Domänen der beiden entsprechenden Proteine besteht eine Homologie von $80 \%$ (Schulte et al. 2010). Eine Ursache für die nicht erfolgreiche Komplementation in $S$. macrospora könnte daher sein, dass die Homologie zwischen der pilzlichen und der Säuger Mob-Domäne mit 35 \% für eine funktionelle Substitution zu gering ist.

Wie bisher dargelegt wurde, interagieren die S. macrospora Proteine PRO11 und SmMOB3 miteinander und die Deletion der beiden entsprechenden Gene verhindert die sexuelle Entwicklung. Es wurde daher hypothetisiert, dass PRO11 und SmMOB3 gemeinsam in einem Signalkomplex wirken, welcher die Fruchtkörperentwicklung in S. macrospora reguliert. Da die Deletion des pro11-Gens einen viel stärkeren Entwicklungsdefekt hervorrief als die des Smmob3Gens, wurde vermutet, dass PRO11 in dem Proteinkomplex mit SmMOB3 eine übergeordnete Funktion übernimmt, welche vermutlich den Gerüstprotein-Eigenschaften von PRO11 zuzuschreiben ist. 
Die erhaltenen Daten der Studie zur Expression von proll und Smmob3 in $\Delta$ Smmob3 und $\Delta$ pro11, sowie die Ergebnisse der RNAi-Studie unterstützen die Theorie von PRO11 und SmMOB3 in einem gemeinsamen Komplex. Das Smmob3-Transkript war in dem $\Delta$ pro11-Stamm im Vergleich zum wt signifikant hochreguliert und eine Herunterregulierung des prol1Transkripts in dem $\Delta$ Smmob3-Stamm und von Smmob3 in der pro11-Mutante führte im Vergleich zu den jeweiligen Einzelmutanten zu einem stärkeren Entwicklungsdefekt.

Auch die nachfolgend diskutierten Ergebnisse der Kreuzungsexperimente mit den Stämmen pro11 und $\Delta$ Smmob3 bestärkten diese Annahme.

\subsection{Die Stämme $\Delta$ Smmob3 und pro11 weisen einen Defekt bei der Hyphenfusion auf}

Unterschiedliche genetische Marker (z. B. Sporenfarbe) in S. macrospora Stämmen können bei einer Kreuzung durch das Fusionieren der Hyphen in beiden Myzelien vermischt werden und spiegeln sich nach der Karyogamie der Kerne, Meiose und postmeiotischer Mitose in der farblichen Ausprägung der acht linear angeordneten Ascosporen in den rekombinanten Asci wieder. Die Kreuzungen zur Generierung einer $\Delta$ Smmob3/pro11-Doppelmutante brachten keine rekombinanten Perithezien hervor, woraus geschlossen wurde, dass durch das Fehlen der Hyphenfusion keine Vermischung der unterschiedlichen Kerne beider Stämme im Cytoplasma und somit auch keine Generierung rekombinanter Asci stattfinden konnte. PRO11 und SmMOB3 müssen somit in einem gemeinsamen Komplex vorliegen, welcher die Fusion der Hyphenzellen vermittelt.

Der Prozess der Hyphenfusion wird in drei Phasen eingeteilt: Prä-Kontakt, Post-Kontakt und Post-Fusion. In der ersten Phase werden die Hyphen, welche miteinander fusionieren induziert und wachsen aufeinander zu. Die zweite Phase ist durch das Anschwellen und die Adhäsion der Hyphenspitzen und den Zellwand-Abbau der beiden aneinander grenzenden Hyphen gekennzeichnet. In der letzten Phase fusionieren die beiden Plasmamembranen miteinander. Dabei wird zunächst eine Fusionspore gebildet, welche den Durchfluss des Cytoplasma und der Zellorganellen erlaubt. Die Fusionspore wird nach und nach vergrößert und in der unmittelbaren Umgebung Septen eingezogen. Die für die zweite und dritte Phase notwendigen Enzyme für den Zellwandabbau und die Membranfusion werden in Vesikeln von dem Spitzenkörper bereitgestellt (Glass et al. 2000, Glass et al. 2004, Hickey et al. 2002)

Es wurden bereits einige $N$. crassa Stämme charakterisiert, welche Defekte bei der Hyphenfusion zeigen. Diese weisen u. a. Mutationen in homologen Komponenten der S. cerevisiae MAPKinase-Signalwege FUS3, KSS1 und HOG1 auf, welche in der Hefe die Pheromonantwort im Rahmen der sexuellen Reproduktion, das Umschalten auf filamentöses Wachstum und die osmotische Stressantwort kontrollieren (Gustin et al. 1998, Herskowitz 1995, Li et al. 2005, 
Maerz et al. 2008, Pandey et al. 2004, Roca et al. 2005). Es wird daher vermutet, dass die Aktivität dieser Signalwege in filamentösen Pilzen zu der Regulation der Hyphenfusion beiträgt. Es ist möglich, dass dabei auch PRO11-Homologe involviert sind. Im Rahmen dieser Arbeit wurde neben dem Hyphenfusionsdefekt eine erhöhte Sensitivität der pro11-Mutante und des $\Delta$ pro11-Stamms gegenüber osmotischem Stress festgestellt. Die osmotische Stressantwort wird in $N$. crassa durch die zu dem HOG1-Signalweg homologe OS-MAPK-Kaskade reguliert. Mutationen in den beteiligten Komponenten verhindern das Wachstum der entsprechenden Stämme auf Osmolarität-erhöhten Medien und gehen mit Hyphenfusionsdefekten und einer gestörten sexuellen Entwicklung einher (Zhang et al. 2002b, Fujimura et al. 2003, Jones et al. 2007, Maerz et al. 2008, Noguchi et al. 2007). Darüber hinaus wurde ein Einfluss der NDRKinase COT1 aus N. crassa auf den zu FUS3- und KSS1-homologen Signalweg NRC-MEKMAK nachgewiesen, da Mutationen in cot-1 den Hyphenfusionsdefekt der MAK2-Mutante unterdrückten (Maerz et al. 2008). Wie bereits erwähnt reguliert vermutlich COT1 durch Phosphorylierung auch das zu PRO11 homologe N. crassa Protein HAM3 (Dettmann, pers. Mittlg.).

Wie nachfolgend aufgeführt, zeigen die korrespondierenden Proteine weiterer $N$. crassa und S. macrospora Hyphenfusionsmutanten Homologien $\mathrm{zu}$ den Komponenten des kürzlich aufgeklärten STRIPAK-Signalkomplexes aus Säugern (Goudreault et al. 2009). Die in dieser Arbeit beschriebenen $S$. macrospora Proteine PRO11 und SmMOB3 stellen dabei die beiden Homologe von Striatin und Mob3 dar. In einer aktuellen Studie von Simonin et al. (2010) wurde gezeigt, dass auch die Deletion des zu proll homologen N. crassa ham-3-Gens in der entsprechenden Sham-3-Mutante einen Hyphenfusionsdefekt bewirkt. Die beiden Gene ham-2 aus N. crassa und pro22 aus S. macrospora kodieren jeweils für ein putatives Membranprotein, welches Homologien zu den STRIPAK-Komponenten STRIP1 und STRIP2 aus Säugern aufweist (Xiang et al. 2002, Rech et al. 2007). Das N. crassa ham-4 kodiert für ein „Forkhead-associated domain“-Protein (FHA) und ist homolog zu SLMAP (Simonin et al. 2010).

Zusammengefasst implizieren diese Ergebnisse, dass Striatin-Homologe pilzlicher STRIPAKKomplexe auf Grund ihrer Proteingerüst-Eigenschaften als Kernelemente fungieren, welche durch die Rekrutierung unterschiedlich zusammengesetzter Protein-Komplexe innerhalb der Zelle eine Vielzahl der für die Hyphenfusion spezifischen Prozesse regulieren können.

So gibt es z. B. mehrere Hinweise auf einen $S$. macrospora STRIPAK-Komplex, welcher über das vakuoläre System zu Fusions- und Entwicklungsprozessen beitragen könnte. 
In dem Basidiomyceten Pisolithus tinctorius wurden Verbindungen zwischen der Vakuole und der Plasmamembran beobachtet und es wurde vermutet, dass die Zelle darüber in einen Cytoplasma-unabhängigen Außenkontakt treten kann, welcher im Rahmen von Fusionsereignissen die Kommunikation der Hyphen untereinander ermöglicht (Cole et al. 1998, Rech 2007). Darüber hinaus könnte die Fusion der Vakuole mit der Plasmamembran der Zulieferung von z. B. Enzymen für den Auf- und Abbau der Zellwand oder anderer notwendiger Komponenten während der Hyphenfusion dienen (Bartnicki-Garcia et al. 1995, Klionsky et al. 1990, Weber und Pitt 1997).

Erste Two-Hybrid Studien wiesen eine Interaktion der beiden $S$. macrospora STRIPAKKomponenten PRO11 und PRO22 nach (Bloemendal, pers. Mittlg.). Für das PRO22-Protein wurde bereits eine Assoziierung mit den Vakuolen gezeigt und auf Grund der vorhergesagten Transmembraneigenschaften des Proteins hypothetisiert, dass es sich bei PRO22 um ein integrales Vakuolen-Membranprotein handeln könnte (Rech 2007). Für das SmMOB3-Protein, welches wie in dieser Arbeit nachgewiesen wiederum mit PRO11 interagiert, wurden in dem Hefe Two-Hybrid „Screen“ Interaktionspartner identifiziert, die ebenfalls in vakuoläre Prozesse involviert sind. So interagiert SmMOB3 mit dem zu S. cerevisiae homologen Pre3p, welche als $\beta$-Untereinheit des 20S-Proteasoms für die Spaltung von Proteinen benötigt wird (Groll et al. 1999). Das 20SProteasom bildet zusammen mit dem 19S-Komplex das 26S-Proteasom, welches den ATP- und Ubiquitin-abhängigen Proteinabbau steuert (Hochstrasser 1996). Ein weiterer Interaktionspartner von SmMOB3 ist das homologe Pbi2p. Dieses Protein ist ein cytosolischer Inhibitor der vakuolären Proteinase B und interagiert wiederum mit Ubiquitin, welches der Markierung der für den selektiven Abbau im 26S-Proteasom bestimmten Proteine dient (Slusarewicz et al. 1997, Shih et al. 2000). Hse1p, welches mit Pbi2p interagiert sortiert die abzubauenden Proteine in Vesikel (Bilodeau et al. 2002).

Interessanterweise zeigen viele Hyphenfusionsmutanten gleichzeitig Beeinträchtigungen in der sexuellen Entwicklung, so dass angenommen wird, dass beiden Prozessen ein gemeinsamer molekularer Regulationsmechanismus zugrunde liegen könnte (Bowman et al. 2006, Fleissner et al. 2005, Fleissner et al. 2009, Li et al. 2005, Maerz et al. 2008, Maerz et al. 2009, Rech et al. 2007, Wei et al. 2003, Xiang et al. 2002). 


\section{Das S. macrospora Protein Sm9375 - Beteiligung eines GPI-geankerten Proteins am SmMOB3/PRO11-Komplex}

Der GPI-Anker ist eine post-translationale Modifikation, welche der Verankerung von Proteinen in der Plasmamembran dient. GPI-geankerte Proteine treten im gesamten eukaryotischen Reich von Protozoen bis Vertebraten auf. Auch in einigen Archaeen konnte die Existenz GPI-geankerter Proteine nachgewiesen werden (Ferguson et al. 1985, Ferguson und Williams 1988, Morita et al. 1996, Takesue et al. 1992, Kobayashi et al. 1997, Eisenhaber et al. 2001).

In einer in silico-Analyse wurden für das Sm9375-Protein aus S. macrospora die strukturellen Eigenschaften eines GPI-geankerten Proteins vorhergesagt. GPI-geankerte Vorläuferproteine besitzen im N-Terminus eine hydrophobe Signalsequenz, welche während der Proteinbiosynthese zu einer Translation des Proteins in das ER führt und nachfolgend abgespalten wird. Der C-Terminus enthält ein zweites hydrophobes Motiv, welches nach einer definierten Position (,ڤ-site“) durch den Transamidase-Komplex entfernt und durch einen GPI-Anker ersetzt wird. Das so modifizierte Protein wird über Transportvesikel zunächst in den Golgi-Apparat und anschließend an die Plasmamembran überführt, auf deren extrazellulärer Seite die Verankerung erfolgt (Gerber et al. 1992, Nosjean et al. 1997, Eisenhaber et al. 1998).

Die Struktur des GPI-Ankers besteht aufeinanderfolgend aus Ethanolaminphosphat, Trimannosyl-Glucan, Glucosamin und Phosphatidylinositol. Der hydrophobe Anteil des GPI-Ankers kann z. B. aus an Glycerol gebundenen Fettsäuren, langkettigen Alkoholen oder Ceramiden aufgebaut sein. Der Ethanolaminphosphat-Teil des Ankers wird kovalent an den C-Terminus des Zielproteins geheftet (Englund 1993, Ikezawa 2002).

Da das zu Sm9375 homologe Protein NCU09375 in dem Two-Hybrid „Screen“ der N. crassa cDNA-Bank als häufigster Interaktionspartner von PRO11 und SmMOB3 identifiziert wurde und der PRO11/SmMOB3-Komplex die sexuelle Entwicklung reguliert, sollte getestet werden, ob auch das Sm9375-Protein einen Einfluss auf die Fruchtkörperentwicklung ausübt. Wie die Gendeletionsstudie zeigte, trägt auch $\operatorname{Sm9375}$ zu der sexuellen Differenzierung von $S$. macrospora bei, da die Anzahl der Fruchtkörper in dem $\Delta$ Sm9375-Stamm im Vergleich zum wt um nahezu die Hälfte reduziert ist. Die Funktion von Sm9375 ist jedoch nicht essentiell, da im Gegensatz zu $\Delta$ pro11 und $\Delta$ Smmob3 Perithezien ausgebildet werden können. Interessanterweise offenbarte die Erzeugung einer $\Delta \mathrm{Sm} 9375 / \Delta$ Smmob3-Doppelmutante eine genetische Abhängigkeit zwischen den beiden entsprechenden Genen. Die Sterilität von $\Delta$ Smmob3 wurde durch die zusätzliche Sm9375-Deletion zum Teil aufgehoben, da die Doppelmutante in der Lage ist, wenn auch wenige, Perithezien zu produzieren. Ein ähnlicher Effekt wurde auch für die beiden 
S. macrospora Gene ste12 und sip2 beobachtet. Das ste12-Gen kodiert für einen Transkriptionsfaktor, dessen Homolog Ste12p in S. cerevisiae an der Regulierung von Genen für die Zelltyp-Spezifität, die Pheromonantwort und das filamentöse Wachstum beteiligt ist (Bruhn und Sprague 1994, Dolan et al. 1989, Madhani und Fink 1997, Nolting und Pöggeler 2006b, Yuan et al. 1993). Eine ste12-Deletion führte in S. macrospora im Vergleich zum wt-Stamm unter anderem zu einer reduzierten Anzahl der Asci in den Perithezien und zu einer um $79 \%$ reduzierten Keimungsrate der Ascosporen (Nolting und Pöggeler 2006b, Elleuche et al. 2010). Das STE12-Protein interagiert mit dem kleinen Serin- und Threonin-reichen Protein SIP2. Der $\Delta$ sip2-Stamm zeigte im Vergleich zum wt keine Unterschiede bei der sexuellen Entwicklung, lediglich die Keimungsrate war um $27 \%$ reduziert. In der $\Delta$ sip2/ste12-fus Doppelmutante war der Defekt des $\Delta$ ste12-Einzelstamms partiell restauriert, denn es wurden mehr Asci pro Perithezium produziert und auch die Keimungsrate war im Vergleich zum wt nur um $49 \%$ reduziert. Aus diesem Ergebnis wurde geschlossen, dass SIP2 im Rahmen der Ascosporogenese und Ascosporenkeimung einen indirekten inhibitorischen Effekt auf STE12 ausübt (Elleuche et al. 2010). Demnach könnte auch Sm9375 inhibierend auf SmMOB3 einwirken.

Im Gegensatz dazu konnte ein direkter Einfluss von Sm9375 auf pro11 ausgeschlossen werden, da der $\Delta$ Sm9375/Dpro11-Stamm denselben Phänotyp zeigte wie der $\Delta$ pro11-Einzelstamm. Die erfolgreiche Herstellung der beiden Doppelmutanten $\Delta \operatorname{Sm} 9375 / \Delta$ pro11 und $\Delta \operatorname{Sm} 9375 / \Delta \operatorname{Smmob3}$ impliziert auch, dass der $\Delta$ Sm9375-Stamm keinen Hyphenfusionsdefekt aufweist, da sonst die Kreuzungen mit den beiden Fusionsmutanten $\Delta$ pro11 und $\Delta$ Smmob3 keine rekombinanten Perithezien hervorgebracht hätten.

Es stellt sich die Frage, wie Sm9375 als GPI-geankertes Protein im Komplex mit PRO11 und SmMOB3 zu sexuellen Differenzierungsprozessen beitragen könnte.

Striatin-Komplexe in Säugern vermitteln vermutlich als Signalosome an spezifischen Mikrodomänen der Plasmamembran Endocytose-Prozesse und $\mathrm{CaM} / \mathrm{Ca}^{2+}$-abhängige Signaltransduktionswege (Benoist et al. 2006). Auch GPI-geankerten Proteinen wird eine Beteiligung an der Ausbildung spezifischer Mikrodomänen zugeschrieben. Darüber hinaus wirken einige GPI-geankerte Proteine durch die Interaktion mit Rezeptoren in Endocytose-Prozessen und können im Rahmen von Signaltransduktionswegen als sekundäre Botenstoffe fungieren (Friedrichson und Kurzchalia 1998, Lakhan et al. 2009, Gaulton und Pratt 1994).

Es bleibt zu jedoch zu diskutieren, ob es sich bei Sm9375 tatsächlich um ein GPI-geankertes Protein handelt. In N. crassa wurden GPI-geankerte Proteine in einen direkten funktionellen Zusammenhang mit Hyphenfusionsprozessen gestellt (Bowman et al. 2006). In S. cerevisiae oder 
A. fumigatus wirkten sich Deletionen oder Mutationen von Genen, welche für GPI-geankerte Proteine kodieren, z. B. auf die osmotische Stresstoleranz oder die Zellwandintegrität aus (Teparic et al. 2004, Li et al. 2007). Für den S. macrospora $\Delta$ Sm9375-Stamm konnten solche Defekte jedoch nicht beobachtet werden.

Da die im Rahmen dieser Arbeit dem Sm9375 zugeordnete Funktion als GPI-geankertes Protein auf einer in silico Analyse basiert, muss demnach in weiterführenden Experimenten zunächst überprüft werden, ob die vorhergesagte Signalsequenz und der GPI-Anker Bereich in Sm9375 tatsächlich funktionell sind. Dies könnte z. B. über die Herstellung verschiedener GFPFusionskonstrukte erfolgen. In Studien von Mayrhofer und Pöggeler (2005) und Nowrousian et al. (2007) wurde bereits gezeigt, dass durch die Fusion der jeweiligen Signalsequenz des PheromonVorläufers PPG1 oder des ER-Proteins PRO41 an GFP, das sekretierte Fluorophor im Kulturmedium durch eine Antikörper-Reaktion und -Detektion nachgewiesen werden konnte. Darüber hinaus verbleibt durch das zusätzliche Anfügen eines KDEL-Retentionssignals das Fusionsprotein im ER und kann fluoreszenmikroskopisch sichtbar gemacht werden (Nowrousian et al. 2007).

Die Identifizierung von Interaktionspartnern des Sm9375-Proteins durch einen Hefe Two-Hybrid „Screen“ oder die Isolierung putativer Sm9375-Proteinkomplexen durch das in vivo TAP-Tag Verfahren, könnte darüber hinaus zu der Aufklärung der zellulären Funktion des Proteins beitragen.

\section{Reguliert der PRO11/SmMOB3-Komplex während Hyphenfusion und Fruchtkörperentwicklung die Endocytose und den Vesikel-Transport?}

Mehrere Hinweise verdichten die Annahme, dass der PRO11/SmMOB3-Komplex durch die Beteiligung an Endozytose und Vesikeltransport $\mathrm{zu}$ Hyphenfusionen und $\mathrm{zu}$ der sexuellen Differenzierung beiträgt. Wie die Säuger Mob3-Proteine beinhalten auch pilzliche MOB3Proteine Sequenzbereiche in der Mob-Domäne, welche eine hohe Ähnlichkeit zu der $\sigma$-Untereinheit von Clathrin-Adaptor-Komplexen und zu einem SH3-Bindemotiv des Typs „PxxDY“ aufweisen (Baillat et al. 2001). Beide Motive sind typisch für Proteine, die in Endocytose und vesikulären Transport involviert sind.

Das SH3-Bindemotiv von Mob3 aus $R$. norvegicus ist ein nicht-kanonisches „PxxDY“-Motiv, welches zuerst als Bindemotiv der Eps8 SH3-Domäne gefunden wurde (Mongiovi et al. 1999). Die variablen AS in diesem Motiv sind in SmMOB3, den anderen pilzlichen Homologen und in $R$. norvegicus Alanin und Isoleucin. Das konservierte Prolin des Motivs ist in den MOB3- 
Proteinen der Pilze durch ein Cystein ersetzt. Mongiovi et al. (1999) zeigten, dass die AS Asparaginsäure und Tyrosin in dem „PxxDY“-Motiv essentiell für die Bindung der SH3-Domäne waren, während das Prolin nur zu der Bindungsspezifität beitrug. Möglicherweise vermittelt das Cystein in dem SH3-Bindemotiv von pilzlichen MOB3-Proteinen die Bindung eines SH3-Proteins mit einer Ascomyceten-spezifischen Funktion.

Wie in I Einführung, 2.2.1 dargelegt, weist die kleine $\sigma$-Untereinheit vermutlich eine stabilisierende Funktion des AP-Komplexes während der Endocytose auf und ist an der CargoSelektion beteiligt (Collins et al. 2002). Die Existenz eines ähnlichen Sequenzmotivs in dem SmMOB3-Protein ließ vermuten, dass SmMOB3 ebenfalls an diesen Prozessen beteiligt ist. Nach einer Myzel-Färbung des $\Delta$ Smmob3-Stamms mit dem Endocytose-Marker FM4-64 zeigte sich jedoch in der Ausprägung der angefärbten Vesikel und des Membransystems kein Unterschied zum wt-Stamm (Daten nicht gezeigt). Eine mögliche Erklärung könnte sein, dass das FM4-64 über einen alternativen Weg in die Hyphenzelle aufgenommen wird. Hierbei wird die Aktivität von Flippasen diskutiert, welche das FM4-64 von der Außenseite auf die Innenseite der Plasmamembran translokieren könnten (Menon 1995). Der Marker wird dann entweder von speziellen Lipid-Transferproteinen zu den intrazellulären Organellmembranen transportiert oder gelangt durch Diffusion dorthin (Record et al. 1998, Illinger und Kuhry 1994, Betz et al. 1996).

Alternativ wäre denkbar, dass SmMOB3 keine grundsätzliche Komponente der EndocytoseMaschinerie darstellt, sondern auf Grund spezifischer Signale während der Hyphenfusion und der Fruchtkörperbildung gezielt an die Plasmamembran rekrutiert wird. Dort könnte SmMOB3 dann im Zusammenspiel mit weiteren Endocytose-assoziierten Proteinen z. B. an der Internalisierung eines Liganden-abhängigen Rezeptors in Clathrin-Vesikel und somit an der Regulierung eines spezifischen „Entwicklungs“-Signals beteiligt sein. Die Gerüstdomäne des PRO11-Proteins könnte dabei möglicherweise die Komplexbildung der beteiligten Proteine gewährleisten.

In Säugern interagiert das Mob3-Protein mit Eps15, NDPK und Dynamin, welchen eine Rolle bei der Endocytose zugeschrieben wird. In den im Rahmen dieser Arbeit durchgeführten Hefe TwoHybrid „Screens“ wurden keine Homologen dieser Proteine als Interaktionspartner von PRO11 oder SmMOB3 gefunden. In der Analyse wurden allerdings stark verkürzte Konstrukte von PRO11 (AS 1-110) und SmMOB3 (AS 1-144) eingesetzt, so dass die für die Interaktionen notwendigen Proteinbereiche möglicherweise nicht vorhanden waren. Es ist außerdem möglich, dass Eps15, NDPK und Dynamin in den cDNA-Banken nicht ausreichend repräsentiert waren. Erste Ergebnisse aus Ko-Immunopräzipitationsanalysen in N. crassa zeigten nämlich, dass HAM3 und NDPK miteinander interagieren können (Dettmann, pers. Mittlg.). 
Die Ergebnisse der Two-Hybrid „Screens“ weisen darauf hin, dass PRO11 und SmMOB3 neben einer möglichen Beteiligung an Endocytose-Prozessen eine Funktion bei dem Vesikel-Transport haben. Es wurden mehrere Interaktionspartner identifiziert, welchen in diesem zellulären Prozess eine direkte oder indirekte Rolle zugeschrieben wird. Wie erwähnt interagiert PRO11 mit dem Homolog der S. cerevisiae Phosphoglucomutase (Pgm2p), welche $\mathrm{CaM} / \mathrm{Ca}^{2+}$-abhängige Signalwege moduliert. Pgm2p wiederum interagiert mit Yiflp, ein integrales Membranprotein, welches für die Fusion ER-generierter Vesikel mit dem Golgi-Apparat benötigt wird (Barrowman et al. 2003, Heidtman et al. 2005). Ein Interaktionspartner von SmMOB3 ist die zu S. cerevisiae homologe Fettsäuredesaturase Ole1p, welche ebenfalls mit Yiflp assoziiert. Darüber hinaus interagiert SmMOB3 mit dem homologen Hefe-Protein Ret2p. Dieses Protein ist die $\delta$ Untereinheit des Co-atomaren Komplexes (COPI), welcher als Hüllprotein für Golgi-generierte Vesikel dient, die zum ER transportiert werden (Cosson et al. 1996).

Sowohl PRO11 als auch SmMOB3 interagieren mit dem zu S. cerevisiae homologen Protein Tvp23p, ein integrales Golgi-Membranprotein, das in den Vesikeltransport vom Endosom zum Golgi-Apparat involviert ist.

Die initialen Ergebnisse der fluoreszenzmikroskopischen Analyse bekräftigen die Hypothese über eine Beteiligung von PRO11 und SmMOB3 bei Endocytose und vesikulärem Transport, da beide mit DsRed fusionierten Proteine eine Lokalisierung in Vesikel-ähnlichen Strukturen aufwiesen. Sowohl Endocytose als auch vesikuläre Transportprozesse involvieren mehrere Zell-Organellen und -Strukturen (Plasmamembran, Endosom, Golgi-Apparat, ER, Aktin) so dass eine eindeutige Zuordnung des Funktionsortes von PRO11 und SmMOB3 innerhalb der Hyphenzelle nur durch Ko-Lokalisierungsstudien mit geeigneten Markerproteinen möglich ist.

Für das PRO11 Homolog StrA aus A. nidulans wurde bereits eine Lokalisierung des Proteins in der Kernhülle und im ER nachgewiesen (Wang et al. 2010). Wobei es sich bei den in S. macrospora detektierten Strukturen handelt muss in weiterführenden Studien durch KoLokalisierung mit Markerproteinen verifiziert werden. Für Pilze wurde der Einsatz verschiedener Organell-Markerproteine etabliert, die in einer solchen fluoreszenzmikroskopischen Analyse zum Einsatz kommen könnten. So wurde z. B. von Higuchi et al. (2006) ein in der Plasmamembran lokalisiertes Permease-GFP-Fusionsprotein für die Visualisierung endocytotischer Prozesse in A. oryzae genutzt. Die Internalisierung des Proteins kann durch die Zugabe von Ammonium stimuliert und durch Natriumazid-, Kälte- und Cytochalasin-Behandlung blockiert werden.

Mehrere Studien verweisen auf eine notwendige Beteiligung von Aktin bei der Endocytose und es wurde gezeigt, dass Endocytose-assoziierte Proteine und Aktin-regulatorische Proteine an kortikalen Aktin-,Patches“ zusammenkommen (Kubler und Riezman 1993, Munn et al. 1995, 
Raths et al. 1993, Kaksonen et al. 2003). Für die Darstellung von F-Aktin in der Zelle wurde das Lifeact-TagRFP-Fusionsprotein etabliert. Es besteht aus einer Fusion der ersten 17 AS des Aktinbindenden Proteins Abp140p aus S. cerevisiae und dem rot-orange fluoreszierenden Protein RFP. Durch dieses Markerprotein können spezifisch runde und tubuläre Aktin-Filamente (,patches“ und „cables“) sichtbar gemacht werden (Riedl et al. 2008).

Der pilzliche Golgi-Apparat wurde mit Hilfe eines CopA-GFP Proteins erfolgreich in A. nidulans visualisiert (Breakspear et al. 2007). CopA ist ein Strukturbestandteil der bereits erwähnten COPIVesikel-Hüllproteine (Whittaker et al. 1999).

Ein geeignetes Markerprotein für eine erste Ko-Lokalisierungsstudie in S. macrospora wäre das in dem Two-Hybrid „Screen“ als Interaktionspartner identifizierte Ret2p-Homolog, welches ebenfalls eine Hüll-Komponente der Golgi-generierten Vesikel repräsentiert. Durch eine KoLokalisierung des $S$. macrospora Ret2p-Homologs mit SmMOB3 würde neben einer möglichen Aufklärung der subzellulären Lokalisierung gleichzeitig die in vivo Bestätigung der SmMOB3Ret2 Interaktion erbracht.

\section{Zusammenfassung der vielfältigen Funktionen von $S$. macrospora PRO11- Proteinkomplexen bei zellulären Differenzierungsprozessen}

Die sexuelle Differenzierung bei Ascomyceten repräsentiert einen energieaufwändigen und hochkomplexen zellulären Umstrukturierungsprozess, da aus einem mehr oder weniger gleichförmig gestalteten Myzel dreidimensionale multizelluläre Fruchtkörper generiert werden.

Daran ist eine Vielzahl unterschiedlicher Prozesse wie z. B. Endocytose, Signaltransduktion, Transkription, Vesikeltransport, Metabolismus oder der Abbau von Stoffwechselprodukten beteiligt. Abbildung 27 fasst die bisherigen Erkenntnisse über PRO11-Signalkomplexe in S. macrospora zusammen. 


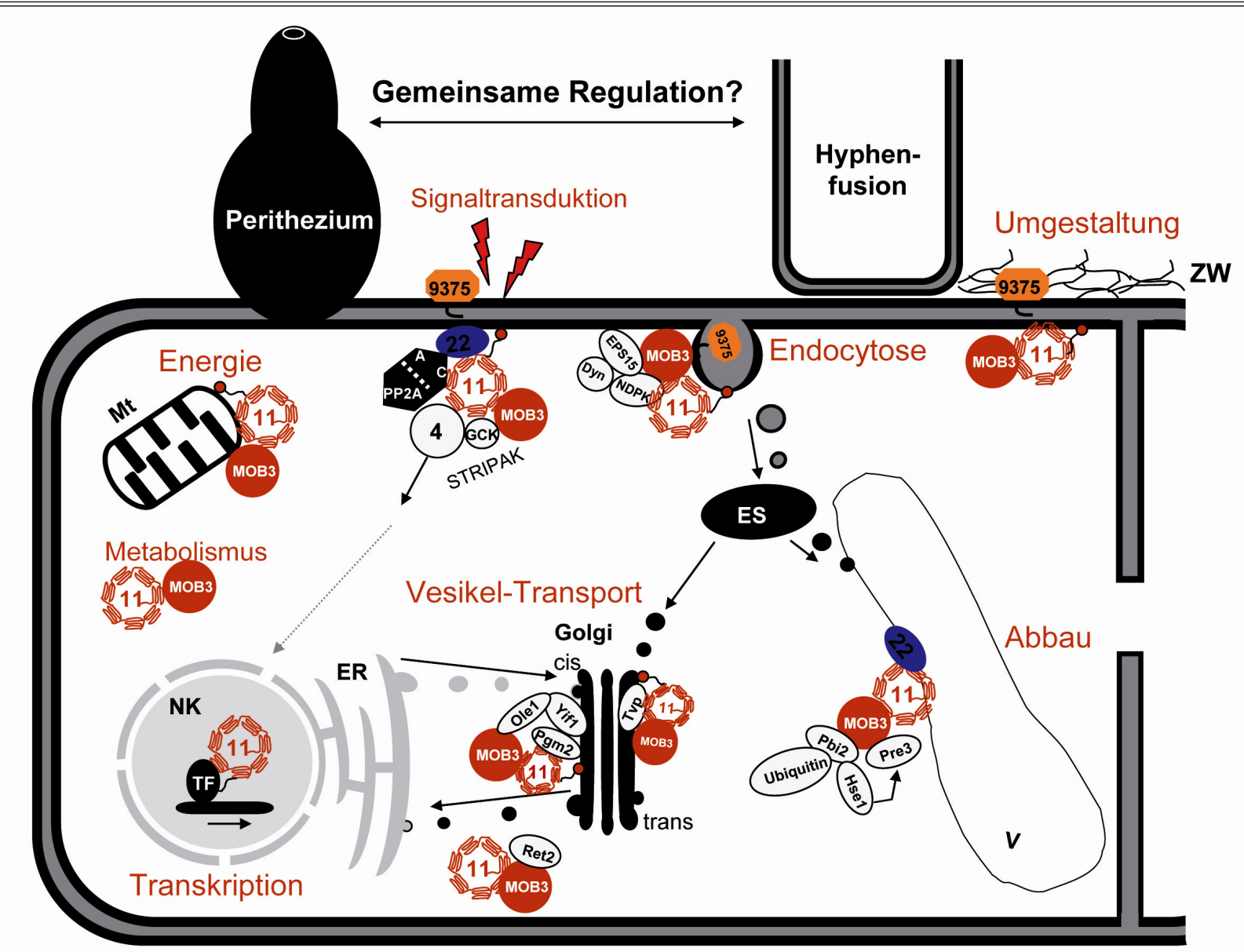

\begin{tabular}{|ll|}
\hline Energie & Umgestaltung \\
NCU00635, EGD2 & NCU01353, TIR4 \\
NCU06550, SNZ3 & NCU00716, CDC123 \\
NCU00995, THI6 & NCU04528, FET5 \\
NCU02499, ZIM17 & NCU08374, YFR016C \\
NCU07112, COX9 & NCU05498, BUD9 \\
NCU05319, MDM35 & \\
NCU08091, OGG1 & \\
\hline
\end{tabular}

\begin{tabular}{|llll|}
\hline Transkription & Vesikel-Transport & Metabolismus & Abbau \\
NCU03905, YAP1 & NCU02733, TVP23 & NCU06727, SPE3 & NCU07947, FTH1 \\
NCU02410, ECM22 & NCU00493, RET2 & NCU00200, TRP3 & NCU01548, PBI2 \\
NCU02621, SFP1 & & NCU05259, OLE1 & NCU09290, PRE3 \\
\hline & & \\
\hline Signaltransduktion & Endocytose & \\
NCU10058, PGM2 & NCU08693, PMR1 \\
\hline
\end{tabular}

Abb. 27 Hypothetisches Modell zellulärer Funktionen von PRO11-Komplexen während der Hyphenfusion und Fruchtkörperentwicklung. Oberer Teil: Die Beschreibung der Proteinkomplexe ergibt sich aus dem Textfluss der Diskussion. Erkenntnisse aus Säugern oder N. crassa wurden teilweise adaptiert. Unterer Teil: Funktionelle Einordnung identifizierter PRO11- und SmMOB3-Interaktionspartner in Prozesse der Hyphenfusion und Fruchtkörperentwicklung. Abkürzungen: Mt-Mitochondrium, NKNukleus, TF-Transkriptionsfaktor, V-Vakuole, ES-Endosom, ZW-Zellwand, 11-PRO11, MOB3SmMOB3, 4-N. crassa HAM4.

Abschließend bleibt festzuhalten, dass pilzliche Striatin-Homologe im Rahmen zellulärer Differenzierungsprogramme vermutlich eine Schlüsselfunktion bei der Regulierung vielfältiger Prozesse einnehmen, deren Komponenten und Wirkungsweise zwischen Pilz und Säugern zumindest teilweise evolutionär konserviert worden sind. 


\section{ZUSAMMENFASSUNG}

\section{Zusammenfassung}

Diese Arbeit beschäftigte sich mit der Untersuchung der molekularen Regulationsmechanismen während der sexuellen Entwicklung des filamentösen Ascomyceten Sordaria macrospora. Dabei stand eine detaillierte funktionelle Analyse der beiden zu striatin und phocein/Mob3 aus Säugern homologen Entwicklungsgene pro11 und Smmob3 im Mittelpunkt des Interesses. Die Ergebnisse dieser Arbeit lassen sich wie folgt zusammenfassen:

\section{- PRO11 und SmMOB3 aus S. macrospora bilden einen Proteinkomplex}

In einer Hefe Two-Hybrid Studie wurde die physikalische Interaktion der beiden Proteine PRO11 und SmMOB3 nachgewiesen. Die für die Interaktion maßgeblichen Proteindomänen konnten auf das „WD-repeat"-Motiv von PRO11 und den N-Terminus von SmMOB3 mit einer der Ascomyceten-spezifischen Domänen und einem Teil der Mob-Domäne eingegrenzt werden. Darüber hinaus wurde eine Homodimerisierung des PRO11-Proteins nachgewiesen.

\section{- Die Gene pro11 und Smmob3 werden während der sexuellen Entwicklung exprimiert}

Mittels quantitativer Real-Time PCR wurde gezeigt, dass die pro11- und Smmob3-Transkripte während aller Stadien, insbesondere in der späten Phase, der sexuellen Entwicklung hochreguliert waren.

\section{- PRO11 und SmMOB3 sind essentiell für die Fruchtkörperentwicklung}

Die Deletion der Gene prol1 und Smmob3 in S. macrospora resultierte jeweils in einem sterilen Phänotyp. Der $\Delta$ pro11-Stamm zeigte mit der Arretierung in der Phase der Ascogonenbildung einen viel stärkeren Entwicklungsdefekt als $\Delta$ Smmob3, welcher Protoperithezien ausbildete. Daher wurde prol1 im Vergleich zu Smmob3 hinsichtlich der sexuellen Differenzierung eine übergeordnete Funktion zugeordnet. Darüber hinaus implizierten die Ergebnisse einer weiteren Expressions- und RNAi-Studie die Regulation der Fruchtkörperbildung durch PRO11 und SmMOB3 in einem gemeinsamen Komplex: Das Smmob3-Transkript war in dem $\Delta$ pro11-Stamm im Vergleich zum wt signifikant hochreguliert und eine Herunterregulierung des prol1Transkripts in dem $\Delta$ Smmob3-Stamm und von Smmob3 in der pro11-Mutante führte im Vergleich zu den jeweiligen Einzelmutanten zu einem stärkeren Entwicklungsdefekt.

In einer $\Delta$ pro11-Komplementationsstudie zeigte sich, dass verschiedene Bereiche des PRO11Proteins die Entwicklung unterschiedlicher Fruchtkörperstadien hervorriefen. Der vollständige NTerminus (AS1-414) und der N-Terminus zusammen mit den ersten beiden „WD-repeats“ (AS 1545) vermittelten die Ausbildung von Protoperithezien. Kürzere N-terminale Teilstücke (AS 1281, 1-180, 1-120) resultierten in der Ausbildung von Ascogonen. Das alternative PRO11Spleißprodukt war für die Fruchtkörperbildung entbehrlich.

Die AS-Sequenz 1-264 des SmMOB3-Proteins, welche die Ascomyceten-spezifische Domäne und die Mob-Domäne umfasste, war für eine vollständige Komplementation des $\Delta$ Smmob3Entwicklungsdefekts ausreichend. Die Komplementation des sterilen N. crassa $\Delta m o b-3$ Stamms mit demselben SmMOB3-Teilstück zeigte die funktionelle Konservierung dieser Domäne in den beiden Ascomyceten. Zwischen Pilzen und Säugern konnte hingegen keine funktionelle Konservierung von Mob3-Proteinen nachgewiesen werden. 


\section{- Der PRO11/SmMOB3-Komplex reguliert Zell-Zell-Fusionen}

Eine Komplementation der Entwicklungsdefekte von $\Delta$ Smmob3 und der pro11-Mutante durch Kreuzung war nicht möglich, woraus geschlossen wurde, dass PRO11 und SmMOB3 in einem gemeinsamen Komplex vorliegen müssen, welcher die Fusion von Hyphenzellen vermittelt.

- PRO11 und SmMOB3 weisen eine Lokalisierung in Vesikel-ähnlichen Strukturen auf

Eine erste fluoreszenzmikroskopische Analyse deutet darauf hin, dass die SmMOB3- und PRO11DsRed-Fusionsproteine in Vesikel-ähnlichen Strukturen lokalisiert sind.

\section{- Das $S$. macrospora Protein Sm9375 ist an der Fruchtkörperentwicklung beteiligt}

Das N. crassa Protein NCU09375 konnte in einem artübergreifenden Hefe Two-Hybrid „Screen“ als Interaktionspartner von PRO11 und SmMOB3 identifiziert werden. Das homologe Gen Sm9375 wurde aus S. macrospora isoliert und kloniert. Der 980 bp ORF weist zwei Introns auf (96 bp, 122 bp) und kodiert für ein putatives 253 AS großes Protein. Eine in silico Analyse zeigte auf, dass Sm9375 die für GPI-Proteine charakteristischen Strukturmerkmale enthält (Signalsequenz, $\omega-,$, site“). Eine Sm9375-Gendeletion resultierte in einer Verringerung der Perithezien-Anzahl um 50 \% im Vergleich zum wt. Sm9375 übt also während der sexuellen Entwicklung einen Einfluss auf die Anzahl der gebildeten Fruchtkörper aus.

Eine durch Kreuzung generierte Deletion des Sm9375-Gens in dem $\Delta$ Smmob3-Stamm führte zu einer partiellen Komplementation des $\Delta$ Smmob3 Entwicklungsdefektes, da wenige reife Perithezien ausgebildet werden konnten. Hieraus wurde geschlossen, dass eine genetische Interaktion zwischen Sm9375 und Smmob3 vorlag.

Im Rahmen der vorliegenden Arbeit wurde eine physikalische Interaktion von homologen Striatin und Mob3 Proteinen aus Säugern erstmalig auch in einem filamentösen Ascomycet gezeigt und darüber hinaus die essentielle funktionelle Bedeutung dieses Proteinkomplexes in Pilzen bei der sexuellen Entwicklung nachgewiesen. Die gewonnenen Erkenntnisse tragen maßgeblich zu dem Verständnis der fundamentalen molekularen Netzwerke bei, welche zelluläre Differenzierungsprozesse steuern und deren Komponenten und Wirkungsweise zwischen Pilzen und Säugern zumindest teilweise evolutionär konserviert worden sind. 


\section{Summary}

This study focused on the investigation of the molecular machinery driving fruiting body development in the filamentous ascomycete Sordaria macrospora. In the limelight of interest was a comprehensive analysis of the conserved developmental genes prol1 and Smmob3 which are homologs of the mammalian striatin and phocein/mob3 genes. The results can be summarized as follows:

\section{- The $S$. macrospora proteins PRO11 and SmMOB3 form a complex}

Yeast two-hybrid study revealed physical interaction of the proteins PRO11 and SmMOB3. The interaction was achieved by the PRO11 WD-repeat motiv and the N-terminal part of SmMOB3 containing one of the ascomycete-specific domains and a small part the conserved mob domain. Furthermore, homodimerization of PRO11 was proved.

\section{- The pro11 and Smmob3 genes are expressed during sexual development}

By means of quantitative real-time PCR an upregulation of prol1 and Smmob3 transcripts was shown during all but especially increasing at late phases of sexual differentiation.

\section{- PRO11 and SmMOB3 are essential for fruiting body development}

Deletion of either pro11 or Smmob3 in S. macrospora resulted in a sterile phenotype. The $\Delta$ pro11 deletion strain was only capable of ascogonia formation thus featuring a more pronounced developmental defect than $\Delta$ Smmob3 accomplishing protoperithecia. Due to this, pro11 was adjudged a superior developmental function compared to Smmob3. Further results of another expression study and an RNAi approach proposed a mutual role of prol1 and Smmob3 in fruiting body development: compared to wt, Smmob3 was significantly upregulated in the $\Delta$ pro11 strain and downregulation of proll in $\Delta \mathrm{Smmob} 3$ or $S m m o b 3$ in $\Delta$ pro11 led to more pronounced phenotypes.

Complementation analysis of $\Delta$ pro1 1 showed a functional correlation between specific PRO11 domains and attained stages of fruiting body development. The complete PRO11 N-terminus (aa 1-414) and the N-terminus together with a part of the WD-repeat motiv (aa 1-545) allowed formation of protoperithecia. Shorter N-terminal parts (aa 1-281, 1-180, 1-120) resulted in development of ascogonia. The PRO11 variant which derived from alternative splicing process was dispensable for fruiting body development.

The N-terminal part of SmMOB3 (aa 1-264) containing one of the ascomycete-specific domains and the conserved mob domain, was sufficient to fully complement the $\Delta$ Smmob3 strain. Complementation of the sterile $N$. crassa $\Delta m o b-3$ strain with SmMOB3 aa 1-264 illustrated a functional conservation of the mob domain in these two ascomycetes. However, a functional conservation of Mob3 proteins could not be proved between fungi and mammals.

\section{- The PRO11/SmMOB3 complex regulates cell-cell fusion events}

Complementation of the developmental defects in the $\Delta$ Smmob3 strain and the pro11 mutant could not be achieved by means of crossing, indicating PRO11 and SmMOB3 to be present in a collective protein complex which mediates hyphal fusion.

\section{- PRO11 and SmMOB3 are localized in vesikel-like structures}

Initial fluorescence microscopy results indicate a localization of PRO11 and SmMOB3 in vesikellike structures. 


\section{- The $S$. macrospora Sm9375 protein participates in fruiting body development}

In a cross-species yeast two-hybrid screen, $N$. crassa NCU09375 was identified as an interaction partner of PRO11 and SmMOB3. The homolog gene Sm9375 was isolated and cloned from $S$. macrospora and sequence analysis revealed a 980 bp Sm9375 ORF containing a 96 bp and 122 bp intron. The derived 253 aa Sm9375 protein exhibits a putative signaling sequence and a $\omega$-site which are both structural characteristics of GPI-anchored proteins. A Sm9375 gene deletion resulted in a $50 \%$ reduction of produced fruiting bodies in comparison to the wt. Therefore, Sm9375 has influence on the number of produced fruiting bodies during sexual development. Additional deletion of $S m 9375$ in the $\Delta$ Smmob3 strain by means of crossing partially complemented the sterile $\Delta$ Smmob3 phenotype, indicating a genetic interaction of $S m 9375$ and Smmob3.

This study for the first time verified protein complex formation of mammalian Striatin and Mob3 homologs from a filamentous ascomycete. Moreover the essential functional role of the fungal protein complex during fruiting body development was shown. The obtained data substantially contribute to the insight of the fundamental molecular networks controlling cellular differentiation processes whose underlying components and their mode of action are at least partly conserved from filamentous fungi to mammals. 


\section{LITERATURVERZEICHNIS}

Abramova N, Sertil O, Mehta S, Lowry CV (2001) Reciprocal regulation of anaerobic and aerobic cell wall mannoprotein gene expression in Saccharomyces cerevisiae. J Bacteriol 183: 2881-2887.

Aiello DP, Fu L, Miseta A, Bedwell DM (2002) Intracellular glucose 1-phosphate and glucose 6phosphate levels modulate Ca2+ homeostasis in Saccharomyces cerevisiae. J Biol Chem 277: 45751-45758.

Aiello DP, Fu L, Miseta A, Sipos K, Bedwell DM (2004) The Ca2+ homeostasis defects in a pgm2Delta strain of Saccharomyces cerevisiae are caused by excessive vacuolar $\mathrm{Ca} 2+$ uptake mediated by the Ca2+-ATPase Pmc1p. J Biol Chem 279: 38495-38502.

Altschul SF, Madden TL, Schaffer AA, Zhang J, Zhang Z, Miller W, Lipman DJ (1997) Gapped BLAST and PSI-BLAST: a new generation of protein database search programs. Nucleic Acids Res 25: 3389-3402.

Apel K, Hirt H (2004) Reactive oxygen species: metabolism, oxidative stress, and signal transduction. Annu Rev Plant Biol 55: 373-399.

Ashman CR (1992) DNA base sequence changes in spontaneous and ethyl methanesulfonateinduced mutations of a chromosomally-integrated gene in Chinese hamster ovary cells. Mutat Res 270: 115-124.

Baillat G, Gaillard S, Castets F, Monneron A (2002) Interactions of phocein with nucleosidediphosphate kinase, Eps15, and Dynamin I. J Biol Chem 277: 18961-18966.

Baillat G, Moqrich A, Castets F, Baude A, Bailly Y, Benmerah A, Monneron A (2001) Molecular cloning and characterization of phocein, a protein found from the Golgi complex to dendritic spines. Mol Biol Cell 12: 663-673.

Bailly YJ, Castets F (2007) Phocein: A potential actor in vesicular trafficking at Purkinje cell dendritic spines. Cerebellum: 1-9.

Bao Y, Sumita K, Kudo T, Withanage K, Nakagawa K, Ikeda M, Ohno K, Wang Y, Hata Y (2009) Roles of mammalian sterile 20-like kinase 2-dependent phosphorylations of Mps one binder $1 \mathrm{~B}$ in the activation of nuclear Dbf2-related kinases. Genes Cells 14: 13691381.

Baronas-Lowell DM, Warner JR (1990) Ribosomal protein L30 is dispensable in the yeast Saccharomyces cerevisiae. Mol Cell Biol 10: 5235-5243.

Barrowman J, Wang W, Zhang Y, Ferro-Novick S (2003) The Yip1p.Yiflp complex is required for the fusion competence of endoplasmic reticulum-derived vesicles. J Biol Chem 278: 19878-19884.

Bartnicki-Garcia S, Bartnicki DD, Gierz G, Lopez-Franco R, Bracker CE (1995) Evidence that Spitzenkorper behavior determines the shape of a fungal hypha: a test of the hyphoid model. Exp Mycol 19: 153-159.

Bartoli M, Monneron A, Ladant D (1998) Interaction of calmodulin with striatin, a WD-repeat protein present in neuronal dendritic spines. J Biol Chem 273: 22248-22253.

Bartoli M, Ternaux JP, Forni C, Portalier P, Salin P, Amalric M, Monneron A (1999) Downregulation of striatin, a neuronal calmodulin-binding protein, impairs rat locomotor activity. J Neurobiol 40: 234-243.

Bayram O, Krappmann S, Ni M, Bok JW, Helmstaedt K, Valerius O, Braus-Stromeyer S, Kwon NJ, Keller NP, Yu JH, Braus GH (2008) VelB/VeA/LaeA complex coordinates light signal with fungal development and secondary metabolism. Science 320: 1504-1506.

Bean LE, Dvorachek WH, Jr., Braun EL, Errett A, Saenz GS, Giles MD, WernerWashburne M, Nelson MA, Natvig DO (2001) Analysis of the pdx-1 (snz-1/sno-1) region of the Neurospora crassa genome: correlation of pyridoxine-requiring phenotypes with mutations in two structural genes. Genetics 157: 1067-1075. 
Becker DM, Lundblad V (2001) Introduction of DNA into yeast cells. Curr Protoc Mol Biol 13: 13-17.

Bendtsen JD, Nielsen H, von Heijne G, Brunak S (2004) Improved prediction of signal peptides: SignalP 3.0. J Mol Biol 340: 783-795.

Benoist M, Baude A, Tasmadjian A, Dargent B, Kessler JP, Castets F (2008) Distribution of zinedin in the rat brain. J Neurochem 106: 969-977.

Benoist M, Gaillard S, Castets F (2006) The striatin family: a new signaling platform in dendritic spines. J Physiol Paris 99: 146-153.

Berepiki A, Lichius A, Shoji JY, Tilsner J, Read ND (2010) F-actin dynamics in Neurospora crassa. Eukaryot Cell 9: 547-557.

Bergametti F, Denier C, Labauge P, Arnoult M, Boetto S, Clanet M, Coubes P, Echenne B, Ibrahim R, Irthum B, Jacquet G, Lonjon M, Moreau JJ, Neau JP, Parker F, Tremoulet M, Tournier-Lasserve E (2005) Mutations within the programmed cell death 10 gene cause cerebral cavernous malformations. Am J Hum Genet 76: 42-51.

Berger B, Wilson DB, Wolf E, Tonchev T, Milla M, Kim PS (1995) Predicting coiled coils by use of pairwise residue correlations. Proc Natl Acad Sci U S A 92: 8259-8263.

Berndt N (2003) Roles and regulation of serine/threonine-specific protein phosphatases in the cell cycle. Prog Cell Cycle Res 5: 497-510.

Bernhards Y (2005) Analyse der Proteine PRO11, MOB1 und PHO1 aus dem Hyphenpilz Sordaria macrospora. Diplomarbeit.

Betz WJ, Mao F, Smith CB (1996) Imaging exocytosis and endocytosis. Curr Opin Neurobiol 6: 365-371.

Bichsel SJ, Tamaskovic R, Stegert MR, Hemmings BA (2004) Mechanism of activation of NDR (nuclear Dbf2-related) protein kinase by the hMOB1 protein. J Biol Chem 279: 35228-35235.

Bieganowski P, Shilinski K, Tsichlis PN, Brenner C (2004) Cdc123 and checkpoint forkhead associated with RING proteins control the cell cycle by controlling eIF2gamma abundance. J Biol Chem 279: 44656-44666.

Bilodeau PS, Urbanowski JL, Winistorfer SC, Piper RC (2002) The Vps27p Hse1p complex binds ubiquitin and mediates endosomal protein sorting. Nat Cell Biol 4: 534-539.

Birnboim HC, Doly J (1979) A rapid alkaline extraction procedure for screening recombinant plasmid DNA. Nucleic Acids Res 7: 1513-1523.

Blom N, Gammeltoft S, Brunak S (1999) Sequence and structure-based prediction of eukaryotic protein phosphorylation sites. J Mol Biol 294: 1351-1362.

Blondeau C, Gaillard S, Ternaux JP, Monneron A, Baude A (2003) Expression and distribution of phocein and members of the striatin family in neurones of rat peripheral ganglia. Histochem Cell Biol 119: 131-138.

Boehm M, Bonifacino JS (2001) Adaptins: the final recount. Mol Biol Cell 12: 2907-2920.

Boles E, Liebetrau W, Hofmann M, Zimmermann FK (1994) A family of hexosephosphate mutases in Saccharomyces cerevisiae. Eur J Biochem 220: 83-96.

Borkovich KA, Alex LA, Yarden O, Freitag M, Turner GE, Read ND, Seiler S, BellPedersen D, Paietta J, Plesofsky N, Plamann M, Goodrich-Tanrikulu M, Schulte U, Mannhaupt G, Nargang FE, Radford A, Selitrennikoff C, Galagan JE, Dunlap JC, Loros JJ, Catcheside D, Inoue H, Aramayo R, Polymenis M, Selker EU, Sachs MS, Marzluf GA, Paulsen I, Davis R, Ebbole DJ, Zelter A, Kalkman ER, O'Rourke R, Bowring F, Yeadon J, Ishii C, Suzuki K, Sakai W, Pratt R (2004) Lessons from the genome sequence of Neurospora crassa: tracing the path from genomic blueprint to multicellular organism. Microbiol Mol Biol Rev 68: 1-108.

Bowman SM, Piwowar A, Al Dabbous M, Vierula J, Free SJ (2006) Mutational analysis of the glycosylphosphatidylinositol (GPI) anchor pathway demonstrates that GPI-anchored 
proteins are required for cell wall biogenesis and normal hyphal growth in Neurospora crassa. Eukaryot Cell 5: 587-600.

Brazer SC, Singh BB, Liu X, Swaim W, Ambudkar IS (2003) Caveolin-1 contributes to assembly of store-operated $\mathrm{Ca} 2+$ influx channels by regulating plasma membrane localization of TRPC1. J Biol Chem 278: 27208-27215.

Breakspear A, Langford KJ, Momany M, Assinder SJ (2007) CopA:GFP localizes to putative Golgi equivalents in Aspergillus nidulans. FEMS Microbiol Lett 277: 90-97.

Breitman M, Zilberberg A, Caspi M, Rosin-Arbesfeld R (2008) The armadillo repeat domain of the APC tumor suppressor protein interacts with Striatin family members. Biochim Biophys Acta 1783: 1792-1802.

Brown DA, London E (1998) Functions of lipid rafts in biological membranes. Annu Rev Cell Dev Biol 14: 111-136.

Bruhn L, Sprague GF, Jr. (1994) MCM1 point mutants deficient in expression of alpha-specific genes: residues important for interaction with alpha 1. Mol Cell Biol 14: 2534-2544.

Bryson K, McGuffin LJ, Marsden RL, Ward JJ, Sodhi JS, Jones DT (2005) Protein structure prediction servers at University College London. Nucleic Acids Res 33: W36-38.

Burke E, Mahoney NM, Almo SC, Barik S (2000) Profilin is required for optimal actindependent transcription of respiratory syncytial virus genome RNA. J Virol 74: 669-675.

Burri L, Vascotto K, Fredersdorf S, Tiedt R, Hall MN, Lithgow T (2004) Zim17, a novel zinc finger protein essential for protein import into mitochondria. J Biol Chem 279: 5024350249.

Busch S, Schwier EU, Nahlik K, Bayram O, Helmstaedt K, Draht OW, Krappmann S, Valerius O, Lipscomb WN, Braus GH (2007) An eight-subunit COP9 signalosome with an intact JAMM motif is required for fungal fruit body formation. Proc Natl Acad Sci U S A 104: 8089-8094.

Cadigan KM, Nusse R (1997) Wnt signaling: a common theme in animal development. Genes Dev 11: 3286-3305.

Carroll AM, Sweigard JA, Valent B (1994) Improved vectors for selecting resistance to hygromycin. Fungal Genet. Newslett. 41: 22.

Castets F, Bartoli M, Barnier JV, Baillat G, Salin P, Moqrich A, Bourgeois JP, Denizot F, Rougon G, Calothy G, Monneron A (1996) A novel calmodulin-binding protein, belonging to the WD-repeat family, is localized in dendrites of a subset of CNS neurons. $\mathbf{J}$ Cell Biol 134: 1051-1062.

Castets F, Rakitina T, Gaillard S, Moqrich A, Mattei MG, Monneron A (2000) Zinedin, SG2NA, and striatin are calmodulin-binding, WD repeat proteins principally expressed in the brain. J Biol Chem 275: 19970-19977.

Chalmers JH, Jr., Seale TW (1971) Supersuppressible mutants in Neurospora: mutants at the tryp-1 and tryp-2 loci affecting the structure of the multienzyme complex in the tryptophan pathway. Genetics 67: 353-363.

Chen HW, Marinissen MJ, Oh SW, Chen X, Melnick M, Perrimon N, Gutkind JS, Hou SX (2002) CKA, a novel multidomain protein, regulates the JUN N-terminal kinase signal transduction pathway in Drosophila. Mol Cell Biol 22: 1792-1803.

Chen K, Keaney $\mathbf{J}$ (2004) Reactive oxygen species-mediated signal transduction in the endothelium. Endothelium 11: 109-121.

Chou JJ, Li S, Klee CB, Bax A (2001) Solution structure of $\mathrm{Ca}(2+)$-calmodulin reveals flexible hand-like properties of its domains. Nat Struct Biol 8: 990-997.

Chow A, Hao Y, Yang X (2010) Molecular characterization of human homologs of yeast MOB1. Int J Cancer 126: 2079-2089.

Christianson TW, Sikorski RS, Dante M, Shero JH, Hieter P (1992) Multifunctional yeast high-copy-number shuttle vectors. Gene 110: 119-122. 
Cole L, Orlovich DA, Ashford AE (1998) Structure, function, and motility of vacuoles in filamentous fungi. Fungal Genet Biol 24: 86-100.

Collins BM, McCoy AJ, Kent HM, Evans PR, Owen DJ (2002) Molecular architecture and functional model of the endocytic AP2 complex. Cell 109: 523-535.

Colomer J, Means AR (2007) Physiological roles of the Ca2+/CaM-dependent protein kinase cascade in health and disease. Subcell Biochem 45: 169-214.

Colot HV, Park G, Turner GE, Ringelberg C, Crew CM, Litvinkova L, Weiss RL, Borkovich KA, Dunlap JC (2006) A high-throughput gene knockout procedure for Neurospora reveals functions for multiple transcription factors. Proc Natl Acad Sci U S A 103: 10352-10357.

Cosson P, Demolliere C, Hennecke S, Duden R, Letourneur F (1996) Delta- and zeta-COP, two coatomer subunits homologous to clathrin-associated proteins, are involved in ER retrieval. EMBO J 15: 1792-1798.

Couet J, Li S, Okamoto T, Ikezu T, Lisanti MP (1997) Identification of peptide and protein ligands for the caveolin-scaffolding domain. Implications for the interaction of caveolin with caveolae-associated proteins. J Biol Chem 272: 6525-6533.

Das T, Mathur M, Gupta AK, Janssen GM, Banerjee AK (1998) RNA polymerase of vesicular stomatitis virus specifically associates with translation elongation factor-1 alphabetagamma for its activity. Proc Natl Acad Sci U S A 95: 1449-1454.

De BP, Burdsall AL, Banerjee AK (1993) Role of cellular actin in human parainfluenza virus type 3 genome transcription. J Biol Chem 268: 5703-5710.

Devroe E, Erdjument-Bromage H, Tempst P, Silver PA, . (2004) Human Mob proteins regulate the NDR1 and NDR2 serine-threonine kinases. J Biol Chem 279: 24444-24451.

Dodge-Kafka KL, Bauman A, Kapiloff MS (2008) A-kinase anchoring proteins as the basis for cAMP signaling. Handb Exp Pharmacol: 3-14.

Dolan JW, Kirkman C, Fields S (1989) The yeast STE12 protein binds to the DNA sequence mediating pheromone induction. Proc Natl Acad Sci U S A 86: 5703-5707.

Duchen MR, Verkhratsky A, Muallem S (2008) Mitochondria and calcium in health and disease. Cell Calcium 44: 1-5.

Dupree P, Parton RG, Raposo G, Kurzchalia TV, Simons K (1993) Caveolae and sorting in the trans-Golgi network of epithelial cells. EMBO J 12: 1597-1605.

Durr G, Strayle J, Plemper R, Elbs S, Klee SK, Catty P, Wolf DH, Rudolph HK (1998) The medial-Golgi ion pump Pmr1 supplies the yeast secretory pathway with $\mathrm{Ca} 2+$ and $\mathrm{Mn} 2+$ required for glycosylation, sorting, and endoplasmic reticulum-associated protein degradation. Mol Biol Cell 9: 1149-1162.

Eisenhaber B, Bork P, Eisenhaber F (1998) Sequence properties of GPI-anchored proteins near the omega-site: constraints for the polypeptide binding site of the putative transamidase. Protein Eng 11: 1155-1161.

Eisenhaber B, Bork P, Eisenhaber F (2001) Post-translational GPI lipid anchor modification of proteins in kingdoms of life: analysis of protein sequence data from complete genomes. Protein Eng 14: 17-25.

Elleuche S, Bernhards Y, Schäfers C, Varghese JM, Nolting N, Pöggeler S (2010) The small serine-threonine protein SIP2 interacts with STE12 and is involved in ascospore germination in Sordaria macrospora. Eur J Cell Biol doi:10.1016/j.ejcb.2010.06.014.

Elleuche S, Pöggeler S (2008) Visualization of peroxisomes via SKL-tagged DsRed protein in Sordaria macrospora. Fungal Genet Rep 55: 9-12.

Elleuche S, Pöggeler S (2009) Beta-carbonic anhydrases play a role in fruiting body development and ascospore germination in the filamentous fungus Sordaria macrospora. PLoS One 4: e5177.

Engh I, Nowrousian M, Kück U (2010) Sordaria macrospora, a model organism to study fungal cellular development. Eur J Cell Biol. 
Engh I, Würtz C, Witzel-Schlömp K, Zhang HY, Hoff B, Nowrousian M, Rottensteiner H, Kück U (2007) The WW domain protein PRO40 is required for fungal fertility and associates with Woronin bodies. Eukaryot Cell 6: 831-843.

Englund PT (1993) The structure and biosynthesis of glycosyl phosphatidylinositol protein anchors. Annu Rev Biochem 62: 121-138.

Esser K (1982) Cryptogams-Cyanaobacteria, Fungi, Algae and Lichens. Cambridge University Press, London.

Feinberg AP, Vogelstein B (1983) A technique for radiolabeling DNA restriction endonuclease fragments to high specific activity. Anal Biochem 132: 6-13.

Ferguson MA, Low MG, Cross GA (1985) Glycosyl-sn-1,2-dimyristylphosphatidylinositol is covalently linked to Trypanosoma brucei variant surface glycoprotein. J Biol Chem 260: 14547-14555.

Ferguson MA, Williams AF (1988) Cell-surface anchoring of proteins via glycosylphosphatidylinositol structures. Annu Rev Biochem 57: 285-320.

Fleissner A, Diamond S, Glass NL (2009) The Saccharomyces cerevisiae PRM1 homolog in Neurospora crassa is involved in vegetative and sexual cell fusion events but also has postfertilization functions. Genetics 181: 497-510.

Fleissner A, Sarkar S, Jacobson DJ, Roca MG, Read ND, Glass NL (2005) The so locus is required for vegetative cell fusion and postfertilization events in Neurospora crassa. Eukaryot Cell 4: 920-930.

Fong HK, Hurley JB, Hopkins RS, Miake-Lye R, Johnson MS, Doolittle RF, Simon MI (1986) Repetitive segmental structure of the transducin beta subunit: homology with the CDC4 gene and identification of related mRNAs. Proc Natl Acad Sci U S A 83: 21622166.

Friedrichson T, Kurzchalia TV (1998) Microdomains of GPI-anchored proteins in living cells revealed by crosslinking. Nature 394: 802-805.

Fujimoto T, Hagiwara H, Aoki T, Kogo H, Nomura R (1998) Caveolae: from a morphological point of view. J Electron Microsc (Tokyo) 47: 451-460.

Fujimura M, Ochiai N, Oshima M, Motoyama T, Ichiishi A, Usami R, Horikoshi K, Yamaguchi I (2003) Putative homologs of SSK22 MAPKK kinase and PBS2 MAPK kinase of Saccharomyces cerevisiae encoded by os-4 and os-5 genes for osmotic sensitivity and fungicide resistance in Neurospora crassa. Biosci Biotechnol Biochem 67: 186-191.

Gabriel K, Milenkovic D, Chacinska A, Muller J, Guiard B, Pfanner N, Meisinger C (2007) Novel mitochondrial intermembrane space proteins as substrates of the MIA import pathway. J Mol Biol 365: 612-620.

Gaillard S, Bailly Y, Benoist M, Rakitina T, Kessler JP, Fronzaroli-Molinieres L, Dargent B, Castets F (2006) Targeting of proteins of the striatin family to dendritic spines: role of the coiled-coil domain. Traffic 7: 74-84.

Gaillard S, Bartoli M, Castets F, Monneron A (2001) Striatin, a calmodulin-dependent scaffolding protein, directly binds caveolin-1. FEBS Lett 508: 49-52.

Gasteiger E, Hoogland C, Gattiker A, Duvaud S, Wilkins MR, Appel RD, Bairoch A (2005) Protein Identification and Analysis Tools on the ExPASy Server. In: Walker, J.M. (ed) The Proteomics Handbook. Humana Press, New York, pp. 571-607.

Gaulton GN, Pratt JC (1994) Glycosylated phosphatidylinositol molecules as second messengers. Semin Immunol 6: 97-104.

George R, Beddoe T, Landl K, Lithgow T (1998) The yeast nascent polypeptide-associated complex initiates protein targeting to mitochondria in vivo. Proc Natl Acad Sci U S A 95: 2296-2301. 
Gerber LD, Kodukula K, Udenfriend S (1992) Phosphatidylinositol glycan (PI-G) anchored membrane proteins. Amino acid requirements adjacent to the site of cleavage and PI-G attachment in the COOH-terminal signal peptide. J Biol Chem 267: 12168-12173.

Germann UA, Muller G, Hunziker PE, Lerch K (1988) Characterization of two allelic forms of Neurospora crassa laccase. Amino- and carboxyl-terminal processing of a precursor. J Biol Chem 263: 885-896.

Glass NL, Jacobson DJ, Shiu PK (2000) The genetics of hyphal fusion and vegetative incompatibility in filamentous ascomycete fungi. Annu Rev Genet 34: 165-186.

Glass NL, Rasmussen C, Roca MG, Read ND (2004) Hyphal homing, fusion and mycelial interconnectedness. Trends Microbiol 12: 135-141.

Gonzalez L, Jr., Woolfson DN, Alber T (1996) Buried polar residues and structural specificity in the GCN4 leucine zipper. Nat Struct Biol 3: 1011-1018.

Goudreault M, D'Ambrosio LM, Kean MJ, Mullin M, Larsen BG, Sanchez A, Chaudhry S, Chen GI, Sicheri F, Nesvizhskii AI, Aebersold R, Raught B, Gingras AC (2009) A PP2A phosphatase high-density interaction network identifies a novel striatin-interacting phosphatase and kinase complex linked to the cerebral cavernous malformation 3 (CCM3) protein. Mol Cell Proteomics 8: 157-171.

Groll M, Heinemeyer W, Jager S, Ullrich T, Bochtler M, Wolf DH, Huber R (1999) The catalytic sites of $20 \mathrm{~S}$ proteasomes and their role in subunit maturation: a mutational and crystallographic study. Proc Natl Acad Sci U S A 96: 10976-10983.

Guclu B, Ozturk AK, Pricola KL, Bilguvar K, Shin D, O'Roak BJ, Gunel M (2005) Mutations in apoptosis-related gene, PDCD10, cause cerebral cavernous malformation 3. Neurosurgery 57: 1008-1013.

Gustin MC, Albertyn J, Alexander M, Davenport K (1998) MAP kinase pathways in the yeast Saccharomyces cerevisiae. Microbiol Mol Biol Rev 62: 1264-1300.

Haeberle AM, Castets F, Bombarde G, Baillat G, Bailly Y (2006) Immunogold localization of phocein in dendritic spines. J Comp Neurol 495: 336-350.

Hamasaki-Katagiri N, Tabor CW, Tabor H (1997) Spermidine biosynthesis in Saccharomyces cerevisae: polyamine requirement of a null mutant of the SPE3 gene (spermidine synthase). Gene 187: 35-43.

Hanahan D, Jessee J, Bloom FR (1991) Plasmid transformation of Escherichia coli and other bacteria. Methods Enzymol 204: 63-113.

Hatzfeld M (1999) The armadillo family of structural proteins. Int Rev Cytol 186: 179-224.

He Y, Emoto K, Fang X, Ren N, Tian X, Jan YN, Adler PN (2005) Drosophila Mob family proteins interact with the related tricornered (Trc) and warts (Wts) kinases. Mol Biol Cell 16: 4139-4152.

Heidtman M, Chen CZ, Collins RN, Barlowe C (2005) Yos1p is a novel subunit of the Yip1pYiflp complex and is required for transport between the endoplasmic reticulum and the Golgi complex. Mol Biol Cell 16: 1673-1683.

Hergovich A, Bichsel SJ, Hemmings BA (2005) Human NDR kinases are rapidly activated by MOB proteins through recruitment to the plasma membrane and phosphorylation. Mol Cell Biol 25: 8259-8272.

Heriche JK, Lebrin F, Rabilloud T, Leroy D, Chambaz EM, Goldberg Y (1997) Regulation of protein phosphatase $2 \mathrm{~A}$ by direct interaction with casein kinase 2alpha. Science 276: 952-955.

Herskowitz I (1995) MAP kinase pathways in yeast: for mating and more. Cell 80: 187-197.

Hickey PC, Jacobson D, Read ND, Louise Glass NL (2002) Live-cell imaging of vegetative hyphal fusion in Neurospora crassa. Fungal Genet Biol 37: 109-119.

Higuchi Y, Nakahama T, Shoji JY, Arioka M, Kitamoto K (2006) Visualization of the endocytic pathway in the filamentous fungus Aspergillus oryzae using an EGFP-fused plasma membrane protein. Biochem Biophys Res Commun 340: 784-791. 
Hochstrasser M (1996) Ubiquitin-dependent protein degradation. Annu Rev Genet 30: 405-439.

Horikami SM, Smallwood S, Bankamp B, Moyer SA (1994) An amino-proximal domain of the $\mathrm{L}$ protein binds to the $\mathrm{P}$ protein in the measles virus RNA polymerase complex. Virology 205: 540-545.

Hou MC, Guertin DA, McCollum D (2004) Initiation of cytokinesis is controlled through multiple modes of regulation of the Sid2p-Mob1p kinase complex. Mol Cell Biol 24: 3262-3276.

Hou MC, Wiley DJ, Verde F, McCollum D (2003) Mob2p interacts with the protein kinase Orb6p to promote coordination of cell polarity with cell cycle progression. J Cell Sci 116: 125-135.

Huang X, Miller M (1991) A time-efficient, linear-space local similarity algorithm. Adv. Appl. Math. 12: 337-357.

Hurley JH (1999) Structure, mechanism, and regulation of mammalian adenylyl cyclase. J Biol Chem 274: 7599-7602.

Ichi-ishi A, Inoue H (1995) Cloning, nucleotide sequence, and expression of tef-1, the gene encoding translation elongation factor 1 alpha (EF-1 alpha) of Neurospora crassa. Jpn J Genet 70: 273-287.

Ikezawa H (2002) Glycosylphosphatidylinositol (GPI)-anchored proteins. Biol Pharm Bull 25: 409-417.

Illinger D, Kuhry JG (1994) The kinetic aspects of intracellular fluorescence labeling with TMA-DPH support the maturation model for endocytosis in L929 cells. J Cell Biol 125: 783-794.

Jacobsen S, Wittig M, Pöggeler S (2002) Interaction between mating-type proteins from the homothallic fungus Sordaria macrospora. Curr Genet 41: 150-158.

Jager S, Groll M, Huber R, Wolf DH, Heinemeyer W (1999) Proteasome beta-type subunits: unequal roles of propeptides in core particle maturation and a hierarchy of active site function. J Mol Biol 291: 997-1013.

James P, Halladay J, Craig EA (1996) Genomic libraries and a host strain designed for highly efficient two-hybrid selection in yeast. Genetics 144: 1425-1236.

Janssens V, Goris J (2001) Protein phosphatase 2A: a highly regulated family of serine/threonine phosphatases implicated in cell growth and signalling. Biochem J 353: 417-439.

Janus D, Hoff B, Hofmann E, Kück U (2007) An efficient fungal RNA-silencing system using the DsRed reporter gene. Appl Environ Microbiol 73: 962-970.

Jones CA, Greer-Phillips SE, Borkovich KA (2007) The response regulator RRG-1 functions upstream of a mitogen-activated protein kinase pathway impacting asexual development, female fertility, osmotic stress, and fungicide resistance in Neurospora crassa. Mol Biol Cell 18: 2123-2136.

Kachidian P, Vuillet J, Bartoli M, Castets F, Nieoullon A, Kerkerian-Le Goff L (1998) Relationships between striatin-containing neurons and cortical or thalamic afferent fibres in the rat striatum. An ultrastructural study by dual labelling. Neuroscience 85: 111-122.

Kaksonen M, Sun Y, Drubin DG (2003) A pathway for association of receptors, adaptors, and actin during endocytic internalization. Cell 115: 475-487.

Kaksonen M, Toret CP, Drubin DG (2006) Harnessing actin dynamics for clathrin-mediated endocytosis. Nat Rev Mol Cell Biol 7: 404-414.

Kammerer RA (1997) Alpha-helical coiled-coil oligomerization domains in extracellular proteins. Matrix Biol 15: 555-565; discussion 567-558.

Karkkainen S, Hiipakka M, Wang JH, Kleino I, Vaha-Jaakkola M, Renkema GH, Liss M, Wagner R, Saksela K (2006) Identification of preferred protein interactions by phagedisplay of the human Src homology-3 proteome. EMBO Rep 7: 186-191.

Kasuga T, Glass NL (2008) Dissecting colony development of Neurospora crassa using mRNA profiling and comparative genomics approaches. Eukaryot Cell 7: 1549-1564. 
Katagiri S, Onai K, Nakashima H (1998) Spermidine determines the sensitivity to the calmodulin antagonist, chlorpromazine, for the circadian conidiation rhythm but not for the mycelial growth in Neurospora crassa. J Biol Rhythms 13: 452-460.

Kaushik R, Shaila MS (2004) Cellular casein kinase II-mediated phosphorylation of rinderpest virus $\mathrm{P}$ protein is a prerequisite for its role in replication/transcription of the genome. $\mathrm{J}$ Gen Virol 85: 687-691.

Keegan L, Gill G, Ptashne M (1986) Separation of DNA binding from the transcriptionactivating function of a eukaryotic regulatory protein. Science 231: 699-704.

Kemp HA, Sprague GF, Jr. (2003) Far3 and five interacting proteins prevent premature recovery from pheromone arrest in the budding yeast Saccharomyces cerevisiae. Mol Cell Biol 23: 1750-1763.

Klionsky DJ, Herman PK, Emr SD (1990) The fungal vacuole: composition, function, and biogenesis. Microbiol Rev 54: 266-292.

Klix V, Nowrousian M, Ringelberg C, Loros JJ, Dunlap JC, Pöggeler S (2010) Functional characterization of MAT1-1-specific mating-type genes in the homothallic ascomycete Sordaria macrospora provides new insights into essential and non-essential sexual regulators. Eukaryot Cell in press.

Kobayashi T, Nishizaki R, Ikezawa H (1997) The presence of GPI-linked protein(s) in an archaeobacterium, Sulfolobus acidocaldarius, closely related to eukaryotes. Biochim Biophys Acta 1334: 1-4.

Kooi EA, Rutgers CA, Kleijmeer MJ, van 't Riet J, Venema J, Raue HA (1994) Mutational analysis of the C-terminal region of Saccharomyces cerevisiae ribosomal protein L25 in vitro and in vivo demonstrates the presence of two distinct functional elements. J Mol Biol 240: 243-255.

Krause-Buchholz U, Gey U, Wunschmann J, Becker S, Rodel G (2006) YIL042c and YOR090c encode the kinase and phosphatase of the Saccharomyces cerevisiae pyruvate dehydrogenase complex. FEBS Lett 580: 2553-2560.

Kubler E, Riezman H (1993) Actin and fimbrin are required for the internalization step of endocytosis in yeast. EMBO J 12: 2855-2862.

Kück U (2005) A Sordaria macrospora mutant lacking the leul gene shows a developmental arrest during fruiting body formation. Mol Genet Genomics 274: 307-315.

Kück U, Pöggeler S, Nowrousian M, Nolting N, Engh I (2009) Sordaria macrospora, a model system for fungal development. In: Anke, T., and Weber, D. (eds) THE MYCOTA XV, Physiology and Genetics: Selected Basic and Applied Aspects. Springer Verlag, Heidelberg, pp. 17-39.

Kuge S, Jones N, Nomoto A (1997) Regulation of yAP-1 nuclear localization in response to oxidative stress. EMBO J 16: 1710-1720.

Lai ZC, Wei X, Shimizu T, Ramos E, Rohrbaugh M, Nikolaidis N, Ho LL, Li Y (2005) Control of cell proliferation and apoptosis by mob as tumor suppressor, mats. Cell 120: 675-685.

Lakhan SE, Sabharanjak S, De A (2009) Endocytosis of glycosylphosphatidylinositol-anchored proteins. J Biomed Sci 16: 93.

Lambright DG, Sondek J, Bohm A, Skiba NP, Hamm HE, Sigler PB (1996) The 2.0 A crystal structure of a heterotrimeric G protein. Nature 379: 311-319.

Landberg G, Tan EM (1994) Characterization of a DNA-binding nuclear autoantigen mainly associated with S phase and G2 cells. Exp Cell Res 212: 255-261.

Lecellier G, Silar P (1994) Rapid methods for nucleic acids extraction from Petri dish-grown mycelia. Curr Genet 25: 122-123.

Lechward K, Awotunde OS, Swiatek W, Muszynska G (2001) Protein phosphatase 2A: variety of forms and diversity of functions. Acta Biochim Pol 48: 921-933. 
Lee SE, Frenz LM, Wells NJ, Johnson AL, Johnston LH (2001) Order of function of the budding-yeast mitotic exit-network proteins Tem1, Cdc15, Mob1, Dbf2, and Cdc5. Curr Biol 11: 784-788.

Li D, Bobrowicz P, Wilkinson HH, Ebbole DJ (2005) A mitogen-activated protein kinase pathway essential for mating and contributing to vegetative growth in Neurospora crassa. Genetics 170: 1091-1104.

Li D, Roberts R (2001) WD-repeat proteins: structure characteristics, biological function, and their involvement in human diseases. Cell Mol Life Sci 58: 2085-2097.

Li H, Zhou H, Luo Y, Ouyang H, Hu H, Jin C (2007) Glycosylphosphatidylinositol (GPI) anchor is required in Aspergillus fumigatus for morphogenesis and virulence. Mol Microbiol 64: 1014-1027.

Li S, Couet J, Lisanti MP (1996a) Src tyrosine kinases, Galpha subunits, and H-Ras share a common membrane-anchored scaffolding protein, caveolin. Caveolin binding negatively regulates the auto-activation of Src tyrosine kinases. J Biol Chem 271: 29182-29190.

Li S, Song KS, Lisanti MP (1996b) Expression and characterization of recombinant caveolin. Purification by polyhistidine tagging and cholesterol-dependent incorporation into defined lipid membranes. J Biol Chem 271: 568-573.

Lu Q, Pallas DC, Surks HK, Baur WE, Mendelsohn ME, Karas RH (2004) Striatin assembles a membrane signaling complex necessary for rapid, nongenomic activation of endothelial NO synthase by estrogen receptor alpha. Proc Natl Acad Sci U S A 101: 17126-17131.

Luca FC, Mody M, Kurischko C, Roof DM, Giddings TH, Winey M (2001) Saccharomyces cerevisiae Mob1p is required for cytokinesis and mitotic exit. Mol Cell Biol 21: 69726983.

Luca FC, Winey M (1998) $M O B 1$, an essential yeast gene required for completion of mitosis and maintenance of ploidy. Mol Biol Cell 9: 29-46.

Lupas A (1996) Prediction and analysis of coiled-coil structures. Methods Enzymol 266: 513 525.

Ma HL, Peng YL, Gong L, Liu WB, Sun S, Liu J, Zheng CB, Fu H, Yuan D, Zhao J, Chen PC, Xie SS, Zeng XM, Xiao YM, Liu Y, Li DW (2009) The goldfish SG2NA gene encodes two alpha-type regulatory subunits for PP-2A and displays distinct developmental expression pattern. Gene Regul Syst Bio 3: 115-129.

Ma J, Benz C, Grimaldi R, Stockdale C, Wyatt P, Frearson J, Hammarton TC (2010) Nuclear DBF-2-related kinases are essential regulators of cytokinesis in bloodstream stage Trypanosoma brucei. J Biol Chem 285: 15356-15368.

Maddi A, Bowman SM, Free SJ (2009) Trifluoromethanesulfonic acid-based proteomic analysis of cell wall and secreted proteins of the ascomycetous fungi Neurospora crassa and Candida albicans. Fungal Genet Biol 46: 768-781.

Madhani HD, Fink GR (1997) Combinatorial control required for the specificity of yeast MAPK signaling. Science 275: 1314-1317.

Maerz S, Dettmann A, Ziv C, Liu Y, Valerius O, Yarden O, Seiler S (2009) Two NDR kinase-MOB complexes function as distinct modules during septum formation and tip extension in Neurospora crassa. Mol Microbiol 74: 707-723.

Maerz S, Ziv C, Vogt N, Helmstaedt K, Cohen N, Gorovits R, Yarden O, Seiler S (2008) The nuclear Dbf2-related kinase COT1 and the mitogen-activated protein kinases MAK1 and MAK2 genetically interact to regulate filamentous growth, hyphal fusion and sexual development in Neurospora crassa. Genetics 179: 1313-1325.

Maller JL (2003) Signal transduction. Fishing at the cell surface. Science 300: 594-595.

Mannhaupt G, Montrone C, Haase D, Mewes HW, Aign V, Hoheisel JD, Fartmann B, Nyakatura G, Kempken F, Maier J, Schulte U (2003) What's in the genome of a filamentous fungus? Analysis of the Neurospora genome sequence. Nucleic Acids Res 31: 1944-1954. 
Marie C, Leyde S, White TC (2008) Cytoplasmic localization of sterol transcription factors Upc2p and Ecm22p in S. cerevisiae. Fungal Genet Biol 45: 1430-1438.

Marion RM, Regev A, Segal E, Barash Y, Koller D, Friedman N, O'Shea EK (2004) Sfp1 is a stress- and nutrient-sensitive regulator of ribosomal protein gene expression. Proc Natl Acad Sci U S A 101: 14315-14322.

Masloff S, Jacobsen S, Pöggeler S, Kück U (2002) Functional analysis of the C6 zinc finger gene prol involved in fungal sexual development. Fungal Genet Biol 36: 107-116.

Masloff S, Pöggeler S, Kück U (1999) The prol(+) gene from Sordaria macrospora encodes a C6 zinc finger transcription factor required for fruiting body development. Genetics 152: 191-199.

Mayer BJ (2001) SH3 domains: complexity in moderation. J Cell Sci 114: 1253-1263.

Mayrhofer S, Pöggeler S (2005) Functional characterization of an alpha-factor-like Sordaria macrospora peptide pheromone and analysis of its interaction with its cognate receptor in Saccharomyces cerevisiae. Eukaryot Cell 4: 661-672.

McNew JA, Coe JG, Sogaard M, Zemelman BV, Wimmer C, Hong W, Sollner TH (1998) Gos1p, a Saccharomyces cerevisiae SNARE protein involved in Golgi transport. FEBS Lett 435: 89-95.

Mellman I (1996) Endocytosis and molecular sorting. Annu Rev Cell Dev Biol 12: 575-625.

Menon AK (1995) Flippases. Trends Cell Biol 5: 355-360.

Merzlyak EM, Goedhart J, Shcherbo D, Bulina ME, Shcheglov AS, Fradkov AF, Gaintzeva A, Lukyanov KA, Lukyanov S, Gadella TW, Chudakov DM (2007) Bright monomeric red fluorescent protein with an extended fluorescence lifetime. Nat Methods 4: 555-557.

Meurs KM, Mauceli E, Lahmers S, Acland GM, White SN, Lindblad-Toh K (2010) Genomewide association identifies a deletion in the 3' untranslated region of Striatin in a canine model of arrhythmogenic right ventricular cardiomyopathy. Hum Genet 128: 315-324.

Mongiovi AM, Romano PR, Panni S, Mendoza M, Wong WT, Musacchio A, Cesareni G, Di Fiore PP (1999) A novel peptide-SH3 interaction. EMBO J 18: 5300-5309.

Moqrich A, Mattei MG, Bartoli M, Rakitina T, Baillat G, Monneron A, Castets F (1998) Cloning of human striatin cDNA (STRN), gene mapping to 2p22-p21, and preferential expression in brain. Genomics 51: 136-139.

Moreno CS, Lane WS, Pallas DC (2001) A mammalian homolog of yeast $M O B 1$ is both a member and a putative substrate of striatin family-protein phosphatase $2 \mathrm{~A}$ complexes. $\mathrm{J}$ Biol Chem 276: 24253-24260.

Moreno CS, Park S, Nelson K, Ashby D, Hubalek F, Lane WS, Pallas DC (2000) WD40 repeat proteins striatin and $\mathrm{S} / \mathrm{G}(2)$ nuclear autoantigen are members of a novel family of calmodulin-binding proteins that associate with protein phosphatase 2A. J Biol Chem 275: 5257-5263.

Morita N, Nakazato H, Okuyama H, Kim Y, Thompson GA, Jr. (1996) Evidence for a glycosylinositolphospholipid-anchored alkaline phosphatase in the aquatic plant Spirodela oligorrhiza. Biochim Biophys Acta 1290: 53-62.

Moyer SA, Baker SC, Horikami SM (1990) Host cell proteins required for measles virus reproduction. J Gen Virol 71 ( Pt 4): 775-783.

Mrkobrada S, Boucher L, Ceccarelli DF, Tyers M, Sicheri F (2006) Structural and functional analysis of Saccharomyces cerevisiae Mob1. J Mol Biol. 362: 430-440.

Mullis KB, Faloona FA (1987) Specific synthesis of DNA in vitro via a polymerase-catalyzed chain reaction. Methods Enzymol 155: 335-350.

Munn AL, Stevenson BJ, Geli MI, Riezman H (1995) end5, end6, and end7: mutations that cause actin delocalization and block the internalization step of endocytosis in Saccharomyces cerevisiae. Mol Biol Cell 6: 1721-1742. 
Murata M, Peranen J, Schreiner R, Wieland F, Kurzchalia TV, Simons K (1995) VIP21/caveolin is a cholesterol-binding protein. Proc Natl Acad Sci U S A 92: 1033910343.

Murata T, Lin MI, Stan RV, Bauer PM, Yu J, Sessa WC (2007) Genetic evidence supporting caveolae microdomain regulation of calcium entry in endothelial cells. J Biol Chem 282: 16631-16643.

Muro Y, Chan EK, Landberg G, Tan EM (1995) A cell-cycle nuclear autoantigen containing WD-40 motifs expressed mainly in S and G2 phase cells. Biochem Biophys Res Commun 207: 1029-1037.

Musacchio A, Gibson T, Lehto VP, Saraste M (1992) SH3--an abundant protein domain in search of a function. FEBS Lett 307: 55-61.

Muthusamy V, Piva TJ (2010) The UV response of the skin: a review of the MAPK, NFkappaB and TNFalpha signal transduction pathways. Arch Dermatol Res 302: 5-17.

Nash HM, Bruner SD, Scharer OD, Kawate T, Addona TA, Spooner E, Lane WS, Verdine GL (1996) Cloning of a yeast 8-oxoguanine DNA glycosylase reveals the existence of a base-excision DNA-repair protein superfamily. Curr Biol 6: 968-980.

Neer EJ, Schmidt CJ, Nambudripad R, Smith TF (1994) The ancient regulatory-protein family of WD-repeat proteins. Nature 371: 297-300.

Newcombe KD, Griffiths AJ (1973) The suppression of AD-3B mutants by supersuppressors in Neurospora crassa. Genetics 75: 615-622.

Ni L, Snyder M (2001) A genomic study of the bipolar bud site selection pattern in Saccharomyces cerevisiae. Mol Biol Cell 12: 2147-2170.

Noguchi R, Banno S, Ichikawa R, Fukumori F, Ichiishi A, Kimura M, Yamaguchi I, Fujimura M (2007) Identification of OS-2 MAP kinase-dependent genes induced in response to osmotic stress, antifungal agent fludioxonil, and heat shock in Neurospora crassa. Fungal Genet Biol 44: 208-218.

Nolting N, Bernhards Y, Pöggeler S (2009) SmATG7 is required for viability in the homothallic ascomycete Sordaria macrospora. Fungal Genet Biol 46: 531-542.

Nolting N, Pöggeler S (2006a) A MADS box protein interacts with a mating-type protein and is required for fruiting body development in the homothallic ascomycete Sordaria macrospora. Eukaryot Cell 5: 1043-1056.

Nolting N, Pöggeler S (2006b) A STE12 homologue of the homothallic ascomycete Sordaria macrospora interacts with the MADS box protein MCM1 and is required for ascosporogenesis. Mol Microbiol 62: 853-868.

Nosaka K, Nishimura H, Kawasaki Y, Tsujihara T, Iwashima A (1994) Isolation and characterization of the THI6 gene encoding a bifunctional thiamin-phosphate pyrophosphorylase/hydroxyethylthiazole kinase from Saccharomyces cerevisiae. J Biol Chem 269: 30510-30516.

Nosjean O, Briolay A, Roux B (1997) Mammalian GPI proteins: sorting, membrane residence and functions. Biochim Biophys Acta 1331: 153-186.

Nowrousian M, Cebula P (2005) The gene for a lectin-like protein is transcriptionally activated during sexual development, but is not essential for fruiting body formation in the filamentous fungus Sordaria macrospora. BMC Microbiol 5: 64.

Nowrousian M, Frank S, Koers S, Strauch P, Weitner T, Ringelberg C, Dunlap JC, Loros JJ, Kück U (2007) The novel ER membrane protein PRO41 is essential for sexual development in the filamentous fungus Sordaria macrospora. Mol Microbiol 64: 923-937.

Nowrousian M, Masloff S, Pöggeler S, Kück U (1999) Cell differentiation during sexual development of the fungus Sordaria macrospora requires ATP citrate lyase activity. Mol Cell Biol 19: 450-460.

Nowrousian M, Stajich JE, Chu M, Engh I, Espagne E, Halliday K, Kamerewerd J, Kempken F, Knab B, Kuo HC, Osiewacz HD, Poggeler S, Read ND, Seiler S, Smith 
KM, Zickler D, Kuck U, Freitag M (2010) De novo assembly of a 40 Mb eukaryotic genome from short sequence reads: Sordaria macrospora, a model organism for fungal morphogenesis. PLoS Genet 6: e1000891.

Nowrousian M, Würtz C, Pöggeler S, Kück U (2004) Comparative sequence analysis of Sordaria macrospora and Neurospora crassa as a means to improve genome annotation. Fungal Genet Biol 41: 285-292.

Ohno H (2006) Physiological roles of clathrin adaptor AP complexes: lessons from mutant animals. J Biochem 139: 943-948.

Padilla PA, Fuge EK, Crawford ME, Errett A, Werner-Washburne M (1998) The highly conserved, coregulated $S N O$ and $S N Z$ gene families in Saccharomyces cerevisiae respond to nutrient limitation. J Bacteriol 180: 5718-5726.

Paluh JL, Zalkin H (1983) Isolation of Saccharomyces cerevisiae TRP3. J Bacteriol 153: 345349.

Pandey A, Roca MG, Read ND, Glass NL (2004) Role of a mitogen-activated protein kinase pathway during conidial germination and hyphal fusion in Neurospora crassa. Eukaryot Cell 3: 348-358.

Pani B, Singh BB (2009) Lipid rafts/caveolae as microdomains of calcium signaling. Cell Calcium 45: 625-633.

Park JH, Aravind L, Wolff EC, Kaevel J, Kim YS, Park MH (2006) Molecular cloning, expression, and structural prediction of deoxyhypusine hydroxylase: a HEAT-repeatcontaining metalloenzyme. Proc Natl Acad Sci U S A 103: 51-56.

Patel HH, Murray F, Insel PA (2008) Caveolae as organizers of pharmacologically relevant signal transduction molecules. Annu Rev Pharmacol Toxicol 48: 359-391.

Petralia RS, Wang YX, Wenthold RJ (2003) Internalization at glutamatergic synapses during development. Eur J Neurosci 18: 3207-3217.

Pfaffl MW, Horgan GW, Dempfle L (2002) Relative expression software tool (REST) for group-wise comparison and statistical analysis of relative expression results in real-time PCR. Nucleic Acids Res 30: e36.

Pike LJ (2006) Rafts defined: a report on the Keystone Symposium on Lipid Rafts and Cell Function. J Lipid Res 47: 1597-1598.

Planta RJ, Mager WH (1998) The list of cytoplasmic ribosomal proteins of Saccharomyces cerevisiae. Yeast 14: 471-477.

Pöggeler S (1997) Sequence characteristics within nuclear genes from Sordaria macrospora. Fungal Genet. Newslett. 41: 41-44.

Pöggeler S, Kück U (2004) A WD40 repeat protein regulates fungal cell differentiation and can be replaced functionally by the mammalian homologue striatin. Eukaryot Cell 3: 232-240.

Pöggeler S, Kück U (2006) Highly efficient generation of signal transduction knockout mutants using a fungal strain deficient in the mammalian ku70 ortholog. Gene 378: 1-10.

Pöggeler S, Masloff S, Hoff B, Mayrhofer S, Kück U (2003) Versatile EGFP reporter plasmids for cellular localization of recombinant gene products in filamentous fungi. Curr Genet 43: 54-61.

Pöggeler S, Nowrousian M, Jacobsen S, Kück U (1997) An efficient procedure to isolate fungal genes from an indexed cosmid library. J. Microbiol. Method. 29: 49-61.

Pöggeler S, Nowrousian M, Kück U (2006a) Fruiting-body development in ascomycetes. In: Kues, U., and Fischer, R. (eds) The Mycota. Springer, Berlin Heidelberg New York, pp. 325-355.

Pöggeler S, Nowrousian M, Ringelberg C, Loros JJ, Dunlap JC, Kück U (2006b) Microarray and real-time PCR analyses reveal mating type-dependent gene expression in a homothallic fungus. Mol Genet Genomics 275: 492-503.

Poisson N, Real E, Gaudin Y, Vaney MC, King S, Jacob Y, Tordo N, Blondel D (2001) Molecular basis for the interaction between rabies virus phosphoprotein $\mathrm{P}$ and the dynein 
light chain LC8: dissociation of dynein-binding properties and transcriptional functionality of P. J Gen Virol 82: 2691-2696.

Polakis P (2000) Wnt signaling and cancer. Genes Dev 14: 1837-1851.

Ponchon L, Dumas C, Fesquet D, Padilla A (2004) Resonance assignments and topology of the 15N, 13C labelled $23 \mathrm{kDa}$ core domain of xenopus Mob1. J Biomol NMR 28: 299-300.

Ptashne M (1988) How eukaryotic transcriptional activators work. Nature 335: 683-689.

Qanungo KR, Shaji D, Mathur M, Banerjee AK (2004) Two RNA polymerase complexes from vesicular stomatitis virus-infected cells that carry out transcription and replication of genome RNA. Proc Natl Acad Sci U S A 101: 5952-5957.

Raths S, Rohrer J, Crausaz F, Riezman H (1993) end3 and end4: two mutants defective in receptor-mediated and fluid-phase endocytosis in Saccharomyces cerevisiae. J Cell Biol 120: $55-65$.

Raz L, Khan MM, Mahesh VB, Vadlamudi RK, Brann DW (2008) Rapid estrogen signaling in the brain. Neurosignals 16: 140-153.

Rech C (2007) Molekulargenetische Charakterisierung des pro22-Gens aus Sordaria macrospora: die funktionelle Beteiligung von PRO22 an der Zelldifferenzierung bei Ascomyceten. Dissertation.

Rech C, Engh I, Kuck U (2007) Detection of hyphal fusion in filamentous fungi using differently fluorescence-labeled histones. Curr Genet 52: 259-266.

Record E, Asther M, Moukha S, Marion D, Burlat V, Ruel K (1998) Localization of a phosphatidylglycerol/phosphatidylinositol transfer protein in Aspergillus oryzae. Can $\mathbf{J}$ Microbiol 44: 945-953.

Reese MG (2001) Application of a time-delay neural network to promoter annotation in the Drosophila melanogaster genome. Comput Chem 26: 51-56.

Reijnst P, Jorde S, Wendland J (2010) Candida albicans SH3-domain proteins involved in hyphal growth, cytokinesis, and vacuolar morphology. Curr Genet 56: 309-319.

Repetto B, Tzagoloff A (1989) Structure and regulation of $K G D 1$, the structural gene for yeast alpha-ketoglutarate dehydrogenase. Mol Cell Biol 9: 2695-2705.

Riedl J, Crevenna AH, Kessenbrock K, Yu JH, Neukirchen D, Bista M, Bradke F, Jenne D, Holak TA, Werb Z, Sixt M, Wedlich-Soldner R (2008) Lifeact: a versatile marker to visualize F-actin. Nat Methods 5: 605-607.

Roca MG, Arlt J, Jeffree CE, Read ND (2005) Cell biology of conidial anastomosis tubes in Neurospora crassa. Eukaryot Cell 4: 911-919.

Salin P, Kachidian P, Bartoli M, Castets F (1998) Distribution of striatin, a newly identified calmodulin-binding protein in the rat brain: an in situ hybridization and immunocytochemical study. J Comp Neurol 397: 41-59.

Samanta MP, Liang S (2003) Predicting protein functions from redundancies in large-scale protein interaction networks. Proc Natl Acad Sci U S A 100: 12579-12583.

Sambrook J, Fritsch E, Maniatis T (2001) Molecular cloning: A laboratory manual. Cold Spring Harbor Laboratory Press, Cold Spring Habor, NY.

Sanghamitra M, Talukder I, Singarapu N, Sindhu KV, Kateriya S, Goswami SK (2008) WD-40 repeat protein SG2NA has multiple splice variants with tissue restricted and growth responsive properties. Gene 420: 48-56.

Sargiacomo M, Scherer PE, Tang Z, Kubler E, Song KS, Sanders MC, Lisanti MP (1995) Oligomeric structure of caveolin: implications for caveolae membrane organization. Proc Natl Acad Sci U S A 92: 9407-9411.

Schirmaier F, Philippsen $P$ (1984) Identification of two genes coding for the translation elongation factor EF-1 alpha of S. cerevisiae. EMBO J 3: 3311-3315.

Schulte J, Sepp KJ, Jorquera RA, Wu C, Song Y, Hong P, Littleton JT (2010) DMob4/Phocein regulates synapse formation, axonal transport, and microtubule organization. J Neurosci 30: 5189-5203. 
Seiler S, Plamann M (2003) The genetic basis of cellular morphogenesis in the filamentous fungus Neurospora crassa. Mol Biol Cell 14: 4352-4364.

Shaner NC, Lin MZ, McKeown MR, Steinbach PA, Hazelwood KL, Davidson MW, Tsien RY (2008) Improving the photostability of bright monomeric orange and red fluorescent proteins. Nat Methods 5: 545-551.

Sheu YJ, Santos B, Fortin N, Costigan C, Snyder M (1998) Spa2p interacts with cell polarity proteins and signaling components involved in yeast cell morphogenesis. Mol Cell Biol 18: 4053-4069.

Shih SC, Sloper-Mould KE, Hicke L (2000) Monoubiquitin carries a novel internalization signal that is appended to activated receptors. EMBO J 19: 187-198.

Shim WB, Sagaram US, Choi YE, So J, Wilkinson HH, Lee YW (2006) FSR1 is essential for virulence and female fertility in Fusarium verticillioides and F. graminearum. Mol Plant Microbe Interact 19: 725-733.

Simonin AR, Rasmussen CG, Yang M, Glass NL (2010) Genes encoding a striatin-like protein (ham-3) and a forkhead associated protein (ham-4) are required for hyphal fusion in Neurospora crassa. Fungal Genet Biol.

Simons K, Toomre D (2000) Lipid rafts and signal transduction. Nat Rev Mol Cell Biol 1: 31-39.

Skatrud PL, Queener SW, Carr LG, Fisher DL (1987) Efficient integrative transformation of Cephalosporium acremonium. Curr Genet 12: 337-348.

Sleeman K, Baron MD (2005) The polymerase (L) protein of rinderpest virus interacts with the host cell protein striatin. Virology 332: 225-234.

Slusarewicz P, Xu Z, Seefeld K, Haas A, Wickner WT (1997) I2B is a small cytosolic protein that participates in vacuole fusion. Proc Natl Acad Sci U S A 94: 5582-5587.

Smith TF, Gaitatzes C, Saxena K, Neer EJ (1999) The WD repeat: a common architecture for diverse functions. Trends Biochem Sci 24: 181-185.

Sondek J, Bohm A, Lambright DG, Hamm HE, Sigler PB (1996) Crystal structure of a Gprotein beta gamma dimer at 2.1A resolution. Nature 379: 369-374.

Song S, Zhang T, Qi W, Zhao W, Xu B, Liu J (1993) Transformation of Escherichia coli with foreign DNA by electroporation. Chin. J. Biotechnol. 9: 197-201.

Spizzo T, Byersdorfer C, Duesterhoeft S, Eide D (1997) The yeast FET5 gene encodes a FET3related multicopper oxidase implicated in iron transport. Mol Gen Genet 256: 547-556.

Stavridi ES, Harris KG, Huyen Y, Bothos J, Verwoerd PM, Stayrook SE, Pavletich NP, Jeffrey PD, Luca FC (2003) Crystal structure of a human Mob1 protein: toward understanding Mob-regulated cell cycle pathways. Structure. 11: 1163-1170.

Stein IS, Gottfried A, Zimmermann J, Fischer von Mollard G (2009) TVP23 interacts genetically with the yeast SNARE VTII and functions in retrograde transport from the early endosome to the late Golgi. Biochem J 419: 229-236.

Stothard $\mathbf{P}$ (2000) The sequence manipulation suite: JavaScript programs for analyzing and formatting protein and DNA sequences. Biotechniques 28: 1102, 1104.

Stotz A, Muller PP, Linder P (1993) Regulation of the ADE2 gene from Saccharomyces cerevisiae. Curr Genet 24: 472-480.

Stukey JE, McDonough VM, Martin CE (1989) Isolation and characterization of OLE1, a gene affecting fatty acid desaturation from Saccharomyces cerevisiae. J Biol Chem 264: 1653716544.

Surana U, Lim HH (2002) MEN, destruction and separation: mechanistic links between mitotic exit and cytokinesis in budding yeast. Bioessays: 659-666.

Takesue S, Yokota K, Miyajima S, Taguchi R, Ikezawa H, Takesue Y (1992) Partial release of aminopeptidase $\mathrm{N}$ from larval midgut cell membranes of the silkworm, Bombyx mori, by phosphatidylinositol-specific phospholipase C. Comp Biochem Physiol B 102: 7-11. 
Tan B, Long X, Nakshatri H, Nephew KP, Bigsby RM (2008) Striatin-3 $\gamma$ inhibits estrogen receptor activity by recruiting a protein phosphatase. J Mol Endocrinol 40: 199-210.

Tan HT, Low J, Lim SG, Chung MC (2009) Serum autoantibodies as biomarkers for early cancer detection. FEBS J 276: 6880-6904.

Tao Y, Chen KY (1994) PCR-based cloning of the full-length Neurospora eukaryotic initiation factor 5A cDNA: polyhistidine-tagging and overexpression for protein affinity binding. Biochem J 302 ( Pt 2): 517-525.

Teparic R, Stuparevic I, Mrsa V (2004) Increased mortality of Saccharomyces cerevisiae cell wall protein mutants. Microbiology 150: 3145-3150.

Thompson JD, Gibson TJ, Plewniak F, Jeanmougin F, Higgins DG (1997) The CLUSTAL_X windows interface: flexible strategies for multiple sequence alignment aided by quality analysis tools. Nucleic Acids Res 25: 4876-4882.

Tian C, Beeson WT, Iavarone AT, Sun J, Marletta MA, Cate JH, Glass NL (2009) Systems analysis of plant cell wall degradation by the model filamentous fungus Neurospora crassa. Proc Natl Acad Sci U S A 106: 22157-22162.

Trammell MA, Mahoney NM, Agard DA, Vale RD (2008) Mob4 plays a role in spindle focusing in Drosophila S2 cells. J Cell Sci 121: $1284-1292$.

Urbanowski JL, Piper RC (1999) The iron transporter Fth1p forms a complex with the Fet5 iron oxidase and resides on the vacuolar membrane. J Biol Chem 274: 38061-38070.

Valasek MA, Repa JJ (2005) The power of real-time PCR. Adv Physiol Educ 29: 151-159.

Videira A, Kasuga T, Tian C, Lemos C, Castro A, Glass NL (2009) Transcriptional analysis of the response of Neurospora crassa to phytosphingosine reveals links to mitochondrial function. Microbiology 155: 3134-3141.

Vitulo N, Vezzi A, Galla G, Citterio S, Marino G, Ruperti B, Zermiani M, Albertini E, Valle G, Barcaccia G (2007) Characterization and evolution of the cell cycle-associated mob domain-containing proteins in eukaryotes. Evol Bioinform Online 3: 121-158.

Walker JR, Corpina RA, Goldberg J (2001) Structure of the Ku heterodimer bound to DNA and its implications for double-strand break repair. Nature 412: 607-614.

Walz M, Kück U (1995) Transformation of Sordaria macrospora to hygromycin B resistance: characterization of transformants by electrophoretic karyotyping and tetrad analysis. Curr Genet 29: 88-95.

Wang CL, Shim WB, Shaw BD (2010) Aspergillus nidulans striatin (StrA) mediates sexual development and localizes to the endoplasmic reticulum. Fungal Genet Biol.

Wang Z, Tarawneh KA, Free SJ (1993) Isolation, sequencing, and characterization of crp-5, a gene encoding a Neurospora ribosomal protein. Curr Genet 23: 330-333.

Wayman GA, Lee YS, Tokumitsu H, Silva AJ, Soderling TR (2008) Calmodulin-kinases: modulators of neuronal development and plasticity. Neuron 59: 914-931.

Weber R, Pitt D (1997) Acid phosphatase secretion by Botrytis cinerea. Mycol. Res. 101: 349356.

Wei H, Requena N, Fischer R (2003) The MAPKK kinase SteC regulates conidiophore morphology and is essential for heterokaryon formation and sexual development in the homothallic fungus Aspergillus nidulans. Mol Microbiol 47: 1577-1588.

Whittaker SL, Lunness P, Milward KJ, Doonan JH, Assinder SJ (1999) sodVIC is an alphaCOP-related gene which is essential for establishing and maintaining polarized growth in Aspergillus nidulans. Fungal Genet Biol 26: 236-252.

Whittaker VP (1993) Thirty years of synaptosome research. J Neurocytol 22: 735-742.

Witczak CA, Sharoff CG, Goodyear LJ (2008) AMP-activated protein kinase in skeletal muscle: from structure and localization to its role as a master regulator of cellular metabolism. Cell Mol Life Sci 65: 3737-3755. 
Wright RM, Dircks LK, Poyton RO (1986) Characterization of COX9, the nuclear gene encoding the yeast mitochondrial protein cytochrome c oxidase subunit VIIa. Subunit VIIa lacks a leader peptide and is an essential component of the holoenzyme. J Biol Chem 261: 17183-17191.

Wu WK, Cho CH, Lee CW, Fan D, Wu K, Yu J, Sung JJ (2010) Dysregulation of cellular signaling in gastric cancer. Cancer Lett 295: 144-153.

Xiang Q, Rasmussen C, Glass NL (2002) The ham-2 locus, encoding a putative transmembrane protein, is required for hyphal fusion in Neurospora crassa. Genetics 160: 169-180.

Xie X, Wilkinson HH, Correa A, Lewis ZA, Bell-Pedersen D, Ebbole DJ (2004) Transcriptional response to glucose starvation and functional analysis of a glucose transporter of Neurospora crassa. Fungal Genet Biol 41: 1104-1119.

Xue C, Hsueh YP, Heitman J (2008) Magnificent seven: roles of G protein-coupled receptors in extracellular sensing in fungi. FEMS Microbiol Rev 32: 1010-1032.

Yamamura Y, Shim WB (2008) The coiled-coil protein-binding motif in Fusarium verticillioides Fsr1 is essential for maize stalk rot virulence. Microbiology 154: 16371645.

Yap KL, Kim J, Truong K, Sherman M, Yuan T, Ikura M (2000) Calmodulin target database. J Struct Funct Genomics 1: 8-14.

Yu XX, Du X, Moreno CS, Green RE, Ogris E, Feng Q, Chou L, McQuoid MJ, Pallas DC (2001) Methylation of the protein phosphatase $2 \mathrm{~A}$ catalytic subunit is essential for association of Balpha regulatory subunit but not SG2NA, striatin, or polyomavirus middle tumor antigen. Mol Biol Cell 12: 185-199.

Yu YB (2002) Coiled-coils: stability, specificity, and drug delivery potential. Adv Drug Deliv Rev 54: 1113-1129.

Yuan YO, Stroke IL, Fields S (1993) Coupling of cell identity to signal response in yeast: interaction between the alpha 1 and STE12 proteins. Genes Dev 7: 1584-1597.

Zanelli CF, Maragno AL, Gregio AP, Komili S, Pandolfi JR, Mestriner CA, Lustri WR, Valentini SR (2006) eIF5A binds to translational machinery components and affects translation in yeast. Biochem Biophys Res Commun 348: 1358-1366.

Zhang X, Glendening C, Linke H, Parks CL, Brooks C, Udem SA, Oglesbee M (2002a) Identification and characterization of a regulatory domain on the carboxyl terminus of the measles virus nucleocapsid protein. J Virol 76: 8737-8746.

Zhang Y, Lamm R, Pillonel C, Lam S, Xu JR (2002b) Osmoregulation and fungicide resistance: the Neurospora crassa os-2 gene encodes a HOG1 mitogen-activated protein kinase homologue. Appl Environ Microbiol 68: 532-538.

Zhu W, Chan EK, Li J, Hemmerich P, Tan EM (2001) Transcription activating property of autoantigen SG2NA and modulating effect of WD-40 repeats. Exp Cell Res 269: 312-321. 


\section{DANKSAGUNG}

Mein besonderer Dank gilt meiner akademischen Lehrerin und Doktormutter Frau Prof. Dr. Stefanie Pöggeler für das mir entgegengebrachte Vertrauen, meine Promotion in ihrer Abteilung zu absolvieren. Ich möchte mich weiterhin bei ihr für die sehr interessante und aktuelle Themenstellung und die großzügige Unterstützung bedanken, welche es mir ermöglichte, meinen wissenschaftlichen Horizont auch auf nationalen und internationalen Tagungen und Kongressen zu erweitern. Darüber hinaus haben ihre wissenschaftlichen und insbesondere auch ihre privaten Anregungen meine Promotion zu einer für mich sehr lehrreichen und wertvollen Zeit gemacht.

Einen großen Dank möchte ich PD Dr. Michael Hoppert für seine Hilfsbereitschaft und für die Übernahme des Korreferats aussprechen.

Vielen Dank an unsere Kooperationspartner Dr. Stephan Seiler und Anne Dettmann aus Göttingen und Prof. Dr. Ulrich Kück, Dr. Ines Engh und Sandra Bloemendal aus Bochum für ihre Diskussionsbereitschaft, ihre hilfreichen wissenschaftlichen Anregungen und die gute Zusammenarbeit bei unseren gemeinsamen Forschungsprojekten.

Ein herzlicher Dank gilt Stefan Frey, Maxi Schütter und Diana Marklein, die im Rahmen von Praktika und einer Diplomarbeit zu dieser Arbeit beigetragen haben. Meinen Doktorbrüdern Oliver Voigt, Ronny Lehneck und Volker Klix danke ich für unsere gemeinsame schöne Zeit im Labor. Für die tolle Atmosphäre, den regen Gedankenaustausch und viele unterhaltsame und kurzweilige Gespräche möchte ich mich insbesondere bei Dr. Nicole Nolting, Dr. Skander Elleuche, Dr. Daniela Justa-Schuch, Dr. Sabine März, Marcel Kunadt und Sabine Riedel bedanken.

Mein ganzer Dank gilt meiner Familie: meinen Großeltern und Eltern danke ich sehr für ihre großzügige materielle Unterstützung, ohne die meine wissenschaftliche Ausbildung so nicht möglich gewesen wäre. Darüber hinaus möchte ich mich bei meinen Eltern für ihr unerschütterliches Vertrauen und ihre moralische Unterstützung bedanken, bei meinem Freund Florian und seiner Familie für ihren großartigen Beistand in allen Lebenslagen, bei meinem Onkel Harti für sein Interesse und die geistreichen Gespräche und bei meinen beiden großen Schwestern und ihren Familien, die mich immer daran erinnern, dass es noch andere wichtige Dinge im Leben gibt. 


\section{Curriculum Vitae}

\section{Yasmine Bernhards}

Anschrift:

Obere Karspüle 12

37073 Göttingen

Geburtsdatum:

02.04 .1980

Geburtsort:

Staatsangehörigkeit:

Dortmund

deutsch

Oktober 2006 - September 2010

Promotion im Fach Biologie an der Georg-August-Universität Göttingen Institut für Mikrobiologie und Genetik Abteilung Genetik eukaryotischer Mikroorganismen Thema: „Untersuchung der Fruchtkörperentwicklung bei dem Hyphenpilz Sordaria macrospora“"

März 2006 - August 2006

Wiss. Angestellte, Goethe-Universität Frankfurt am Main Institut für Molekulare Biowissenschaften Arbeitskreis Molekulare Entwicklungsbiologie

September 2005 - Februar 2006

Wiss. Angestellte, Ruhr-Universität Bochum Fakultät für Biologie und Biotechnologie Lehrstuhl Allgemeine und Molekulare Botanik

Oktober 2000 - September 2005

Oktober 1999 - März 2000

Biologie-Studium an der Ruhr-Universität Bochum Abschluss: Diplom-Biologin Diplomarbeit: „Analyse der Proteine PRO11, MOB1 und PHO1 aus dem Hyphenpilz Sordaria macrospora“

Diplomprüfungen:

Botanik und Genetik (Hauptfach)

Biophysik und Paläontologie (Nebenfach)

Studium der Umweltwissenschaften, Universität Lüneburg

$1990-1999$

Gymnasium an der Schweizer Allee, Dortmund Abschluss: Abitur

$1986-1990$

Aplerbecker-Mark-Grundschule, Dortmund 